Emerging Technologies and Approaches to Minimize Discharges into Lake Michigan

Phase 2, Module 4 Report

Energy Systems Division 


\section{About Argonne National Laboratory}

Argonne is a U.S. Department of Energy laboratory managed by UChicago Argonne, LLC under contract DE-AC02-06CH11357. The Laboratory's main facility is outside Chicago, at 9700 South Cass Avenue, Argonne, Illinois 60439. For information about Argonne, see www.anl.gov.

\section{Disclaimer}

This material was prepared as an account of work sponsored by Purdue University. Neither the authors, United States Government nor any agency thereof, nor the UChicago Argonne LLC, nor any of their employees or officers, makes any warranty, express or implied, or assumes any legal liability or responsibility for the accuracy, completeness, or usefulness of any information, apparatus, product, or process disclosed, or represents that its use would not infringe privately owned rights. Reference herein to any specific commercial product, process, or service by trade name, trademark, manufacturer, or otherwise, does not necessarily constitute or imply its endorsement, recommendation, or favoring by the United States Government or any agency thereof. The views and opinions of authors expressed herein do not necessarily state or reflect those of the United States Government or any agency thereof. 


\section{Emerging Technologies and Approaches to Minimize Discharges into Lake Michigan}

Phase 2, Module 4 Report

by

Argonne National Laboratory and

Purdue University Calumet Water Institute

March 2012 


\section{THIS PAGE LEFT BLANK}




\section{Glossary and Acronyms}

ANL: Argonne National Laboratory

CE: Clarifier Effluent

CIP: Clean In Place

Dissolved Hg: Hg that will pass through a $0.45 \mu \mathrm{m}$ membrane filter

ETL: Effluent to Lake

Flux: Volume of permeate produced per unit area and time

GLI: Great Lakes Initiative

gpm: gallon per minute

Influent: Feed water

M: Million

MDL: Method Detection Limit

MGD: Million Gallons per Day

Permeate: Water passing through the membrane unit

pre-ETL: Effluent prior to lake

P\& ID: Piping and Instrumentation Diagram/Drawing

PLC: Programmable Logic Controller

PSA: Particle Size Analysis

ppb: parts per billion $(\mu \mathrm{g} / \mathrm{L})$

ppt: parts per trillion (ng/L)

PUC: Purdue University Calumet

PVDF: polyvinlylidenefluoride

Reject: Concentrated stream generated after filtration

Retentate: Retained at the feed side of membrane

TCLP: Toxicity Characteristic Leaching Procedure 
TMP: Transmembrane pressure

UF: Ultrafiltration

WWTP: Wastewater Treatment Plant 


\section{Joint Executive Summary}

The Great Lakes Initiative (GLI) established new water quality-based discharge criteria for mercury (Hg), thereby increasing the need for many municipal and industrial wastewater treatment plants in the region to lower the mercury in their effluents. Information on deployable technologies to satisfy these requirements for industrial and municipal dischargers in the Great Lakes region is scarce. Therefore, BP funded Purdue University Calumet and Argonne to identify deployable $\mathrm{Hg}$ removal technologies to meet the GLI discharge criterion at its Whiting Refinery in Indiana. The joint PUC/Argonne project was divided into two phases. Results from Phase I and Phase II Modules $1-3$ have been previously reported ${ }^{1-3}$. This report summarizes the work done in Phase 3 Module 4, which consisted of the pilot scale testing of Hg removal technologies previously selected in Module 3. The pilot testing was an Argonne/PUC jointly directed project that was hosted at and funded by the BP refinery in Whiting, IN. As two organizations were involved in data analysis and interpretation, this report combines two independent sets of evaluations of the testing that was done, prepared respectively by Argonne and Purdue. Each organization retains sole responsibility for its respective analysis, conclusions and recommendations.

Based on Module 3 bench testing with pre-Effluent To Lake (pre-ETL) and clarifier effluent (CE) samples from the Whiting refinery, three different technologies were chosen for pilot testing:

- Ultrafiltration (using GE ZeeWeed® Technology, $0.04 \mu \mathrm{m}$ pore size and made up of PVDF) for particulate mercury removal,

- Adsorption using Mersorb® LW, a sulfur-impregnated activated carbon, for dissolved mercury removal if present and

- The Blue PRO® reactive filtration process for both particulate and dissolved (if present) mercury removal.

The ultrafiltration and the Blue $\mathrm{PRO} \otimes$ reactive filtration pilot studies were done simultaneously at the BP Whiting refinery using a slipstream of wastewater taken just prior to the Effluent to Lake (pre-ETL) outfall. It was the intention of this pilot testing to demonstrate proof of concept, i.e. can the discharge limits obtained at bench scale be consistently met at the pilot scale. Although Mersorb® LW was selected for dissolved mercury removal testing, this technology was not pilot tested because of a lack of dissolved mercury in the test wastewater during the pilot study. The overall objective of this pilot testing was to demonstrate the effectiveness of the tested technologies with continuous and varying feed conditions to meet the GLI criterion (1.3 ppt). Optimization for full-scale design was outside of the scope of this work. In addition to demonstrating whether the $\mathrm{Hg}$ criterion can be met, information on residue generation rate, frequency of backwashing 
and other maintenance issues were collected to better understand the implications for a full-scale system.

Key findings and achievements resulting from this project include:

\section{Wastewater Characterization}

- Pre-ETL samples throughout Module 4 confirmed what was seen during Module 3 bench-scale testing, namely, that the $\mathrm{Hg}$ in the BP Whiting refinery wastewater was primarily associated with particulates - very little dissolved $\mathrm{Hg}$ was detected during the test period.

\section{Ultrafiltration Pilot Study:}

- Both Argonne and Purdue have concluded that the UF membrane pilot unit consistently provided permeate that was less than $0.5 \mathrm{ppt} \mathrm{Hg}$, which met and exceeded the treatment target of $1.3 \mathrm{ppt}$ of $\mathrm{Hg}$. This permeate quality was consistently produced at all tested operating conditions and was independent of the feed water characteristics and feed Hg concentration. This confirms the bench-scale Module 3 findings that there is no fundamental physical or chemical barrier in achieving $<1.3 p p t \mathrm{Hg}$ in the tested refinery wastewater at the pilot-scale at least under these testing conditions of little dissolved mercury in the pre-ETL $(<0.5-$ $1.05 \mathrm{ppt}$ ).

- Argonne's estimate of the full-scale cost varied between \$39M-147M for a 40 MGD design capacity process depending on the criteria used in cost calculations, such as land acquisition, engineering, site development, waste disposal, etc. It should be noted that the vendor did not provide a full-scale cost estimate therefore this estimate was produced using literature data and methodologies.

- Weekly maintenance cleans with hypochlorite solution and the monthly clean in place (CIP) were very effective in consistently restoring the membrane permeability during the pilot-study.

- Testing is needed to determine treatment options for the full scale reject stream which collects and concentrates the mercury removed from the effluent.

Reactive Filtration Pilot Study:

- Both Argonne and Purdue have concluded that effluent from the $25 \mathrm{gpm}$ Blue PRO® pilot met the 1.3 ppt Hg treatment goal $92.7 \%$ of the time during the 97 day pilot.

- Mercury breakthrough in the effluent was seen after 46 days of operation without chemical addition. This Hg breakthrough lasted for five consecutive days.

- Effluent quality after Hg breakthrough was restored when Nalmet® 1689 was added to each filter's influent, however, the brevity of these test conditions (three 
weeks) prevent definitive conclusions from being made regarding long term effectiveness.

- Mercury accumulation was seen in the filter sand during Nalmet ${ }^{\circledR}$ addition, suggesting that the effluent quality may decline over long-term operation - the filter sand may have a finite capacity for Nalmet ${ }^{\circledR}$ and the associated $\mathrm{Hg}$, and this trial did not last long enough to determine when this capacity might be reached.

- Argonne's interpretation of the pilot data is that a full-scale Blue PRO® treatment system should have the equivalent of two filters in series, and Nalmet ${ }^{\circledR} 1689$ addition to the influent of each filter. Based on the vendor supplied equipment cost, the installed capital cost estimate including equipment purchase and installation, instrumentation, construction and land acquisition would be approximately $\$ 21$ $38 \mathrm{M}$ for a $40 \mathrm{MGD}$ design capacity process. It should be noted that site-specific installation costs are needed to develop refined costs. This cost estimate also does not include the treatment and disposal costs for the reject stream since the vendor has recommended that this stream be recycled upstream; however the feasibility of doing so has not been evaluated.

- Optimization of the Nalmet ${ }^{\circledR} 1689$ dosage is needed to minimize treatment costs.

- Testing is also needed to determine how to manage the full-scale reject stream.

\section{Alternative option for consideration:}

- Another potential Hg treatment option that has arisen from testing the Blue PRO® process is Nalmet ${ }^{\circledR}$ addition before BP Whiting's sand filters. Although this has not been tested yet, if successful it would have a significantly lower installed capital cost. Although this option is outside of the scope of this work and has not been tested at the pilot scale, Argonne has suggested it as it is a simplification of the Blue PRO® process, which successfully treated pre-ETL $92.7 \%$ of the time. Additionally, bench-scale testing with clarifier effluent using plain sand with Nalmet $®$ addition showed $99 \% \mathrm{Hg}$ removal with a $0.23 \pm 0.06 \mathrm{ppt}$ effluent. Testing is also needed to determine how to manage the full-scale backwash stream that will be generated from this alternative process. Bench-scale testing on the reject stream is planned.

\section{Challenges and limitations during both pilot studies:}

- Statistically representative wastewater samples were difficult to obtain through grab sampling. This may be caused by the variability in wastewater composition as well as the heterogeneity of the wastewater samples caused by the presence of solids. Two days of composite sampling events for the ultrafiltration pilot were conducted to obtain a measure of variability. These two sampling events showed that the standard deviations were very high and ranged from 41.5 to $59 \%$ in feed and membrane backwash samples. 
- In consideration of this data, Argonne suggests that future pilot work should consider the use of grab samples for the rapid preliminary assessment of pilot performance supplemented by composite sampling to obtain more representative samples and improved process analysis.

- Despite the technical success of both pilots, both Argonne and Purdue have some operational concerns. Further testing is needed to determine appropriate disposal of the secondary waste, which contains concentrated levels of Hg. The accumulation of $\mathrm{Hg}$ in the Blue PRO $囚$ sand is also a concern. Argonne does not recommend further pilot testing of the Blue $\mathrm{PRO} \otimes$ process until the $\mathrm{Hg}$ accumulation in the sand issue is better understood.

In summary, Argonne and Purdue have concluded that both piloted technologies have successfully demonstrated the ability to meet and exceed the treatment goal of $1.3 \mathrm{ppt} \mathrm{Hg}$ on a consistent basis during the 3 month simultaneous studies, maintaining the effluent quality despite variations in the wastewater feed. These proof of concept pilots demonstrated that there is no fundamental physical or chemical barrier in achieving $<1.3 p p t \mathrm{Hg}$ in the tested refinery wastewater at the pilot-scale at least under these testing conditions of little dissolved mercury in the pre-ETL $(<0.5-1.05 \mathrm{ppt})$. Each pilot unit exhibited its own challenges that typically are addressed during longer term pilot studies before full-scale implementation. Reject handling is a major area for further study for both technologies.

Based on the Module 4 pilot study test results, both PUC and Argonne recommend that a long term ( $>6$ months) pilot test of ultrafiltration membrane technology be done at the Whiting Refinery. For further consideration of the Blue PRO® process, Purdue suggests long term testing of the Blue PRO $®$ process with Nalmet ${ }^{\circledR}$ addition in order to determine whether Hg breakthrough would happen even with the addition of Nalmet ${ }^{\circledR}$. On the other hand, Argonne recommends that long term testing of the alternative option proposed by Argonne, namely, Nalmet ${ }^{\circledR} 1689$ addition prior to the sand filters, be done prior to any long term Blue PRO ${ }^{\circledR}$ testing. These long term pilot studies, together with a study of treatment options for concentrated reject and backwash streams, will help provide information needed for full-scale design and implementation of a Hg removal technology for BP-Whiting's ETL, hence will help BP Whiting to meet the future GLI discharge criterion.

${ }^{1}$ Emerging Technologies and Approaches to Minimize Discharges into Lake Michigan - Task 2 Report, Purdue University Calumet-Argonne National Laboratory Task Force. July 3, 2008.

${ }^{2}$ Comparative Analysis of Discharges into Lake Michigan. Phase I, Southern Lake Michigan. Argonne National Laboratory, Environmental Science Division ANL/EVS/R-08/1, June 2008.

${ }^{3}$ Comparative Analysis of Discharges into Lake Michigan. Phase II, The Entire Lake. Argonne National Laboratory, Environmental Science Division. ANL/EVS/R-09/3, June 2010.

These reports are available at www.purduecal.edu/pwi, and at www.es.anl.gov/Energy Systems/Research/process technology/index.html . 


\section{Module 4 Testing Report}

\section{Table of Contents}

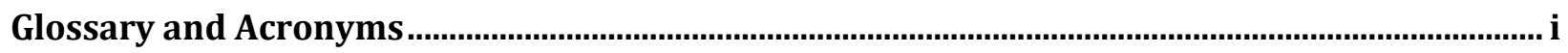

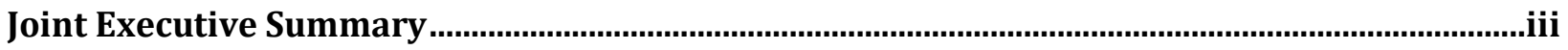

Executive Summary (Argonne)

1. Introduction: Background and Report Organization (Argonne) ................................................ 1

1.1 Background and summary of previous work ……......................................................................... 1

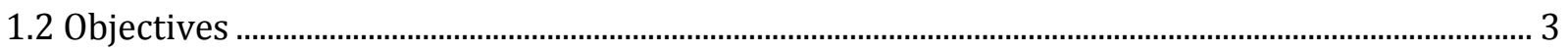

1.3 Technical team format and structure, roles and responsibilities........................................................ 4

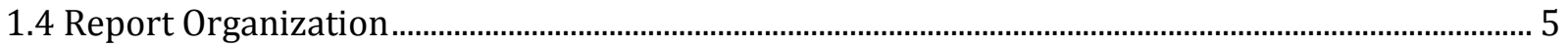

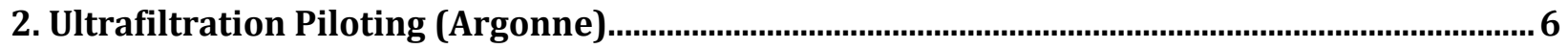

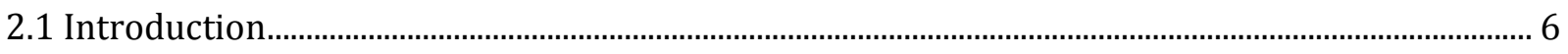

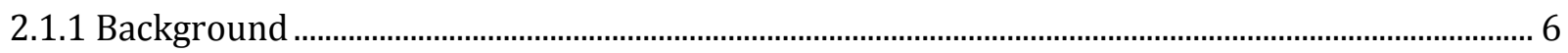

2.1.2 Overview of GE's UF Technology ............................................................................................ 6

2.2 Pilot Testing

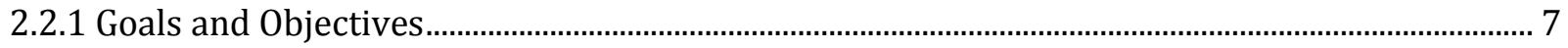

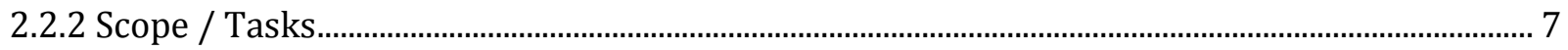

2.2.3 Membrane, Process, and Pilot Descriptions ….......................................................................................... 8

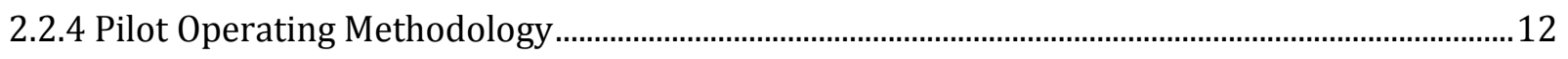

2.2.5 Operational, Analytical and QA/QC Requirements..........................................................................17

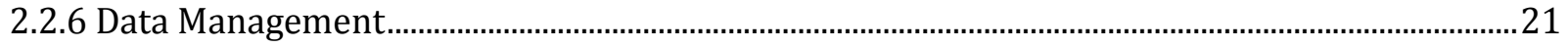

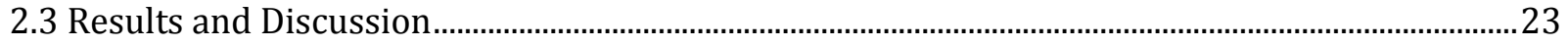

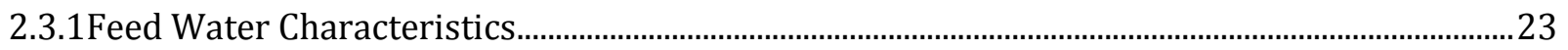

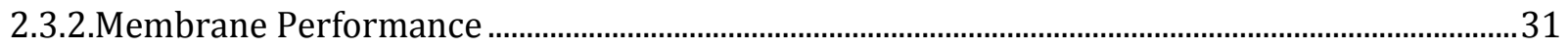

2.3.3 Hg Analysis in Backwash Stream before and after each Cleaning Event.....................................37

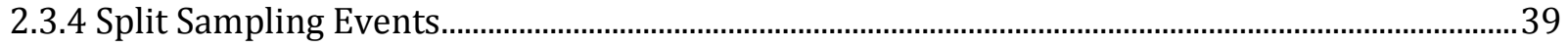

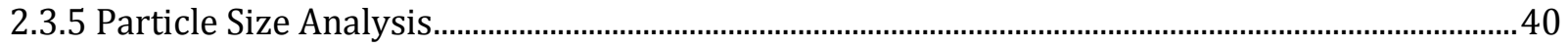

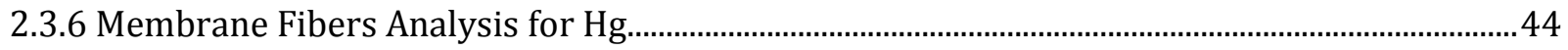

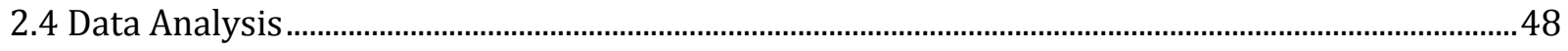

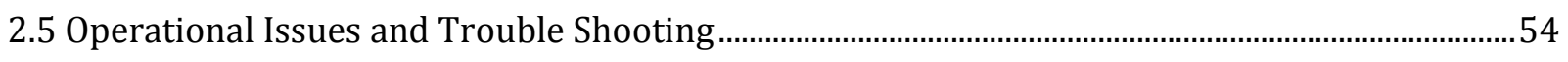

2.6 Implications of the Pilot-Test Results to Full-Scale Process Design..................................................55

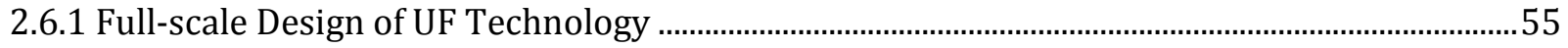


2.6.2 Cost of Ownership of This Technology at Full-scale ..........................................................................58

2.7 Implications of UF Process for Full-scale Application At Whiting- Evaluation of UF...................60

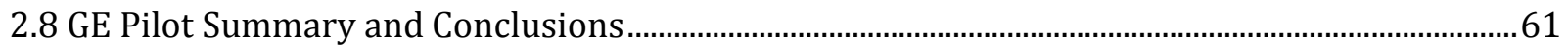

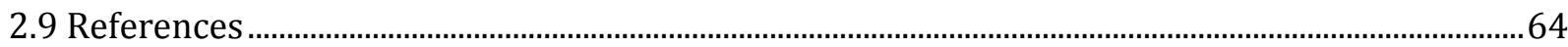

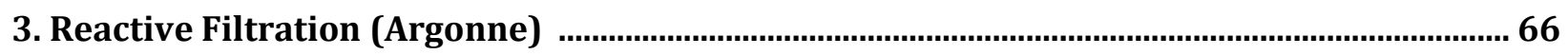

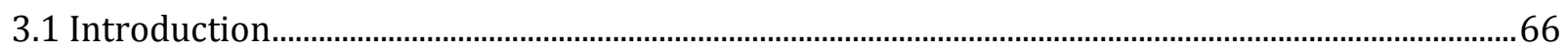

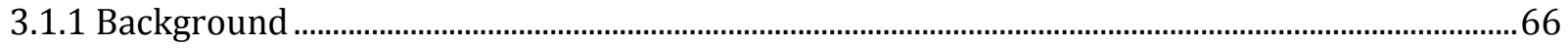

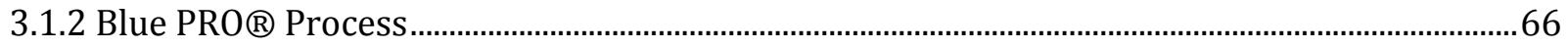

3.2 Pilot Preparatory Module 4 Bench-scale Testing...............................................................................69

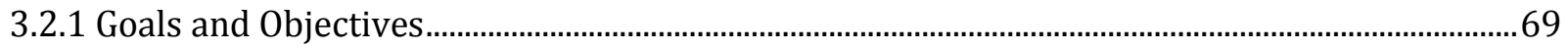

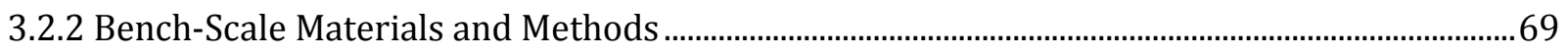

3.2.3 Bench-Scale Results and Discussion ............................................................................................ 72

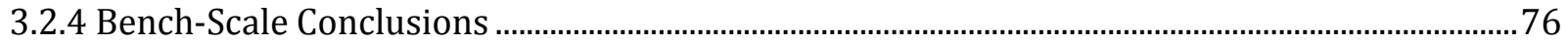

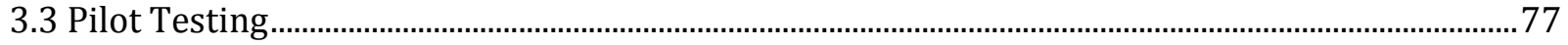

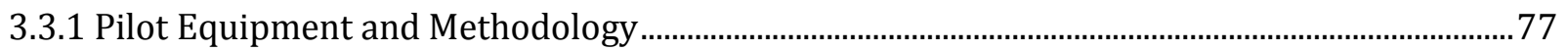

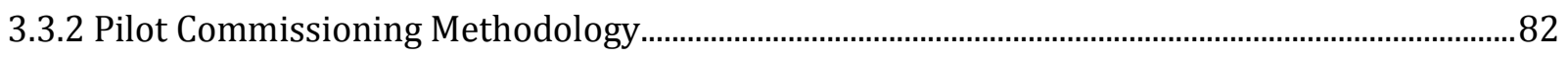

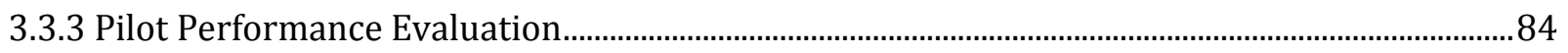

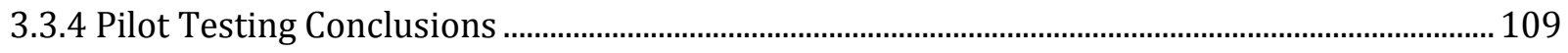

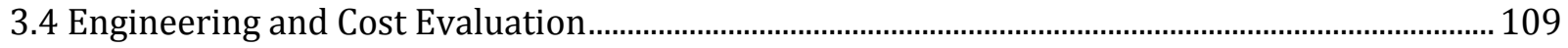

3.4.1 Preliminary Blue PRO® full-scale system ............................................................................................. 109

3.4.2 Alternative Option for Further Consideration................................................................................. 113

3.4.3 Full-Scale Options for Reject Management ………..................................................................... 115

3.5 Blue PRO® Pilot Summary and Conclusions ………..................................................................... 117

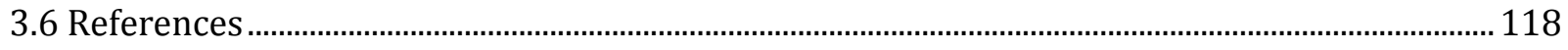

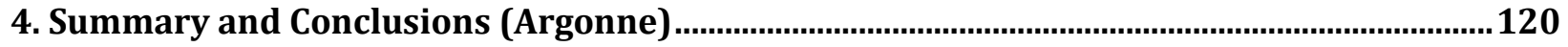

5. Results Evaluation from Purdue University Calumet Water Institute......................................125

6. Module 4 Report Argonne/Purdue Joint Summary and Conclusions .....................................155

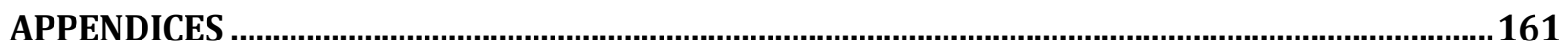

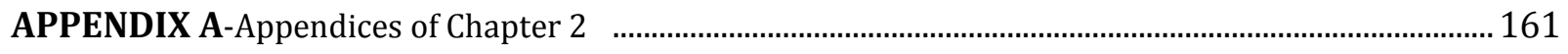

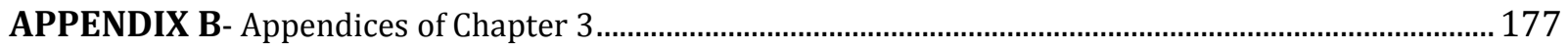




\title{
EMERGING TECHNOLOGIES AND APPROACHES TO MINIMIZE DISCHARGES INTO LAKE MICHIGAN PHASE 2, MODULE 4 REPORT
}

\author{
BY \\ M. C. NEGRI \\ P. GILlENWATER \\ M. URGUN-DEMIRTAS
}

ARGONNE NATIONAL LABORATORY

MARCH 2012

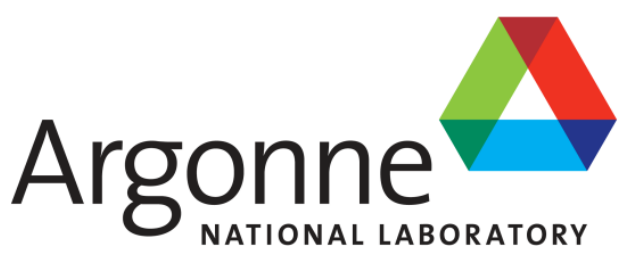




\section{Executive Summary (Argonne)}

BP has funded Purdue University Calumet (PUC) and Argonne National Laboratory (Argonne) to identify deployable technologies to meet future wastewater GLI discharge criteria for their Whiting, IN refinery. The project was divided in two phases, with each phase having multiple modules. This report summarizes the work done in Phase II Module 4 (pilot scale testing). The Module 4 testing was an Argonne/PUC directed project that was hosted and funded by the BP refinery in Whiting, IN. As part of this Module, a limited number of bench-scale tests were conducted at Argonne in preparation for piloting work. As two organizations were involved in data analysis and interpretation, this report combines two independent sets of evaluations of the testing that was done, prepared respectively by Argonne and Purdue. Each organization retains sole responsibility for its respective analysis, conclusions and recommendations.

During Module 3 it was found that most of the mercury in the wastewater was associated with particulates, and very little mercury was found to be in the dissolved form, i.e. present after $0.45 \mu \mathrm{m}$ filtration. Results from Module 3 also showed that particulate mercury removal was in most cases sufficient to enable the wastewater to meet the proposed 1.3 ppt mercury discharge standard. However, historical data from the spring of 2009 showed that mercury in the dissolved form was present in the Whiting ETL at levels above nondetect levels $(0.5 \mathrm{ppt})$ during 4 of 9 sampling events. In addition, 3 out of 9 samples were above 1.3 ppt. Hence, options were needed to remove both particulate and dissolved Hg. Given these requirements, three different technologies were chosen at the end of Module 3 for further evaluation:

- Ultrafiltration (using GE ZeeWeed® Technology, $0.04 \mu \mathrm{m}$ pore size),

- Adsorption using Mersorb® LW, a sulfur-impregnated activated carbon, and

- The Blue PRO® reactive filtration process.

During Module 4, ultrafiltration was pilot tested for particulate mercury removal. Although activated carbon adsorption (Mersorb® LW) was selected for dissolved mercury removal, this technology was not pilot tested because of a lack of dissolved mercury in the test wastewater during the pilot study. An emerging technology, the Blue PRO $®$ reactive filtration process, was also tested because Module 3 bench-scale testing showed that it removed both particulate and dissolved mercury. The ultrafiltration and the Blue PRO® reactive filtration pilot studies were done simultaneously at the BP Whiting refinery using a slipstream of wastewater taken just prior to the Effluent to Lake (ETL) outfall. In preparation for the Blue PRO® pilot, additional bench-scale testing was also done in this module to identify operating conditions that should be tested at the pilot-scale. It was the intention of this pilot testing to demonstrate proof of concept, i.e. can the discharge limits 
obtained at bench scale be consistently met at the pilot scale. Optimization for full-scale design was outside of the scope of this work.

The objectives of this project module were:

- Further bench scale optimization of process conditions in preparation for the Blue PROß pilot testing

- Confirmation of bench-scale performance to achieve concentrations less than 1.3 ppt mercury and determination of removal of other metals such as selenium, arsenic and vanadium as specified in the work plan. Mercury removal performance was the primary measure of success.

- Demonstrate performance under continuous feed conditions and variable wastewater composition

- Understand the implications for scale up to full-scale

- Understand the relative need and implications in the treatment of particulate vs. dissolved mercury

- Provide the data necessary (but not necessarily sufficient) for preliminary full-scale process design (this is a simplified design rather than a detailed design)

- Understand residue generation rate, power consumption, frequency of backwashing, other maintenance and waste disposal issues (sustainability indices).

Key findings and achievements resulting from this project include:

\section{Ultrafiltration Pilot Study:}

- The UF membrane process consistently provided a constant permeate quality at the tested operating conditions, virtually independent of the feed water characteristics and feed $\mathrm{Hg}$ concentration. The treatment target of less than $1.3 \mathrm{ppt}$ of $\mathrm{Hg}$ was met and exceeded for all tested conditions during the pilot study. This demonstrates that there is no fundamental physical or chemical barrier in achieving <1.3ppt Hg in the tested refinery wastewater at the pilot-scale at least under these testing conditions of little dissolved mercury in the pre-ETL $(<0.5-1.05 \mathrm{ppt})$.

- Transmembrane pressure (TMP) values were below the vendor's specification of (negative) 7-12 psi at all tested conditions during the pilot study.

- Weekly maintenance cleans and the monthly CIP were very effective in restoring the membrane permeability consistently during the pilot-study.

- Low membrane fouling rates ranging from 0.0125-0.05 psi/day at $20{ }^{\circ} \mathrm{C}$ resulted in an expected cleaning interval of greater than 90 days when the unit was operated at a Flux A flux rate and $\mathrm{X}, \mathrm{Y}$ and $\mathrm{Z} \%$ percent recoveries.

- The fouling rate increased (0.836 psi/day at $\left.20^{\circ} \mathrm{C}\right)$ when the system was operated at a Flux B flux rate and X\% recovery, resulting in a corresponding expected cleaning interval of 14.4 days. Running the membrane at this higher flux rate did not 
impact the Hg removal performance, but it did impact the CIP cleaning interval of the membrane unit.

- Argonne's estimate of the full-scale cost varied between \$39M-147M for a 40 MGD design capacity process depending on the criteria used in cost calculations, such as land acquisition, engineering, site development, waste disposal, etc. It should be noted that the vendor did not provide a full-scale cost estimate therefore this estimate was produced using literature data and methodologies.

- Despite the technical success, the auxiliary operation was problematic. Although minor shutdowns resulted in a gap in operation of less than 24 hours, fixing the feed line related problems took more than 30 days.

- Based on the four month pilot-study test results, Argonne recommends ultrafiltration membrane technology for further evaluation at the Whiting Refinery.

\section{Reactive Filtration Pilot Study:}

- Effluent from the $25 \mathrm{gpm}$ Blue PRO® pilot met the $1.3 \mathrm{ppt} \mathrm{Hg}$ treatment goal $92 \%$ of the time during the 97 day pilot.

- Mercury breakthrough in the effluent was seen after 46 days of operation without chemical addition. This Hg breakthrough lasted for five consecutive days.

- Effluent quality after Hg breakthrough was restored when Nalmet ${ }^{\circledR} 1689$ was added to each filter's influent, however, the brevity of these test conditions (three weeks) prevent definitive conclusions from being made

- In general, the unit operated well mechanically, running $91 \%$ of the time during the pilot. Of the 9 days of shutdown, 8 of the days were related to feed supply or sampling location modifications. Only 1 of the shutdown days was related to the process.

- Mercury accumulation was seen in the filter sand during Nalmet ${ }^{\circledR}$ addition, suggesting that the effluent quality may decline over long-term operation - the filter sand may have a finite capacity for Nalmet ${ }^{\circledR}$ and the associated $\mathrm{Hg}$ and this trial did not last long enough to determine when this capacity might be reached.

- Pilot data suggests that a full-scale Blue PROß treatment system should have the equivalent of two filters in series, and Nalmet ${ }^{\circledR} 1689$ addition to the influent of each filter. Based on the vendor supplied equipment cost, the installed capital cost would be approximately $\$ 20$ - 36M.

- Optimization of the Nalmet ${ }^{\circledR} 1689$ dosage is needed to minimize treatment costs.

- Testing is also needed to determine how to manage the full-scale reject stream

- Argonne does not recommend further pilot testing of the Blue PRO® process until the $\mathrm{Hg}$ accumulation in the sand issue is better understood.

\section{Alternative option for consideration:}


Another potential option for full-scale $\mathrm{Hg}$ treatment that has arisen from consideration of the Blue PRO $®$ process is Nalmet $₫$ addition before BP Whiting's sand filters, which would have a significantly lower installed capital cost of approximately $\$ 1.5 \mathrm{M}$. Although this option is outside of the scope of this work and has not been tested at the pilot scale, it is suggested as it is a simplification of the Blue PRO ${ }^{\circ}$ process, which successfully treated effluent. Additionally, bench-scale testing of plain sand with Nalmet ${ }^{\circledR}$ addition showed $99 \% \mathrm{Hg}$ removal with a $0.23 \pm$ 0.06 ppt effluent.

- Testing is needed to determine how to manage the full-scale backwash stream. Bench-scale testing is planned.

- Before moving forward with any further testing of the Blue PRO® process, Argonne suggests that a pilot test of this alternative option (Nalmet ${ }^{\circledR}$ addition before the sand filters) be done.

\section{Challenges and limitations during both pilot studies:}

- Representative wastewater samples were difficult to obtain due to the variability in wastewater composition as well as the heterogeneity of the wastewater samples. Two days of composite sampling events for the ultrafiltration pilot showed that the standard deviations were very high and ranged from 41.5 to $59 \%$ in feed and membrane backwash samples. Future pilot work should consider the use of grab samples for the rapid preliminary assessment of pilot performance. These grab samples should be supplemented with the use of composite sampling in order to obtain more representative samples and improved process analysis.

In summary, both of the pilot technologies demonstrated the ability to meet and exceed the treatment goal of $1.3 \mathrm{ppt} \mathrm{Hg}$ on a consistent basis during the 3 month simultaneous studies, maintaining the effluent quality despite variations in the wastewater feed. These proof of concept pilots demonstrated that there is no fundamental physical or chemical barrier in achieving $<1.3 \mathrm{ppt} \mathrm{Hg}$ in the tested refinery wastewater at the pilot-scale at least under these testing conditions of little dissolved mercury in the pre-ETL $(<0.5-1.05 \mathrm{ppt})$. Argonne recommends long term pilot studies for both ultrafiltration and an alternative approach consisting of adding Nalmet ${ }^{\circledR} 1689$ before BP Whiting's sand filters to obtain the information needed for full-scale design and implementation of a Hg removal technology for BP-Whiting's ETL. The information from these long term pilot studies will help to ensure that BP-Whiting's future ETL will meet the $1.3 \mathrm{ppt} \mathrm{Hg} \mathrm{discharge} \mathrm{criterion} \mathrm{set} \mathrm{by} \mathrm{the}$ Great Lakes Initiative. 


\section{Introduction: Background and Report Organization}

\subsection{Background and Summary of Previous Work}

The Great Lakes Initiative (GLI) established new water quality-based discharge criteria for mercury (Hg), thereby increasing the need for many municipal and industrial wastewater treatment plants (WWTPs) in the region to lower the mercury in their effluents. Information on deployable technologies to satisfy these requirements for industrial and municipal dischargers in the Great Lakes region is scarce. Therefore, BP funded Purdue University Calumet (PUC) and Argonne (ANL) to identify deployable $\mathrm{Hg}$ removal technologies to meet GLI discharge criteria at its Whiting Refinery in Indiana.

Phase I of this project, which started in the fall of 2007, focused on reviewing technologies for the treatment of total suspended solids and of ammonia in refinery wastewater, and was completed in June 2008. Phase II focused on the treatment of mercury and vanadium to meet future permit limits. This phase began in February 2009 and includes several modular elements funded sequentially. Module 1 included the search and identification of potentially applicable technologies from available literature; Module 2 included the sampling and analysis of a number of waste streams at the Whiting Refinery to aid in selecting the wastewater stream as well as the technologies to test; and Module 3 included the bench-scale testing of selected technologies identified in Module 1, as well as the selection of a subset of potential technologies for pilot testing. Module 4, which is described in this report, covers in detail the testing of the promising technologies identified in Module 3 at the bench and/or pilot scale. The Module 4 testing was an Argonne/PUC directed project that was hosted and funded by the BP refinery in Whiting, IN for the pilot scale tests, with additional bench-scale tests conducted at Argonne. It was the intention of this pilot testing to demonstrate proof of concept, i.e. can the results obtained at bench scale be consistently met at the pilot scale. Optimization for full-scale design was outside of the scope of this work.

During Module 3, selected technologies were tested under uniform conditions at the benchscale using discrete batches of "Effluent to Lake" (ETL) / clarifier effluent (CE) from the BP Whiting refinery. Vendor input on optimum testing conditions were used so that best performance from each technology could be obtained. Results from this uniform set of testing were then compared to determine which technologies should be selected for pilot testing. The initial selection was made on the basis of whether or not the technology was able to meet the performance criteria based on effluent quality. Bench-scale data were used to determine and compare each technology's preliminary performance, engineering configuration, cost, energy usage and waste generation, and therefore to provide the basis for the selection of those to test at the pilot-scale. Additionally, technology readiness (full- 
scale installations) and vendor qualifications were used to assess which technologies should or could be pilot tested, which vendors could be available to conduct the tests, and which were the technical requirements and logistics to conduct the tests at Whiting.

Mercury removal was the focus of the work in Module 4. Module 3 testing results showed that that some technologies were effective on particulate mercury while others were effective on dissolved mercury. One emerging technology was found to be effective on both particulate and dissolved mercury. Most of the mercury in the treated effluent was found to be associated with particulates, and very little mercury was found to be in the dissolved form, i.e. present after $0.45 \mu \mathrm{m}$ filtration. Results from Module 3 also showed that particulate mercury removal was in most cases sufficient to enable the wastewater to meet the proposed $1.3 \mathrm{ppt}$ mercury discharge criterion. However, historical data from the spring of 2009 showed that mercury in the dissolved form was present in the Whiting ETL at levels above non-detect levels ( $0.5 \mathrm{ppt}$ ) during 4 of 9 sampling events. In addition, 3 out of 9 samples were above $1.3 \mathrm{ppt}$. Hence, options need to be devised for wastewater treatment of both particulate and dissolved mercury removal.

Given these requirements, three different technologies were chosen for further evaluation:

- Ultrafiltration (using GE ZeeWeed® Technology, $0.04 \mu \mathrm{m}$ pore size and made up of PVDF) for particulate mercury removal,

- Adsorption using Mersorb® LW, a sulfur-impregnated activated carbon for dissolved mercury removal, and

- The Blue PRO® reactive filtration process, for both particulate and dissolved mercury removal.

Ultrafiltration, an established technology with many full-scale applications in water and wastewater treatment as well as for membrane bioreactors, was chosen for particulate mercury removal. Activated carbon adsorption with Mersorb ${ }^{\circledR}$ LW, another established technology, was selected for dissolved mercury removal, however, this technology was not pilot tested because of a lack of dissolved mercury in the test wastewater for the duration of the test period. An emerging technology, the Blue PRO ${ }^{8}$ reactive filtration process, was also selected for testing as an attractive option because it combines several different processes that may be able to control at the same time both particulate and dissolved mercury.

Due to the large volumes of water needed for pilot testing, the pilot work was conducted at the BP Whiting refinery using a slipstream of wastewater taken just prior to the Effluent to Lake (pre-ETL) outfall - as the influent waste stream. BP leased the pilot test equipment directly, and provided all connections and supplies on site. The start-up of these pilot skids was done by the vendors, BP engineers and operators with technical input by Argonne and 
PUC personnel. Following startup, the pilot skids were run by BP operators, with oversight from Argonne and PUC engineers. BP operators were responsible for checking and maintaining the pilot skid operation (including recording process data as necessary) as directed by the vendors, while a third-party external analytical laboratory was contracted to collect process samples and conduct the required sampling and data collection at the frequency requested in the experimental work plan. BP engineers also implemented any changes to experimental test conditions as jointly decided on by Argonne, PUC, and BP personnel in consultation with the vendor.

A detailed list of analytes and their sampling frequency was refined as part of the experimental work plan. The majority of the samples, including feed characterization and technology performance assessment samples, were collected and analyzed by a third party analytical laboratory. All mercury performance samples were collected by the third party analytical lab personnel using appropriate sampling techniques such as the "clean hands" and "dirty hands" protocol described in EPA Method 1669 for mercury samples. Additionally, during steady state operation a limited number of samples were sent to a specialized laboratory for mercury analysis to confirm the analyses done by the third party laboratory. Furthermore, selected samples were sent to Argonne and analyzed for particle size distribution by Argonne.

\subsection{Objectives}

The overall objective of this work was to demonstrate the effectiveness of the tested technologies with continuous and varying feed conditions to meet the GLI Hg criterion (1.3 ppt). The specific objectives of this work were:

- Further bench scale optimization of process conditions in preparation for the Blue PRO® pilot testing

- Confirmation of bench-scale performance to achieve concentrations less than 1.3 ppt mercury and determination of removal of other analytes as specified in the work plan. Mercury removal performance was the primary measure of success.

- Demonstrate performance under continuous feed conditions and variable wastewater composition

- Understand the implications for scale up to full-scale

- Understand the relative need and implications in the treatment of particulate vs. dissolved mercury

- Provide the data necessary (but not necessarily sufficient) for preliminary full-scale process design (this is a simplified design rather than a detailed design)

- Understand residue generation rate, power consumption, frequency of backwashing, other maintenance and waste disposal issues (sustainability indices).

- Investigate treatability and disposal options for reject streams 
For each of the technologies tested, the work included 4 subtasks:

1- Preparation and review of pilot testing experimental plan

2- Start-up assistance

3- Pilot testing monitoring and support

4- Data analysis and final report.

\subsection{Technical Team Format and Structure, Roles and Responsibilities}

This project required extensive coordination of activities by a project team comprising BP (the Sponsor and Host), Purdue and Argonne (the technical evaluators and monitors), and the Vendors, (who provided the specific technology and equipment for the tests), as well as by third party analytical labs (sample collection and analysis). No significant decision was taken by any team member affecting the work plan without specific consent of the rest of the team, and deviations from the work plan were made by consensus by the technical team comprised of BP, Argonne and Purdue in consultation with vendor as necessary.

Roles and responsibilities of each Team Member Organization are summarized as follows:

- BP Whiting Refinery: hosts the pilot tests, provides site support, skilled operator monitoring of the pilot plants including hookups (flange-to-flange) up to vendor equipment and runs/monitors/maintains the pilot-skids upon vendor instruction, records process data and collects process samples for hand held analytical instruments to determine the operational performance of the pilots, and facilitates third party lab visit to site for sample pick up and/or collection at the frequency requested in the experimental plans, informs vendor/ANL/Purdue technical personnel of trouble if the problem can't be fixed by site personnel, and ensures safe operation. Leases or purchases equipment directly from vendor. Purchases or provides chemicals and other supplies if needed for operation of pilot skids, is responsible for waste disposal, handling and/or processing. Attends weekly teleconferences and other technical meetings.

- Vendors (GE, Blue Water Technologies, Inc.) provide assistance to develop an experimental plan to meet the objectives of this study, provide and commission the skid at the site as contracted, supervise equipment start up, provide operator training including demonstration of pilot equipment operation and required daily maintenance, support operation by site visits, phone \& e-mail to assist with day-today project requirements including trouble shooting etc. Attend weekly or periodic teleconferences and other technical meetings. Work by vendors was detailed in the BP-Vendor contracts. 
- Argonne National Laboratory provided organization and project management, preparation of experimental plan including change management procedures, startup assistance, bench testing operations, pilot test monitoring and support, subcontracting with third party analytical labs, coordination of sample collection and analysis by third party analytical laboratories, data analysis and final report.

- Purdue participated in pilot-scale startup and training, in weekly teleconference and other meetings, reviewed and analyzed analytical data from third party labs and operating data, assisted in evaluating the performance and providing comments to optimize the pilot unit, shared their observations with the project team, and prepared an evaluation of the performance of the pilot units for inclusion in this final report to BP.

\subsection{Report Organization}

This report summarizes the Module 4 results in a comprehensive format. As two organizations were involved in data analysis and interpretation, this report collects two independent sets of evaluations of the testing that was conducted, prepared respectively by Argonne and Purdue University Calumet. The main body of the report (sections 1-4) was prepared by Argonne and includes an account of the activities and data interpretation conducted by Argonne. Results from Purdue are found in a separate section (section 5). Each organization retains sole responsibility for its respective analysis, conclusions and recommendations.

After a brief introduction and summary of previous work (Section 1), Section 2 summarizes the results from the Membrane Ultrafiltration testing, and Section 3 summarizes the Blue PROß Reactive filtration testing. A general summary and conclusions of Argonne are found in Section 4. The evaluation of the performance of both pilot units from the Purdue team is found in Section 5. Section 6 includes Argonne and PUC the joint summary and conclusions. 


\section{Ultrafiltration Pilot Testing}

\subsection{Introduction}

\subsubsection{Background}

Module 4 Ultrafiltration pilot testing, which is described in this section of the report, covers in detail the pilot testing of the membrane ultrafiltration technology identified as promising at the bench-scale in Module 3 [1]. The Module 4 membrane filtration pilot-scale testing was an Argonne/PUC directed project that was hosted by the BP refinery in Whiting, IN.

Ultrafiltration, an established technology with many full-scale applications in water and wastewater treatments and in membrane bioreactors, was chosen for the removal of particulate mercury. Among many vendors' technologies, GE’s ZeeWeed ${ }^{\circledR}$ UF hollow fiber membrane technology $(0.04 \mu \mathrm{m}$ nominal pore size and made up of PVDF) was selected based on a decision matrix criteria, including technology readiness, installations and experience at large plants, applicability to treat 40 MGD of refinery wastewater, experience in the treatment of refinery wastewater, scalability, skid availability, operation assistance, etc.[1]. Testing this GE pilot-scale membrane skid required high wastewater flow rates and therefore was performed at the Whiting Refinery.

This pilot-study included feed (pre-ETL) characterization activities, demonstration of the pilot-scale performance of the membrane ultrafiltration technology with continuous feed and varying pre-ETL compositions and data analysis for further technology evaluation.

\subsubsection{Overview of GE's UF Technology $[2,3]$}

The ZeeWeed ${ }^{\circledR} 500$ system operates under a low-pressure vacuum that is induced within the hollow membrane fibers by a connection to the suction side of a permeate pump. The membrane with 0.04 micron pore size potentially ensures no particulates pass through into the treated water. The treated water is drawn through the membrane by vacuum, enters the hollow fibers and is pumped out by the permeate pumps. Airflow is intermittently introduced at the bottom of the membrane module to create turbulence that scrubs and cleans the outside of the membrane fibers. This reduces the solids accumulation on the membrane surface. It also provides mixing within the process tank to maintain solids in suspension. For further cleaning, a backpulse of filtered water is periodically passed from the inside to the outside of the membrane to disrupt any particles that may be physically lodged in the membrane interstices. 


\subsection{Pilot Testing}

\subsubsection{Goals and Objectives}

The UF pilot testing was performed at the Whiting Refinery using a slipstream of treated effluent taken just prior to the Effluent to Lake (pre-ETL) outfall as the influent waste stream to demonstrate performance with continuous but varying feed conditions over a protracted period. It was the intention of this pilot testing to demonstrate proof of concept, i.e. can the results obtained at bench-scale be consistently met at the pilot scale. Optimization for full-scale design was outside of the scope of this work.

The overall objective of this work was to demonstrate the effectiveness of membrane UF technology with continuous and varying feed conditions to meet the future Great Lakes $\mathrm{Hg}$ criterion (1.3 ppt). The specific objectives of this work were discussed on page 3.

\subsubsection{Scope / Tasks}

The pilot-scale study was designed and performed in such a manner as to achieve the project objectives by conducting the following tasks:

- Demonstrate the suitability of the ZeeWeed ${ }^{\circledR} 500$ technology to remove $\mathrm{Hg}$ (mostly in particulate and colloidal form) from pre-ETL to a level that meets the Great Lakes criterion over a 17 week period under varying feed conditions. Goals for the discharge were to meet the Great Lakes Hg criterion of $1.3 \mathrm{ppt}$ as well as to determine the capability of UF in removing $\mathrm{V}$, As and Se from pre-ETL.

- Schedule samplings based on the operational needs and coordinate the collection and analysis of samples by the third party analytical laboratory.

- Identify reproducibility of the obtained test results (when the system is at steady state) and plan for multiple sampling/analysis events to understand test and analytical error as well as to determine the background Hg contamination level at site, equipment and reagent blank samples and Hg contamination/loss in method blank samples.

- Monitor and review process and performance data to be provided by GE/BP and third party analytical labs, respectively on determination of optimal design parameters that would generate stable membrane performance.

- Evaluate the effectiveness of cleaning regimes developed by GE to minimize the membrane fouling and provide insight for the treatment of backwash waste.

- Evaluate the process performance of the ZeeWeed $500 ®$ technology with respect to the operating parameters and design criteria for scale-up. 


\subsubsection{Membrane, Process, and Pilot Descriptions $[2,3]$}

The pilot study was performed using a ZeeWeed® 500 pilot unit (Figure 2.1) with three (3) low energy immersed ZeeWeed® 500 membrane modules (Figure 2.2 and Table 2.1) manufactured by GE Water \& Process Technologies in Hungary. The ZeeWeed® low energy immersed membrane process consisted of outside-in, hollow-fiber modules immersed directly in the wastewater feed source.

In order to evaluate the performance of membrane unit, the following operating parameters were measured and monitored over the study:

1. Flux: The pilot unit was operated at constant flux (Flux A and Flux B) with varying system recoveries ( $\mathrm{X}, \mathrm{Y}$ and $\mathrm{Z} \%$ ). Flux is a temperature dependent operating parameter. In order to compare the flux values, all data were recalculated to obtain flux values at constant temperature, $20^{\circ} \mathrm{C}$ using the formula given below:

Flux at $20^{\circ} \mathrm{C}=$ Flux at $\mathrm{T} \times 1.025^{(20-\mathrm{T})}$

where $\mathrm{T}$ is the operating temperature (in ${ }^{\circ} \mathrm{C}$ ). During the pilot study, instantaneous fluxes were measured. Net flux including backwash was also determined for the fullscale membrane process design.

2. Transmembrane pressure (TMP): As mentioned before, the pilot unit is designed to operate at a constant flux. As the membrane becomes fouled, the TMP increases. A recovery clean is required once the membrane pressure reaches approximately 8 to 12 psi.

TMP is also a temperature dependent operating parameter. In order to compare the TMP values, all data were recalculated to obtain TMP values at constant temperature, $20^{\circ} \mathrm{C}$, using the formula given below

TMP at $20^{\circ} \mathrm{C}=\mathrm{TMPat} \mathrm{T} / 1.025^{(20-\mathrm{T})}$

3. Permeability: Membrane permeability is calculated by dividing the flux values by the measured TMP values. Permeability is also another temperature dependent parameter. In order to compare the permeability values, all data were recalculated to obtain permeability values at constant temperature $\left(20^{\circ} \mathrm{C}\right)$ so that the membrane fouling could be easily determined. The following formula was used for the permeability calculations:

Permeabili ty at $20^{\circ} \mathrm{C}=$ Permeabil ity at $\mathrm{T} \times 1.025^{(20-\mathrm{T})}$ 
4. Recovery: The pilot unit was operated at three different system recoveries: $\mathrm{X}, \mathrm{Y}$ and $\mathrm{Z} \%{ }^{1}$. The reject stream flow was calculated to maintain the desired recovery setpoint at the unit.

5. Backwash properties: During this pilot study, the backpulse flux was varied. The reject stream was continuously directed to the floor drain. Backpulse pressure is the transmembrane pressure required to push clean water from the inside to outside of the membrane during a backpulse. Backpulse permeability is a calculated parameter that represents the permeability of the membrane observed when the flow through the membrane is reversed. The backwash samples were collected in the middle of the backwash cycle to collect representative sample for $\mathrm{Hg}$ analysis.

Air is applied during the backwash, deconcentration and maintenance clean procedures for the ZeeWeed® 500 process. During the pilot test, airflow to the modules was provided during backwash or maintenance cleans. Only one deconcentration was employed during pilot operation due to prolonged shut down of the system.

6. Membrane cleaning: The ZeeWeed® 500 process utilizes maintenance cleans, using sodium hypochlorite solution for organic fouling, to mitigate the membrane fouling rate and prolong time between recovery cleans. The maintenance clean refers to a period of non-production. In the case of this pilot study, full tank soak-type maintenance cleans were employed on a weekly basis, utilizing sodium hypochlorite to control organic fouling. During this type of maintenance clean, the membrane tank was first drained and the hypochlorite solution was added while the tank was refilled with potable water. Then, the membranes were allowed to soak for several minutes. This maintenance clean regimen was employed as a precautionary measure to mitigate any potential organics fouling.

A recovery clean or Clean-in-Place (CIP) is required to restore the permeability of the membrane once the membrane is fouled to the extent that it cannot produce the desired quantity of water or it has reached a predetermined length of operation. In a ZeeWeed® 500 pilot system, if terminal TMP reaches 7-12 psi in less than 30 days, a recovery clean should be performed. Two CIP events were performed during the pilot study. A CIP was performed on August 26, 2011 to assess the percent loss of permeability and determine if irreversible fouling had occurred after the prolonged unit shutdown. This cleaning involved a 4 hour soak in a citric acid solution to mitigate the inorganic fouling, followed by a 4 hour soak in a sodium hypochlorite solution. The cleaning solutions were not heated since the solution temperatures ranged from $26^{\circ} \mathrm{C}$ to $28{ }^{\circ} \mathrm{C}$. At the conclusion of the pilot study, September $22 \mathrm{nd}$, the

\footnotetext{
${ }^{1}$ Actual operating conditions are proprietary to GE and therefore cannot be disclosed in this report.
} 
second CIP was performed. This clean again involved a 4 hour soak in a citric acid solution, followed by a 4 hour soak in a sodium hypochlorite solution. The cleaning solutions were not heated since the solution temperatures ranged from $22{ }^{\circ} \mathrm{C}$ to 24 ${ }^{\circ} \mathrm{C}$.

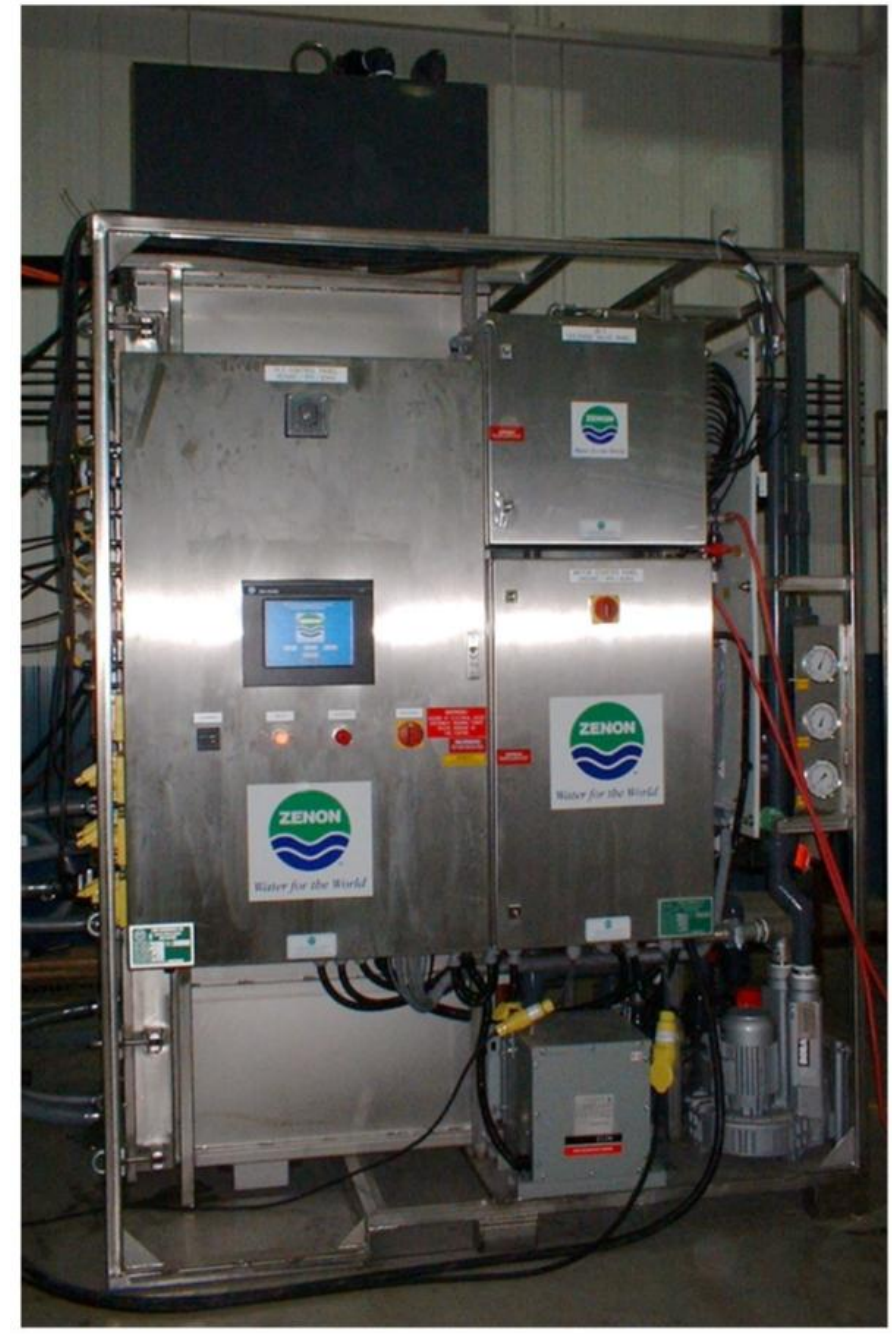

Figure 2.1 GE Pilot-unit Used in This Study

(Permission to use photograph granted by GE Power \& Water) 

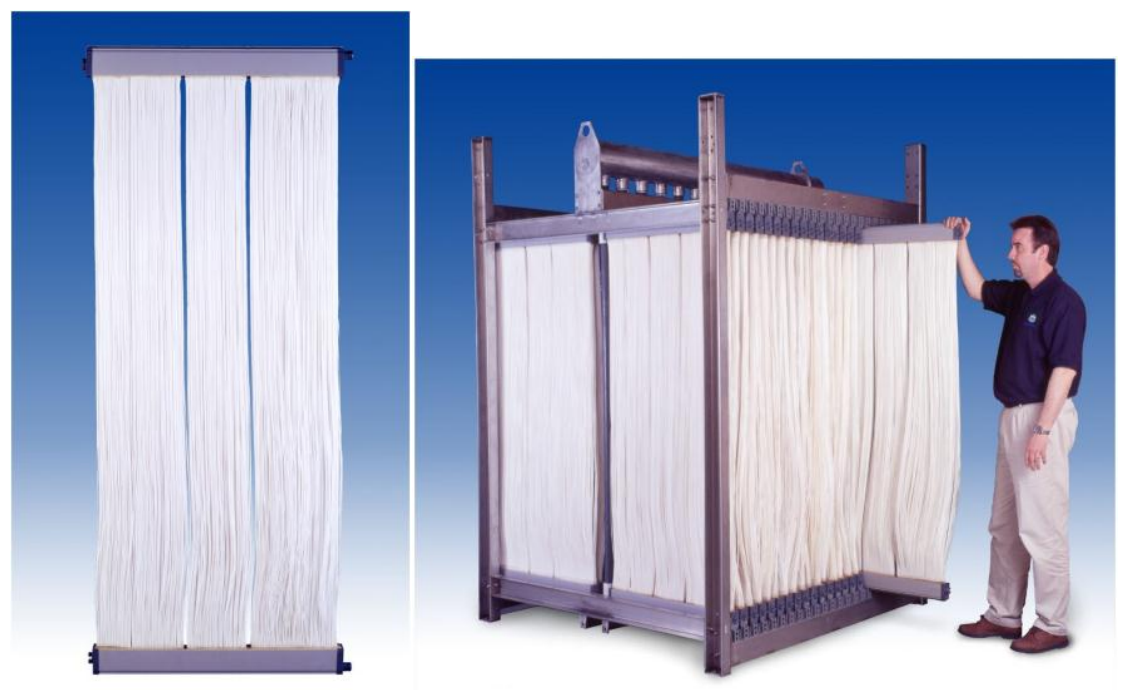

ZeeWeed ® 500 Cassette

ZeeWeed® 500Module

Figure 2.2 Membrane Module and Cassette

(Permission to use photograph granted by GE Power \& Water)

Table 2.1 ZeeWeed $® 500$ Membrane Module Characteristics

\begin{tabular}{|l|l|}
\hline Characteristics & Value \\
\hline Nominal membrane pore size & $0.04 \mu \mathrm{m}$ \\
\hline $\begin{array}{l}\text { Typical operating transmembrane } \\
\text { pressure }\end{array}$ & -1 to $-12 \mathrm{psi}$ \\
\hline Maximum operating temperature & $40^{\circ} \mathrm{C}$ \\
\hline Operating pH range & 5.0 to 9.5 \\
\hline
\end{tabular}


Pilot feed water was sourced from the ETL-line just prior to outfall (pre-ETL) at the BP Whiting Wastewater Treatment Plant. The stream was planned to pass through a 500 micron basket strainer prior to entering the treatment equipment to protect the pilot equipment and membranes from potentially damaging objects and not to provide any treatment. However, it was decided not to use it over the pilot-study due to pressure buildup at the feed line (Please see section 2.5). Therefore, the wastewater was directly treated by the ZeeWeed ${ }^{\circledR} 500$ pilot system to remove the suspended mercury as well as any particulates. The permeate and the backwash streams were directed to a floor drain for disposal and further treatment within the refinery's wastewater treatment plant.

In its most basic mode of semi-batch operation, the ZeeWeed $®$ system alternated between permeation and backpulsing. The permeation refers to the period of time when treated water is drawn through the membrane fibers by vacuum and is pumped out for distribution (or, in the case of the pilot, to drain). During backpulsing, filtered water from the backpulse tank containing permeate is passed from the inside to the outside of the membrane to disrupt any particles that may be physically lodged in the membrane interstices. As clean water is pulled through the membrane during permeation, solids are left behind and the process tank becomes ever-increasingly concentrated. By rejecting some of the water from the tank at a pre-determined rate, the solids' concentration is controlled (Figure 2.3). Reject is achieved through a continuous bleed of process tank water while the membrane tank level is maintained by controlling feed flow. The amount of reject controls the overall system recovery (i.e. \% of feed water that becomes treated water), so that the system achieves a desired recovery $[2,3]$.

During the skid operation air is used for all the operation modes, including filtration, backwash and cleaning. At the end of the filtration cycle (typically 10 to 30 minutes), a backwash is performed for 10-20 seconds. During the backwash, the membranes are simultaneously aerated and backpulsed to dislodge solids. The filtration cycle then resumes.

\subsubsection{Pilot Operating Methodology [2, 3,]}

The GE pilot unit is designed to operate at constant flux rate. Backwash flux can be varied during the skid operation. The vacuum pressure is in the range of 1-12 psi to maintain the desired flux rates. During the skid operation air flow rate is kept constant. The maintenance clean frequency is typically once or twice a week.

The best operating conditions for UF membrane were determined as a function of the flux rates and the system recovery during the pilot-study. Each operating condition was tested at least for 12 days by monitoring the system performance and evaluating the analytical data. The performance of UF membrane technology was not only evaluated in terms of its 
ability to meet targeted Hg effluent limits in the treated pre-ETL, but also in terms of maintaining a stable process performance over the study.

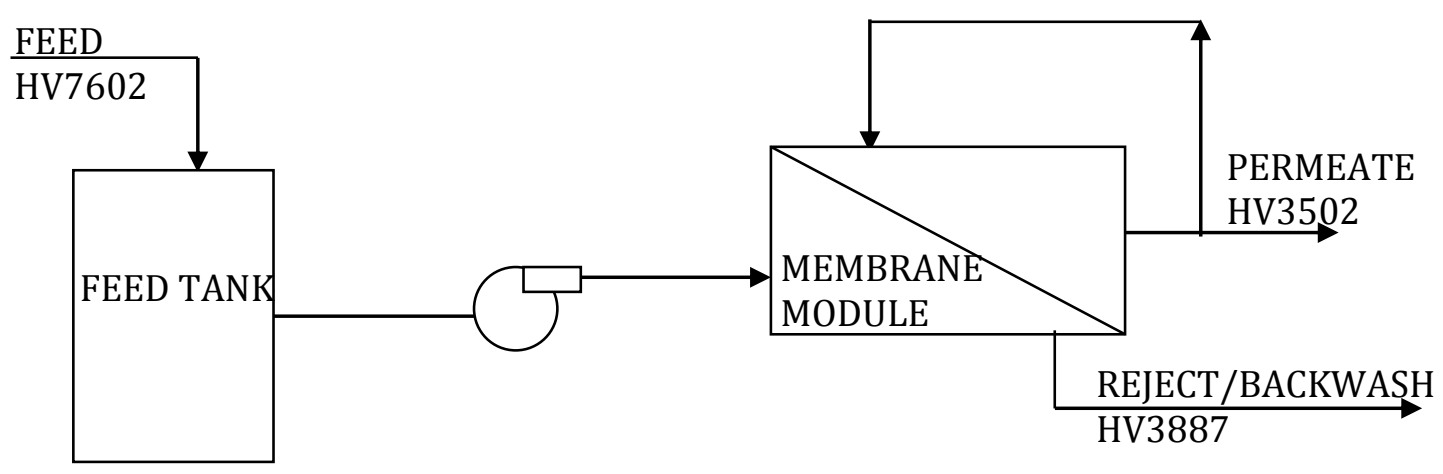

Figure 2.3 GE UF Pilot Process Schematic

\subsubsection{Pilot-study Work Plan and Pilot Operation}

As mentioned before, the best operating conditions for the UF membrane were determined as a function of the flux rates and the system recoveries during the pilot study. The UF membrane technology performance was evaluated in terms of its ability to meet target of $1.3 \mathrm{ppt} \mathrm{Hg}$ concentration in the treated ETL as well as maintaining a stable performance of the unit over the study period. Table 2.2 outlines the project schedule with the respective tasks to be achieved during the piloting.

Table 2.2 GE UF Pilot-study Schedule

\begin{tabular}{|l|l|l|}
\hline \multicolumn{2}{|l|}{ Time Period } & Task \\
\hline $\begin{array}{l}\text { Pilot } \\
\text { commissioning }\end{array}$ & $\begin{array}{l}\text { 2 and 1/2 days } \\
\text { (May 24-26, 2011) }\end{array}$ & Pilot commissioning and start up \\
\hline Phase 1 & $\begin{array}{l}\text { 26 days of operation } \\
\text { (May 26- June 21, } \\
\text { 2011) }\end{array}$ & $\begin{array}{l}\text {-Steady-state operation- Flux A with } \\
\text { X\% recovery } \\
\text {-Demonstration of Hg removal }\end{array}$ \\
\hline Phase 2a & $\begin{array}{l}\text { 15 days of operation } \\
\text { (June 21-Aug 16, } \\
\text { 2011) }\end{array}$ & $\begin{array}{l}\text {-Optimization of pilot operation: } \\
\text { Flux B with X\% recovery }\end{array}$ \\
\hline Phase 2b & $\begin{array}{l}\text { 21 days of operation } \\
\text { (Aug 16-Sep 9, 2011) }\end{array}$ & $\begin{array}{l}\text {-Optimization of pilot operation: } \\
\text { Flux A with Y\% recovery }\end{array}$ \\
\hline Phase 2c & $\begin{array}{l}\text { 12 days of operation } \\
\text { (Sep 9-Sep 22, 2011) }\end{array}$ & $\begin{array}{l}\text {-Optimization of pilot operation: } \\
\text { Flux A with Z\% recovery }\end{array}$ \\
\hline $\begin{array}{l}\text { Phase 3 days } \\
\text { Pilot } \\
\text { Decommissioning }\end{array}$ & $\begin{array}{l}\text { Collection of membrane and final } \\
\text { rinse samples for Hg analysis and } \\
\text { pack-up pilot equipment }\end{array}$ \\
\hline
\end{tabular}


After the delivery of the pilot unit to BP Whiting, it was set up by GE personnel. All plumbing and all electrical connections were done by BP personnel per guidance from GE.

\section{Pilot Commissioning and Start-up}

The first week was allotted for the pilot equipment start-up. During this time the pilot operability was verified, the control systems were tuned, and the data and the sample collection programs were initiated.

The initial start-up of this pilot skid was done by the GE pilot engineer and BP engineers/operators based on technical input by ANL personnel. The pilot commissioning included the following activities:

a. Blanks Collection.

An EPA certified analytical lab, namely Lab A, collected reagent and equipment blanks and background samples (environmental samples) with oversight from Argonne.

$\underline{\text { Reagent blanks }}$

All reagents that were used during the pilot testing were sampled during the initial startup of the pilot unit and analyzed for mercury and other metals by Lab A with oversight from Argonne. The aim was to determine whether the chemicals and potable water were adding mercury or other metals of interest to the system. The citric acid (50\% Batch 1125 , GE Betz Inc., Trevose, PA) and sodium hypochlorite (12.5\%) were sampled in triplicates for total $\mathrm{Hg}$ analysis while potable water was sampled in five replicates for total Hg analysis.

Method, equipment and environmental blanks

Prior to pilot testing of the GE UF membrane unit for the ETL treatment, two different blanks were planned: equipment and reagent blanks. As the skid cannot be operated without membrane modules, the collection of method blanks was not possible. The equipment blanks were collected from the pilot skid operating on potable water provided by the Whiting Refinery. Potable water was run through the membrane system as an equipment blank to identify whether the skid was contributing mercury or other metals of interest. The potable water was sampled before it was introduced to the membrane unit and after 24 hours of membrane operation to determine the gain or loss of mercury, or other metals of interest. The skid was run with $\sim 250$ gallons of potable water under batch mode for 24 hours. The retentate stream was also analyzed for mercury and other metals to identify any contamination (gain) or loss during operation of the unit.

A series of background samples (environmental blanks) were also collected by Lab A to determine the contamination potential of the air in the pilot unit location. The environmental blanks were collected by placing sample bottles used for $\mathrm{Hg}$ analysis next to 
or near the location of the pilot unit. The bottles were left open for about one hour. The main focus of the testing was to establish whether any of the mercury present in the air (if any) was transferring to the liquid phase used during the pilot study. Although the feed to the unit was in an enclosed pipe, the feed and effluent streams were only exposed to air during the sampling. This was done to determine whether any contamination during the sampling was introduced to the collected samples as a part of QA/QC plan. An additional test for arsenic (As), selenium (Se), and vanadium (V) was also conducted to ensure completeness.

b. Clean Membrane Permeability.

During the initial startup, the skid was operated with the potable water under batch-mode. The permeate rates and TMP values that were recorded automatically on the skid were used to determine the clean membrane permeability. This data was important to understand the fouling characteristics of pre-ETL wastewater and served as a basis of comparison for the permeability values during the membrane operation as well as after cleaning procedures. The effectiveness of membrane cleaning procedures in improving the flux recovery was mostly determined based on the comparison with the clean membrane permeability. Clean membrane permeability data is not given in this report because it is GE's proprietary information.

c. Calibration of the Hand-held Instruments and Pumps.

Instrumentation calibration: During the pilot commissioning, Argonne personnel and a BP operator calibrated hand-held instrumentation according to procedures provided by Project Team (Appendix 2A).

Pump calibration: Before being used, the pumps that fed the citric acid and hypochlorite solutions to the pilot-skid were calibrated by GE and ANL personnel to measure the flow rate as a function of the pump setting. During each pump's calibration, each flow rate was measured with a graduated cylinder and stopwatch in triplicate. An average flow rate for each pump setting was determined and used during the pilot-study.

Following initial start-up, the pilot skid was run by BP operators, according to procedures provided by the Project Team [2, Appendix 2A]. BP operators were responsible for checking and maintaining the pilot skid operation (including recording and collection of process data as necessary) as directed by the Project Team while Lab A contracted by Argonne collected performance samples and conducted the required analysis at the frequency requested in section 2.2.5. BP operators also implemented any changes to the experimental test conditions as recommended by the Project Team. 


\section{Phase 1 - Method Validation \& Determination of Design Conditions}

Phase 1 of the study started after the skid commissioning. The goal of this phase was to demonstrate the mercury removal capability of the membrane process and to determine the optimum process conditions for the membrane system. The priorities during the piloting were as follows:

I. Achieve low Hg levels in the effluent

II. Maximize percentage recovery

III. Obtain economically viable flux rates based on vendor-set criteria (proprietary).

Maintaining a stable TMP (with a $10-20 \%$ fluctuation was also an important criterion during the operation of pilot unit.

The pilot operating conditions during this phase are shown in Table 2.2. The skid was operated under a constant flux rate and recovery (Flux A and $\mathrm{X} \%$ recovery) to meet the target effluent $\mathrm{Hg}$ concentration $(\mathrm{Hg}<1.3 \mathrm{ppt}$ ). The maintenance clean frequency was typically once or twice a week. This cleaning frequency was sufficient to maintain a stable membrane performance.

\section{Phase 2 - Determination of Optimum Conditions}

Phase 2 was conducted to demonstrate the amount of mercury removal and to evaluate the system performance over changing operating conditions.

Phase 2a: Flux B and X\% recovery The optimum operating conditions for the UF membrane were determined by increasing the flux rate to Flux B while maintaining the percentage recovery constant at X\% to meet the target effluent $\mathrm{Hg}$ during the Phase 2a. Increasing the flux rate tends to stress out the system and increase TMP, resulting in an increased membrane fouling rate (section 2.3.2.2). Furthermore, the pilot study was performed over the summer $\left(\mathrm{T}_{\text {avg }}=32.9^{\circ} \mathrm{C}\right)$. The operation might be more challenging at the same flux rate during the winter. It may be harder to obtain the same process stability during the winter because of the higher viscosity of the wastewater. BP's historical data indicates that the average feed temperature was $26.7^{\circ} \mathrm{C}$ in 2009 , ranging from $18.3^{\circ} \mathrm{C}$ to $37.8^{\circ} \mathrm{C}[1]$.

\section{Phase 2b: Flux A and Y\% recovery:}

Lower water temperature results in higher resistance to flow because the viscosity of the water increases as temperature decreases. Considering the seasonal variations in the feed temperature, the flux rate was decreased to Flux A while the system recovery was increased to Y\% during Phase $2 \mathrm{~b}$. 


\section{Phase 2c: Flux A and Z\% recovery}

During Phase $2 b$, TMP values were very stable and didn't reach the critical 7-12 psi level when the unit was operated at Flux A and Y\% recovery. Therefore, Phase 2c experiments were conducted at Flux A and Z\% recovery.

\section{Phase 3 - Equipment Decommissioning}

As mentioned in section 2.2.4, the second CIP was performed at the conclusion of this pilot study. Following the pilot study completion, the post recovery cleaning samples were collected for total $\mathrm{Hg}$ analysis. Prior to decommissioning of the pilot, the backwash stream was also collected by Lab A for further backwash treatment studies at Argonne. A GE W\&PT representative was on site to decommission all equipment and aid BP in preparing the equipment for shipping. Membrane fibers were also collected during the equipment decommissioning. The collected samples were analyzed for Hg by Lab A and GE W\&PT.

\subsubsection{Operational, Analytical and QA/QC Requirements}

\subsubsection{Sample Collection and Analysis Schedule}

The operational requirements to run and maintain the pilot-skid properly are described in GE's Pilot Manual (ZeeWeed ${ }^{\circledR} 500$ Pilot Manual) [3] and were explained by GE's pilot engineer during the operator training after the pilot unit commissioning.

A detailed list of the analytes and their sampling frequency was refined as a part of the experimental work plan (Appendix 2B). The majority of the samples, including feed characterization and technology performance assessment samples, were collected and analyzed by a third party analytical laboratory for the parameters listed in Table $2 \mathrm{C}-1$ of Appendix 2B. The project team revised the analytical schedule after one month of the sampling events (Table 2.3). Proper collection techniques were employed for the target tests. The roles and the responsibilities of the third party labs in this pilot-study are discussed in detail in section 2.2.5.2. 
Table 2.3 Revised Sample Collection and Analysis Schedule

\begin{tabular}{|l|l|l|l|l|l|l|}
\hline Parameter & Method & $\begin{array}{l}\text { Pilot } \\
\text { Feed } \\
\text { HV7602 }\end{array}$ & $\begin{array}{l}\text { Pilot } \\
\text { Permeate } \\
\text { HV3502 }\end{array}$ & $\begin{array}{l}\text { Pilot } \\
\text { Backwash } \\
\text { Reject } \\
\text { stream } \\
\text { HV3887 }\end{array}$ & $\begin{array}{l}\text { Maintenance } \\
\text { Clean Waste } \\
\text { HV3887 }\end{array}$ & $\begin{array}{l}\text { Sample } \\
\text { Analysis/Collection }\end{array}$ \\
\hline Turbidity & - & On-line & On-line & - & - & On-line and Lab A \\
\hline Temperature & - & On-line & -- & - & Wn-line and Hand \\
pH & $\underline{\text { SM 4500 }}$ & MWF & MWF & MWF & Hand Held (BP) \\
\hline TSS & $\underline{\text { SM 2540 }}$ & M-F & - & M-F & W & Lab A \\
\hline $\begin{array}{l}\text { Specific } \\
\text { conductivity }\end{array}$ & - & MWF & MWF & MWF & W & $\underline{\text { Hand Held (BP) }}$ \\
\hline $\begin{array}{l}\text { Mercury Size } \\
\text { Distribution }\end{array}$ & SM 2560B & W & W & W & W & Lab A / Argonne \\
\hline Total Hg & EPA 1631 & M-F & M-F & M-F & W & Lab A and Lab B \\
\hline Dissolved Hg & EPA 1631 & M-F & -- & M-F & W & Lab A and Lab B \\
\hline
\end{tabular}


In order to determine the operational performance of the pilot tests, there were several parameters that needed to be recorded at various frequencies onsite. A list of operational parameters and their respective recording frequencies are provided in the "Daily Log Sheet" in Appendix 2B. All process samples were collected and measured by BP operators. Hand held instruments were utilized for the onsite measurements. The results were recorded on the "Daily Log Sheet". BP operators collected and recorded data daily to verify that the pilot unit was running as desired. The sample collection procedures were provided by Argonne.

\subsubsection{Quality Assurance and Quality Control Plan}

\subsection{Sampling and Analysis during the Pilot-study}

Argonne contracted two analytical laboratories to conduct analyses of the Whiting Refinery wastewater in support of the pilot-scale tests. Both laboratories offer certified qualitydriven services and comply with all quality requirements mandated by regulators. Lab A is authorized to access the Whiting Refinery Wastewater Treatment Plant and is proficient both in collecting samples by using the "clean hands-dirty hands" procedure required by the EPA 1669 method and in conducting low-level mercury analysis per the EPA 1631E method $[4,5]$. Lab A collected samples at the frequency requested in the pilot work plans (Appendix 2B).

Argonne routinely instructed Lab A for the collection of samples, management of sample labeling, coding and tracking and the selection of appropriate method for analysis. During the Phase $2 \mathrm{~b}$ and Phase 2c, Lab A collected and delivered samples to Argonne weekly.

During Phase $2 \mathrm{~b}$ and Phase 2c, Argonne also requested Lab A to collect split samples from each sampling point and send one set of samples to Lab B for a side-by-side comparison analysis to confirm the pilot-test results. Lab B was used for the confirmation of pilot test results reported by Lab A during Phase $2 \mathrm{~b}$ and Phase $2 \mathrm{c}$ of this pilot-study. Lab B offers advanced analytical capabilities in mercury analysis and has been extensively involved in the development of the EPA 1631E method [5]. Lab B offers an advantage in that it is able to further refine the EPA $1631 \mathrm{E}$ method so that the recovery rates are higher, thus providing better resolution of differences among samples at very low concentrations near the detection limit. For this comparison, eight weekly sampling events were conducted to obtain statistically meaningful data. The details of these sampling events are discussed in section 2.7.2.4.

Equipment and reagent blanks, field sampling blanks, and trip blanks were collected and analyzed by Lab A. The blanks generated from the initial start- up were analyzed for total mercury and total concentration of other metals as discussed in detail in section 2.2.4.1. The equipment blanks were taken after the system was flushed with nonpotable water. 
This served to establish background levels of the analytes within the pilot-skid. Reagent blanks were collected for the reagents used in this pilot-study to establish the sources of potential interference. The reagents used during the UF piloting were given in section 2.2.4.1.

If the analysis of any blank resulted in the detection of interfering levels of $\mathrm{Hg}$ or metal of interest, an evaluation of the source took place, such as the presence of $\mathrm{Hg}$ in the cleaning reagents. The analytical results generated from the blank collection events were analyzed for $\mathrm{Hg}$ to determine whether it would be accepted with appropriate qualifications or rejected.

\subsection{Analytical Lab Test Results}

The reported recoveries of the matrix spike (MS) /matrix spike duplicates (MSD) were reviewed to determine whether they fulfilled the requirements of Method 1631E (a large bracket of 71-125\%)[5] and other methods specified in Table 2B-1 of Appendix 2B as well as to assess the precision and the recovery of the analysis performed by the third party labs. Method and field blanks were also reviewed to ensure that pilot data had acceptable quality.

\subsection{Instrument Calibration: $\mathrm{pH} / \mathrm{ORP} /$ Conductivity Meter and Turbidity Meter}

Throughout the pilot work, the various hand-held instruments were used and calibrated according to the methods outlined in the manufacturers' instruction manuals. Each month, the $\mathrm{pH} / \mathrm{mV} /$ conductivity probes were calibrated with the standard $\mathrm{pH}$ solutions $\mathrm{pH} 4.0$, 7.0 and 10.0) (Hanna Instruments, Italy), the conductivity standard solutions (84 microS/cm and 1413 microS/cm) (Hanna Instruments, Italy), and the ORP standard solution (YSI, Yellow Spring, $\mathrm{OH}$ ). The turbidimeter was also calibrated monthly with a turbidity standard solution (20 NTU) (Hach, Loveland, CO).

The calibration test results were recorded on the calibration documentation worksheet and kept in the project folder. The calibration documentation worksheet was not only served as a document for the calibration of instruments for QA/QC purposes, but also tracked the performance of the hand-held instruments during the piloting.

\subsubsection{Split Sample Collection Events}

During Phase $2 \mathrm{~b}$ and Phase 2c, Lab A collected samples from each stream and sent one set of the split samples to Lab B for a side-by-side comparison analysis for the confirmation of pilot-test results as discussed in section 2.2.5.2.2. 


\subsubsection{Particle Size and Size Distribution Analysis}

Argonne performed particle size and size distribution analysis during the Phase $2 \mathrm{~b}$ and Phase 2c to determine the correlation between Hg concentrations and particle size distribution and obtain a better understanding of the Hg removal mechanism by ultrafiltration membrane technology. The feed, permeate and backwash samples were collected for this analysis when the split samples were collected by Lab A (see schedule in Appendix 2B). The collected samples were analyzed at Argonne within one day after sample collection. The particle size and size distribution analysis (PSA) were conducted by using a Cilas 1190 (Orleans, France) analyzer with an MDL of $0.04 \mu \mathrm{m}$. This analyzer works on the principle of light obscuration. The test results were presented both as volume and number distributions for eight sampling events at each stream.

\subsubsection{Data Management}

\subsubsection{BP Generated Data}

BP hosted the pilot demonstration at the Whiting Refinery. During the pilot-study, BP operators collected the process samples and recorded the process data (Daily Log Sheet in Appendix 2B) as discussed in section 2.2.5.1.

The project folder was kept onsite to log pilot study observations, sampling events, process data, equipment/instrument calibration and maintenance. During the pilot testing, BP operators scanned the folder contents weekly and sent them to Argonne in electronic form, such as an Excel Spreadsheet or pdf scans of the daily log sheets. Argonne shared BP generated data with the project team members before the weekly teleconference meetings, so that the project team could use this information to verify that the pilot operation was proceeding as planned, and to plan future pilot operation conditions and to analyze the pilot-data.

\subsubsection{GE Generated Data}

Following the completion of the study, GE prepared and submitted a report collected from the entire pilot testing program. GE's report was not included in this report since it contains GE proprietary and confidential information. Some of the online recorded operational parameters including flux rate, TMP, turbidity, temperature are summarized later in section 2.3 . 


\subsubsection{Analytical Data}

Both Lab A and Lab B provided test results in electronic form, such as pdf and excel format within the agreed upon turnaround time (5-10 days) to designated ANL personnel. Both labs reported the test results with a Level II data package which included the matrix spike (MS) /matrix spike duplicates (MSD) recoveries.

\subsubsection{Argonne Generated Data}

Argonne generated data includes the pilot sampling test results that were received from the third party analytical laboratories as well as the analysis of these test results. The raw and analyzed data are given and discussed later in section 2.3.

During the pilot scale testing, data reduction, processing and review were continuously conducted by Argonne to determine the optimal design parameters that would generate a stable membrane performance as well as to make any needed modifications in the experimental plan. In addition, the pilot-scale test data were used to conduct assessments of the potential implementation costs, the space requirements, the waste generation, and potential process issues that may have arisen.

Argonne also analyzed the particle size and size distribution in the samples collected and delivered by Lab A during the Phase $2 \mathrm{~b}$ and Phase 2c. The data generated from these analyses were recorded in the lab notebook. Test results are summarized later in section 2.3 of this report.

\subsubsection{Management of Proprietary Data from BP and GE}

In order to provide an informed, technically valid test program, Argonne acquired proprietary information from both BP and GE. IP control is governed by two-way Non Disclosure Agreements between Argonne and each of the project team members.

Proprietary information was not be transmitted outside of the project team unless specific approval was obtained from the owner of the information in question (Table 2.4).

Table 2.4 Proprietary Information

\begin{tabular}{|l|l|}
\hline Owner & Proprietary information \\
\hline BP & $\begin{array}{l}\text { 1. Wastewater characteristics } \\
\text { 2. Pilot-test results }\end{array}$ \\
\hline GE & $\begin{array}{l}\text { 1. ZeeWeed } \AA \text { membrane technology } \\
\text { 2. Operating conditions }\end{array}$ \\
\hline
\end{tabular}




\subsection{Results and Discussion}

The on-site pilot testing was conducted from May 26 through Sep 22, 2011 with a GE pilot membrane unit. The optimum operating conditions were determined as a function of the operating flux rate and the system recovery. As mentioned before, this pilot study was separated into three phases. Different operating conditions were tested for each phase to determine effectiveness of the membrane technology in terms of its ability to meet targeted limits in the treated ETL consistently as well as to maintain a stable TMP during the operation of the unit. An understanding of the nature of the pre-ETL characteristics was fundamental for the assessment of the effectiveness of the membrane technology. One of the problems that needed thorough consideration was the variation in feed $\mathrm{Hg}$ concentrations throughout the day compared to monitoring the feed stream with a daily grab sample collection. The UF membrane process consistently provided a constant permeate quality at the tested operating conditions, virtually independent of the feed water characteristics and feed $\mathrm{Hg}$ concentration. The permeate quality consistently met or exceeded the treatment goals of $<1.3 \mathrm{ppt} \mathrm{Hg}$. The four months of operating experience provided many useful insights into the design, operational and performance aspect of implementing an UF membrane process. This section includes wastewater characterization activities, demonstration of the membrane ultrafiltration technology performance and data analysis for further technology evaluation.

\subsubsection{Feed Water Characteristics}

Detailed wastewater characterization data required to determine the membrane performance were collected by four distinct sampling events: a) daily sampling events: to determine key wastewater characteristics required for monitoring the membrane unit performance b) weekly sampling events: to determine typical wastewater characteristics and their impact on the membrane operation c) composite sampling events d) split sampling events.

Table 2.5 presents a summary of the key wastewater characteristics required for the assessment of the membrane performance during the pilot study. The average feed $\mathrm{Hg}$ concentration of 41 sampling events was 5.95 ppt. The variations in the total $\mathrm{Hg}$ concentration were summarized in Table 2.5. Test results also revealed that most of the $\mathrm{Hg}$ in the ETL was in particulate or non-dissolved form. This data confirms the findings of the Module 3 report [1]. The average feed water turbidity was $5.1 \mathrm{NTU}$, ranging from $0.5 \mathrm{NTU}$ to $11.0 \mathrm{NTU}$. The average feed TSS concentration was $5.14 \mathrm{ppm}$, ranging from $1 \mathrm{ppm}$ to 16 ppm. Since the observed TSS and turbidity measurements were low, there was no need for the pretreatment of feed water. The wastewater temperatures ranged from $23.3^{\circ} \mathrm{C}$ to $38.6^{\circ} \mathrm{C}$ with an average of $32.9^{\circ} \mathrm{C}$. Temperature is an important parameter for both the operation of the membrane treatment process and the assessment of the membrane performance. As mentioned in section 2.2.4.1, most of the membrane performance 
parameters are temperature dependent. For example, TMP values required to maintain the same flux within the system are higher in the winter than that of the summer since the viscosity of water increases with decreasing temperature.

Organics, cations, and anions concentrations were measured as knowledge of these basic parameter was needed to determine the typical characteristics of the wastewater to assess impact on the membrane performance and to determine their fate as a results of the membrane filtration. The characteristics of the pre-ETL were not changed significantly during the weekly sampling events (Table 2.6). Based on the project team's evaluation, these analysis for these parameters were dropped after four sampling events due to following reasons:

a) Most of the measured analytes concentrations were relatively constant over the pilot study.

b) There were no big differences in feed and permeate streams test results with time as shown in Table 2.6.

c) The measured analytes concentrations didn't have any impact on the operation of the membrane process. 
Table 2.5 Key ETL Water Characteristics

\begin{tabular}{|c|c|}
\hline Parameter & Value \\
\hline $\begin{array}{ll}\text { Hg } & \\
\text { Minimum } \\
\text { Maximum } \\
\text { Average } \\
\text { \# of samples } \\
\end{array}$ & $\begin{array}{l}0.5 \mathrm{ppt} \\
22.7 \mathrm{ppt} \\
5.95 \mathrm{ppt} \\
41 \\
\end{array}$ \\
\hline $\begin{array}{l}\text { Dissolved } \mathrm{Hg}^{*} \\
\text { Minimum } \\
\text { Maximum } \\
\text { \# of samples } \\
\text { \# of detects } \\
\text { Average concentration with } \mathrm{Hg} \\
\text { detected samples } \\
\end{array}$ & $\begin{array}{l}<0.5 \mathrm{ppt} \\
1.05 \mathrm{ppt} \\
41 \\
3 \\
0.52 \mathrm{ppt}\end{array}$ \\
\hline $\begin{array}{l}\text { Turbidity } \\
\text { Minimum } \\
\text { Maximum } \\
\text { Average } \\
\text { \# of samples } \\
\end{array}$ & $\begin{array}{l}0.5 \mathrm{NTU} \\
11 \mathrm{NTU} \\
5.1 \mathrm{NTU} \\
16 \\
\end{array}$ \\
\hline $\begin{array}{l}\text { Temperature } \\
\text { Minimum } \\
\text { Maximum } \\
\text { Average } \\
\text { \# of samples } \\
\end{array}$ & $\begin{array}{l}23.3^{\circ} \mathrm{C} \\
38.6^{\circ} \mathrm{C} \\
32.9^{\circ} \mathrm{C} \\
50\end{array}$ \\
\hline $\begin{array}{l}\text { Minimum } \\
\text { Maximum } \\
\text { Average } \\
\text { \# of samples }\end{array}$ & $\begin{array}{l}6.78 \\
8.36 \\
7.62 \\
50\end{array}$ \\
\hline $\begin{array}{l}\text { Minimum } \\
\text { Maximum } \\
\text { Average } \\
\text { \# of samples }\end{array}$ & $\begin{array}{l}1 \mathrm{ppm} \\
16 \mathrm{ppm} \\
5.14 \mathrm{ppm} \\
38\end{array}$ \\
\hline
\end{tabular}

*Average calculated assuming $<0.5 \mathrm{ppt}=0.5 \mathrm{ppt}$ 
Table 2.6 Typical Characteristics of pre-ETL Wastewater

\begin{tabular}{|l|l|l|l|l|l|l|}
\hline Date & $\begin{array}{l}\text { FOG } \\
\text { (ppm) }\end{array}$ & $\begin{array}{l}\text { Total } \\
\text { Alkalinity } \\
(\mathbf{p p m})\end{array}$ & $\begin{array}{l}\text { Total } \\
\text { TOC } \\
\mathbf{( p p m )}\end{array}$ & $\begin{array}{l}\text { DOC } \\
\text { (ppm) }\end{array}$ & $\begin{array}{l}\text { COD } \\
\text { (ppm) }\end{array}$ & $\begin{array}{l}\text { Silica } \\
\text { (ppm) }\end{array}$ \\
\hline June 1, 2011 & $<5.0$ & 130 & 9.4 & 7.5 & 12 & 4.9 \\
\hline June 8, 2011 & $<5.0$ & 130 & 9.4 & 7.5 & 11 & 4.9 \\
\hline June 15, 2011 & $<5.0$ & ND & 8.1 & 7.1 & ND & 4.6 \\
\hline June 21, 2011 & $<5.0$ & 185 & 10 & 8.9 & $<10$ & 3.3 \\
\hline
\end{tabular}

Cations

\begin{tabular}{|l|l|l|l|l|l|l|}
\hline Date & $\begin{array}{l}\text { Al } \\
\text { (ppm) }\end{array}$ & $\begin{array}{l}\text { Mn } \\
(\mathbf{p p m})\end{array}$ & $\begin{array}{l}\mathbf{C a} \\
\text { (ppm) }\end{array}$ & $\begin{array}{l}\text { Mg } \\
\text { (ppm) }\end{array}$ & $\begin{array}{l}\text { Na } \\
\text { (ppm) }\end{array}$ & $\begin{array}{l}\text { K } \\
\text { (ppm) }\end{array}$ \\
\hline June 1, 2011 & 0.43 & 0.11 & 62 & 21 & 380 & 5.7 \\
\hline June 8, 2011 & 0.43 & 0.11 & 62 & 21 & 380 & 5.7 \\
\hline June 15, 2011 & 0.42 & 0.094 & 53 & 19 & 340 & 4.4 \\
\hline June 21, 2011 & 0.46 & 0.092 & 60 & 22 & 400 & 5.3 \\
\hline
\end{tabular}

Anions

\begin{tabular}{|c|l|l|l|l|l|l|}
\hline Date & $\begin{array}{l}\text { Cl } \\
\text { (ppm) }\end{array}$ & $\begin{array}{l}\text { Br } \\
\text { (ppm) }\end{array}$ & $\begin{array}{l}\text { F } \\
\text { (ppm) }\end{array}$ & $\begin{array}{l}\text { S04 } \\
\text { (ppm) }\end{array}$ & $\begin{array}{l}\text { NO3+NO2 } \\
\text { (ppm) }\end{array}$ & $\begin{array}{l}\text { PO4 } \\
\text { (ppm) }\end{array}$ \\
\hline June 1, 2011 & 212 & $<0.25$ & 0.385 & 594 & 0.062 & $<0.2$ \\
\hline June 8, 2011 & 212 & $<0.25$ & 0.385 & 594 & 0.062 & $<0.2$ \\
\hline June 15, 2011 & 254 & $<0.25$ & 0.662 & 624 & 0.158 & 0.29 \\
\hline June 21, 2011 & 229 & $<0.25$ & 0.777 & 686 & 0.413 & 0.32 \\
\hline
\end{tabular}

Other Metals

\begin{tabular}{|l|l|l|l|l|}
\hline Date & $\begin{array}{l}\text { Total As } \\
\text { (ppm) }\end{array}$ & $\begin{array}{l}\text { Total Fe } \\
\text { (ppm) }\end{array}$ & $\begin{array}{l}\text { Total Se } \\
\text { (ppm) }\end{array}$ & $\begin{array}{l}\text { Total V } \\
\text { (ppm) }\end{array}$ \\
\hline June 1, 2011 & $<0.01$ & 0.15 & $<0.03$ & 0.033 \\
\hline June 8, 2011 & $<0.01$ & 0.44 & $<0.03$ & 0.017 \\
\hline June 15, 2011 & $<0.01$ & 0.55 & $<0.03$ & 0.016 \\
\hline June 21, 2011 & $<0.01$ & 0.21 & 0.039 & 0.098 \\
\hline
\end{tabular}

The daily composite sampling was not employed routinely during the pilot-study because of its cost and inconvenience due to the special handling requirements for the collection of samples for low level Hg analysis (Method 1669 and 1631E) [4, 5]. Therefore, the pilot performance was monitored by the analysis of the collected grab samples which may not be as representative of the feed and backwash streams characteristics or long term average of the feed and backwash characteristics. Because of the variations in the feed $\mathrm{Hg}$ 
concentrations depending on upstream operations and the heterogeneity of the water samples due to presence of $\mathrm{Hg}$ in particulate form, sometimes analytical results showed large variations in two split samples. For example, two consecutive ("split") samples were collected one minute apart from each other during the Aug 22, 2011 backwash sampling. One of the backwash samples contained $145 \mathrm{ppt}$ of $\mathrm{Hg}$ while the second one contained 73 ppt of Hg. Please note that these samples were analyzed in triplicate by Lab A. Sometimes the reported Hg concentrations for backwash samples were much higher than that of the feed samples. The feed/reject ratio wasn't consistent with the system recovery rate during the operation of the membrane unit. Although the collected feed samples did not have any dissolved $\mathrm{Hg}(<0.5 \mathrm{ppt})$ on Sep 7, 2011, the backwash sample had $1.02 \mathrm{ppt}$ of dissolved Hg. This might be due to variations in the $\mathrm{Hg}$ concentrations of the feed stream that were not caught during the sampling or yet to be understood changes in $\mathrm{Hg}$ chemistry.

In order to determine the variations in the feed and backwash samples throughout the day, a composite sampling event in the feed and backwash streams was designed and executed at the end of the pilot study (September 20-22, 2011). A composite sampler with an 8 bottles capacity (Model 7612, Teledyne Isco Inc., NE) allowed the collection of 8 samples over a 24 hour period since it has a 3 hour sampling interval. The composite sampler collected $500 \mathrm{~mL}$ of the sample every hour so that the total volume of each collected sample was $1,500 \mathrm{~mL}$ at the end of the 3 hour sampling period. In other words, three grab samples were combined and mixed into a single sample in each bottle during the 3 hour sampling interval. After eight samples were collected by Lab A, an equal volume of the sample taken from each bottle was combined and mixed into a separate bottle (Bottle 9). The measurement of a single composite sample was important to determine the closeness of the average of eight individual sample measurements.

Prior to sample collection, equipment blanks were conducted on two of the composite samplers to ensure that the sample collection procedures were not introducing any $\mathrm{Hg}$ contamination into the collected samples. MilliQ water $\left(18 \mathrm{M} \Omega . \mathrm{cm}^{-1}\right.$ resistivity) was pumped through the composite samplers, and then samples were collected for $\mathrm{Hg}$ analysis. The results presented in Table 2.7 show that there was no addition of $\mathrm{Hg}$ to the MilliQ water and hence the composite sampler should not be expected to contaminate the wastewater samples during the sampling event. 
Table 2.7 Equipment Blanks

\begin{tabular}{|l|l|}
\hline Composite Sampler Location & Total Hg, ppt \\
\hline HV 7602 & $<0.5$ \\
(Feed) & $<0.5$ \\
& $<0.5$ \\
\hline HV3887 & $<0.5$ \\
(Backwash) & $<0.5$ \\
\hline
\end{tabular}

Table 2.8 shows the measured Hg concentrations for the feed and backwash streams. On the first day of the sampling event, the feed $\mathrm{Hg}$ concentrations averaged $1.49 \pm 0.70 \mathrm{ppt}$ ranging from 0.93 to $3.0 \mathrm{ppt}$. The feed $\mathrm{Hg}$ concentration in Bottle 9 was $1.51 \mathrm{ppt}$ which was very consistent with the average measurement of the other 8 bottles. Due to a computer problem, seven samples were collected from the backwash stream on the first day of the sampling event. The backwash stream had an average of $17.04 \pm 7.07 \mathrm{ppt} \mathrm{Hg}$ ranging from 9.97 to $31.80 \mathrm{ppt} \mathrm{Hg}$. The backwash Hg concentration in Bottle 9 was 18.2 ppt which was very consistent with the average measurement of the other 7 bottles $(17.04 \mathrm{ppt})$. On the second day of the sampling event, the variations in the $\mathrm{Hg}$ concentrations of the feed $(0.5$ $2.22 \mathrm{ppt}$ ) and the backwash stream (6.54-30.20 ppt) were higher than that of the first day of the sampling event. On the second day of the sampling event, the feed Hg concentration in Bottle 9 was $2.07 \mathrm{ppt}$ while the feed $\mathrm{Hg}$ concentrations averaged $1.05 \pm 0.58 \mathrm{ppt}$. The backwash Hg concentration in Bottle 9 was 17.20 ppt while the backwash Hg concentrations averaged $15.01 \pm 8.89$ ppt.

In summary, the standard deviations were very high and ranged from 41.5 to $59 \%$ during the two days of composite sampling event. There was no linear relationship between the feed $\mathrm{Hg}$ concentration and the backwash stream concentration as the backwash $\mathrm{Hg}$ concentration was expected to be higher than that of the feed concentrations depending on the percentage recovery.

These test results show that the composite sampling can provide an improved sampling precision and reduce the sample variability over a 24 hour. Considering the variability in the wastewater composition and the difficulty in obtaining a representative sample in highly variable conditions, grab sampling should be used for a rapid preliminary assessment of a treatment process. However, composite sampling should be used to obtain a representative sample when the objective of the sampling is to evaluate with more precision the performance of the membrane process. 
Table 2.8 Composite Sampling Event Test Results

Sampling Event \#1: Sep 20-Sep 21, 2011

Feed Samples (HV7602)

\begin{tabular}{|l|l|l|l|}
\hline $\begin{array}{l}\# \\
\text { Bottle }\end{array}$ & Collection Time & $\begin{array}{l}\text { Total Hg } \\
\text { ppt }\end{array}$ & $\begin{array}{l}\text { Dissolved Hg } \\
\text { ppt }\end{array}$ \\
\hline 1 & $9: 20-11: 20$ & 0.929 & $<0.5$ \\
\hline 2 & $12: 20-14: 20$ & 1.2 & $<0.5$ \\
\hline 3 & $15: 20-17: 20$ & 2.02 & $<0.5$ \\
\hline 4 & $18: 20-20: 20$ & 1.33 & $<0.5$ \\
\hline 5 & $21: 20-23: 20$ & 1.51 & $<0.5$ \\
\hline 6 & $0: 20-2: 20$ & 1.11 & $<0.5$ \\
\hline 7 & $3: 20-5: 20$ & 0.985 & $<0.5$ \\
\hline 8 & $6: 20-8: 20$ & 3 & $<0.5$ \\
\hline 9 & Composite 1-8 & 1.49 & $<0.5$ \\
\hline & Averages of bottles 1-8 & 1.51 & $<0.5$ \\
\hline & stdev of bottles 1-8 & 0.70 & \\
\hline & $\%$ stdev & 46.02 & \\
\hline
\end{tabular}

\section{Backwash Samples (HV3887)}

\begin{tabular}{|l|l|l|l|}
\hline $\begin{array}{l}\# \\
\text { Bottle }\end{array}$ & Collection Time & $\begin{array}{l}\text { Total Hg } \\
\text { ppt }\end{array}$ & $\begin{array}{l}\text { Dissolved Hg } \\
\text { ppt }\end{array}$ \\
\hline 1 & $9: 10-11: 10$ & 31.8 & $<0.5$ \\
\hline 2 & $12: 10-14: 10$ & 9.97 & $<0.5$ \\
\hline 3 & $15: 10-17: 10$ & 15.6 & $<0.5$ \\
\hline 4 & $18: 10-20: 10$ & 17.6 & $<0.5$ \\
\hline 5 & $21: 10-23: 10$ & 12.9 & $<0.5$ \\
\hline 6 & $0: 10-2: 10$ & 13.6 & $<0.5$ \\
\hline 7 & $3: 10-5: 10$ & 17.8 & $<0.5$ \\
\hline 8 & $6: 10-8: 10$ & \multicolumn{2}{|l|}{ o sample collection } \\
\hline 9 & Composite 1-7 & 18.2 & $<0.5$ \\
\hline & Averages of bottles 1-7 & 17.04 & $<0.5$ \\
\hline & stdev of bottles 1-7 & 7.07 & \\
\hline & $\%$ stdev & 41.49 & \\
\hline
\end{tabular}


Table 2.8 Composite Sampling Event Test Results (continued)

Sampling Event \#2: Sep 21-Sep 22, 2011

Feed Samples (HV7602)

\begin{tabular}{|l|l|l|l|}
\hline $\begin{array}{l}\# \\
\text { Bottle }\end{array}$ & Collection Time & $\begin{array}{l}\text { Total Hg } \\
\text { ppt }\end{array}$ & $\begin{array}{l}\text { Dissolved Hg } \\
\text { ppt }\end{array}$ \\
\hline 1 & $11: 15-13: 15$ & 0.50 & $<0.5$ \\
\hline 2 & $14: 15-16: 15$ & 0.66 & $<0.5$ \\
\hline 3 & $17: 15-19: 15$ & 0.575 & $<0.5$ \\
\hline 4 & $20: 15-22: 15$ & 0.873 & $<0.5$ \\
\hline 5 & $23: 15-1: 15$ & 0.789 & $<0.5$ \\
\hline 6 & $2: 15-4: 15$ & 2.22 & $<0.5$ \\
\hline 7 & $5: 15-7: 15$ & 1.34 & $<0.5$ \\
\hline 8 & $8: 15-10: 15$ & 1.44 & $<0.5$ \\
\hline 9 & Composite 1-8 & 2.07 & $<0.5$ \\
\hline & Averages of bottles 1-8 & 1.05 & $<0.5$ \\
\hline & stdev of bottles 1-8 & 0.58 & \\
\hline & $\%$ stdev & 55.61 & \\
\hline
\end{tabular}

\section{Backwash Samples (HV3887)}

\begin{tabular}{|l|l|l|l|}
\hline $\begin{array}{l}\# \\
\text { Bottle }\end{array}$ & Collection Time & $\begin{array}{l}\text { Total Hg } \\
\text { ppt }\end{array}$ & $\begin{array}{l}\text { Dissolved Hg } \\
\text { ppt }\end{array}$ \\
\hline 1 & $11: 40-13: 40$ & 6.54 & $<0.5$ \\
\hline 2 & $14: 40-16: 40$ & 7.19 & $<0.5$ \\
\hline 3 & $17: 40-19: 40$ & 8.61 & $<0.5$ \\
\hline 4 & $20: 40-22: 40$ & 10.3 & $<0.5$ \\
\hline 5 & $23: 40-1: 40$ & 13.5 & $<0.5$ \\
\hline 6 & $2: 40-4: 40$ & 17.9 & $<0.5$ \\
\hline 7 & $5: 40-7: 40$ & 25.8 & $<0.5$ \\
\hline 8 & $8: 40-10: 40$ & 30.2 & 0.885 \\
\hline 9 & Composite 1-8 & 17.2 & $<0.5$ \\
\hline & Averages of bottles 1-8 & 15.01 & 0.55 \\
\hline & stdev of bottles 1-8 & 8.89 & \\
\hline & $\%$ stdev & 59.28 & \\
\hline
\end{tabular}




\subsubsection{Membrane Performance}

The four months of operating experience provided many useful insights into the design, operational and performance aspect of implementing an UF membrane process. The permeate quality consistently met or exceeded the treatment goals of $<1.3 \mathrm{ppt} \mathrm{Hg}$. The membrane process performance is discussed in detail in the following sections.

\subsubsection{Permeate Quality}

\section{Hg Removal Performance}

The UF membrane system performed very well under continuous and varying operating conditions. Figure 2.4 shows the variations in the $\mathrm{Hg}$ concentration in the feed, permeate and backwash streams over the pilot-study. After weekly maintenance cleaning, samples were also collected when the tank level was half full and analyzed for Hg (identified as MCW in Figure 2.4). The pilot testing started with the operating condition of Flux A flux rate and $\mathrm{X} \%$ recovery. During the twenty-seven days of operation under these initial conditions, the pilot unit demonstrated the ability to meet $<0.5 \mathrm{ppt}$ of $\mathrm{Hg}$ in the effluent. The initial results were very encouraging with respect to mercury as the unit consistently provided less than $0.5 \mathrm{ppt}$ in the permeate concentration. During the second stage, the pilot unit operated at Flux B flux rate and X\% recovery for 19 days (Phase 2a). The pilot continued to produce excellent effluent quality which was consistently $<0.5 \mathrm{ppt}$ of $\mathrm{Hg}$ under testing conditions of little dissolved mercury in the pre-ETL $(<0.5-1.05 \mathrm{ppt})$. During Phase $2 \mathrm{~b}$ and Phase $2 \mathrm{c}$ testing, the pilot unit continued to demonstrate the ability to meet $<0.5 \mathrm{ppt}$ of $\mathrm{Hg}$. The UF membrane process consistently provided a constant permeate quality at the tested operating conditions, virtually independent of the feed water characteristics and the feed $\mathrm{Hg}$ concentration in the test period. These test results also show that the permeate water quality is independent of operational parameters as the membranes with a $0.04 \mu \mathrm{m}$ pore size provide a physical barrier. Changes in the operational parameters only affect the cleaning interval of the system. The treatment target of less than $1.3 \mathrm{ppt}$ of $\mathrm{Hg}$ was met and exceeded for all the tested conditions during the pilot study. 


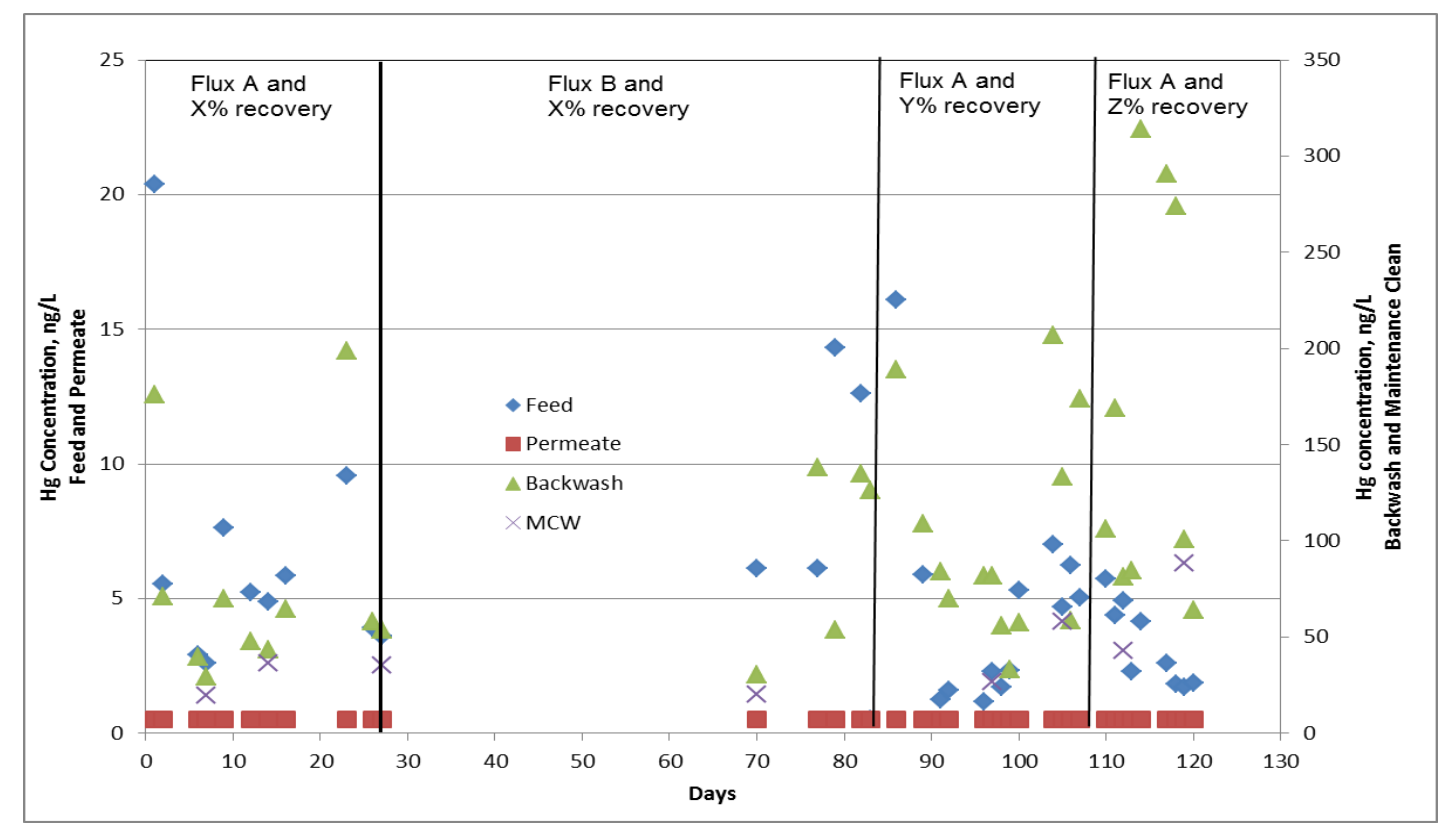

Operating conditions:

1- 27 days: Flux A flux rate and $\mathrm{X} \%$ recovery

2- 28-34 days and 69-82 days: Flux B flux rate and X\% recovery

3- 83-106 days: Flux A flux rate and Y\% recovery

4- 107-121 days: Flux A flux rate and Z\% recovery

*MCW: maintenance clean wash

Figure 2.4 Mercury Removal Performance of Membrane Unit*

\section{Turbidity}

The permeate turbidity was continuously recorded with an on-line turbidimeter (HACH 1720D turbidimeter, Loveland, CO). Figure 2.5 shows the changes in the feed and permeate turbidities over the pilot-study. The average turbidities of feed and permeate samples were 2.1 NTU and 0.073 NTU, respectively. The permeate turbidity was below 0.164 NTU 95\% of the time over the study. It should be noted that the readings from Aug 2-Sep 1, 2011 were not included in this calculation since the permeate turbidimeter was not working properly due to low feed flow or no flow in the sample loop. The turbidimeter readings returned back to normal ( $\sim 0.1 \mathrm{NTU})$ after resuming flow to the turbidimeter. The turbidity measurements (MDL=0.5 NTU) in the collected permeate samples also confirmed the online measurements. Turbidity measurements were less than 0.5 NTU $85 \%$ of the time. Only two permeate samples out of 13 had high turbidities ( 0.59 and 0.83 NTU).

\section{Solids Removal Performance}

Total suspended solids concentration in the collected permeate samples was less than or equal to $1 \mathrm{ppm} 100 \%$ of the time (Table 2.9). As discussed in section 2.3 .5 , the particle size analysis showed that there were a few large particles in the permeate samples (5-10 per 50 $\mathrm{mL}$ ). The membrane unit which had a $0.04 \mu \mathrm{m}$ pore size showed excellent performance in 
retaining the particle bound $\mathrm{Hg}$ within the membrane unit and hence removal of the particles from the permeate. Higher TSS concentrations in the feed did not impact the permeate quality. For example, higher TSS concentrations and turbidity values in the feed over the weekend of Aug 13-14, 2011 did not deteriorate the permeate quality.

Table 2.8 is a statistical summary of the permeate quality over the study.

Table 2.9 Typical Permeate Characteristics

\begin{tabular}{|l|l|}
\hline Parameter & Value \\
\hline Turbidity & Less than or equal to 0.164 NTU $95 \%$ of the time \\
\hline TSS & Less than or equal to $1 \mathrm{ppm} 100 \%$ of the time \\
\hline Total $\mathrm{Hg}$ & Less than or equal to $0.5 \mathrm{ng} / \mathrm{L} 95 \%$ of the time \\
\hline $\begin{array}{l}\text { Total number of } \\
\text { particles }\end{array}$ & $\begin{array}{l}10-15 \text { particles per } 50 \mathrm{~mL} \text { of permeate } 100 \% \text { of the } \\
\text { time }\end{array}$ \\
\hline
\end{tabular}

\section{Turbidity}

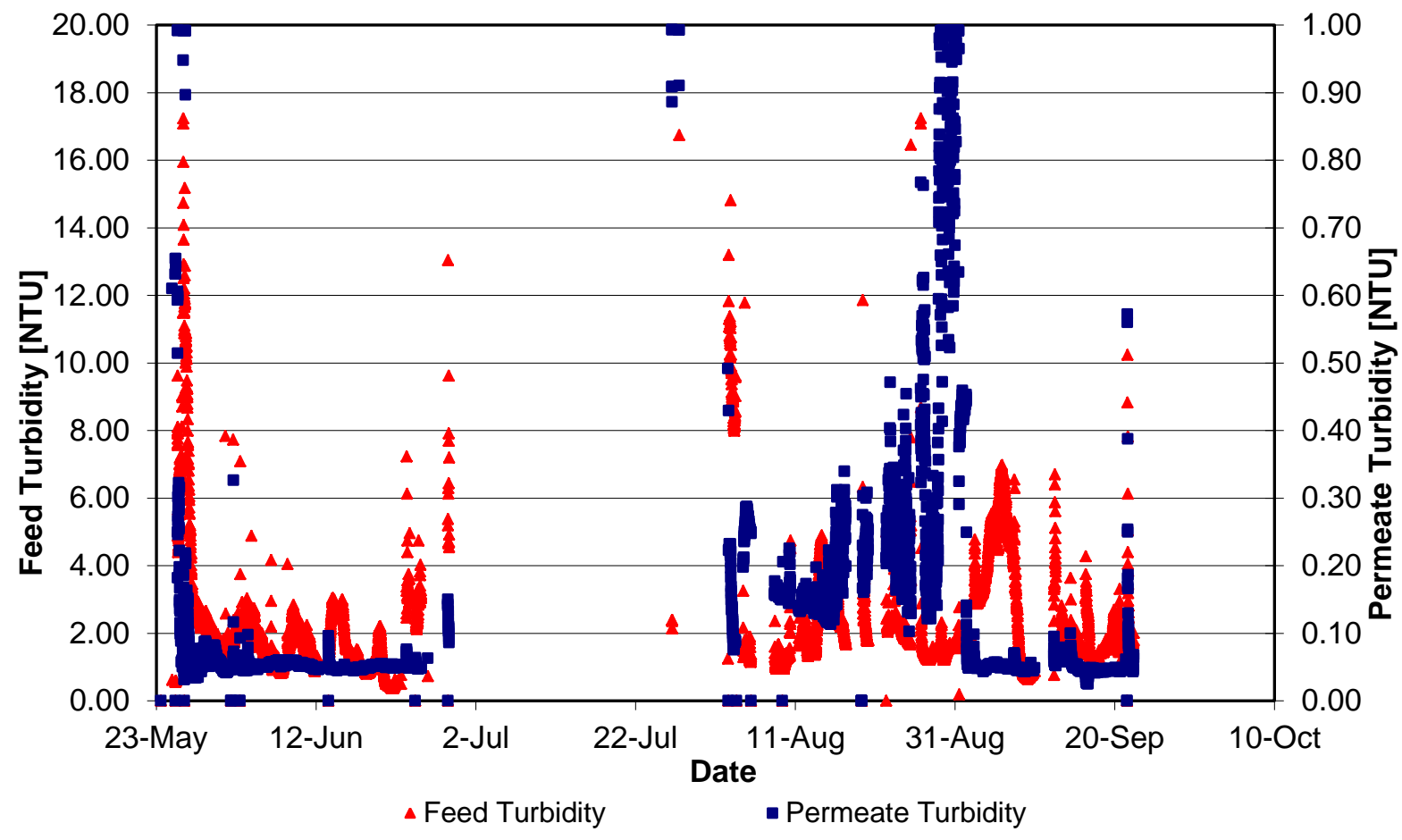

Figure 2.5 Feed and Permeate Turbidity during Pilot Testing*

*Permeate data from Aug 2 to Sep 1 may not be accurate due to low or no flow to cell. 
During Phase 1, the effectiveness of the pilot unit was also tested for As, Fe, Se and V removal from the ETL (Table 2.10). It's difficult to draw any conclusion on the membrane performance since As and Se concentrations in the feed water were below the method detection levels. The membrane unit was able to remove $4-17.6 \%$ of $\mathrm{V}$. The membrane unit also removed $66.7-91 \%$ of Fe from the ETL. Since the focus of this project was mercury, the removal of these metals was not evaluated for the remaining part of the study.

Table 2.10 Effectiveness of UF Process in Removing Heavy Metals

\begin{tabular}{|c|c|c|c|c|c|}
\hline Date & $\begin{array}{l}\text { Sampling } \\
\text { locations }\end{array}$ & $\begin{array}{l}\text { Total As } \\
\text { (ppm) }\end{array}$ & $\begin{array}{l}\text { Total Fe } \\
\text { (ppm) }\end{array}$ & \begin{tabular}{|l|} 
Total Se \\
$(\mathrm{ppm})$
\end{tabular} & $\begin{array}{l}\text { Total V } \\
\text { (ppm) }\end{array}$ \\
\hline \multirow{4}{*}{ June 1, 2011} & Feed & $<0.01$ & 0.15 & $<0.03$ & 0.033 \\
\hline & Permeate & $<0.01$ & $<0.05$ & $<0.03$ & 0.029 \\
\hline & Reject & $<0.01$ & 0.82 & $<0.03$ & 0.047 \\
\hline & $\begin{array}{l}\text { Maintenance } \\
\text { Clean Waste }\end{array}$ & $<0.01$ & 0.72 & $<0.03$ & 0.044 \\
\hline \multirow{4}{*}{ June 8, 2011} & Feed & $<0.01$ & 0.44 & $<0.03$ & 0.017 \\
\hline & Permeate & $<0.01$ & 0.061 & $<0.03$ & 0.014 \\
\hline & Reject & 0.014 & & $<0.03$ & 0.041 \\
\hline & $\begin{array}{l}\text { Maintenance } \\
\text { Clean Waste }\end{array}$ & $<0.01$ & & $<0.03$ & 0.042 \\
\hline \multirow{4}{*}{ June 15, 2011} & Feed & $<0.01$ & 0.55 & $<0.03$ & 0.016 \\
\hline & \begin{tabular}{|l|} 
Permeate \\
\end{tabular} & $<0.01$ & $<0.05$ & $<0.03$ & 0.0099 \\
\hline & Reject & $<0.01$ & & $<0.03$ & 0.026 \\
\hline & $\begin{array}{l}\text { Maintenance } \\
\text { Clean Waste }\end{array}$ & 0.02 & & $<0.03$ & 0.070 \\
\hline \multirow{4}{*}{ June 21, 2011} & Feed & $<0.01$ & 0.21 & 0.039 & 0.098 \\
\hline & Permeate & $<0.01$ & $<0.05$ & 0.032 & 0.094 \\
\hline & Reject & $<0.01$ & 2.0 & $<0.03$ & 0.13 \\
\hline & $\begin{array}{l}\text { Maintenance } \\
\text { Clean Waste }\end{array}$ & $<0.01$ & 1.8 & $<0.03$ & 0.12 \\
\hline
\end{tabular}

\subsubsection{Hydraulic Performance}

The performance data presented in this section summarizes the data recorded and measured by GE. The details of these data were given in the report prepared by GE. 
Key hydraulic variables, such as flux, TMP, membrane permeability were continuously monitored over the study period. Since the key hydraulic variables are temperature dependent parameters, temperature corrected values are presented in this section. Figure 2.6 shows the flux rates tested for this pilot-study. Two different flux rates, namely Flux A and Flux B were tested over the pilot-study. The flux rates remained constant since the ZeeWeed ${ }^{\circledR}$ system is designed to operate at constant flux rates and alternate between permeation and backpulsing. Higher flux rates during the backpulsing were due to use of permeate stream to clean up the membrane unit.

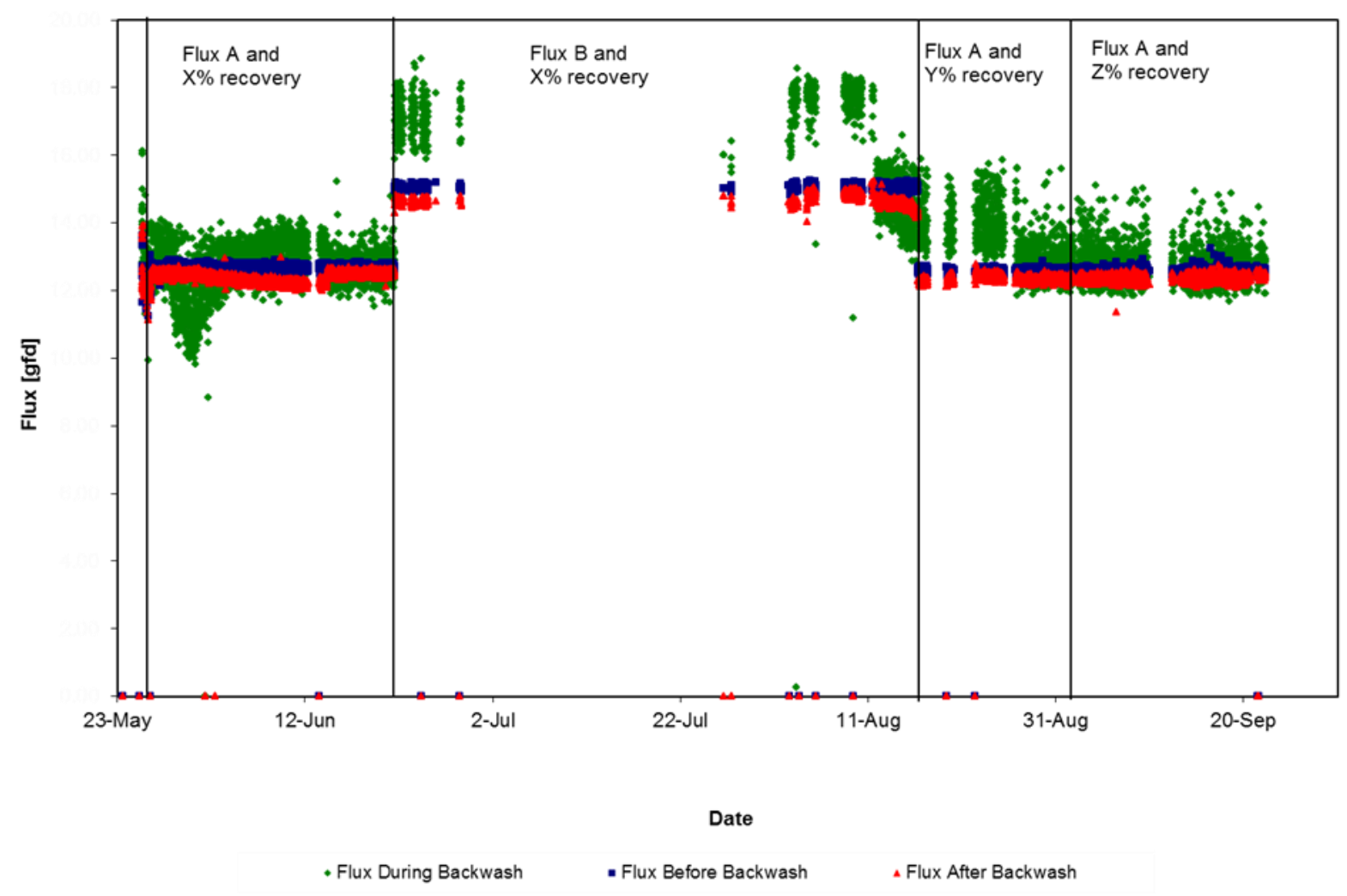

Figure 2.6 Flux Rates for the Entire Pilot-study

TMP Stability

Figure 2.7 shows the temperature corrected TMP values over the study. TMP values were below the contractual maximum of $12 \mathrm{psi}$ at all tested conditions during the pilot-study. During Phase 1 , the fouling rate was calculated as 0.045 psi per day at $20^{\circ} \mathrm{C}$. From this data, the membrane cleaning interval can be calculated as 266 days, which is longer than the 90 day interval of the planned CIP event. 
During Phase 2a, there were many interruptions (please see Appendix 2C for the pilot calendar) in the operation of the pilot unit when it was run at Flux B and Y\% recovery conditions. The fouling rate was calculated as $0.836 \mathrm{psi} /$ day at $20^{\circ} \mathrm{C}$ for 11.73 days of the operating time. Operating the unit at high flux rate (Flux B) increased the membrane fouling rate. The membrane cleaning interval can be calculated as 14.4 days which is shorter than the 90 days interval of the planned CIP event. The membrane fouling rate might also have been impacted by a short upset of the clarifiers which happened during the test period. BP reported that an oil sheen was seen in the pre-ETL over the weekend of Aug 13-Aug 14, 2011. Since there was no sample collection scheduled for weekends, this upset wasn't caught in this pilot study. However, higher TSS concentrations and turbidity values were measured in the pre-ETL over the weekend of Aug 12-14, 2011 according to BP engineers. O\& G concentration was 1.3 ppm in the grab samples collected on Aug 15, 2011.

The TMP values immediately decreased when the membrane operating conditions were changed from a Flux B flux rate and X\% recovery to a Flux A and Y\% recovery (Phase 2b). TMP values remained relatively constant. The unit was down at 8:37 am on Aug 17, 2011 due to a PLC (Programmable Logic Controller) problem. After the faulty PLC was fixed, the unit was restarted up on Aug 19. The TMP values remained stable till Aug 20, 2011. The TMP values were decreased further when the unit was restarted on Aug 22, and later increased on Aug 26, 2011. The decrease in the TMP values when the pilot was down indicated that the accumulated solids within the membrane tank contributed to the fouling. The unit was shut down for a CIP cleaning on August 26, 2011. After cleaning, the TMP values immediately decreased and then stayed relatively constant, then gradually increased during Phase $2 \mathrm{~b}$. The fouling rate was calculated as 0.024 psi per day at $20^{\circ} \mathrm{C}$. The TMP values used for this fouling rate calculation were obtained from the operation period of Aug 17 to Sep 7, 2011. The system recovery was changed to Z\% on Sep 9, 2011 (Phase 2c). The change in the membrane operating condition did not impact the TMP values significantly. They stayed relatively constant to the end of the pilot study.

From these results, it can be concluded that the fouling rates resulting from running the membrane unit at Flux A flux rate and $\mathrm{X}, \mathrm{Y}$ and $\mathrm{Z} \%$ recoveries were very low and hence the corresponding expected cleaning interval was longer than the 90 days that had been expected. However, the fouling rate was high when the system was operated at a Flux B flux rate and $\mathrm{X} \%$ recovery, with a corresponding expected cleaning interval of 14.4 days. Running the membrane at a high flux rate did not impact the $\mathrm{Hg}$ removal performance as discussed in section 2.3.2.1, but it would impact the cleaning interval of the membrane unit at full-scale. 


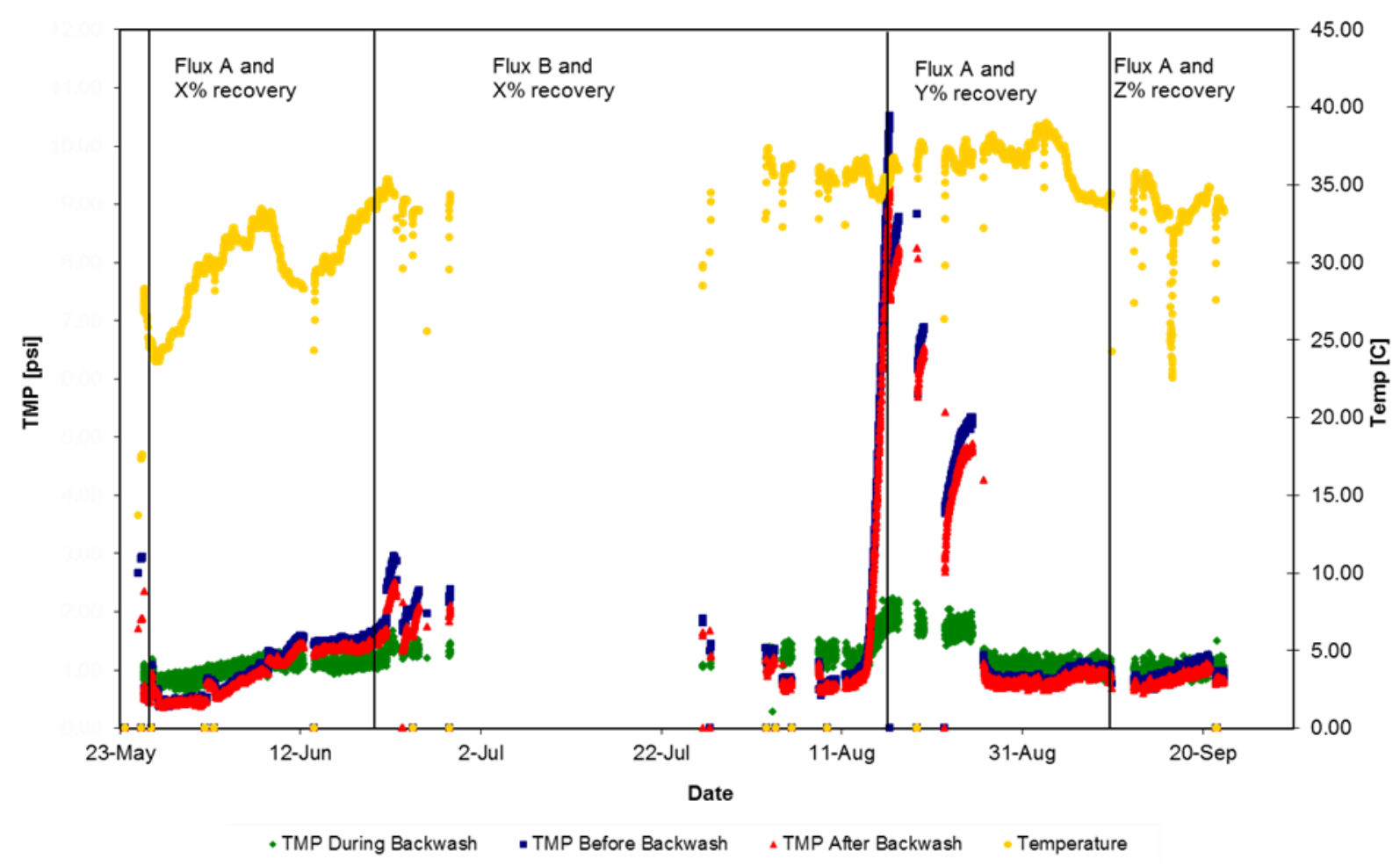

Figure 2.7 TMP for the Entire Pilot-study

\subsubsection{Hg Analysis in Backwash Stream before and after each Cleaning Event}

Weekly maintenance clean and CIP events were performed to restore the membrane performance by removing the accumulated solids on the membrane surface. As a result of these cleaning procedures, particle bound $\mathrm{Hg}$ was also removed from the membrane tank. Figure 2.4 also shows the changes in the $\mathrm{Hg}$ concentration before and after the maintenance cleaning. Table 2.11 shows the total $\mathrm{Hg}$ concentration in the samples collected at the end of the each cleaning cycle.

The final recovery cleaning was started on September 23, 2011 with the citric acid cleaning which took about 4 hours. Then, the hypochlorite cleaning was performed for about 4 hours. The samples collected from the membrane unit at the end of the each cleaning cycle were analyzed by Lab A. 
Table 2.11 Recovery Cleaning

Sampling Date: Aug 26, 2011

\begin{tabular}{|l|l|}
\hline Sample Description & $\begin{array}{l}\text { Total Hg } \\
\text { ppt }\end{array}$ \\
\hline Before Recovery Cleaning & 360 \\
\hline Post Citric Acid Wash & 61 \\
\hline Post Hypochlorite Wash & 27 \\
\hline
\end{tabular}

Sampling Date: Sep 23-26, 2011

\begin{tabular}{|l|l|}
\hline Sample Description & $\begin{array}{l}\text { Total Hg } \\
\text { ppt }\end{array}$ \\
\hline Before Recovery Cleaning & 65 \\
\hline Post Citric Acid Wash & $<10$ \\
\hline Post Hypochlorite Wash & 15 \\
\hline Post rinse with nonpotable water & 20 \\
\hline During the draining of membrane unit & 36 \\
& 39 \\
& 59 \\
\hline
\end{tabular}

Because of safety and security restrictions, no pictures were taken to document the condition of the membrane fibers before and after exposure to ETL as well as before and after the CIP event at the end of the piloting. However, there are pictures in the literature which can be used as examples to show the changes in the membrane fibers [6]. Figure 2.8 shows the fate of membrane fibers. The color of the ZeeWeed ${ }^{\circledR}$ membrane fibers used in this study was white. The membrane fibers color changed from white to brown after being exposed to pre-ETL similarly to what is shown in Figure 2.8. Upon inspection, we saw that the solids accumulated at the bottom and the top of the membrane fibers (approximately 12 inches) even after CIP. It should be also noted that there was no fiber breakage observed at the end of the pilot-study. 

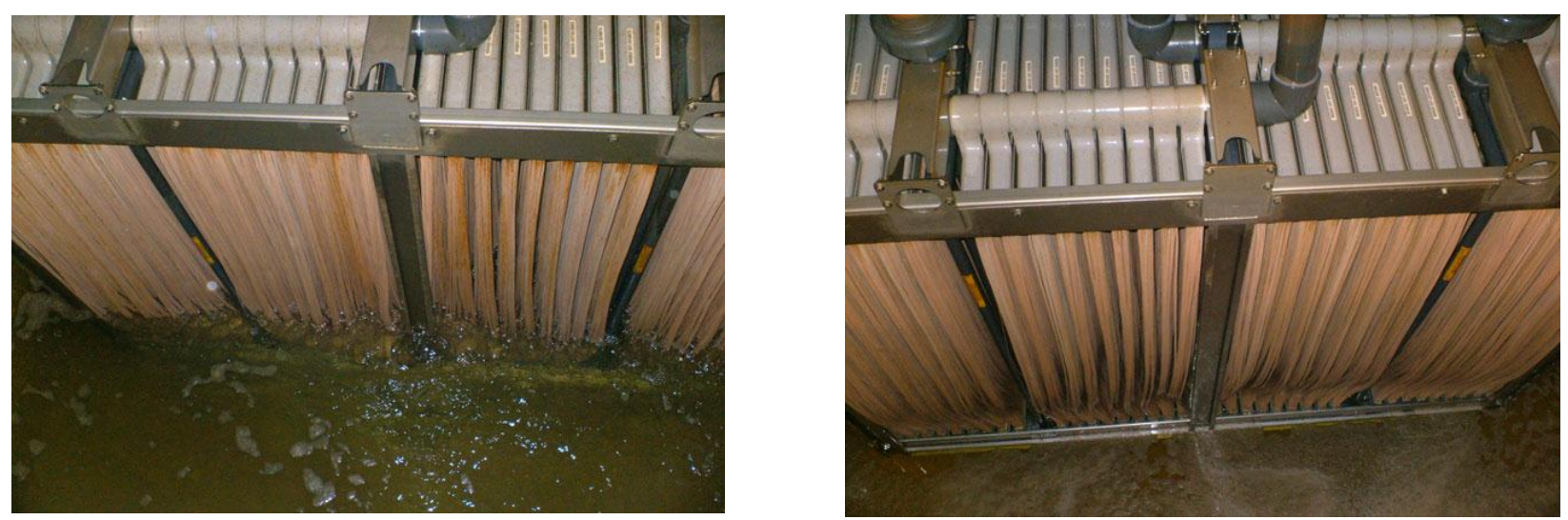

Figure 2.8 Membrane Cassette Before and After Recovery Cleaning (Bergman et al., 2006)[6]

\subsubsection{Split Sampling Events}

Argonne requested Lab A to collect samples from each stream including feed, permeate, backwash and maintenance clean and sent one set of the split samples to Lab B for a sideby-side comparison analysis. A total of 28 samples were collected from Aug 10, 2011 to Sep 21,2011 , were analyzed by both Lab A and Lab B for comparison purposes. The results obtained from Lab B usually had higher recoveries and lower detection limits (Table 2.12). Although Lab A couldn't detect less than 0.5 ppt of Hg levels, Lab B was able to report less than $0.5 \mathrm{ppt}$ of $\mathrm{Hg}$ concentrations because of the lower method detection levels ( $0.08 \mathrm{ppt}$ ). Lab $B$ results showed that the average permeate $\mathrm{Hg}$ concentration was $0.54 \mathrm{ppt}$, ranging from $0.41 \mathrm{ppt}$ to $0.73 \mathrm{ppt}$. Lab B test results also confirmed Lab A's test results, hence confirming the effectiveness of the membrane process in achieving less than $1.3 \mathrm{ppt}$ of $\mathrm{Hg}$. The test results were also analyzed by a paired t-test at $95 \%$ confidence interval since each stream's samples were collected one minute apart each other. The statistical analysis indicated that the differences in test results obtained from both labs were considered to be not statistically significant at a $95 \%$ confidence interval, P values equaling to $0.216,0.354$, 0.115 and 0.209 for feed, permeate, backwash and maintenance clean samples, respectively. The confirmation of Lab A test results is important for the validation of the pilot test results. Although both lab results were not statistically significant overall, some of the individual test results highlighted in Table 2.12 were significantly different from each other. For example, Hg concentration in the feed samples collected on Aug 31, 2011 was reported as 1.69 and $4.02 \mathrm{ppt}$ by Lab A and Lab B, respectively. The Lab B reported Hg concentration for this sample was $2 \mathrm{X}$ more than the Lab A test results. This might be due to differences in the wastewater characteristics depending on the upstream operation as well as the heterogeneity of water samples because of the presence of $\mathrm{Hg}$ in particulate form. 
Table 2.12 Split Sampling Events during Phase $2 b$ and Phase 2c of the Pilot-study

\begin{tabular}{|c|c|c|c|c|c|}
\hline \multirow{2}{*}{$\begin{array}{l}\text { Sampling } \\
\text { Date }\end{array}$} & \multirow[t]{2}{*}{ Sampling Location } & \multicolumn{2}{|l|}{ Lab A } & \multicolumn{2}{|l|}{ Lab B } \\
\hline & & $\begin{array}{l}\text { Total Hg } \\
\text { ppt }\end{array}$ & $\begin{array}{l}\text { MDL } \\
\text { ppt }\end{array}$ & $\begin{array}{l}\text { Total Hg } \\
\text { ppt }\end{array}$ & $\begin{array}{l}\text { MDL } \\
\text { ppt }\end{array}$ \\
\hline \multirow{3}{*}{ Aug 10, 2011} & Feed, HV 7602 & 16.3 & 0.5 & 17.6 & 0.17 \\
\hline & Permeate, HV 3502 & $<0.5$ & 0.5 & 0.41 & 0.08 \\
\hline & Backwash, HV 3887 & 138 & 5 & 103 & 1.68 \\
\hline \multirow{3}{*}{ Aug 12, 2011} & Feed, HV 7602 & 14.3 & 0.5 & 8.47 & 0.08 \\
\hline & Permeate, HV 3502 & $<0.5$ & 0.5 & 0.69 & 0.08 \\
\hline & Backwash, HV 3887 & 53.5 & 0.5 & 61.6 & 0.84 \\
\hline \multirow{3}{*}{ Aug 15, 2011} & Feed, HV 7602 & 12.6 & 0.5 & 19.2 & 0.17 \\
\hline & Permeate, HV 3502 & $<0.5$ & 0.5 & 0.44 & 0.08 \\
\hline & Backwash, HV 3887 & 135 & 5 & 127 & 1.68 \\
\hline \multirow{3}{*}{ Aug 19, 2011} & Feed, HV 7602 & 16.1 & 0.5 & 19.1 & 0.17 \\
\hline & Permeate, HV 3502 & $<0.5$ & 0.5 & 0.64 & 0.08 \\
\hline & Backwash, HV 3887 & 189 & 5 & 193 & 1.68 \\
\hline \multirow{4}{*}{ Aug 31, 2011} & Feed, HV 7602 & 1.69 & 0.5 & 4.02 & 0.08 \\
\hline & Permeate, HV 3502 & $<0.5$ & 0.5 & 0.44 & 0.08 \\
\hline & Backwash, HV 3887 & 56.1 & 0.5 & 54.8 & 0.84 \\
\hline & MCW, HV 3887 & 26.8 & 0.5 & 33.9 & 0.84 \\
\hline \multirow{4}{*}{ Sep 7, 2011} & Feed, HV 7602 & 4.67 & 0.5 & 7.25 & 0.08 \\
\hline & Permeate, HV 3502 & $<0.5$ & 0.5 & 0.51 & 0.08 \\
\hline & Backwash, HV 3887 & 133 & 5 & 80.2 & 1.68 \\
\hline & MCW, HV 3887 & 58.1 & 0.5 & 52.9 & 0.17 \\
\hline \multirow{4}{*}{ Sep 14, 2011} & Feed, HV 7602 & 4.92 & 0.5 & 7.05 & 0.08 \\
\hline & Permeate, HV 3502 & $<0.5$ & 0.5 & 0.49 & 0.08 \\
\hline & Backwash, HV 3887 & 81.4 & 5 & 63.3 & 0.17 \\
\hline & MCW, HV 3887 & 42.6 & 0.5 & 54.2 & 0.84 \\
\hline \multirow{4}{*}{ Sep 21, 2011} & Feed, HV 7602 & 1.72 & 0.5 & 2.95 & 0.17 \\
\hline & Permeate, HV 3502 & $<0.5$ & 0.5 & 0.73 & 0.08 \\
\hline & Backwash, HV 3887 & 101 & 5 & 97.3 & 0.84 \\
\hline & MCW, HV 3887 & 88.4 & 5 & 101 & 0.84 \\
\hline
\end{tabular}

\subsubsection{Particle Size Analysis}

A particle size distribution analysis (PSA) was conducted with a Cilas 1190 (Orleans, France) with an MDL of $0.04 \mu \mathrm{m}$ to obtain a better understanding of mercury removal mechanisms by the ultrafiltration technology. During each sampling event (Phase $2 \mathrm{~b}$ and 
2c), samples were not only collected for $\mathrm{Hg}$ analysis, but also for the PSA. The samples were collected from the feed, permeate and backwash streams. The particle size distribution analysis for the permeate samples filtered through $0.04 \mu \mathrm{m}$ membranes could not be determined, since the samples included only a few very large particles and particle concentrations were below the detection limits of the particle size analyzer. Because of their size, they have skewed the analysis. The PSA results confirmed the excellent performance of the ultrafiltration in retaining the particle bound $\mathrm{Hg}$ within the membrane unit and hence the removal of particles from the permeate.

The test results for feed and backwash samples are presented based on the volume distributions for eight sampling events (Figures 2.9 and 2.10). A consistent particle size distribution was obtained from 8 different feed sampling events even though key wastewater characteristics (Table 2.5) were usually different at each sampling event.

The PSA results of the backwash samples showed also a reproducible size distribution and were overlapped with the results for the ETL samples (Figure 2.11). Moreover, the standard deviations of the backwash samples were smaller than that of the feed samples since the membrane module is size selective in that larger particles are progressively removed from the feed. The morphology and size distribution of particles in the backwash stream are very similar to the morphology and size distribution of the particles in the feed stream. There was a relative tendency of the particles present in the backwash samples to grow their size after ultrafiltration. As shown in Table 2.13, the volume based mean particle size increased in the backwash stream after filtration. The mean particle size of the ETL "as-is" samples was $29.08 \pm 3.4 \mu \mathrm{m}$, increasing to $36.92 \pm 2.87 \mu \mathrm{m}$ in the backwash stream. Table 2.13 also shows that $90 \%$ of the particles contained in the ETL "as-is" samples were below $54.15 \pm 4.81 \mu \mathrm{m}$, while $90 \%$ of the particles were less than $60.41 \pm$ $2.53 \mu \mathrm{m}$ in backwash stream. The size of the particles and percentage of larger particles increased in the backwash stream. This indicates that the membranes with a $0.04 \mu \mathrm{m}$ nominal pore size can reject most of the particles contained in the feed samples.

From the volume based particle size analysis, the number based size distribution was calculated. The diameter of $90 \%$ of the particles contained in the ETL was $<1.4 \mu \mathrm{m}$. Less than $50 \%$ of the particles in all of the tested feed samples were below $0.54 \mu \mathrm{m}$. The diameter of $90 \%$ of the particles in backwash samples was below $17 \mu \mathrm{m}$ while less than $50 \%$ of the particles in all of the tested backwash samples were below $1.1 \mu \mathrm{m}$. This shows that size of the particles ( $90 \%$ of the particles below $1.4 \mu \mathrm{m}$ ) in the feed water increases after passing through the ultrafiltration membrane as the diameter of $90 \%$ of the particles in backwash samples was below $17 \mu \mathrm{m}$.

From these test results, it can be concluded that removal of particles from the pre-ETL removal is critical in achieving less than $1.3 \mathrm{ppt}$ of $\mathrm{Hg}$ in this treated effluent as $\mathrm{Hg}$ is mostly 
present in particle-bound form in the ETL. PSA techniques is a valuable tool in determining the characteristics of the feed as well as the permeate and backwash streams.

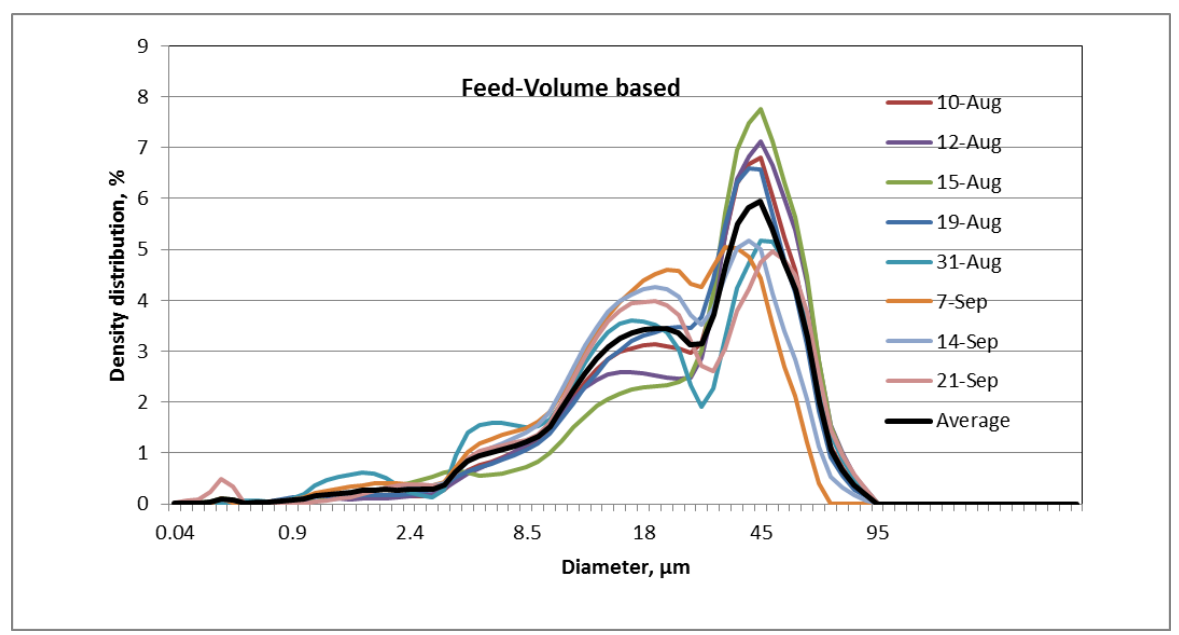

Figure 2.9 Particle Size Distributions in Feed Samples

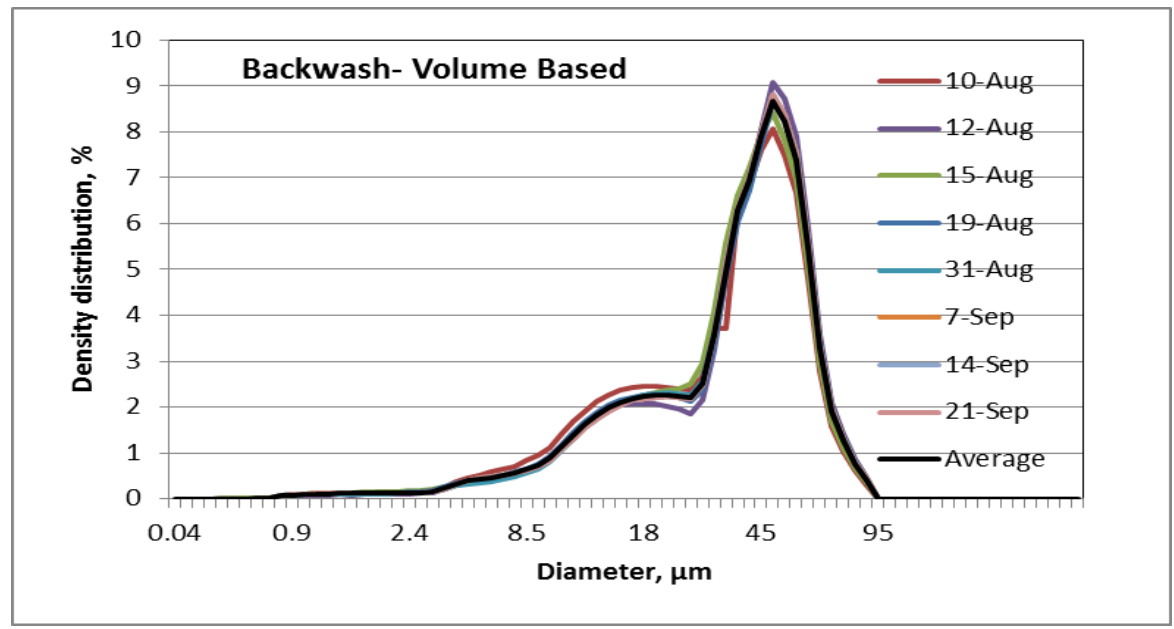

Figure 2.10 Particle Size Distributions in Backwash Samples 


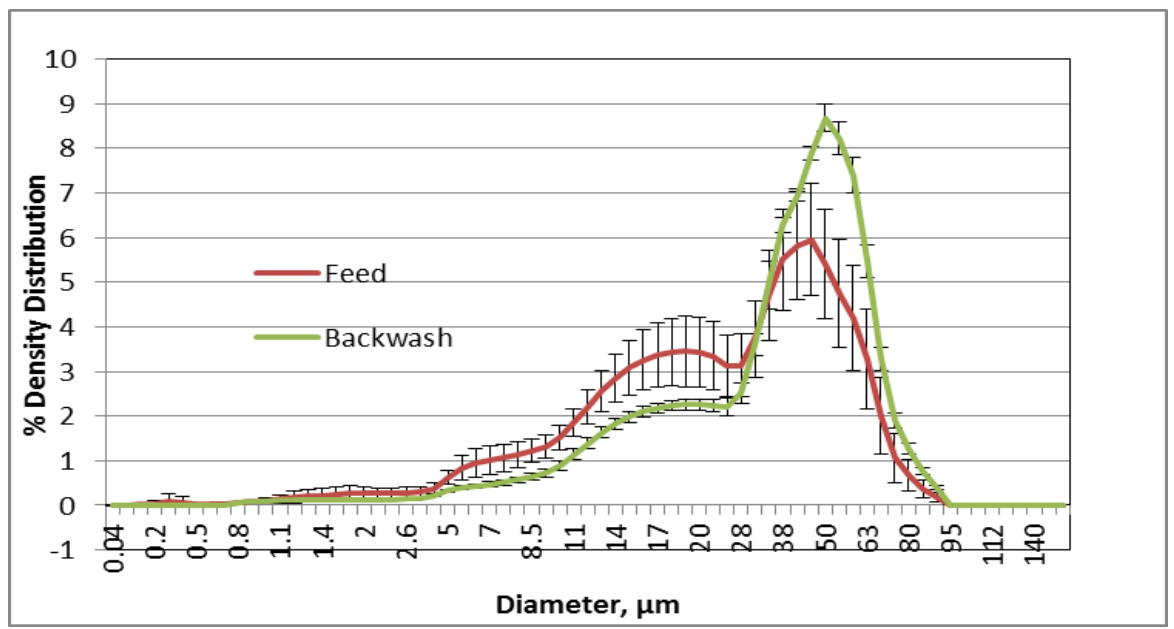

Figure 2.11 Comparison of Feed and Backwash Streams PSA Results* ${ }^{*}$ An average of 8 sampling events 
Table 2.13 Cumulative Particle Size Distribution in Feed and Backwash Samples (Volume based)

\begin{tabular}{|c|r|r|r|r|r|r|}
\hline \multicolumn{7}{|c|}{ Feed } \\
\hline Date & $10 \%$ & $20 \%$ & $50 \%$ & $90 \%$ & $95 \%$ & Mean \\
\hline 10-Aug & 8.58 & 13.53 & 30.71 & 55.48 & 62.44 & 31.25 \\
\hline 12-Aug & 8.98 & 13.9 & 33.59 & 58.44 & 65.35 & 33.23 \\
\hline 15-Aug & 5.64 & 13.69 & 34.22 & 58.1 & 64.89 & 33.08 \\
\hline 19-Aug & 8.24 & 13.52 & 29.14 & 53.81 & 60.98 & 30.23 \\
\hline 31-Aug & 5.08 & 8.93 & 21.85 & 56.51 & 63.84 & 27.86 \\
\hline 7-Sep & 5.77 & 10.35 & 21.13 & 44.72 & 50.64 & 23.74 \\
\hline 14-Sep & 6.2 & 10.94 & 21.88 & 49.24 & 56.3 & 25.69 \\
\hline 21-Sep & 3.84 & 9.59 & 21.86 & 56.86 & 64.37 & 27.56 \\
\hline Average & 6.54 & 11.81 & 26.80 & 54.15 & 61.10 & 29.08 \\
\hline Stdev & 1.85 & 2.07 & 5.70 & 4.81 & 5.14 & 3.44 \\
\hline
\end{tabular}

\begin{tabular}{|c|r|r|r|r|r|r|}
\hline \multicolumn{7}{|c|}{ Backwash } \\
\hline Date & $10 \%$ & $20 \%$ & $50 \%$ & $90 \%$ & $95 \%$ & Mean \\
\hline 10-Aug & 8.58 & 13.53 & 30.71 & 55.48 & 62.44 & 31.25 \\
\hline 12-Aug & 11.65 & 18.26 & 40 & 61.55 & 68.27 & 38.14 \\
\hline 15-Aug & 11.45 & 18.09 & 37.47 & 59.6 & 66.27 & 36.37 \\
\hline 19-Aug & 11.04 & 17.35 & 38.78 & 61.04 & 67.79 & 37.13 \\
\hline 31-Aug & 11.58 & 18.29 & 38.96 & 60.88 & 67.6 & 37.43 \\
\hline 7-Sep & 12.22 & 18.77 & 39.05 & 61 & 67.73 & 37.67 \\
\hline 14-Sep & 11.24 & 17.32 & 36.7 & 59.25 & 65.91 & 35.78 \\
\hline 21-Sep & 14.18 & 22.52 & 43.62 & 64.46 & 70.55 & 41.55 \\
\hline Average & 11.49 & 18.02 & 38.16 & 60.41 & 67.07 & 36.92 \\
\hline Stdev & 1.54 & 2.45 & 3.65 & 2.53 & 2.34 & 2.87 \\
\hline
\end{tabular}

\subsubsection{Membrane Fibers Analysis for $\mathrm{Hg}$}

15 membrane samples were collected at the end of the pilot-study (Figure 2.12). Samples were collected after the final CIP event. Each collected membrane sample was cut into three pieces, and then analyzed for Hg by US EPA Method 7471 [7]. Table 2.14 shows the amount of $\mathrm{Hg}$ in the membranes. The amount of $\mathrm{Hg}$ in the membranes was calculated by multiplication of the measured membrane weights ( $\mathrm{g}$ of membrane fiber) with the measured $\mathrm{Hg}$ concentrations, $\mathrm{ng} \mathrm{Hg} / \mathrm{kg}$ of membrane fiber. The total amount of $\mathrm{Hg}$ in the fifteen membrane fibers was $335.18 \mathrm{ng}$. The amount of $\mathrm{Hg}$ per fiber was also calculated based on the averages of 15 measurements. It was equal to $22.35 \pm 0.81 \mathrm{ng} \mathrm{Hg}$. The 
observed standard deviation was very low (3.62\%) considering variations in the feed $\mathrm{Hg}$ concentration. It should be also noted that there is no significant relationship between the amount of $\mathrm{Hg}$ in the membrane and the fibers location (top, middle or bottom) as it was observed that accumulated solids were visibly greater at the bottom and top of the membrane fibers.

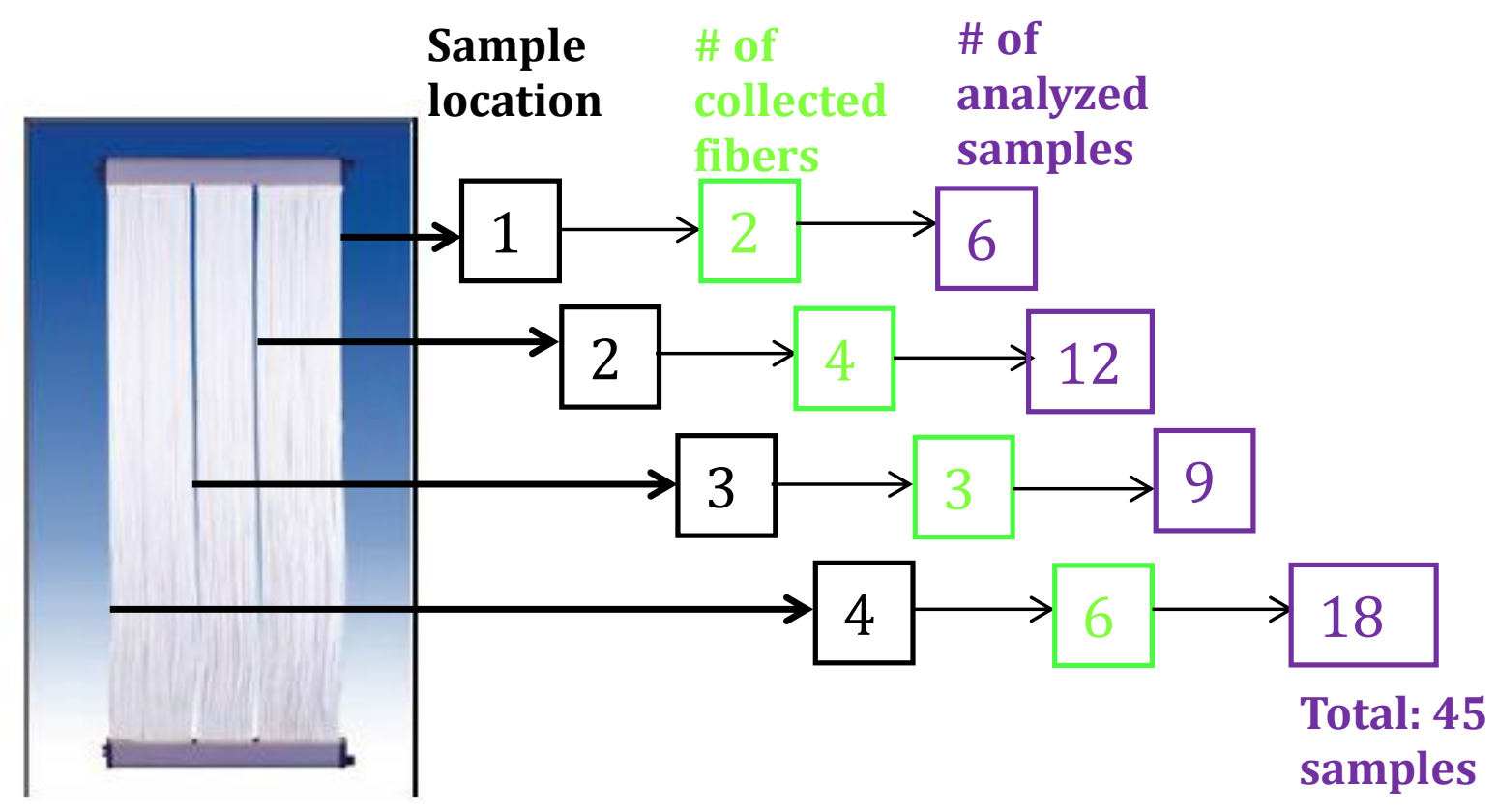

Figure 2.12 Sampling Locations in the Membrane Module (Permission to use photograph granted by GE Power \& Water)

Table 2.14 Analysis of Membrane Fibers

\begin{tabular}{|c|c|c|c|c|c|}
\hline $\begin{array}{l}\text { Membrane Fiber } \\
\text { Location }\end{array}$ & Sample Description & Hg (ng/kg) & $\begin{array}{l}\text { Membrane } \\
\text { weight, g }\end{array}$ & $\begin{array}{l}\text { Amount of } \\
\mathrm{Hg}, \mathrm{ng}\end{array}$ & $\begin{array}{l}\text { Total } \\
\text { amount of } \\
\text { Hg per } \\
\text { fiber, } \\
\text { ng/fiber }\end{array}$ \\
\hline \multirow{6}{*}{ \#1 } & Sample 1-67" & 12000 & 0.65 & 7.80 & \multirow{3}{*}{20.37} \\
\hline & Sample 1-67" & 4100 & 1.59 & 6.52 & \\
\hline & Sample 1-67" & 4200 & 1.44 & 6.05 & \\
\hline & Sample 2-67 3/4" & 6500 & 1.09 & 7.09 & \multirow{3}{*}{22.06} \\
\hline & Sample 2-67 3/4" & 6500 & 1.15 & 7.48 & \\
\hline & Sample 2-67 3/4" & 6200 & 1.21 & 7.50 & \\
\hline
\end{tabular}


Table 2.14 Analysis of Membrane Fibers (continued)

\begin{tabular}{|c|c|c|c|c|c|}
\hline $\begin{array}{l}\text { Membrane Fiber } \\
\text { Location }\end{array}$ & Sample Description & Hg (ng/kg) & $\begin{array}{l}\text { Membrane } \\
\text { weight, g }\end{array}$ & $\begin{array}{l}\text { Amount of } \\
\mathrm{Hg}, \mathrm{ng}\end{array}$ & $\begin{array}{l}\text { Total } \\
\text { amount of } \\
\text { Hg per } \\
\text { fiber, } \\
\text { ng/fiber } \\
\end{array}$ \\
\hline \multirow{12}{*}{ \#2 } & Sample 1-66 1/2" & 6800 & 1.14 & 7.75 & \multirow{3}{*}{22.91} \\
\hline & Sample 1-66 1/2" & 7400 & 1.00 & 7.40 & \\
\hline & Sample 1-66 1/2" & 8000 & 0.97 & 7.76 & \\
\hline & Sample 2-67" & 5900 & 1.34 & 7.91 & \multirow{3}{*}{23.57} \\
\hline & Sample 2-67" & 9000 & 0.89 & 8.01 & \\
\hline & Sample 2-67" & 6600 & 1.16 & 7.66 & \\
\hline & Sample 3-67 1/4" & 6600 & 1.14 & 7.52 & \multirow{3}{*}{23.00} \\
\hline & Sample 3-67 1/4" & 6200 & 1.25 & 7.75 & \\
\hline & Sample 3-67 1/4" & 6900 & 1.12 & 7.73 & \\
\hline & Sample 4-67 1/4" & 6400 & 1.20 & 7.68 & \multirow{3}{*}{22.63} \\
\hline & Sample 4-67 1/4" & 7300 & 1.05 & 7.67 & \\
\hline & Sample 4-67 1/4" & 5600 & 1.30 & 7.28 & \\
\hline
\end{tabular}

\begin{tabular}{|c|c|c|c|c|c|}
\hline $\begin{array}{l}\text { Membrane Fiber } \\
\text { Location }\end{array}$ & Sample Description & Hg (ng/kg) & $\begin{array}{l}\text { Membrane } \\
\text { weight, g }\end{array}$ & \begin{tabular}{|l} 
Amount of \\
$\mathrm{Hg}, \mathrm{ng}$
\end{tabular} & $\begin{array}{l}\text { Total } \\
\text { amount of } \\
\text { Hg per } \\
\text { fiber, } \\
\text { ng/fiber }\end{array}$ \\
\hline \multirow{9}{*}{$\# 3$} & Sample 1-67" & 7400 & 0.97 & 7.18 & \multirow{3}{*}{22.02} \\
\hline & Sample 1-67" & 6900 & 1.01 & 6.97 & \\
\hline & Sample 1-67" & 4400 & 1.79 & 7.88 & \\
\hline & Sample 2-67 1/8" & 6700 & 1.13 & 7.57 & \multirow{3}{*}{23.80} \\
\hline & Sample 2-67 1/8" & 9300 & 0.89 & 8.28 & \\
\hline & Sample 2-67 1/8" & 5600 & 1.42 & 7.95 & \\
\hline & Sample 3-67 1/4" & 5100 & 1.50 & 7.65 & \multirow{3}{*}{22.22} \\
\hline & Sample 3-67 1/4" & 8400 & 0.86 & 7.22 & \\
\hline & Sample 3-67 1/4" & 6500 & 1.13 & 7.35 & \\
\hline
\end{tabular}


Table 2.14 Analysis of Membrane Fibers (continued)

\begin{tabular}{|c|c|c|c|c|c|}
\hline $\begin{array}{l}\text { Membrane Fiber } \\
\text { Location }\end{array}$ & Sample Description & Hg (ng/kg) & $\begin{array}{l}\text { Membran } \\
\text { weight, g }\end{array}$ & $\begin{array}{l}\text { Amount of } \\
\mathrm{Hg}, \mathrm{ng}\end{array}$ & $\begin{array}{l}\text { Total } \\
\text { amount of } \\
\text { Hg per } \\
\text { fiber, } \\
\text { ng/fiber }\end{array}$ \\
\hline \multirow{18}{*}{$\# 4$} & Sample 1-69 7/8" & 7200 & 1.03 & 7.42 & \multirow{3}{*}{22.19} \\
\hline & Sample 1-69 7/8" & 7600 & 0.94 & 7.14 & \\
\hline & Sample 1-69 7/8" & 4100 & 1.86 & 7.63 & \\
\hline & Sample 2-69 7/8" & 7200 & 1.01 & 7.27 & \multirow{3}{*}{21.75} \\
\hline & Sample 2-69 7/8" & 9600 & 0.73 & 7.01 & \\
\hline & Sample 2-69 7/8" & 3700 & 2.02 & 7.47 & \\
\hline & Sample 3-70 1/8" & 6800 & 1.06 & 7.21 & \multirow{3}{*}{22.10} \\
\hline & Sample 3-70 1/8" & 6500 & 1.12 & 7.28 & \\
\hline & Sample 3-70 1/8" & 5400 & 1.41 & 7.61 & \\
\hline & Sample 4-70 1/8" & 7100 & 1.04 & 7.38 & \multirow{3}{*}{22.29} \\
\hline & Sample 4-70 1/8" & 6200 & 1.19 & 7.38 & \\
\hline & Sample 4-70 1/8" & 5300 & 1.42 & 7.53 & \\
\hline & Sample 5-70 1/4" & 7800 & 0.90 & 7.02 & \multirow{3}{*}{22.05} \\
\hline & Sample 5-70 1/4" & 5700 & 1.35 & 7.70 & \\
\hline & Sample 5-70 1/4" & 5600 & 1.31 & 7.34 & \\
\hline & Sample 6-70 1/4" & 6700 & 1.14 & 7.64 & \multirow{3}{*}{22.22} \\
\hline & Sample 6-70 1/4" & 6000 & 1.17 & 7.02 & \\
\hline & Sample 6-70 1/4" & 5600 & 1.35 & 7.56 & \\
\hline
\end{tabular}

\begin{tabular}{|l|l|}
\hline \multicolumn{2}{|c|}{ Overall Membrane Fibers Analysis } \\
\hline Total Hg adsorbed on 15 membrane fibers & $335.18 \mathrm{ng}$ \\
\hline Average Hg per fiber & $22.35 \mathrm{ng}$ \\
\hline Standard Deviation & $0.81 \mathrm{ng}$ \\
\hline \% Standard Deviation & 3.62 \\
\hline
\end{tabular}


Energy-dispersive X-ray spectroscopy (EDS) at GE's Research Lab was used to determine the changes on the surface morphology of the membrane fibers after the pilot-study. The EDS with a $0.2 \mathrm{ppb}$ detection limit shows that there was no $\mathrm{Hg}$ adsorption above the method detection limit on the membrane surface (Figure 2.13). Please note this analytical method didn't require the use of any destructive pretreatment, such as acid digestion, and therefore is different from the one used by the analytical labs.

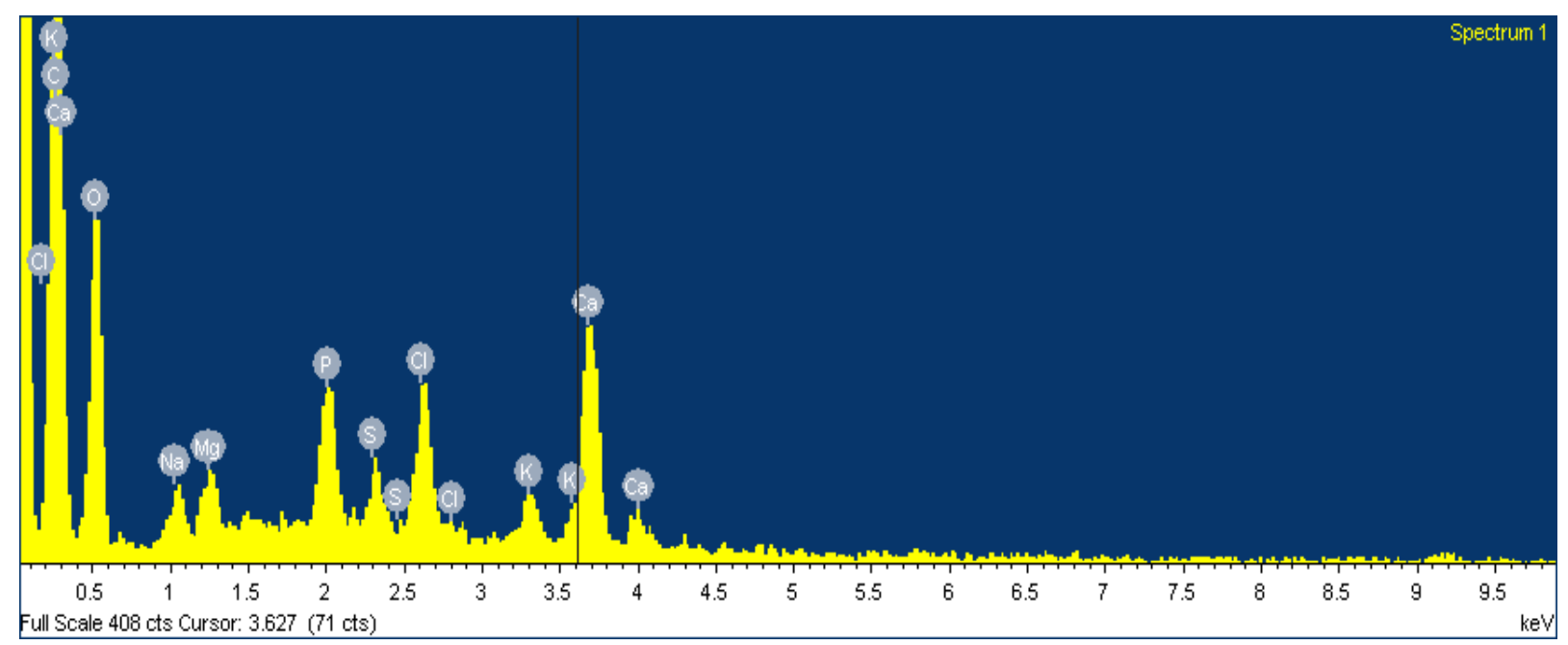

Figure 2.13 Energy-dispersive X-ray Spectroscopy of Membrane Fibers

Considering the equipment blank results which showed there was no $\mathrm{Hg}$ contribution from the system, mercury found in the membrane fibers at the end of the testing was only found when using harsh digestion technique employed in US EPA Method 7471. The digestion with acid aliquant might have caused the leaching of $\mathrm{Hg}$ from the membrane. It should be also noted that the measured $\mathrm{Hg}$ per each fiber was at ng levels (22.35 ng) by Method 7471 while the method detection limit for the EDS was $0.2 \mathrm{ppb}$ or $200 \mathrm{ppt}$, which can't detect these low $\mathrm{Hg}$ concentrations. It should be also noted that the virgin membranes were not analyzed for Hg by Method 7471. Therefore, it is hard to determine the source of $\mathrm{Hg}$ in the fibers. It might be due to the ETL or coming from the virgin membrane fibers or both.

\subsection{Data Analysis}

An overall mercury mass balance was performed on the membrane unit to determine the fate of $\mathrm{Hg}$ over the pilot study. The pilot data analysis was based on the performance and operating data obtained from the proof of concept testing of the membrane ultrafiltration technology. A schematic of the pilot-unit configuration is shown in Figure 2.14. As mentioned before, a portion of the permeate is recirculated back to the membrane module for 10-20 seconds per 10-30 minutes to decrease the concentration of solids since the solid 
concentration in the membrane unit increases as a function of the amount of solids concentration in the feed stream.

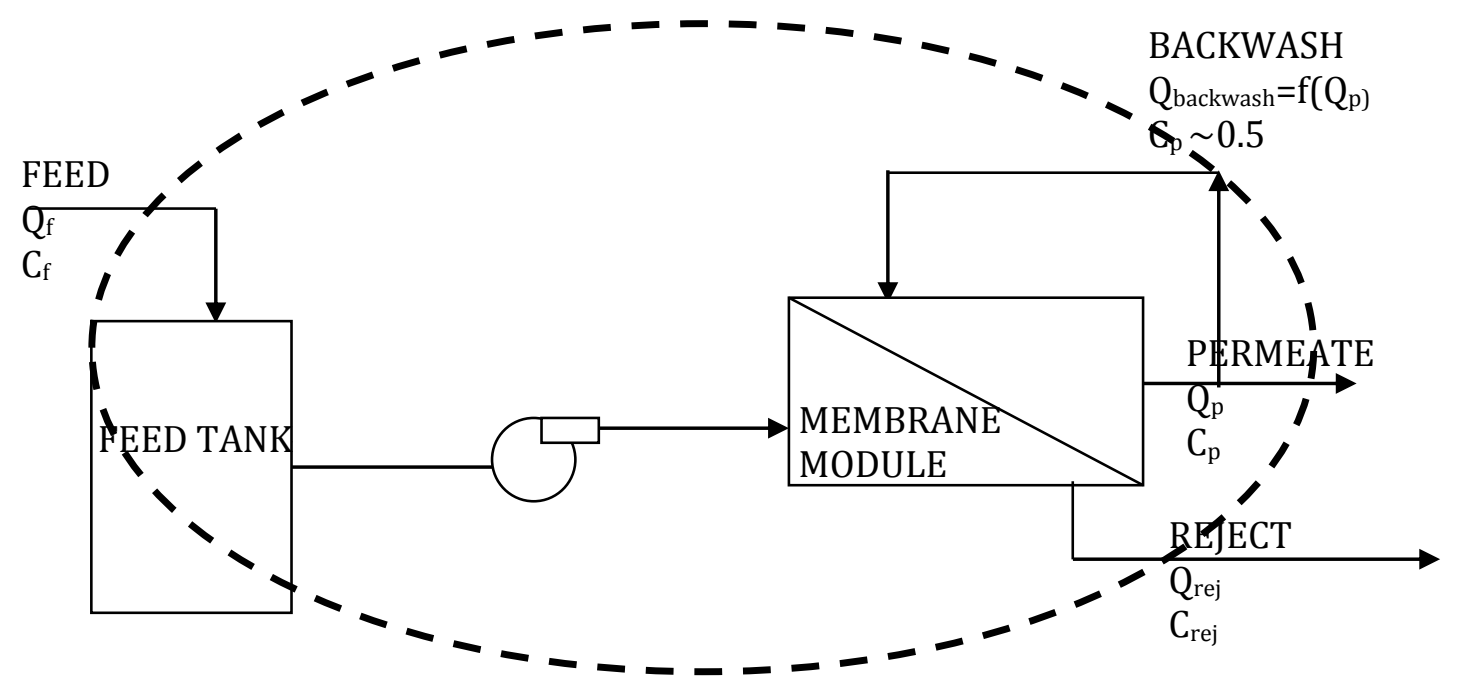

Figure 2.14 A Schematic of the Pilot-unit Configuration

Daily Mercury Accumulation

The membrane was operated at a constant flux rate and the feed flow rate was maintained by the water level in the membrane tank.

Assumptions:

1. For each day of operation an average flow rate for each stream was calculated and assumed constant.

2. The recorded feed flow rates were inaccurate. The feed flow rates were increased by $10-15 \%$ to balance the eqn (1) as the recorded flow rates did not provide any hydraulic balance between the input and the output streams.

3. The liquid level in the membrane unit was assumed to be constant since the algorithm for maintaining the level in the pilot was unavailable to Argonne.

4. The missing Hg concentrations were estimated by using a five day moving average of the known data.

An overall hydraulic balance for the membrane unit is given by:

$Q_{\text {feed }}=Q_{\text {permeate }}+Q_{\text {reject }}$

where the flow rates of the feed, permeate and reject (waste) streams are $Q_{\text {feed, }} Q_{\text {permeate }}$ and Qreject, respectively. 
The accumulation in the membrane tank can be defined by:

Accumulation within membrane unit $=Q_{\text {feed }} \times C_{\text {feed }}-Q_{\text {permeate }} \times C_{\text {permeate }}-Q_{\text {reject }} \times C_{\text {reject }}$

where the $\mathrm{Hg}$ concentrations in the feed, permeate and reject (waste) streams are $\mathrm{C}_{\text {feed, }}$ $\mathrm{C}_{\text {permeate }}$ and $\mathrm{C}_{\text {reject, }}$ respectively.

Hg Loss due to Backpulsing

Basis:

a. Permeate flows through the unit for 10-20 seconds per 10-30 minutes.

b. $Q_{\text {backwash }}=f\left(Q_{\text {permeate }}\right)$

Assumptions:

5. There was no Hg concentration gradient in the membrane unit.

6. The mercury concentration within the membrane tank was constant throughout day.

7. The amount of mercury in the permeate stream is negligible.

The amount of $\mathrm{Hg}$ in the membrane unit after backpulsing can be calculated by multiplying the total volume of the permeate backpulsed per day with the mercury concentration of backwash stream measured with the daily collected grab sample from the backwash sampling valve.

Maintenance Cleaning and CIP

During the membrane cleaning, there was no permeate production. First, the tank was drained and then refilled with the feed or potable water along with a sodium hypochlorite solution and/or citric acid solution. As discussed in section 2.2.4, CIP and weekly maintenance cleanings were performed to reduce membrane fouling by minimizing the solid accumulation on the membrane surface, thereby increasing the removal of particle bound $\mathrm{Hg}$ from the unit.

Mercury loss from the system after CIP:

Assumptions:

8. There was no Hg concentration gradient during the cleaning solution disposal since each sample was taken when the water level in the tank reached half of its original height ( $\sim 51 / 2$ inches). 
The amount of disposed $\mathrm{Hg}$ after each CIP event can be calculated by multiplying the measured $\mathrm{Hg}$ concentration at each cleaning step given in Table 2.10 by the total volume of the membrane tank. Total mercury losses were calculated as $0.59 \mathrm{mg}$ and $0.12 \mathrm{mg}$ for the two CIP events on Aug 26 and Sep 23-26, 2011 respectively. Figure 2.15 shows the changes in the mercury concentration over the study. Mercury accumulation in the membrane unit over the study is shown in Figure 2.16. Both Figures 2.15 and 2.16 include the Hg losses from the Aug 26 CIP event.

Mercury in the membrane fibers:

As discussed in section 2.3.6, the total amount of mercury in the 15 membrane fibers was measured as $335.18 \mathrm{ng}$ of $\mathrm{Hg}$ with an average of $22.35 \mathrm{ng} \mathrm{Hg}$ per fiber.

From this information, the total amount of $\mathrm{Hg}$ in the membrane fibers can be calculated as $0.23 \mathrm{mg} \mathrm{Hg}$. 


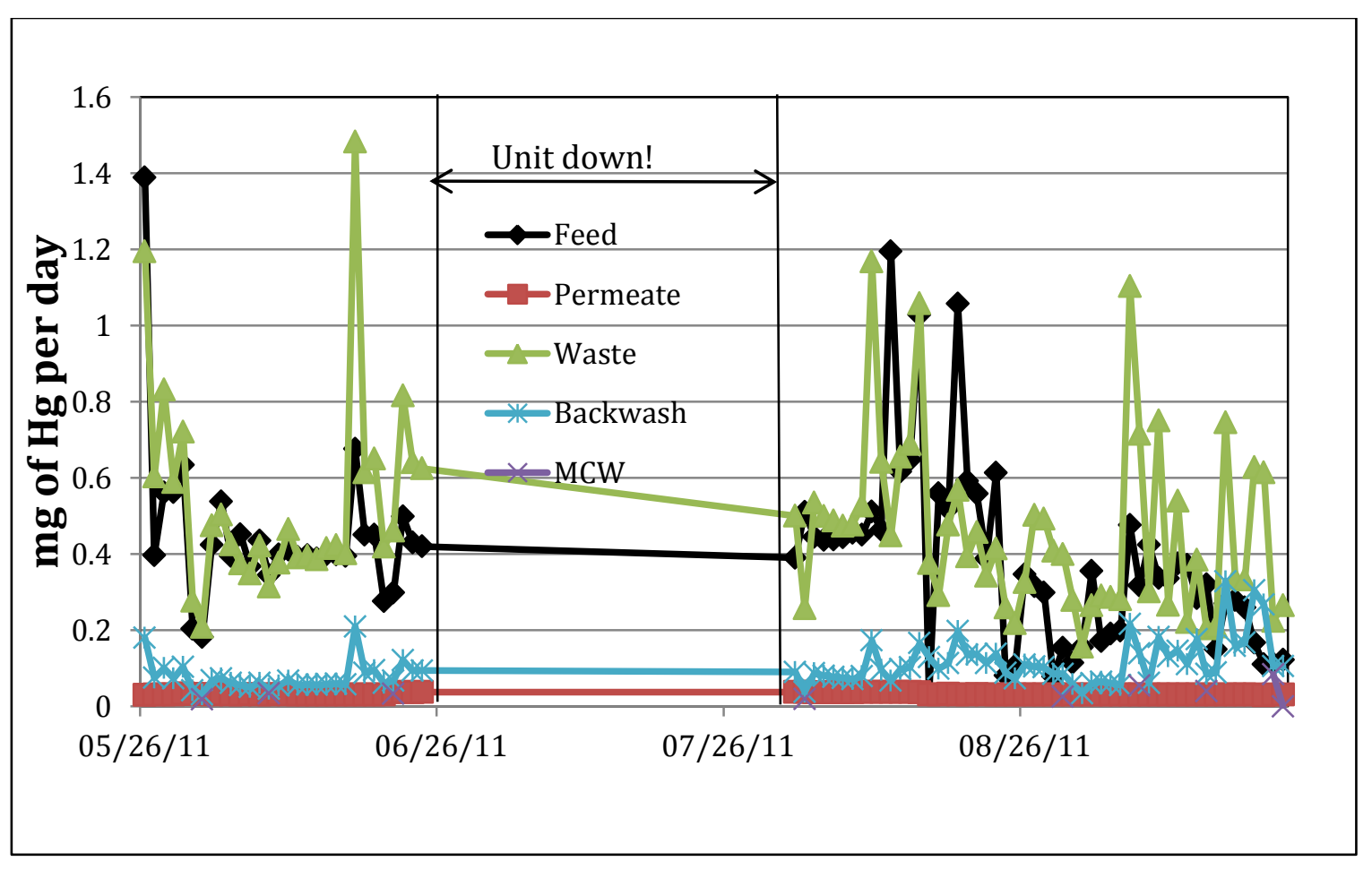

Figure 2.15 Changes in the Mercury Concentration over the Study

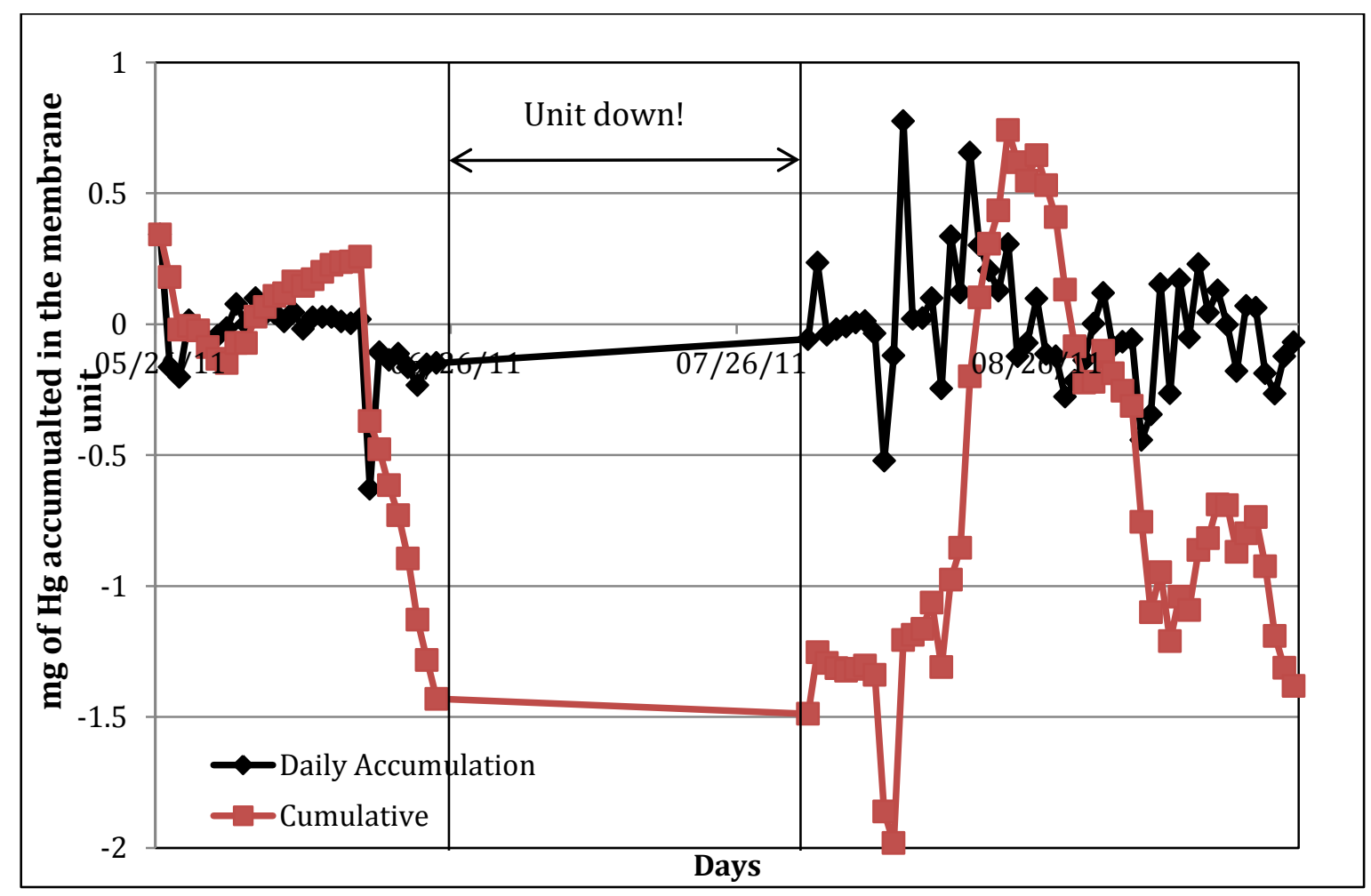

Figure 2.16 Mercury Accumulation in the Pilot-unit over the Study 
Figure 2.16 shows that the mercury accumulation in the last day of pilot was negative while the membrane fibers analysis shows that the accumulated mercury in the fibers was 0.23 $\mathrm{mg}$. The total amount of $\mathrm{Hg}$ fed to the membrane unit was estimated as $33.2 \mathrm{mg}$ during the pilot test. The accumulated mercury in the fibers can be negligible since it constitutes $0.7 \%$ of the total $\mathrm{Hg}$ fed to the membrane unit. The main sources of discrepancies in the $\mathrm{Hg}$ mass balance include:

a) The variations (41.5-59\%) in the feed and backwash stream Hg concentrations over the 24 hours of period that may not be caught with grab samples as discussed in section 2.3.1.

b) The inaccurate flow measurements (10-15\% variations).

c) The use of a five day moving average to estimate the mercury concentrations in the feed and backwash streams when these streams were not sampled, such as weekends.

d) Although it was assumed that there was no mercury gradient in the membrane unit, in reality the solids were accumulated at the bottom and top the membrane fibers and walls of the membrane unit even after CIP event as well as in the piping. Please also note that the mercury contribution from the virgin membranes was assumed negligible since the virgin membrane fibers were not analyzed by Method 7471 [7] as discussed in section 2.3.6.

e) Assumption of $\mathrm{C}_{\text {permeate }}=0.5 \mathrm{ppt}$ if $\mathrm{C}_{\text {permeate }}<0.5 \mathrm{ppt}$

Although solids inventory control was out of the scope of this study, it's one of the most important control parameters because of the nature of the mercury in the ETL. Understanding the fate of solids is also necessary to determine the amount of solids accumulated within the membrane unit since it has broad implications for the process performance and efficiency, the membrane capacity and the cleaning interval, hence operating costs [10].

An overall solid accountability analysis was also performed on the membrane unit (data not shown). The discrepancy of more than \pm 40 percent in the mass balance points to a need to review the sample collection location, procedure and frequency, as well as to calibrate the flow meters to reduce the variations. A maximum \pm 15 percent discrepancy is suggested for the solids inventory control at wastewater treatment plants [10]. During the mass balance, it was also assumed that the change in the solids concentration with the height of the membrane tank and within a one day time frame was negligible. However, there was a solid gradient within the membrane tank. This condition can't be represented by a daily grab sample collection from the backwash sampling valve. It should also be noted that the amount of solids accumulated within the membrane unit could not be determined accurately over the study period since the solids accumulation was observed at stagnant locations within the sealed membrane unit- such as in pipes and connectors as well as the 
bottom and walls of the membrane tank during the decommissioning of the membrane unit.

\subsection{Operational Issues and Trouble Shooting}

Despite the technical success, the auxiliary operation was problematic. Table 2.15 summarizes the problems that stopped the pilot unit operation over the study period (Please also see Appendix 2C for Pilot Calendar). Although minor shutdowns resulted in a gap in operation of less than 24 hours each, fixing the feed line related problems took more than 30 days. The original plan was to conduct a 17 week period of study with two weeks dedicated to start up and decommissioning. In other words, testing period was 85 days (15 weeks). The unit was run for 4 months to compensate for the downtime during the pilotstudy.

The unit was down on June 12, 2011 since the blower tripped off. This might be due to the changes in the voltage ratings. The unit was restarted on June 13, 2011. On June 22, a strainer was installed on the feed line to protect the pilot equipment and the membranes from potentially damaging objects. The strainer installation caused a pressure build up on the feed line. The second attempt to fix the feed line was unsuccessful on June 29, 2011. The PLC failed on July 5, 2011 and the pilot couldn't be restarted. The damaged PLC card was replaced by GE personnel on July 7-8, 2011. The blower was tripped off again on July 9, 2011 and the pilot unit stayed down till July 11 . The blower was reset on July 11 . After the blower was fixed by BP personnel, the feed line was blown out again on July 11, 2011. The issues with the couplings between the strainer and the feed tubing continued from July 12 through July 142011 . Although BP tried to solve the pressure build up problem on the feed line, all attempts failed. Therefore, the project team decided to remove the strainer from the feed line on July 15, 2011. The strainer was removed from the unit on July 18, 2011. On July 21, the plan was to restart the skid, but the computer screen was not functioning and thus the unit was not accessible. The touch screen problem might have been heatrelated since the ambient temperature was above $40^{\circ} \mathrm{C}$ in the pilot-area. The unit was powered down to allow the unit to cool until Friday morning. Then, the unit started to work normally on July 26, 2011. However, high pressure in the feed line and blower tripping off again did not allow a restart of the unit on July 26, 2011. The unit stayed down till Aug 2, 2011. Regarding the blower problem, GE sent a new blower to Whiting to replace the current blower. The feed line related problem was fixed by BP. The unit was restarted on Aug 2, 2011. Due to a compressor related problem, it was down again on Aug 3, 2011. The unit was restarted on Aug 4, 2011 after fixing the compressor related problem. In summary, the unit was down for more than 6 weeks (June 23 to Aug 4, 2011) mostly due to 
the blower faulting, loss of the influent pipe connection due to high pressure as well as touch screen and compressor problems.

Operators couldn't log in to the GE system when the maintenance cleaning was initiated on Aug 16, 2011. GE fixed the touch screen problem after updating the software. The pilot unit was down over the weekend (Sep 9-11, 2011) and late Monday afternoon (Sep 12) through Tuesday morning (Sep 13, 2011) due to high permeate flow rates. During this time, the unit was operated at a high recovery and the waste flow was maintained constant. The necessary changes were made to the controls of the pilot to compensate for the low flow. This flow rate was at the lower end of the set point.

Table 2.15 A summary of Pilot Operation and Problems

Pilot duration: May 25 - Sep 22, 2011 (121 days)
74 days of continuous operation ( $61 \%$ in operation)
47 days of pilot shut down due to:
Blower -3 days
High pressure at feed line-16 days
Computer related problems -10 days
Strainer installation- caused high pressure build up at feed line
12 days
Connectivity -3 days
Membrane cleaning- 1 day
Low feed alarm- 2 days

\subsection{Implications of the Pilot-Test Results to Full-Scale Process Design}

\subsubsection{Full-scale Design of UF Technology}

\subsubsection{Conceptual Design of the Process Based on the Pilot-study Test Results (Argonne)}

The conceptual design of the full-scale membrane process was based on the proof of concept testing at the pilot-scale. The system was designed based on the process performance evaluation at the tested flux rates and percentage recoveries used during the pilot-study. The clarifier upsets were not considered in this design since the membrane unit wasn't exposed to prolonged upsets during the study. It should be noted that the GE 
did not provide a conceptual full-scale design therefore the full-scale membrane process was designed using literature data and methodologies.

The Bergman et al. (2006)[6] study was used as a template for designing the full-scale process since the same technology was scaled up to treat 50 MGD of reclaimed wastewater. Table 2.15 summarizes the criteria for the design of the full-scale membrane process. In order to ensure the process reliability and to minimize the system shutdown, all major components were designed with a high level of redundancy as described by Bergman et al. (2006) [6] to accommodate off- line time for the system in the event of a CIP or an emergency outage. The full-scale membrane process was designed to treat 40 MGD of ETL.

As discussed before in sections 2.2.4.1 and 2.3.2.2, operating the unit at a Flux B flux rate increased the fouling rate of the membrane. The operation might be more challenging at the desired flux rate during the winter because of the higher viscosity of the wastewater. However, running the membrane at high flux rate did not impact the Hg removal performance since the $0.04 \mu \mathrm{m}$ pore size membrane is a physical barrier. On the other hand, would impact the cleaning interval of the membrane unit at full-scale. Therefore, two design approaches were selected to design the full-scale UF membrane process. In conservative design approach, a Flux A and Z\% recovery were used as the design criteria. For the aggressive design approach, the main design criteria were a Flux B flux rate and Y\% and $\mathrm{Z} \%$ recovery rates.

With the conservative design approach, the final design of UF system consists of 18 parallel treatment trains (16 plus 2 extra treatment trains). The design capacity of each treatment train is 2.53 MGD. The target permeate capacity with $\mathrm{Z} \%$ recovery can be met with 16 treatment trains in service.

Two extra treatment trains are used in this process design to maintain continuous permeate production at the WWTP. The presence of two extra treatment trains minimizes the system shutdowns due to an emergency outage and CIP event.

Depending vendor's warranty for the membrane life time, recovery cleaning intervals are subject to change. 
Table 2.16 Selected Full-Scale Membrane System Design Criteria for GE ZW500d Conservative Design Approach: Flux A and Z\% recovery

\begin{tabular}{|l|l|}
\hline Criteria & Criteria Value \\
\hline Membrane pore size rating (micron) & 0.04 nominal \\
\hline Total system feed capacity & 40 mgd \\
\hline Membrane recovery & $\mathrm{Z} \%$ \\
\hline Backpulse (backwash) & $\begin{array}{l}10-20 \text { seconds every } 10- \\
30 \text { minutes }\end{array}$ \\
\hline Number of membrane cassettes per train & 13 (space for 14$)$ \\
\hline Number of trains & $\begin{array}{l}18(16 \text { in service plus } \\
\text { two additional) }\end{array}$ \\
\hline Membrane train feed capacity & 2.53 mgd \\
\hline $\begin{array}{l}\text { Maximum individual train time off-line for } \\
\text { hypochlorite and citric acid recovery clean }\end{array}$ & $\begin{array}{l}240 \text { min each (total } 480 \\
\text { min) per 3 months }\end{array}$ \\
\hline
\end{tabular}

Aggressive Design Approach: Flux B and Z\% recovery

\begin{tabular}{|c|c|}
\hline Criteria & Criteria Value \\
\hline Membrane pore size rating (micron) & 0.04 nominal \\
\hline Total system feed capacity & $40 \mathrm{mgd}$ \\
\hline Membrane recovery & $\mathrm{Z} \%$ \\
\hline Backpulse (backwash) & $\begin{array}{l}10-20 \text { seconds every } 10- \\
30 \text { minutes }\end{array}$ \\
\hline Number of membrane cassettes per train & 15 (space for 16 ) \\
\hline Number of trains & $\begin{array}{l}12(10 \text { in service plus } \\
\text { two additional) }\end{array}$ \\
\hline Membrane train feed capacity & $4.283 \mathrm{mgd}$ \\
\hline $\begin{array}{l}\text { Maximum individual train time off-line for } \\
\text { hypochlorite and citric acid recovery clean }\end{array}$ & $\begin{array}{l}240 \text { min each (total } 480 \\
\text { min) per } 14.4 \text { days }\end{array}$ \\
\hline
\end{tabular}


Aggressive Design Approach: Flux B and Y \% recovery

\begin{tabular}{|l|l|}
\hline Criteria & Criteria Value \\
\hline Membrane pore size rating (micron) & 0.04 nominal \\
\hline Total system feed capacity & 40 mgd \\
\hline Backpulse (backwash) & $\begin{array}{l}10-20 \text { seconds every 10- } \\
30 \text { minutes }\end{array}$ \\
\hline Number of membrane cassettes per train & 13 (space for 14) \\
\hline Number of trains & $\begin{array}{l}14 \text { (12 in service plus } \\
\text { two additional) }\end{array}$ \\
\hline Membrane train feed capacity & 3.375 mgd \\
\hline $\begin{array}{l}\text { Maximum individual train time off-line for } \\
\text { hypochlorite and citric acid recovery clean }\end{array}$ & $\begin{array}{l}240 \text { min each (total } 480 \\
\text { min) per } 14.4 \text { days }\end{array}$ \\
\hline
\end{tabular}

\subsubsection{Cost of Ownership of This Technology at Full-scale}

\subsubsection{Capital Cost and O\&M Cost Calculations based on the Literature (Argonne)}

The capital and O\&M costs for the ownership of this technology are highly vendor specific (technology, membrane life time), wastewater specific (raw water quality and variability) and site specific (space availability, peak hydraulic factor) and can vary widely. It should be noted that the GE did not provide a full-scale cost estimate therefore this estimate was produced using literature data and methodologies. However, indicative full-scale data found in the literature were used to estimate the potential costs of this technology. Please see Appendix 2D for more details.

1. Cost calculations based on the AWWA and US Bureau of Reclamation funded study (2005) [11]:

Total plant costs were calculated by using the equation described in the AWWA report (2005).

To treat $40 \mathrm{MGD}$ of ETL, the required capital cost was calculated to be $\$ 46 \mathrm{M}$. The membrane system cost for the 40 MGD design capacity of a plant was calculated to be $\$ 12$ $\mathrm{M}$ using the equation developed in the AWWA report. Please note that these cost calculations did not include the land acquisition, engineering, site development. Total annual O\& M costs with a median of US $\$ 0.34$ per 1,000 gallons were calculated as $\$ 2.3 \mathrm{M}$ 
for a plant with an average daily flow of 18.6 million gallons. $0 \& \mathrm{M}$ costs include labor costs, chemical costs, energy cost, parts and chemical disposal costs. All costs were adjusted to 2011 October prices by using the Engineering News Record Construction Index (ENR CCI) since all cost data given in the AWWA report were based on the 2003 ENR CCI [12].

2. Cost calculations based on the Water Research Foundation and EPA funded study (2009)[13]:

Capital costs given in Table 2D-4 of Appendix 2 included membranes, feed pumps, associated chemical feed equipment, and electrical and instrumentation and did not include pre-treatment and post-treatment processes because they are highly dependent on the specific source water quality. Using capital cost and O\&M costs provided in this report, the capital cost and O\&M costs curves as a function of plant design capacity were developed to determine the relationship that can be used to calculate capital cost to treat $40 \mathrm{MGD}$ of wastewater as well as to calculate 0\&M cost to treat 18.6 MGD of wastewater (Please see Appendix 2D). O\& M costs included power, replacement parts, membrane replacement, and maintenance labor and did not include pre-treatment and post-treatment, such as reject treatment, costs. Please note that these cost estimates did not include any site specific costs. From these equations, the capital cost for a plant with a 40 MGD design capacity was calculated to be $\$ 39 \mathrm{M}$ while the annual O\&M costs for a plant with an average daily flow of 18.6 MGD were calculated as $\$ 1 \mathrm{M}$.

3. The total cost of ownership (TCO) of an UF process (Knops and Fay 2008 and Alhumoud et al., 2010) [14, 15]

The TCO of UF was within the range of 12 to 16 US cents per $\mathrm{m}^{3}$ of permeate based on a 20 year service life assumption. The treatment of 40 MGD of wastewater (38.8 MGD permeate) could cost $\$ 147 \mathrm{M}$ when the 12 cents per $\mathrm{m}^{3}$ of permeate production was taken as a basis for this calculation.

The life expectancy of a membrane depends on the manufacturer's warranty (typically 7-10 years). Membrane replacement frequency is a significant factor in operation and maintenance cost comparisons and should be considered in the selection of the process.

A more complete site-specific assessment of the membrane technology is needed to determine the actual treatment cost. The site specific and vendor specific costs were not included in these cost estimates. 


\subsection{Implications of UF Process for Full-scale Application At Whiting - Evaluation of UF}

\subsubsection{Investigation of Treatment and Disposal Options for Reject Stream}

According to the EPA manual (2005) [16] and WateReuse Foundation and AWWA reports $[8,11]$, the majority of the plants employing a backwash return the recovered backwash water to the headworks of the plant. A second stage membrane treatment was the most frequently applied treatment process. The second most employed treatment method was sedimentation or chemically assisted sedimentation. Based on this information, Argonne will be testing several backwash stream treatment options at the bench-scale. A brief discussion of the planned test is provided below. Results will be provided separately from this report. Please note that disposal of spent cleaning chemicals will not be considered in this bench-scale study since the disposal of this stream usually requires a permit [11]. Neutralization followed by discharge to sanitary sewer or recycle back to the intake is the most applied practice in the disposal of this stream [11].

\subsubsection{Argonne Bench-scale Testing of Backwash Stream}

The treatment technology selection for the bench-scale testing was made based on the current practices at WWTPs as well as by considering the characteristics of the backwash stream. The initial screening experiments include testing of 3 different treatment alternatives, namely ferric precipitation, membrane filtration and a combination of precipitation and membrane filtration processes) to determine the best candidate treatment process(es) for the focused testing.

- Ferric sulfate precipitation is a good candidate because of its capability to remove heavy metals including $\mathrm{Hg}$ regardless of their form (i.e., soluble, complexed, chelated, colloidal, emulsified, and particulate) due to the involvement of several different removal mechanisms, including adsorption, co-precipitation, encapsulation, complexation, ion exchange, etc. [17]. Method blanks using the "as is" backwash stream with no precipitant will also be a part of the precipitation experiments. Method blanks will stimulate simple gravity settling and serves as a "base case" to compare the effectiveness of ferric precipitation in mercury removal. Reagent blanks will monitor the levels of mercury in the ferric sulfate.

- A second-stage membrane unit will be used to reduce the volume of backwash stream that needs to be disposed of. The treatment of the backwash stream could also increase the percentage recovery as well.

- Precipitation followed by filtration (second-stage membrane unit) is also likely to be successful in achieving target concentrations of mercury. Walterick et al. [18] reported that a combined treatment of precipitation and microfiltration/ultrafiltration is 
necessary to achieve extremely low mercury effluent concentrations ( $\leq 1.3 \mathrm{ppt})$ in refinery wastewater containing similar concentrations of $\mathrm{Hg}$ in the backwash stream.

The backwash stream collected at the end of the pilot-study will be used for these experiments. A time-zero analysis will allow us to determine if changes in the mercury partitioning between dissolved and particulate has occurred. A short description of each experiment is given below:

- Fe precipitation: The experiments will be performed by testing ferric sulfate at four different doses ranging from 5- $25 \mathrm{ppm}$ to determine the effectiveness of ferric sulfate in removing higher concentrations of $\mathrm{Hg}(80-200 \mathrm{ppt})$ from the backwash stream.

- Membrane filtration (UF): The collected stream will be directly fed to a secondary membrane unit to determine the effectiveness of UF filters in treating the backwash stream containing higher concentrations of $\mathrm{Hg}$ than that of the tested pre-ETL. Experiments will be conducted by using a laboratory scale membrane unit with a UF filter made of PVDF with a pore size of $0.04 \mu \mathrm{m}$ size, so that similar results can be obtained with the GE’s ZeeWeed® technology.

- Fe precipitation + Membrane filtration (UF). Ferric sulfate will be used as a pretreatment method before membrane filtration (second-stage membrane) to maximize the $\mathrm{Hg}$ removal rate if target $\mathrm{Hg}$ concentrations ( $<1.3 \mathrm{ppt}$ ) are not met after secondary membrane treatment or precipitation experiments. The ferric addition will be in the range of $5-20 \mathrm{ppm}$ as Fe. This pretreatment will be done in a jar tester as described above. The ferric sulfate will be added to the backwash stream to generate the pin-sized flocs that are just big enough to be removed by either sand filters or membranes. Then, the supernatant will be analyzed for $\mathrm{Hg}$ as well as collected to feed the second stage membrane unit. Ferric sulfate can also be used later in treatment of reject stream generated during the operation of the second-stage membrane unit.

The focused testing experiments will be conducted based upon the test results obtained from the initial screening experiments, by testing more specific treatment conditions (example: pressure, doses, etc.).

\subsection{GE Pilot Summary and Conclusions}

In this project module, assessment of the UF membrane process previously identified in Module 3 was determined at the pilot-scale. The Module 4 membrane UF pilot-scale testing was an Argonne/PUC directed project that was hosted by the BP refinery in Whiting, IN. GE's ZeeWeed® UF hollow fiber membrane technology $(0.04 \mu \mathrm{m}$ pore size and made up of PVDF) was tested based on the decision matrix criteria as discussed in detail in Module 3 report. 
The membrane UF technology was tested using the Whiting Refinery's end-of-pipe wastewater: effluent to Lake (ETL) as the influent waste stream to demonstrate performance with continuous but varying feed conditions over a protracted period. The objective of this pilot testing was to demonstrate the proof of concept, i.e. can the target treatment limit of less than 1.3 ppt obtained at bench-scale be consistently met at the pilot scale. The optimization for full-scale process design was outside of the scope of this study.

The project team designed a comprehensive work plan which also included GE's work plan to demonstrate performance under continuous feed conditions and variable wastewater composition and to provide the data necessary (but not necessarily sufficient) for preliminary full-scale process design. Quality control is an essential element of this pilotstudy which was conducted in the field. In addition to standardized pilot monitoring procedures, the pilot quality control included the collection and analysis of the equipment blanks, reagent blanks, environmental blanks and field blanks to determine how much of the removal was actually due to the technology. The confirmation of performance data is also a critical component of the quality control for the validation of pilot test results. A total of 28 split samples were collected from August 10 to September 21, 2011 for analysis. Two EPA certified analytical labs analyzed these samples for comparison purposes. The statistical analysis indicated that the differences in the test results obtained from both labs were considered to be not statistically significant at a $95 \%$ confidence interval $(P<0.5)$.

The pilot testing of this technology was accomplished in three phases. The priorities during the piloting were identified as a) Achieve target $\mathrm{Hg}$ levels in the effluent ( $<1.3 \mathrm{ppt}) \mathrm{b}$ ) Maximize percentage recovery c) Maintaining a stable operation (with a 10-20\%TMP fluctuation) at the pilot unit d) Obtain economically viable flux rates based on GE-defined targets for the scale up of this process. The best operating conditions for the UF membrane were determined by changing the flux rates (Flux A and Flux B) and the percentage recoveries ( $\mathrm{X}, \mathrm{Y}$ and $\mathrm{Z} \%$ ) to meet the target effluent $\mathrm{Hg}$ concentrations. Key hydraulic variables, such as flux, TMP, membrane permeability were continuously monitored over the study period.

A conceptual design of the full-scale membrane process was based on the proof of concept testing at the pilot-scale. The system was designed based on the evaluation of process performance at the tested flux rates and percentage recoveries over the pilot-study.

The major findings in this study can be summarized as follows:

\section{Effluent water quality:}

- The UF membrane process consistently provided a constant permeate quality at all tested operating conditions, virtually independent of the feed water characteristics and the feed $\mathrm{Hg}$ concentration. The treatment target of less than $1.3 \mathrm{ppt}$ of $\mathrm{Hg}$ was 
met and exceeded for all tested conditions during the pilot study. This demonstrates that there is no fundamental physical or chemical barrier in achieving $<1.3 p p t \mathrm{Hg}$ in the tested refinery wastewater at the pilot-scale at least under these testing conditions of little dissolved mercury in the pre-ETL $(<0.5-1.05 \mathrm{ppt})$. Engineering issues that will be addressed during the scale-up and optimization phases.

- Turbidity measurements were less than 0.5 NTU (with a MDL of 0.5 NTU) $85 \%$ of the time and $<0.16$ NTU 95\% of the time when analyzed on-line.

- The particle size and the size distribution analysis confirmed the excellent performance of the ultrafiltration in retaining the particle bound $\mathrm{Hg}$ within the membrane unit as well as the removal of particles from the permeate. Particle removal is a must for particle-bound $\mathrm{Hg}$ removal, which is necessary to achieve less than 1.3 ppt of $\mathrm{Hg}$ in ETL.

\section{Process performance:}

- The TMP values were below the specification of (negative) 7-12 psi at all tested conditions during the pilot-study.

- Weekly maintenance cleans and monthly CIP events were very effective in consistently restoring the membrane permeability during the pilot-study.

- Low membrane fouling rates ranging from $0.0125-0.05 \mathrm{psi} /$ day at $20^{\circ} \mathrm{C}$ resulted in an expected cleaning interval of longer than 90 days when the unit was operated at a Flux A flux rate and $\mathrm{X}, \mathrm{Y}$ and $\mathrm{Z} \%$ percent recoveries.

- The fouling rate was higher $\left(0.836 \mathrm{psi} /\right.$ day at $\left.20^{\circ} \mathrm{C}\right)$ when the system was operated at a Flux $\mathrm{B}$ flux rate and $\mathrm{X} \%$ recovery. The corresponding expected cleaning interval was 14.4 days. Running the membrane at a higher flux rate did not impact the $\mathrm{Hg}$ removal performance, but it did impact the cleaning interval of the membrane unit.

Challenges and limitations during the pilot-scale technology demonstration and evaluation:

- During the pilot study, the membrane performance was evaluated by forty one grab sample collection events. However, there is a possibility that representative feed and reject samples were not collected considering the variability in wastewater composition as well as the heterogeneity of water samples because of the presence of $\mathrm{Hg}$ in particulate form. Two days of composite sampling showed that the standard deviations were very high and ranged from 41.5 to $59 \%$ in the feed and backwash samples.

- The composite sampling provided improved sampling precision and reduced the sample variability over the 24 hour. Grab sampling should be used for a rapid preliminary assessment of a treatment process for the removal of particle bound $\mathrm{Hg}$. However, the use of composite sampling to obtain a representative sample should 
be adopted when the objective of the sampling is to evaluate with greater precision the performance of the membrane process.

Full-scale considerations and planning:

- The four months of operating experience provided many useful insights into the design, operational and performance aspect of implementing a UF membrane process.

- Argonne's estimate of the full-scale cost varied between $\$ 39 \mathrm{M}-147 \mathrm{M}$ for a $40 \mathrm{mgd}$ design capacity process depending on the criteria used in cost calculations, such as land acquisition, engineering, site development, waste disposal, etc. It should be noted that the vendor did not provide a full-scale cost estimate therefore this estimate was produced using literature data and methodologies.

- On the basis of the four month pilot-study test results, the Argonne team recommends ultrafiltration membrane technology for further evaluation at the Whiting Refinery.

- The proven effectiveness of ultrafiltration in the removal of other particulate contaminants at existing full-scale applications suggests an increased likelihood of success under conditions of little dissolved mercury in the pre-ETL $(<0.5-1.05 \mathrm{ppt})$ in achieving target mercury concentrations at the Whiting Refinery, following optimization and scalability studies.

\subsection{References}

1. Negri M.C., Gillenwater P., Urgun-Demirtas M (2011) Emerging Technologies and Approaches to Minimize Discharges into Lake Michigan Phase 2, Module 3 Report.

2. GE Water \& Process Technologies Pilot Study Proposal, February 2011.

3. ZeeWeed® 500 Immersed Membrane Water Treatment System Pilot Manual, Zenon 2004.

4. EPA Method 1669- Sampling Ambient Water for Trace Metals at EPA Water Quality Criteria Levels

5. EPA Method 1631E- Mercury in Water by Oxidation, Purge and Trap, and Cold Vapor Atomic Fluorescence Spectrophotometry, August 2002.

6. Bergman R. A., Porter R., Joffe D., Minchew E. (2006) Commissioning and Operation of a 50 mgd Ultrafiltration Advanced Reclamation Facility for Gwinnett County, Georgia, WEFTEC'06 Conference Proceedings, pp 2698-2715 http://www.environmentalexpert.com/Files\%5C5306\%5Carticles\%5C9263\%5C213.pdf

7. EPA Method 7471B Mercury in Solid or Semisolid Waste (Manual Cold-Vapor Technique) (1994) 
http://www.epa.gov/epawaste/hazard/testmethods/sw846/pdfs/1311.pdf, accessed $10 / 1 / 2011$

8. Rimer AE, Kobylinski EA, Hunter GL, DiGiano FA, Bierck B (2008) The Impact of Membrane Process Residuals on Wastewater Treatment: Guidance Manual Watereuse Foundation, Alexandria, Virginia.

9. Calderon A (2011) GE Water Technologies, email communication, November 17.

10. Solids Inventory Control For Wastewater Treatment Plant Optimization (2004) Federation of Canadian Municipalities and National Research Council http://www.fcm.ca/Documents/reports/Infraguide/Solids_Inventory_Control_for_Was tewater_Treatment_Plant_Optimization_EN.pdf

11. Adham S, Chiu K-P, Gramith K, Oppenheimer J (2005)Development of a Microfiltration and Ultrafiltration Knowledge Base Funded by AWWA Research Foundation and US Department of the Interior, Bureau of Water Reclamation.

12. http://enr.construction.com/economics (Accessed on October 2011)

13. Schendel D.B., Chowdhury Z.K., Hill C.P, Summers R.S., Towler E., Balaji R., Raucher R.S., Cromwell J. (2009) Decision Tool to Help Utilities Develop Simultaneous Compliance Strategies. Jointly sponsored by Water Research Foundation and U.S. Environmental Protection Agency. Publication by Water Research Foundation

14. Knops F., Phay W. (2008) Economic Evaluation of a New UF Membrane for SWRO Pretreatment. Water and Wastewater Asia, March/April pg.36-41

15. Alhumoud J.M., Al-Humaidi H., Alhumoud A.M. (2010) Cost/Benefit Evaluation of Sulaibiya Wastewater Treatment in Kuwait. International Business \& Economics Research Journal, February 2010, Vol. 9 (2), 23-32.

16. Membrane Filtration Guidance Manual (2005) EPA 815-R06-009, November.

17. Patoczka, J., R.K. Johnson, and J.J. Scheri (1998,) "Trace Heavy Metals Removal with Ferric Chloride," Water Environment Federation Industrial Wastes Technical Conference, Nashville, TN.

18. Walterick, Jr., G.C., S.R. Vasconcellos, and D.Gereaghty (2010), "Method for Removing Mercury from Wastewater and Other Liquid Streams," U.S. Patent No: US 2010/0051553 A1. 


\section{Reactive Filtration \\ 3.1 Introduction}

\subsubsection{Background}

During Module 3, a wide variety of technologies were tested at the bench-scale for mercury removal. Of the technologies tested, three were recommended by ANL and PUC for piloting during Module 4. Among these technologies is Blue Water Technology's (BWT) Blue PRO ${ }^{\circledR}$ reactive filtration process which combines precipitation, filtration and adsorption. This process has shown the potential at the bench-scale to remove both particulate and dissolved mercury.

In the Blue PRO $®$ process, precipitation chemicals (ferric sulfate and/or a polymer (Nalmet ${ }^{1}$ 1689)) are added to the wastewater stream prior to introduction to a moving bed sand filter that uses ferric sulfate coated sand. Based on vendor recommendation, during the Module 3 bench-scale testing the process was simplified to two static columns of ferric sulfate coated sand (1). Although testing with the static columns produced effluent that met the future Great Lakes criterion of $1.3 \mathrm{ppt} \mathrm{Hg}$, the role of the various components of the system (the precipitation chemicals and the ferric coated sand) was unclear. Hence, additional bench-scale testing at ANL was done as part of Module 4 prior to the pilot work to examine the effectiveness of specific process conditions such as reagent dose and sand properties (ferric coated vs. uncoated) on mercury removal performance and to generate optimized test conditions for the pilot scale testing. It was planned to use the information from this bench-scale testing to reduce the number of conditions tested during the piloting and to maximize the length of piloting time spent at a steady state condition.

After the additional bench-scale testing, a Blue PRO® pilot system which incorporates the entire process (including the moving bed sand filter) was tested at BP's Whiting Refinery. The pilot test was conducted to determine the performance of the technology with continuous and varying feed conditions over a three month time period. Optimization for full-scale design was not done.

\subsubsection{Blue $\mathrm{PRO}^{\circledast}$ Process}

The Blue $\mathrm{PRO} \circledast$ process is a reactive filtration process that combines precipitation, sand filtration and adsorption. Precipitants are added to the wastewater prior to the moving bed sand filter, which filters out particulate contaminants. According to the vendor, a ferric coating on the sand enables additional contaminant removal via adsorption. The coating on the sand is continuously ground off by the action of the moving bed of sand, creating fresh sites for adsorption, and then continuously reapplied through the addition of the precipitation chemical. The process operates continuously and does not require batch 
backwashing or other system cycling. The process produces a reject stream which potentially can be recycled to the head of the wastewater treatment plant.

For this mercury removal application, ferric sulfate and/or Nalmet ${ }^{\circledR} 1689$ are added as precipitants to the influent wastewater which then passes through a "Rapid Conditioning Zone"TM to enable proper mixing of the chemicals. The mixture enters the moving bed sand filter through an outside jacket of the central assembly and is then fed through distribution arms at the bottom of the sand bed, subsequently flowing upward through the sand bed. After filtration, clean water discharges from the top of the filter (on the right of Figure 3.1). Within the filter the sand moves slowly from top to bottom and then returns to the top of the filter via an airlift located in the central assembly. A washbox at the top of the filter separates sand from waste particles. The sand falls back to the top of the bed while the residuals, including the iron and mercury, exit in a separate reject stream line. It should be noted that the reject rate from the pilot system ( $24 \%$ of feed flow rate) does not linearly scale to the full-scale system. According to the vendor, the reject rate from the full-scale system is proportionately smaller ( $7-10 \%$ of feed flow rate). 


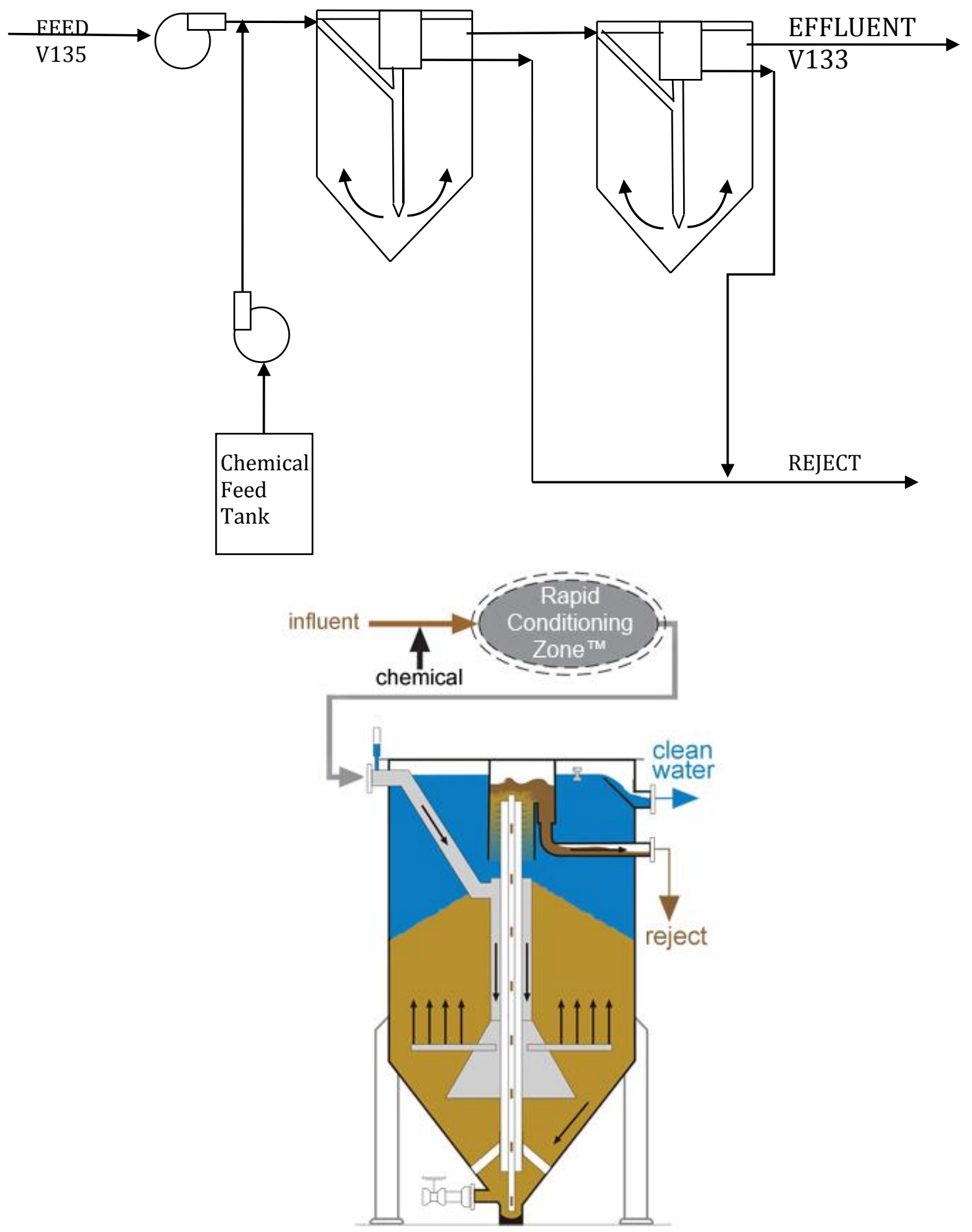

Figure 3.1 Blue PRO® process schematic (2)

(Permission to use photograph granted by Blue Water Technologies Inc.) 


\subsection{Pilot Preparatory Module 4 Bench-scale Testing}

\subsubsection{Goals and Objectives}

Module 3 bench-scale testing with the static ferric coated sand columns showed that the system was effective in removing both particulate and dissolved mercury (1). Effluent from the series of two columns was below 1.3 ppt Hg when Nalmet ${ }^{\circledR} 1689$ was used as a precipitant chemical. Ferric sulfate addition alone did not produce effluent that was below $1.3 \mathrm{ppt} \mathrm{Hg}$.

These positive removal results along with a first-cut economic evaluation led to the selection of the Blue PRO $®$ system as one of the technologies that will be piloted at Whiting. However, the bench-scale tests left several unanswered questions about the role of the precipitants and the sand coating. Specific questions included:

- Is a ferric sand coating needed? Or is plain sand sufficient?

- What is the effect of Nalmet $\AA^{1689}$ on dissolved Hg removal?

- What is the effect of ferric sulfate addition on dissolved Hg removal?

- What is the effect of sand filtration on Hg removal?

In preparation for the pilot work, additional bench-scale testing was done as part of Module 4 to determine the roles of the precipitants and the sand in the Blue PRO $®$ process. This was done to help shorten the pilot optimization time period and to maximize the pilot testing done at steady-state.

\subsubsection{Bench-Scale Materials and Methods}

\subsubsection{Water Samples}

BP Whiting Refinery's Clarifier Effluent (CE) was used for the testing. Samples were collected using the "clean hands, dirty hands" procedure specified in EPA's Method 1669 (3). Upon receipt, the wastewater was stored in a $4^{\circ} \mathrm{C}$ cold room before use. Testing was done with one batch of wastewater which was used up within one week of receipt. This was done so that changes in mercury speciation and composition would be negligible.

\subsubsection{Reagents and Experimental Equipment}

Ferric sulfate solutions were prepared using ACS-grade Iron (III) sulfate hydrate (97\%) provided by Sigma-Aldrich. The Nalmet® 1689 was provided by BWT, who obtained it from the manufacturer, Nalco. The ferric sulfate-coated silica sand was provided by BWT. Both sizes of plain sand were obtained from Carbon Enterprises, Ohio. The $10 \mu \mathrm{g} / \mathrm{mL}$ mercury standard that was used for spiking the filtered CE was manufactured by Spex Certiprep, New Jersey. 
The testing was done in Argonne's Class 100 clean room using the same static column equipment used for the Module 3 Blue PRO $®$ process testing (1). One difference in this Module 4 work was that some of the tests used plain uncoated sand within the columns. Two different types of sand were used to form a dual media filter similar to what is planned to be used at Whiting for their new sand filters. The details are given in Table 3.1 below. For comparison, the size of the sand to be used for the Blue PRO® pilot is included, however, it should be noted that the Blue PRO® system is a moving bed system.

Table 3.1 Comparison of Sand Filters - Future Whiting and Bench-Scale

\begin{tabular}{|c|c|c|}
\hline $\begin{array}{c}\text { Future Whiting Sand } \\
\text { Filter(4) }\end{array}$ & $\begin{array}{c}\text { Bench-Scale Plain Sand } \\
\text { Filter }\end{array}$ & Blue PRO® Pilot \\
\hline 20 " of blended anthracite & 20 " of coarse sand & Initial sand is $0.841-1.68$ \\
$(2.3-3.0 \mathrm{~mm})$ & $(1.6-3.2 \mathrm{~mm})$ & $\mathrm{mm}$ \\
\hline 10 " of sand media & 10 " of finer sand & After coating, size change \\
$(1.2-1.4 \mathrm{~mm})$ & $(1.20-1.60 \mathrm{~mm})$ & is minimal (5). \\
\hline
\end{tabular}

\subsubsection{Experimental Procedure and Test Plan}

The procedure followed was the same as was used for the Module 3 testing (1). Specifically, the flux to the columns was in the range of 1.9 to $2.2 \mathrm{gpm} / \mathrm{ft}^{2}$ and the EBCTs ranged from 10 - 11 minutes. Eight bed void volumes of CE feed was fed to the columns prior to sampling, which was done in triplicate. After each run, 4.5 bed void volumes of MilliQ water was used to flush out the system. The feed and effluents from the two benchscale columns were sampled and analyzed for Hg using EPA Method 1631e.

The test plan is shown below in Table 3.2. In order to minimize the accumulation of precipitation chemicals on the plain sand and the resulting impact on the testing, the columns were reloaded several times with new sand as per Table 3.2. 
Table 3.2 Additional Bench-Scale Static Column Tests

\begin{tabular}{|c|c|c|c|c|}
\hline Test & $\begin{array}{c}\text { Type of } \\
\text { Sand }\end{array}$ & Ferric Sulfate & Nalmet $\circledast 1689$ & Type of CE \\
\hline \multicolumn{5}{|l|}{ New sand } \\
\hline 1 & plain (a) & No & no & $\begin{array}{c}\text { filtered \& spiked } \\
\text { (b) }\end{array}$ \\
\hline 2 & plain & No & no & as-is \\
\hline 3 & plain & No & $\begin{array}{l}0.5 \mathrm{ppm} \text { to each } \\
\text { column }\end{array}$ & filtered \& spiked \\
\hline 4 & plain & No & $\begin{array}{l}0.5 \text { ppm to each } \\
\text { column }\end{array}$ & as-is \\
\hline \multicolumn{5}{|l|}{$\begin{array}{l}\text { Reload new } \\
\text { sand }\end{array}$} \\
\hline 5 & plain & $\begin{array}{c}5 \mathrm{ppm} \mathrm{Fe} \text { to first } \\
2 \mathrm{ppm} \mathrm{Fe} \text { to second }\end{array}$ & no & filtered \& spiked \\
\hline 6 & plain & $\begin{array}{c}5 \mathrm{ppm} \mathrm{Fe} \text { to first } \\
2 \mathrm{ppm} \mathrm{Fe} \text { to second }\end{array}$ & no & as-is \\
\hline \multicolumn{5}{|l|}{$\begin{array}{c}\text { Reload new } \\
\text { sand }\end{array}$} \\
\hline 7 (c) & plain & $\begin{array}{c}5 \mathrm{ppm} \mathrm{Fe} \text { to first } \\
2 \mathrm{ppm} \mathrm{Fe} \text { to second }\end{array}$ & $\begin{array}{l}0.5 \text { ppm to each } \\
\text { column }\end{array}$ & filtered \& spiked \\
\hline 8 (c) & plain & $\begin{array}{c}5 \mathrm{ppm} \mathrm{Fe} \text { to first } \\
2 \mathrm{ppm} \mathrm{Fe} \text { to second }\end{array}$ & $\begin{array}{l}0.5 \mathrm{ppm} \text { to each } \\
\text { column }\end{array}$ & as-is \\
\hline \multicolumn{5}{|l|}{$\begin{array}{l}\text { Reload with Fe } \\
\text { coated sand }\end{array}$} \\
\hline 9 & Fe coated & $\begin{array}{c}5 \mathrm{ppm} \mathrm{Fe} \text { to first } \\
2 \mathrm{ppm} \mathrm{Fe} \text { to second }\end{array}$ & no & filtered \& spiked \\
\hline 10 & Fe coated & no & $\begin{array}{l}0.5 \mathrm{ppm} \text { to each } \\
\text { column }\end{array}$ & filtered \& spiked \\
\hline
\end{tabular}

(a) Total of 30 " of sand - 20" of coarser sand, 10 " of finer sand.

(b) Filtered with $0.45 \mu \mathrm{m}$ filter and spiked with $10 \mathrm{ppt}$ of $\mathrm{Hg}^{+2}$.

(c) Test was not done due to plant upset.

The coated sand used was from the same batch that was previously supplied by BWT for the Module 3 testing. It was previously used for the three Bulwer tests. To compensate for the higher mercury levels found in the Bulwer wastewater, extra MilliQ flushing of the columns was done. Additionally, a sample of the final MilliQ flush was taken to see if any mercury was leaching from the column. MilliQ water tends to leach the iron coating from the sand, so ferric sulfate addition with the coated sand (Test 9) was tested first before Nalmet ${ }^{\circledR} 1689$ addition (Test 10) in an attempt to add back a small amount of ferric sulfate coating and hence compensate for what may have been lost during the extra MilliQ water flushing. This is particularly important since Tests 9 and 10 are looking at dissolved $\mathrm{Hg}$ removal which may be partially done through adsorption onto the sand ferric coating. 
Although it was originally planned to test the effect of adding ferric sulfate and Nalmet ${ }^{\circledR}$ 1689 while using plain sand (Tests 7 and 8), a plant upset at Whiting prevented the collection of wastewater for the tests. After the plant upset was resolved, it was decided to not do these tests but rather to use the information from the testing that had been completed to determine pilot conditions.

\subsubsection{Bench-Scale Results and Discussion}

The wastewater used for the bench-scale testing is characterized in Table 3.3. Compared to the typical concentration ranges seen during the Module 3 testing, most of the components were within the ranges seen and reported during Module 3 testing, with the exception of Total Hg, TSS and sulfate, which were all higher than what was previously seen during Module 3 testing (1). For the bench-scale testing, it is noteworthy that the Total $\mathrm{Hg}$ was 2.5 times higher than the typical Module 3 range of 1-10 ppt.

Table 3.3 Wastewater Characterization for Bench-Scale Testing

\begin{tabular}{|l|c|}
\hline Analyte & $\begin{array}{c}\text { Concentration (ppm } \\
\text { or as noted) }\end{array}$ \\
\hline Total $\mathrm{Hg}$ & $25.65 \mathrm{ppt}$ \\
\hline Dissolved $\mathrm{Hg}$ & $<0.5 \mathrm{ppt}$ \\
\hline Total Suspended Solids & 28 \\
\hline Total Dissolved Solids & 1500 \\
\hline Hardness (as $\left.\mathrm{CaCO}_{3}\right)$ & 210 \\
\hline Chloride & 246 \\
\hline Fluoride & 0.262 \\
\hline Total Phosphorus & 0.495 \\
\hline Sulfate & 1010 \\
\hline
\end{tabular}

A summary of the equipment and reagent blanks is shown in Table 3.4. The equipment and sand blanks were done by pumping MilliQ water $\left(18 \mathrm{M} \Omega . \mathrm{cm}\right.$ resistivity at $\left.25^{\circ} \mathrm{C}\right)$ through either the equipment or sand columns. Both the in-line filtration equipment and the Blue PRO ${ }^{\circledR}$ bench-scale apparatus contributed minimal amounts of $\mathrm{Hg}$ to the MilliQ water flowing through it. For the sand blanks, samples of MilliQ effluent were collected after 4.5 and 15 bed void volumes for the plain sand and the coated sand, respectively. The coated sand was flushed for a longer time period because it had been previously used for Bulwer wastewater testing, which had higher mercury levels than Whiting CE. Despite this longer flushing of the coated sand, the blank (21.6 ppt $\mathrm{Hg}$ ) suggests that adsorbed $\mathrm{Hg}$ was still leaching off of the sand's ferric coating in the presence of MilliQ water. The plain sand blank showed a small, but for the purposes of this testing, significant amount of $\mathrm{Hg}$ (1.06 ppt), which suggests that the MilliQ was leaching off $\mathrm{Hg}$ that was adsorbed onto or 
associated with the sand - i.e. that the plain unused sand may have $\mathrm{Hg}$ associated with it. The ferric sulfate stock reagent blank showed a significant amount of mercury (165 ppt) while the Nalmet ${ }^{\circledR} 1689$ polymer reagent blank showed a minimal level of $\mathrm{Hg}$ ( $\left.0.1 \mathrm{ppt}\right)$.

Table 3.4 Equipment and Reagent Blank Summary

\begin{tabular}{|l|c|}
\hline & $\begin{array}{c}\text { Total Hg } \\
\text { (ppt) }\end{array}$ \\
\hline In-line Filtration Blank (a) & $<0.5$ \\
\hline Blue PRO® Equipment Blank (a) & 0.09 \\
\hline Plain Sand Blank & 1.06 \\
\hline Coated Sand Blank & 21.6 \\
\hline $\begin{array}{l}\text { Ferric Sulfate (300 ppm as Fe) Solution } \\
\text { Blank (a) }\end{array}$ & 165 \\
\hline $\begin{array}{l}\text { Nalmet@ } 1689 \text { (10 ppm) Solution Blank } \\
\text { (a) }\end{array}$ & 0.1 \\
\hline
\end{tabular}

(a) From Module 3 Testing (1).

When CE "as-is" was tested with plain sand (Table 3.5), all of the effluents were below the 1.3 ppt Hg treatment goal. Low doses of Nalmet ${ }^{\circledR}$ (Test 4, $0.5 \mathrm{ppm}$ to each column) gave the effluent with the lowest Hg concentration (0.23 ppt) and the best Hg removal (99.1\%). The use of plain sand without any chemical addition (Test 2) also met the treatment goal, suggesting that sand filtration alone may be sufficient to meet the treatment goal. 
Table 3.5 Bench-scale Static Column Testing with Plain Sand and CE as-is

\begin{tabular}{|c|c|c|c|c|c|c|c|c|}
\hline & \multicolumn{2}{|c|}{ Feed } & \multicolumn{3}{|c|}{ Column 1 Effluent } & \multicolumn{3}{|c|}{ Column 2 Effluent } \\
\hline Test & $\begin{array}{c}\text { Ave. } \\
\text { Hg } \\
\text { (ppt) }\end{array}$ & $\begin{array}{l}\text { St. } \\
\text { Dev. }\end{array}$ & $\begin{array}{c}\text { Ave. } \\
\text { Hg } \\
\text { (ppt) }\end{array}$ & $\begin{array}{l}\text { St. } \\
\text { Dev }\end{array}$ & $\begin{array}{c}\text { \% Hg } \\
\text { Remove } \\
\text { d }\end{array}$ & $\begin{array}{c}\text { Ave. } \\
\text { Hg } \\
\text { (ppt) }\end{array}$ & $\begin{array}{l}\text { St. } \\
\text { Dev. }\end{array}$ & $\begin{array}{c}\text { \% Hg } \\
\text { Remove } \\
\text { d }\end{array}$ \\
\hline $\begin{array}{l}2 \text { - CE as-is } \\
\text { Plain sand } \\
\text { No ferric sulfate } \\
\text { No Nalmet }{ }^{\circledR}\end{array}$ & 19.53 & 2.20 & 0.57 & 0.05 & $97.1 \%$ & 0.75 & 0.02 & $96.1 \%$ \\
\hline $\begin{array}{l}4 \text { - CE as-is } \\
\text { Plain sand } \\
\text { No ferric sulfate } \\
0.5 \& 0.5 \text { ppm } \\
\text { Nalmet@ }\end{array}$ & 25.27 & 2.72 & 0.27 & 0.09 & $98.9 \%$ & 0.23 & 0.06 & $99.1 \%$ \\
\hline $\begin{array}{l}\text { New Sand in } \\
\text { columns }\end{array}$ & & & & & & & & \\
\hline $\begin{array}{l}6 \text { - CE as-is } \\
\text { Plain sand } \\
5 \text { \& } 2 \text { ppm Fe } \\
\text { No Nalmet }{ }^{\circledR}\end{array}$ & 18.67 & 1.43 & 0.67 & 0.08 & $96.4 \%$ & 1.05 & 0.12 & $94.4 \%$ \\
\hline
\end{tabular}

The results of the dissolved $\mathrm{Hg}$ removal testing with plain sand columns are shown in Table 3.6 below. Adding Nalmet ${ }^{\circledR}$ to CE prior to the sand columns resulted in an $82.2 \% \mathrm{Hg}$ removal, yet the effluent still did not meet the treatment goal. Neither plain sand without any chemical addition nor ferric sulfate provided any significant dissolved Hg removal. 
Table 3.6 Bench-Scale Static Column Testing with Plain Sand, Filtered and Spiked CE $\left(0.45 \mu \mathrm{m}, 10\right.$ ppt $\mathrm{Hg}^{+2}$ )

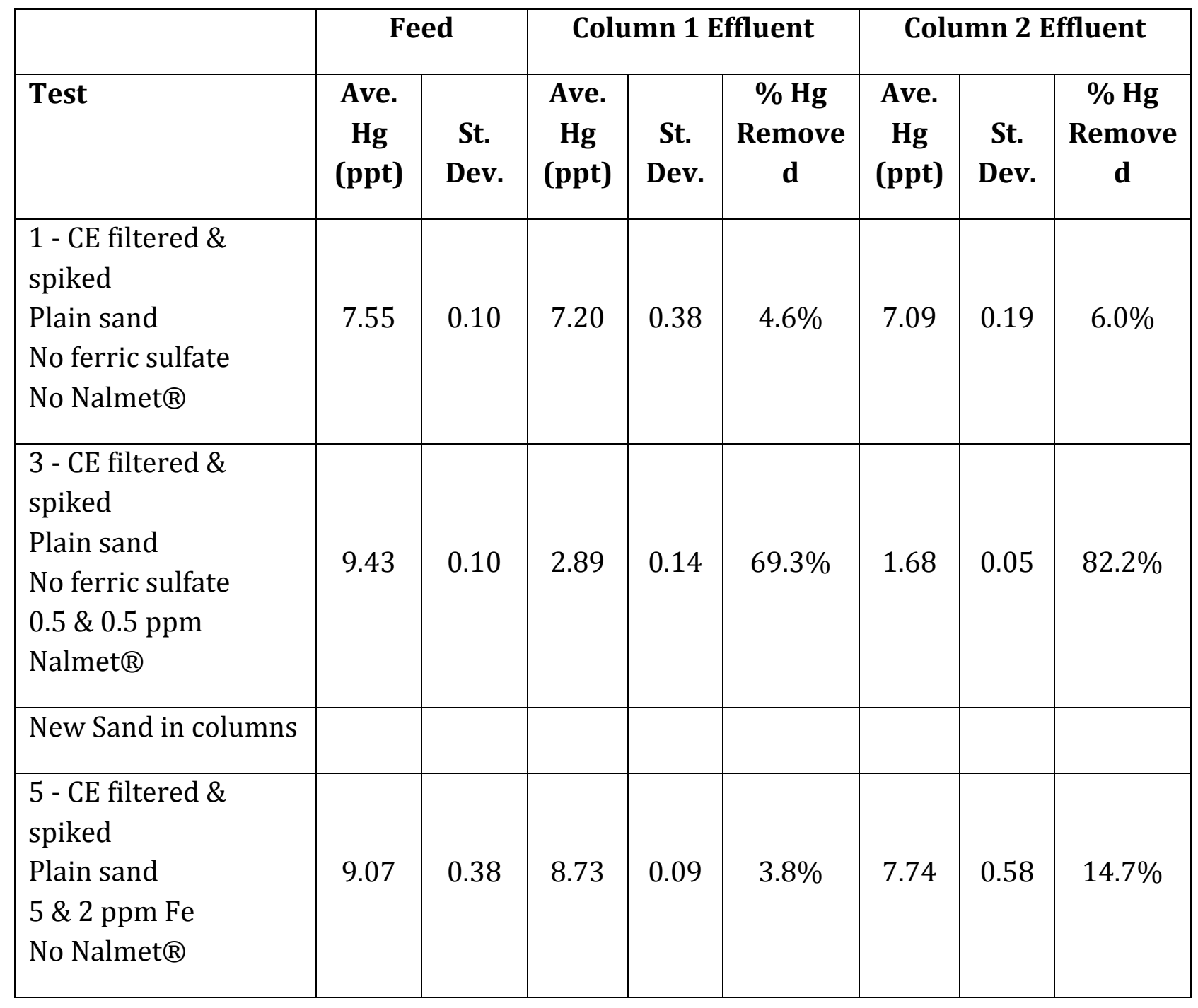

Testing was also done to determine dissolved Hg removal using ferric coated sand, as shown in Table 3.7. The tests were done in numerical sequence - Test 9 and then Test 10. The high levels of Hg in Test 9's effluent (21.5 ppt) are similar to what was seen during the ferric coated sand blank with MilliQ water (21.6 ppt), suggesting that Bulwer-related $\mathrm{Hg}$ was still being flushed off the sand. The addition of Nalmet ${ }^{\circledR}$ alone without ferric sulfate produced effluent with a lower $\mathrm{Hg}$ concentration (5.68 ppt). However, this effluent still did not meet the treatment goal of $1.3 \mathrm{ppt}$. 
Table 3.7 Bench-Scale Static Column Testing with Ferric Coated Sand, Filtered and Spiked CE (0.45 $\left.\mu \mathrm{m}, 10 \mathrm{ppt} \mathrm{Hg}^{+2}\right)$

\begin{tabular}{|l|c|c|c|c|c|c|c|c|}
\hline & \multicolumn{2}{|c|}{ Feed } & \multicolumn{2}{c|}{ Column 1 Effluent } & \multicolumn{2}{c|}{ Column 2 Effluent } \\
\hline \multicolumn{1}{|c|}{ Test } & $\begin{array}{c}\text { Ave. } \\
\text { Hg } \\
\text { (ppt) }\end{array}$ & $\begin{array}{c}\text { St. } \\
\text { Dev. }\end{array}$ & $\begin{array}{c}\text { Ave. } \\
\text { Hg } \\
\text { (ppt) }\end{array}$ & $\begin{array}{c}\text { St. } \\
\text { Dev. }\end{array}$ & $\begin{array}{c}\text { Remove } \\
\text { d }\end{array}$ & $\begin{array}{c}\text { Ave. } \\
\text { Hg } \\
\text { (ppt) }\end{array}$ & $\begin{array}{c}\text { St. } \\
\text { Dev. }\end{array}$ & $\begin{array}{c}\text { Remove } \\
\text { d }\end{array}$ \\
\hline $\begin{array}{l}\text { 9- CE filtered \& } \\
\text { spiked } \\
\text { Fe coated sand } \\
5 \text { and 2 ppm Fe } \\
\text { No Nalmet@ }\end{array}$ & 7.68 & 0.92 & 14.97 & 1.01 & $-94.8 \%$ & 21.53 & 0.23 & $-280.3 \%$ \\
\hline $\begin{array}{l}10 \text { - CE filtered \& } \\
\text { spiked } \\
\begin{array}{l}\text { Fe coated sand } \\
\text { No ferric sulfate } \\
0.5 \text { \& 0.5 ppm } \\
\text { Nalmet }\end{array}\end{array}$ & 8.59 & 0.85 & 8.00 & 0.29 & $6.9 \%$ & 5.68 & 0.77 & $33.9 \%$ \\
\hline
\end{tabular}

\subsubsection{Bench-Scale Conclusions}

The conclusions from this additional bench-scale testing are summarized below. For completeness, applicable conclusions from the Module 3 testing are also included.

Bench-Scale Plain Sand Testing:

- The best particulate Hg removal was given with Nalmet@ 1689 (0.23 ppt, 99.1\% removal).

- Particulate Hg removal with plain sand alone and with ferric sulfate also met the treatment goal ( 0.75 and 1.05 ppt, $96.1 \%$ and $94.4 \%$, respectively).

- For dissolved Hg, Nalmet® gave the best removal (82.2\%), however, the effluent (1.68 ppt) did not meet the $1.3 \mathrm{ppt}$ treatment goal.

Bench-Scale Coated Sand Testing:

- The best particulate Hg removal was given with Nalmet@ 1689 (0.35 ppt, 98.7\% removal) (1).

- Particulate Hg removal with Nalmet ${ }^{\circledR}$ in combination with ferric sulfate also met the treatment goal (0.74 ppt, $92.2 \%$ removal) (1). 
- For particulate Hg, ferric sulfate alone was not sufficient to meet the treatment goal (2.61 ppt, 44.1\% removal) (1).

- Dissolved Hg removal testing results may be skewed due to previous testing with the column, but suggest that neither ferric sulfate alone nor Nalmet $®$ alone can remove a significant amount of dissolved $\mathrm{Hg}$.

The results of this additional testing were discussed with the Project Team on May 16 just prior to the start of the pilot testing. Further details on how these bench-scale testing results were incorporated into the pilot testing plan are given in Section 3.3.2.3.

\subsection{Pilot Testing}

\subsubsection{Pilot Equipment and Methodology}

\subsubsection{Pilot Feed Wastewater}

The wastewater feed to the pilot was taken from the pipeline leading to the Effluent To Lake outfall. It technically was taken upstream of the ETL outfall and it is referred as preETL. The wastewater was fed to the pilot through approximately 100 ' of 3" plastic corrugated hose.

\subsubsection{Pilot Equipment}

The pilot study was performed using two Blue PRO ${ }^{\circledR}$ filters operating in series as shown in Figure 3.2. The two filters are Centra-flo ${ }^{\mathrm{TM}} \mathrm{CF}-7$ moving bed sand filters mounted on frames with the internals modified for the Blue PRO ${ }^{\circledR}$ process. Specifications for these filters are

given in Table 3.8. The rest of the pilot equipment was supplied in a cargo container as shown in Figure 3.3 and included influent wastewater pumps, an air compressor, chemical pumps and feed systems as well as the system control panels. 


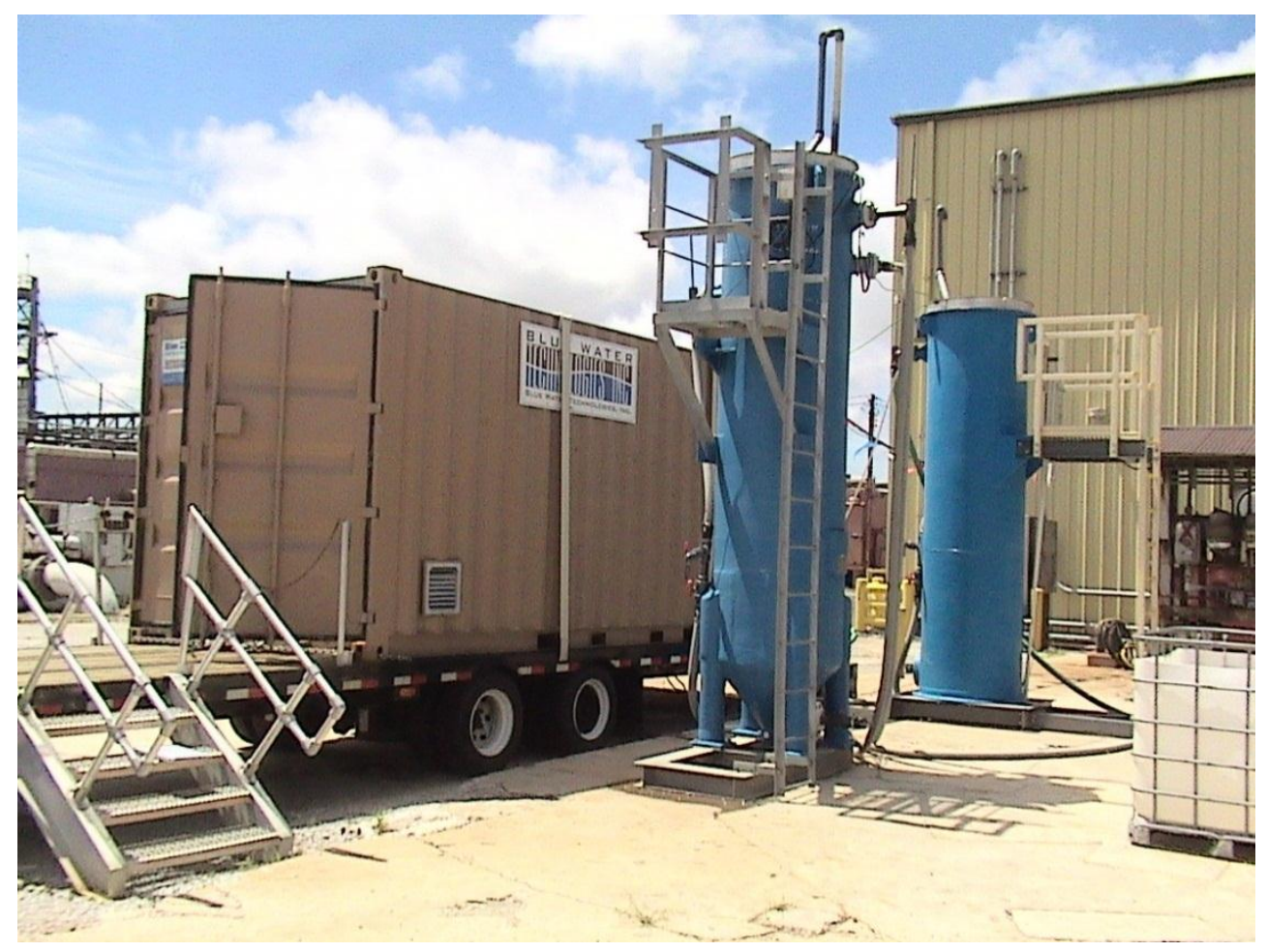

Figure 3.2 Blue PRO® Pilot Filters

(Permission to use photograph granted by Blue Water Technologies Inc.)

Table 3.8 CF-7 Moving Bed Sand Filter Specifications $(2,6)$

\begin{tabular}{|l|l|}
\hline Wastewater Influent Rate & $25 \mathrm{gpm}$ \\
\hline Reject Rate & $3 \mathrm{gpm}$ from each filter, total 6 gpm \\
\hline Hydraulic Loading Rate (average) & $3.5 \mathrm{gpm} / \mathrm{ft}^{2}$ \\
\hline Air Flow (1.0” airlift) & $15-30 \mathrm{scfh}$ \\
\hline Bed Turnover Rate & $0.2-0.4 \mathrm{in} / \mathrm{min}$ \\
\hline Filter 1 Dimensions & $13^{\prime} 3.5^{\prime \prime}$ height; $3^{\prime}$ diameter \\
\hline Filter 2 Dimensions & $9^{\prime} 9^{\prime \prime}$ height; $3^{\prime}$ diameter \\
\hline Sand Bed Height in each Filter (approx.) & $5^{\prime}$ \\
\hline
\end{tabular}



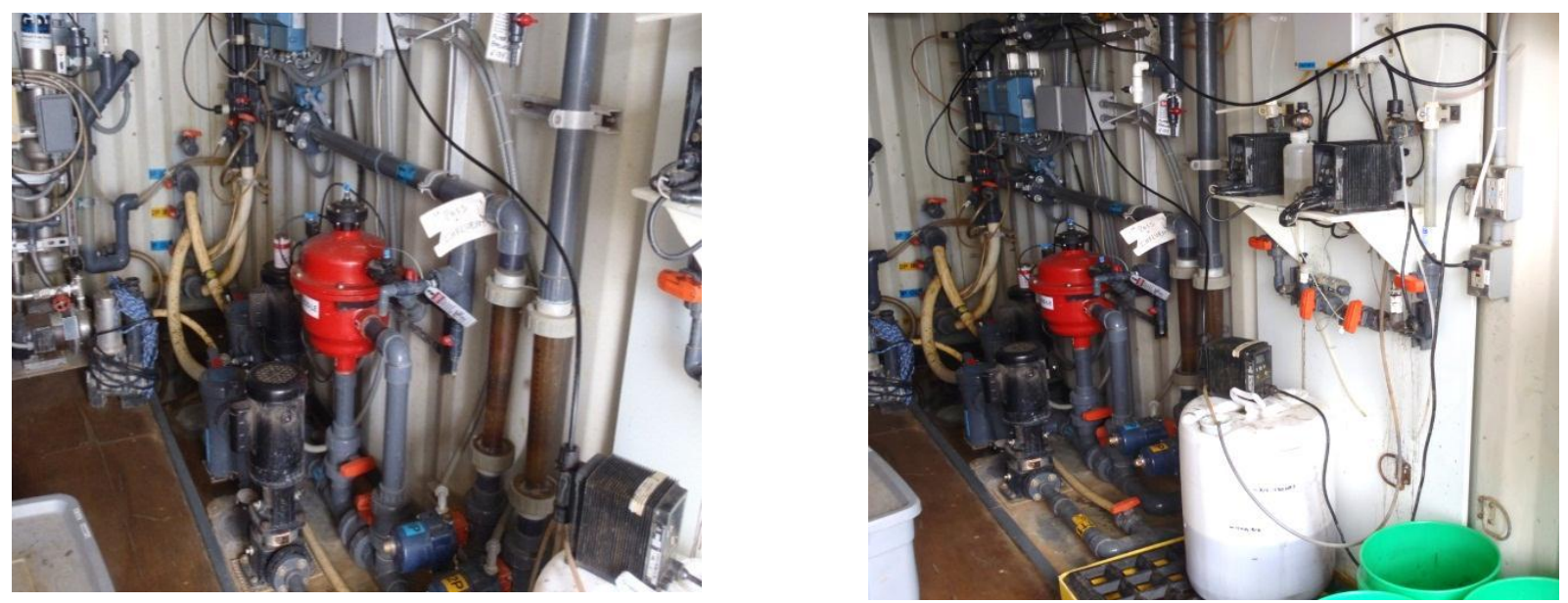

Figure 3.3 Wastewater Feed Pumps (left) and Chemical Feed System (right)

(Permission to use photograph granted by Blue Water Technologies Inc.)

The P\&ID for the pilot system is provided in the vendor's report in Appendix 3F.

Wastewater was fed to the system with a centrifugal pump. Influent wastewater flow rate was controlled with a pneumatic valve and measured with both a rotameter and an electronic flow meter that read out at the control panel. Both the Nalmet ${ }^{\circledR} 1689$ and the ferric sulfate solutions are individually fed to the influent wastewater lines with diaphragm metering pumps ( 0.66 gpm capacity). The pump settings controlled the flow rate while the overall amount of each chemical fed to the system was verified by noting the change in liquid level in the chemical feed tanks. A vertical two-stage air compressor equipped with an air dryer provided air flow to the unit. The air flow rate was read and controlled at the control panel. The reject flow rate from each sand filter was controlled with an adjustable weir in each filter's central washbox. Measurement of the reject flow rate was done with a bucket and stopwatch. A second centrifugal pump was used to transfer effluent from the first filter to the inlet of the second filter. Wastewater flow rate into the second sand filter was measured with both a rotameter and an electronic flow meter which read out at the control panel. The water level in each filter was controlled with electronic level controllers.

\subsubsection{Data Collection, Sampling and Analytical}

After commissioning, pilot operation was turned over to BP. Operating data was manually recorded by BP personnel during the normal work week (Monday through Friday). Additionally, samples were taken of the feed, the effluents from Filter 1 and Filter 2, and the rejects from Filter 1 and Filter 2.

The reject sample was a combined sample with approximately equal amounts from each reject stream. Originally each filter's reject sampling was done where the reject hoses emptied to a drain, approximately 30' from the filters. After it was noticed that solids were 
settling out in the long horizontal hose runs, sampling ports were added adjacent to the filter on the vertical hose immediately exiting the filters, as shown in Figure 3.4. This change was made on $6 / 23$, however, on $7 / 6$ it was noticed that the Filter 2's reject line was incorrectly installed and was actually sampling effluent. This was corrected on $7 / 6$.

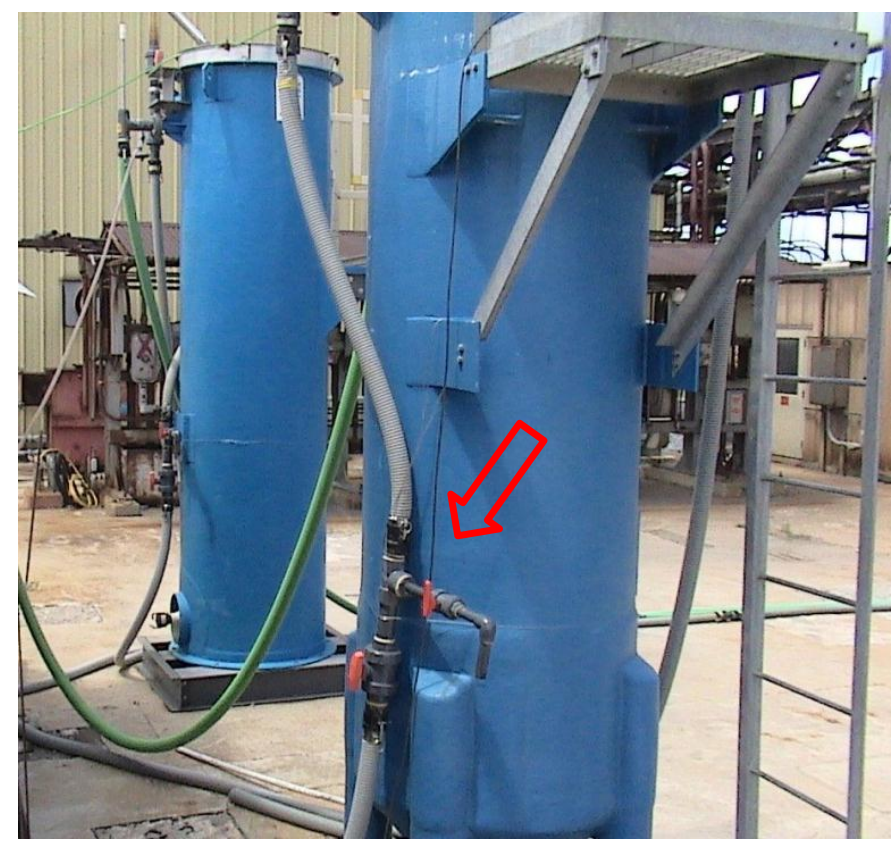

Figure 3.4 Improved Reject Sampling Location

(Permission to use photograph granted by Blue Water Technologies Inc.)

The samples of the feed, effluents and rejects were analyzed by BP personnel for $\mathrm{pH}$, temperature and turbidity. The $\mathrm{pH}$ and temperature were measured with a hand-held probe (YSI Professional Plus pH Meter) while the turbidity was measured with a Hach $2100 \mathrm{P}$ turbidimeter. Weekly calibration of these instruments was requested by Argonne.

Performance sampling was done by field sampling personnel from a local third party certified analytical lab. Samples containing Hg were collected with the "clean hands, dirty hands" protocol described in EPA Method 1669 (3). This local third party lab (Lab A) also did the majority of the performance sample analyses. A limited number of split performance samples were also analyzed by a second certified third party lab (Lab B) for comparison.

The initial performance sampling schedule is shown in Table 3.9. The initial emphasis of the analytical sampling was to determine Total Hg and TSS removal (feed vs. final effluent) as well as to characterize the feed and determine As, Se and V removal from the process. The filter reject streams were sampled as a composite sample, with each filter's reject stream supplying about half of the sample. 
Table 3.9 Initial Analytical Sampling Schedule

\begin{tabular}{|c|c|c|c|c|c|c|}
\hline & Method & $\begin{array}{c}\text { Feed } \\
\text { V-135 }\end{array}$ & $\begin{array}{c}\text { First } \\
\text { Pass } \\
\text { Effluent } \\
\text { V-134 } \\
\end{array}$ & $\begin{array}{c}\text { Second } \\
\text { Pass } \\
\text { Effluent } \\
\text { V-133 } \\
\end{array}$ & $\begin{array}{c}\text { Pilot } \\
\text { Reject } 1 \\
\text { and } 2 \\
\text { (combined } \\
\text { sample) } \\
\end{array}$ & $\begin{array}{c}\text { Sampling and } \\
\text { Analysis }\end{array}$ \\
\hline Total Hg & $1631 \mathrm{E}$ & MWF & - & MWF & MWF & $3^{\text {rd }}$ party lab \\
\hline Dissolved Hg & $1631 \mathrm{E}$ & MWF & - & - & - & $3^{\text {rd }}$ party lab \\
\hline $\begin{array}{l}\text { Cations (V, } \\
\mathrm{As}, \mathrm{Se}, \mathrm{Fe})\end{array}$ & 200.7 & MWF & - & MWF & MWF & $3^{\text {rd }}$ party lab \\
\hline TSS & SM 2540 D & MWF & - & MWF & MWF & $3^{\text {rd }}$ party lab \\
\hline $\begin{array}{l}\text { Anions (Cl, } \\
\text { Br, F, SO4, } \\
\text { NO3, NO2, } \\
\text { P04) }\end{array}$ & 300 & W & - & - & - & $3^{\text {rd }}$ party lab \\
\hline $\begin{array}{l}\text { Cations (Ca, } \\
\mathrm{Mn}, \mathrm{Na}, \mathrm{K}, \\
\mathrm{Cu}, \mathrm{Pb}, \mathrm{Si}, \\
\mathrm{Zn} \text { ) }\end{array}$ & 200.7 & W & - & - & - & $3^{\text {rd }}$ party lab \\
\hline $\begin{array}{l}\text { Total } \\
\text { Alkalinity }\end{array}$ & SM 2320B & W & & - & - & $3^{\text {rd }}$ party lab \\
\hline
\end{tabular}

After about seven weeks, the feed characterization, with the exception of Total and Dissolved Hg and TSS, was ended since the other characterization analytes were either not detected or were fairly consistent in concentration. Additionally, the As, Se and V analyses were ended at the same time since the pilot feed samples showed that these analytes were either not detected or were very low in concentration. Shortly after these changes, additional sampling points were added, including Filter 1 effluent and individual reject sampling from each filter. Sampling frequency was increased from three times a week to daily (Monday - Friday). The revised sampling schedule is shown below in Table 3.10. 
Table 3.10 Revised Analytical Sampling Schedule

\begin{tabular}{|c|c|c|c|c|c|c|c|}
\hline & Method & $\begin{array}{c}\text { Feed } \\
\text { V-135 }\end{array}$ & $\begin{array}{c}\text { First } \\
\text { Pass } \\
\text { Effluent } \\
\text { V-134 } \\
\end{array}$ & $\begin{array}{c}\text { Second } \\
\text { Pass } \\
\text { Effluent } \\
\text { V-133 } \\
\end{array}$ & $\begin{array}{c}\text { Reject } \\
\text { Filter } \\
1 \\
\end{array}$ & $\begin{array}{c}\text { Reject } \\
\text { Filter } \\
2 \\
\end{array}$ & $\begin{array}{c}\text { Sampling } \\
\text { and } \\
\text { Analysis }\end{array}$ \\
\hline Total Hg & $1631 \mathrm{E}$ & $M-F$ & $\mathrm{M}-\mathrm{F}$ & $\mathrm{M}-\mathrm{F}$ & $\mathrm{M}-\mathrm{F}$ & $\mathrm{M}-\mathrm{F}$ & $\begin{array}{c}3^{\text {rd }} \text { party } \\
\text { lab }\end{array}$ \\
\hline $\begin{array}{l}\text { Dissolved } \\
\mathrm{Hg}\end{array}$ & $1631 \mathrm{E}$ & $\mathrm{M}-\mathrm{F}$ & - & - & - & - & $\begin{array}{c}3^{\text {rd }} \text { party } \\
\text { lab }\end{array}$ \\
\hline TSS & $\begin{array}{c}\text { SM } \\
2540 \mathrm{D}\end{array}$ & $M-F$ & $M-F$ & $M-F$ & $M-F$ & $M-F$ & $\begin{array}{c}3^{\text {rd }} \text { party } \\
\text { lab }\end{array}$ \\
\hline
\end{tabular}

In addition to the above mentioned characterization and performance samples, the local third party analytical lab also did split sampling of the feed, Filter 2 effluent and the combined reject on four occasions in conjunction with the split sampling that was done for the GE pilot. One set of samples was analyzed by the local third party analytical lab while the other set was analyzed by a second third party analytical lab.

The local third party analytical lab also sampled the sand from the top of each filter on four different days. A sampling dipper attached to a long pole was used to collect the samples from the top of the bed at the same location for each sampling event. At the end of the pilot, during sand removal from the filters, sand samples were taken by BP personnel from sand at the top, middle and bottom of each filter. All sand samples were analyzed by method SW-846 7471a.

Samples of the pilot's feed, effluent and reject streams (combined sample) were also periodically taken by the third party analytical lab for particle size distribution analysis by Argonne. The analyses were done on a CILAS 1190 particle size analyzer.

\subsubsection{Pilot Commissioning Methodology}

\subsubsection{Blanks - Equipment, Method, Reagent and Background}

The equipment blank was done during the pilot commissioning before either wastewater or sand were introduced to the filters. It was done to determine if the equipment contributed any mercury to water flowing through it. The equipment blank was done by filling both filters as close to the top as possible with potable water and then sampling the effluent from each filter. 
The method blank was done after the equipment blank but before any sand was placed in the filters. It was done to determine the amount of mercury lost from the wastewater as it pumped through the pilot system without any sand filtration or chemical addition so that the amount of mercury removal actually due to the process could be determined. The potable water used for the equipment blank was drained from the system, and the system was filled with ETL feed. A continuous flow of ETL feed was then pumped through the pilot system while air was fed to each filter's central airlift at $30 \mathrm{scfh}$ to simulate normal operation (without sand). Both the feed and effluent were sampled ( $n=5)$. The ETL feed used for the method blank was highly turbid (essentially black) since it was coming from an infrequently used line. Highly turbid water had been flowing from the ETL line for a day and a half before the method blank was done. Although less turbid water that would better represent the normal feed to the pilot unit would have been preferred, after waiting for better water quality for a day and a half, the decision was made to use the current turbid water in order to expedite the start-up of actual pilot operation.

The reagent blank was done to determine the amount of mercury added to the system by the chemical feed to the process. Although a sample of the Nalmet ${ }^{\circledR} 1689$ used during the pilot was taken from the bulk chemical tote at the pilot, third party analytical lab was unable to analyze the sample due to a precipitate forming during sample digestion. Instead, 25 ppm samples of Nalmet ${ }^{\circledR} 1689$ were prepared in a standard chemistry lab at Argonne, and sent to a second third party analytical lab (Lab B) for analysis.

A series of background blanks was taken to determine whether the potential for contamination by mercury was present in the air at the Whiting pilot area. These blanks were done on four separate days during pilot operation at both the outdoor sampling point for the Filter 2 effluent and at the pilot influent sampling point inside the equipment trailer. These blanks were done by opening blank sampling bottles filled with MilliQ water near the process sampling points just prior to the start of normal process sample collection. At the end of the normal process sample collection, the blank sampling bottles were closed.

\subsubsection{Flow Rate Calibrations}

Both the influent flow meter and the chemical feed metering pumps were calibrated as part of the pilot study. The procedures used for these calibrations and the calibration results can be found in Appendix 3A. To summarize, the influent flow meter readout showed good agreement with actual measured flow at flow rates below $20 \mathrm{gpm}$, but at higher flow rates the actual measured flow was significantly lower than the readout (13 - 16\% lower). During the high flow rate calibrations, surging was seen in the effluent and reject flows, suggesting that the liquid level in the filters wasn't constant. The chemical feed pump calibrations showed that the chemical pump feeding the first filter was $30 \%$ high while the chemical pump used to feed the second filter was $5 \%$ high. 


\subsubsection{Pilot Test Plan}

The initial plans for the pilot study were to have a commissioning phase (one week), a start-up phase (3 weeks) and a steady-state phase (6-10 weeks). During the one week commissioning phase, the blank testing would be done, the equipment would be started up, the pumps and hand-held instruments would be calibrated, the operators trained, the sand introduced to the filters and the data and sample collection would begin. The three week start-up phase would then be used for short-term (one week) tests to determine which set of process conditions would be needed to achieve the Hg treatment goal. The steady-state phase would be used for a longer term test ( $6-10$ weeks) of one of the successful process conditions determined during the start-up phase.

The additional bench-scale testing described in Section 2 was done to determine which process conditions should be tested during the start-up phase. A Project Team meeting to discuss the bench-scale results was held on May 16. Based on the discussion at this meeting, it was decided to start initially with plain sand (no chemical addition), then to test Nalmet ${ }^{\circledR} 1689$ addition, and finally, to test Nalmet ${ }^{\circledR}$ and ferric sulfate addition combined.

\subsubsection{Pilot Performance Evaluation}

\subsubsection{Pilot Blanks - Equipment, Method, Reagent, Background}

The results from the blank testing are summarized in Table 3.11. Detailed results can be found in Appendix 3B.

Table 3.11 Summary of Blanks

\begin{tabular}{|c|c|c|}
\hline & $\begin{array}{c}\text { Average Total } \\
\text { Hg (ppt) }\end{array}$ & $\begin{array}{c}\text { Standard } \\
\text { Deviation }\end{array}$ \\
\hline Equipment Blank (n=3) & & \\
\hline Potable Water Influent & 1.14 & 0.13 \\
\hline Filter 1 Effluent (Potable Water) & 0.71 & 0.05 \\
\hline Filter 2 Effluent (Potable Water) & 0.97 & 0.19 \\
\hline Method Blank (n=5) ETL Influent & 11.58 & 1.02 \\
\hline Filter 2 Effluent (n=4) & 51.38 & 2.21 \\
\hline Nalmet@ 1689 Blank (n=3) & 0.22 & 0.10 \\
\hline Background Blank (n=4) & & \\
\hline Influent Valve 135 (inside trailer) & $<0.5$ & - \\
\hline Filter 2 Effluent Valve 133 \\
(outdoors)
\end{tabular}


The equipment blank showed a small loss of $\mathrm{Hg}(14.9 \%)$ in the effluent compared to the influent potable water, suggesting that some of the $\mathrm{Hg}$ in the potable water might be adhering to the interior of the pilot system. One possibility might be the walls of the filters, which were made of fiberglass and had a rough interior which would allow for particulate Hg to adhere to the walls.

Although the method blank was done with five samples taken of both the influent and the effluent, the first sample taken of the Filter 2 effluent had $0.5 \mathrm{ppt}$ of Total Hg, suggesting that the sampling line had not been completely drained of clean water prior to sampling. This data point was excluded from the calculation of the average Total Hg for the effluent. During the method blank, a $444 \%$ increase in Total Hg was seen between the influent and the effluent. This highlights the variability of the incoming feed, since the system hydraulic residence time with no sand present is approximately 53 minutes. The standard deviations for both the influent sampling and the effluent sampling are relatively low (8.8 and 4.3\%, respectively). Most likely a slug of pre-ETL with an elevated particulate level was captured during the Filter 2 effluent sampling (or it could have been something dislodged from the line carrying the ETL to the pilot unit and not be representative of typical pre-ETL). Given this variability in feed, a conclusion as to whether $\mathrm{Hg}$ is lost during the method cannot be made. For the purpose of additional analysis, such as the mass balance calculations, the method loss will be assumed to be negligible.

The Nalmet ${ }^{\circledR} 1689$ blank, which was done at a 25 ppm concentration level, shows a slight contribution $(0.22 \mathrm{ppt})$ of $\mathrm{Hg}$ to the pilot process. This is consistent with similar reagent blanks taken of Nalmet ${ }^{\circledR} 1689$ during the Module 3 bench-scale testing (1). Both sets of background blanks (inside the trailer near the influent sampling point and outdoors near the Filter 2 effluent sampling point) showed non-detectable levels of $\mathrm{Hg}$, suggesting that there was no addition of $\mathrm{Hg}$ to the samples from the air at the Whiting pilot area.

\subsubsection{Pilot Operating Summary}

The Blue PRO® pilot at BP Whiting's wastewater treatment plant operated for a total of 97 days (May 19 - August 24). The pilot was shut down due to various reasons for a total of 9 days, and hence was operational $90.7 \%$ of the time. The reasons for the shut downs included loss of feed (1 day), excessive feed pressure (1 day), high head loss in Filter 1 and reject sampling valve modifications ( 5 days), overflow from Filter 1 (1 day) and a leak in the feed line (1 day).

Two different process conditions were tested during the pilot. The first condition used plain sand without any chemical addition. This condition was tested for a total of 69 days at primarily two different feed flow rates. The first flow rate $(22 \mathrm{gpm}$ per the flow meter) was tested for a total of 28 days. The flow rate was then increased to $30 \mathrm{gpm}$ (per the flow meter), and this condition was tested for a total of 29 days. The plain sand testing also 
included 2 days at a 20 gpm flow rate and 10 days at a $25 \mathrm{gpm}$ flow rate. The second condition used plain sand with Nalmet® 1689 addition. This condition was tested for 19 days at a 25 gpm (per the flow meter) flow rate.

Detailed process data collected during the pilot operation is in Appendix 3C. Table 3C.1 contains the flow rates associated with the process. Table 3C. 2 contains the process parameters measured on-site - temperature, $\mathrm{pH}$ and turbidity.

\subsubsection{Pilot Wastewater Feed Characterization}

The feed to the Blue PRO® pilot was characterized on a weekly basis at the beginning of the pilot. The results, summarized in Table 3.12 with details shown in Appendix 3C, Tables 3C.1 and 3C.4, show a fairly broad range of Total Hg in the feed (1.45 - 24.2 ppt). The pilot feed's Total Hg analytical results are also presented graphically in Figure 3.5. Dissolved Hg usually could not be detected ( 36 out of 45 samples). Two of the times when it was detected were split sampling events - the second sample on both of these events was $<0.5$ ppt. For the 9 times that dissolved $\mathrm{Hg}$ was seen above the detection limit, the average was $1.36 \mathrm{ppt}$. The TSS in the feed also covered a broad range $(2-25 \mathrm{ppm})$. The vendor recommended TSS limit of $15 \mathrm{ppm}$ was exceeded on only one occasion. Analysis of the other parameters was done to characterize the wastewater, and their values were fairly consistent. For this reason, the feed characterization for these non-performance parameters was ended after six weeks. Feed characterization for the performance parameters of Hg (Total and Dissolved) and TSS continued throughout the pilot. 
Table 3.12 Summary of Pilot Wastewater Feed

\begin{tabular}{|l|c|}
\hline Analyte & $\begin{array}{c}\text { Avg. Concentration (Range) } \\
\text { (ppm) or as noted }\end{array}$ \\
\hline Total Hg & $8.04(1.45-24.2) \mathrm{ppt}$ \\
\hline Dissolved Hg & $0.68(<0.5-3.61) \mathrm{ppt}(\mathrm{a})$ \\
\hline TSS & $6.3(2-25)$ \\
\hline Total Alkalinity (as $\left.\mathrm{CaCO}_{3}\right)$ & $120.7(44-160)$ \\
\hline Total Phosphorus (as P) & $0.32(<0.20-0.4)$ \\
\hline Nitrate + Nitrite (as N) & $0.23(<0.00560-0.835)$ \\
\hline $\mathrm{Ca}$ & $59.80(53-66)$ \\
\hline $\mathrm{Cu}$ & $<0.010$ \\
\hline $\mathrm{Fe}$ & $0.48(<0.050-3.8)$ \\
\hline $\mathrm{Pb}$ & $<0.0075$ \\
\hline $\mathrm{Mn}$ & $0.10(0.072-0.11)$ \\
\hline $\mathrm{K}$ & $5.36(4.3-6.4)$ \\
\hline $\mathrm{Si}$ & $4.66(4.0-5.2)$ \\
\hline $\mathrm{Na}$ & $418.0(330-530)$ \\
\hline $\mathrm{Zn}$ & $0.02(<0.020-0.034)$ \\
\hline $\mathrm{Cl}$ & $224.2(184-288)$ \\
\hline $\mathrm{F}$ & $0.39(0.34-0.452)$ \\
\hline $\mathrm{Bromide}$ & $<4.99$ \\
\hline Sulfate & $655.2(480-818)$ \\
\hline
\end{tabular}

(a) Average calculated assuming $<0.5 \mathrm{ppt}=0.5 \mathrm{ppt}$.

\subsubsection{Pilot Hg Removal Performance}

The Hg removal results for the pilot are summarized in Figure 3.5. Detailed Hg results are in Appendix 3C, Table 3C.3. 


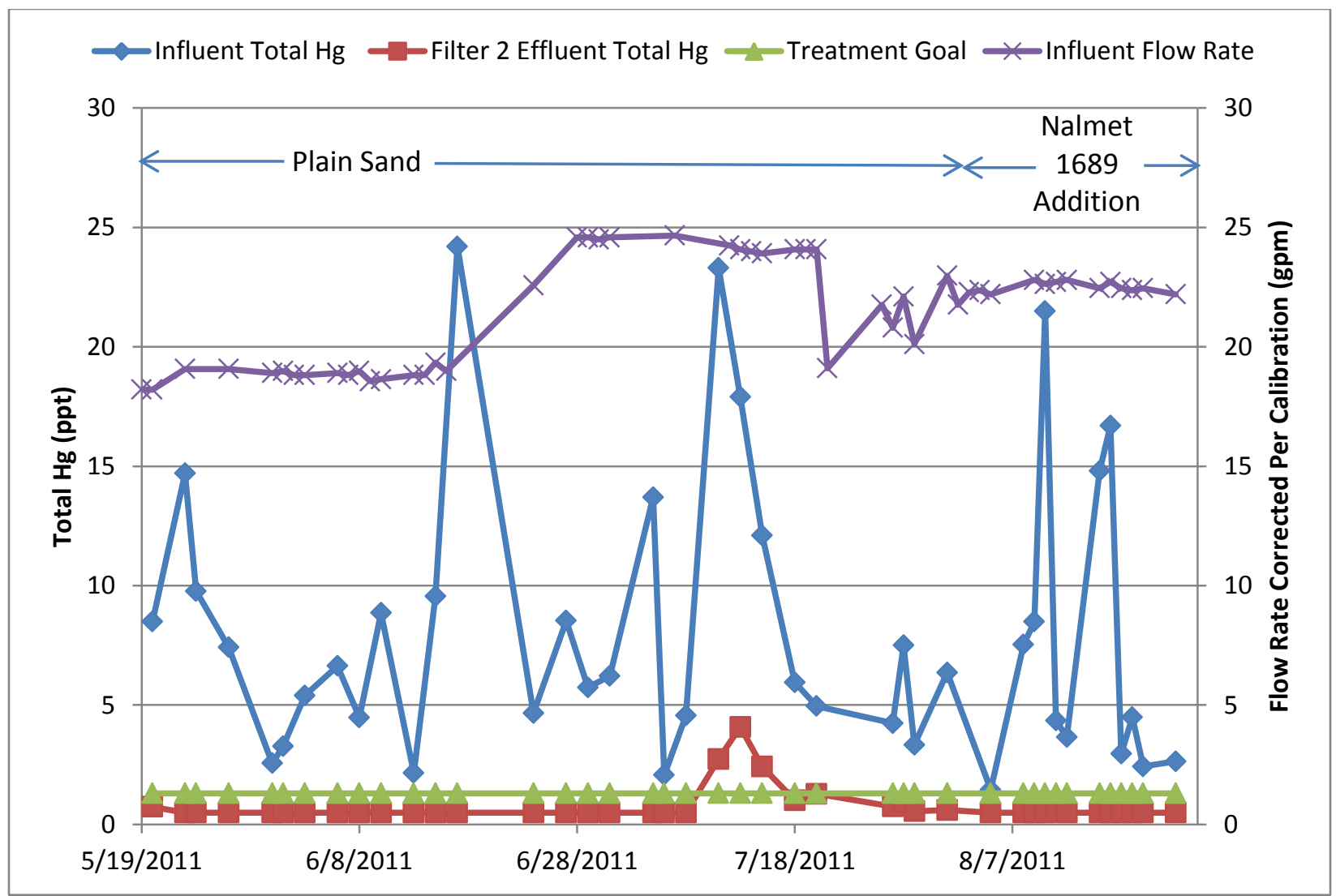

Figure 3.5 Summary of Hg Removal during Blue PRO® Pilot

The pilot was started up with plain sand and an initial flow rate of 22 gpm (19 gpm or 2.7 $\mathrm{gpm} / \mathrm{ft}^{2}$ corrected for calibration). During this four week time period, the effluent from the second filter was consistently below the $1.3 \mathrm{ppt} \mathrm{Hg}$ treatment goal. With the exception of one data point at the beginning ( $0.737 \mathrm{ppt})$, the effluent was consistently $<0.5 \mathrm{ppt} \mathrm{Hg}$.

After running successfully at this condition, it was decided to challenge the system with a higher flow rate of $29 \mathrm{gpm}$ ( $25 \mathrm{gpm}$ or $3.5 \mathrm{gpm} / \mathrm{ft}^{2}$ corrected for calibration). The second filter continued to produce effluent that was $<0.5 \mathrm{ppt} \mathrm{Hg}$ for 18 days. On the $19^{\text {th }}$ day of this higher flow rate, $\mathrm{Hg}$ breakthrough was seen, as shown in Table 3.13. 
Table 3.13 Details of Mercury Breakthrough with Plain Sand

\begin{tabular}{|l|c|c|}
\hline Date & $\begin{array}{c}\text { Days of Operation } \\
\text { at 29 gpm }\end{array}$ & $\begin{array}{c}\text { Filter 2 } \\
\text { Effluent } \\
\text { Total Hg } \\
\text { (ppt) }\end{array}$ \\
\hline $7 / 11 / 2011$ & 19 & $3.13,2.34$ \\
\hline $7 / 13 / 2011$ & 21 & 4.08 \\
\hline $7 / 15 / 2011$ & 23 & 2.42 \\
\hline $7 / 18 / 2011$ & 26 & $0.957,1.07$ \\
\hline $7 / 20 / 2011$ & 28 & 1.28 \\
\hline $7 / 27 / 2011$ & 35 & 0.753 \\
\hline $7 / 28 / 2011$ & 36 & 0.956 \\
\hline $7 / 29 / 2011$ & 37 & 0.556 \\
\hline $8 / 1 / 2011$ & 40 & $0.643,0.567$ \\
\hline $8 / 5 / 2011$ & 44 & $<0.5$ (a) \\
\hline
\end{tabular}

(a) Nalmet ${ }^{\circledR}$ feed had started on $8 / 2 / 11$ but was intermittent until 8/5/11.

The initial day of $\mathrm{Hg}$ breakthrough corresponded to an influent peak of $23.3 \mathrm{ppt} \mathrm{Hg}$, which could possibly explain the breakthrough. However, the pilot system had successfully treated a previous peak of $24.2 \mathrm{ppt} \mathrm{Hg}$ on $6 / 17 / 11$, producing $<0.5$ ppt Hg effluent. One notable difference between the two days of influent Hg peaks is the influent flow rate - the system successfully treated the 6/17/11 Hg influent peak at a lower flow rate of $19 \mathrm{gpm}$ whereas during the second influent $\mathrm{Hg}$ peak the system was operating at a higher flow rate of $25 \mathrm{gpm}$. Another explanation for the breakthrough could be that the sand filters had reached their capacity for holding Hg-laden particulates.

After $\mathrm{Hg}$ breakthrough had started on $7 / 11 / 11$, the system continued to run at $29 \mathrm{gpm}$ (25 gpm or $3.5 \mathrm{gpm} / \mathrm{ft}^{2}$ corrected for calibration) for 9 more days. The Hg breakthrough was not known or confirmed immediately since the $\mathrm{Hg}$ analyses were being run on a 7 day turnaround time. As a result of a test on $7 / 21 / 11$ to determine the maximum possible flow rate to the pilot system, high headloss and overflow from Filter 1 was seen when the flow rate was increased to $35 \mathrm{gpm}$ ( $29 \mathrm{gpm}$ or $4.1 \mathrm{gpm} / \mathrm{ft}^{2}$ calibration corrected). The flow rate to the system was then reduced to $22 \mathrm{gpm}$ to allow the system to recover. On 7/29/11 the flow rate was set to $25 \mathrm{gpm}$ ( $22 \mathrm{gpm}$ or $3.1 \mathrm{gpm} / \mathrm{ft}^{2}$ when corrected for calibration), and kept there for the rest of the pilot.

When the Hg breakthrough was seen, it was thought that chemical addition was needed to rectify the effluent quality. Using the bench-scale testing results for guidance, the project team decided to start adding Nalmet ${ }^{\circledR} 1689$ to the influent of both filters. Based on vendor 
recommendation (7), and recognizing that there wasn't time to optimize the dosage, a relatively high dose of $25 \mathrm{ppm}$ Nalmet ${ }^{\circledR}$ was fed individually to each filter for the rest of the pilot (19 days). It should be noted that this dose was significantly higher than the 0.5 ppm dose that was tested at the bench-scale. Based on calibrations done near the end of the pilot, the actual Nalmet® dose to the first filter was $36 \mathrm{ppm}$ while the actual dose to the second filter was $28 \mathrm{ppm}$.

As shown in Table 3.13, the Hg concentration in Filter 2's effluent had already started to trend lower while preparations to start Nalmet® addition were made. Although the conclusion could be made that the pilot system was recovering on its own, the effluent did not return to its original level of $<0.5 \mathrm{ppt} \mathrm{Hg}$ until after the Nalmet ${ }^{\circledR}$ addition had started. The circumstances of the Nalmet ${ }^{\circledR}$ start-up were such that initially a large amount of Nalmet ${ }^{\circledR}$ was fed to the system without any wastewater feed. The Nalmet ${ }^{\circledR}$ was started on $8 / 2 / 11$, but wastewater feed to the pilot was stopped that night due to a leak in the feed line. The Nalmet ${ }^{\circledR}$ was not turned off, and continued to be fed to the filters for several hours. When this was discovered the next day while restarting the unit, the Nalmet@ was turned off, the feed lines were flushed out and the system was run without chemical addition for a day to try to flush out the excess Nalmet ${ }^{\circledR}$. Despite best efforts to remove the excess Nalmet ${ }^{\circledR}$, most likely a slug of Nalmet ${ }^{\circledR}$ did get to the filters. Effluent sampled the day after the flushing was the first effluent that was $<0.5 \mathrm{ppt} \mathrm{Hg}$ since $\mathrm{Hg}$ breakthrough started. This suggests that the initial large dose of Nalmet ${ }^{\circledR}$ helped the effluent to recover to original $\mathrm{Hg}$ levels of $<0.5 \mathrm{ppt}$.

During the 19 days of Nalmet@ addition, the Filter 2 effluent was consistently $<0.5$ ppt with the exception of one day $(8 / 11 / 11)$ when the effluent was 0.510 ppt. Longer term testing with Nalmet ${ }^{\circledR}$ addition is needed to verify that this level of effluent quality can be maintained over a longer time frame.

A comparison of $\mathrm{Hg}$ concentration for the influent and reject streams is shown in Figure 3.6. During plain sand operation, the ratio of combined reject to influent Hg averaged 3.2: 1 when the $7 / 6 / 11$ outlier (86 ppt in the reject) data point was excluded. During Nalmet ${ }^{\circledR}$ addition, the ratio of combined reject to influent $\mathrm{Hg}$ was lower at $1.1: 1$. To calculate this ratio during Nalmet ${ }^{\circledR}$ addition, when the rejects were sampled separately, a combined reject concentration was estimated by using equal amounts of each reject's concentration, similar to how the actual combined reject sampling was done during the first phase of the testing. The fact that the reject $\mathrm{Hg}$ concentrations were frequently lower than the feed $\mathrm{Hg}$ concentration during Nalmet ${ }^{\circledR}$ addition suggests that the washboxes were not operating correctly and that $\mathrm{Hg}$ was accumulating in the sand. It is interesting to note that TSS was being effectively rejected, particularly after Nalmet ${ }^{\circledR}$ addition was started, as shown in Figure 3.10. One possible explanation for this is that a portion of the $\mathrm{Hg}$ was adsorbing to the sand in the presence of the Nalmet ${ }^{\circledR}$. Another more likely explanation is that the 
performance based Hg analytical method (EPA 1631e), which was developed for relatively clean wastewaters, requires additional adjustment in the sample preparation digestion for complete Hg detection in the presence of the reject stream's increased solids. Further evaluation needs to be done.

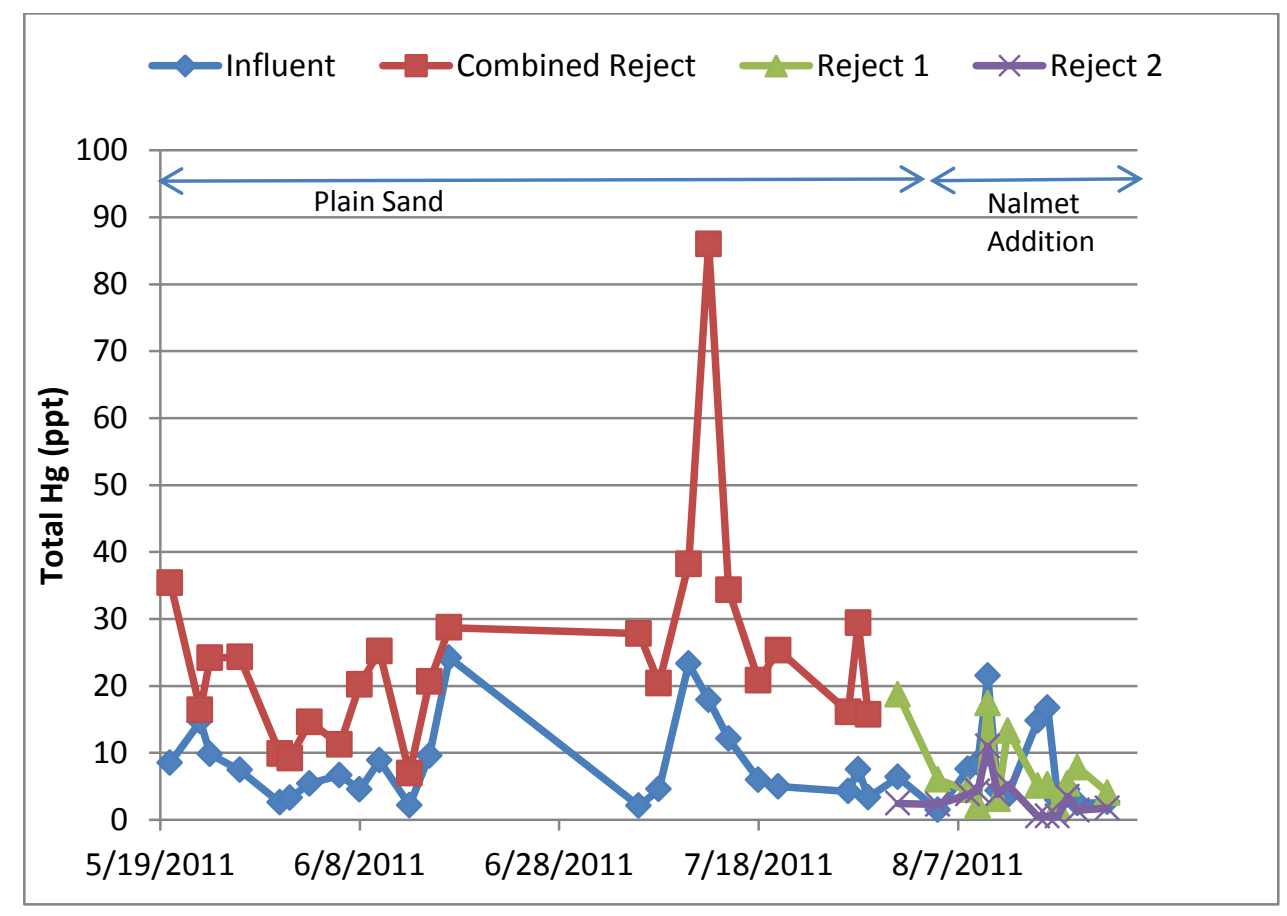

Figure 3.6 Hg in Reject (a)

(a) Excludes time period from 6/23 - 7/6/11 when Filter 2 reject sampling line was actually sampling effluent.

The pilot's successful Hg removal performance leads to the question of whether one or two filters are needed to achieve the treatment goal. For the initial period of the pilot test, Filter 1 effluent was sampled very infrequently, only four times. Each time, the effluent was $<0.5 \mathrm{ppt} \mathrm{Hg.} \mathrm{More} \mathrm{frequent} \mathrm{sampling} \mathrm{began} \mathrm{on} 7 / 27 / 11$ and continued through the end of the pilot. During these 27 days, 16 samples of Filter 1 effluent were taken, which showed that the $1.3 \mathrm{ppt} \mathrm{Hg}$ treatment goal was exceeded three times $(19 \%$ of samples taken) during this time period as shown in Figure 3.7. One of the samples above the treatment goal (8/10) occurred during a Hg spike in the feed, as shown in Figure 3.8. Other samples above the treatment goal did not correspond to increased $\mathrm{Hg}$ in the feed. The treatment goal, however, is a monthly average. For this time period, assuming that $<0.5$ ppt results were $0.5 \mathrm{ppt}$ for the sake of calculating an average, the average effluent from Filter 1 was $0.86 \mathrm{ppt} \mathrm{Hg.} \mathrm{For} \mathrm{the} \mathrm{same} \mathrm{time} \mathrm{period,} \mathrm{the} \mathrm{average} \mathrm{effluent} \mathrm{from} \mathrm{Filter} 2$ was $0.56 \mathrm{ppt} \mathrm{Hg}$. Although the data suggests that a single filter may be sufficient to meet the 
treatment goal, a more conservative approach would be to use two filters. This would provide additional removal capacity and better ensure compliance, particularly since pilot performance may not directly scale up to full-scale performance.

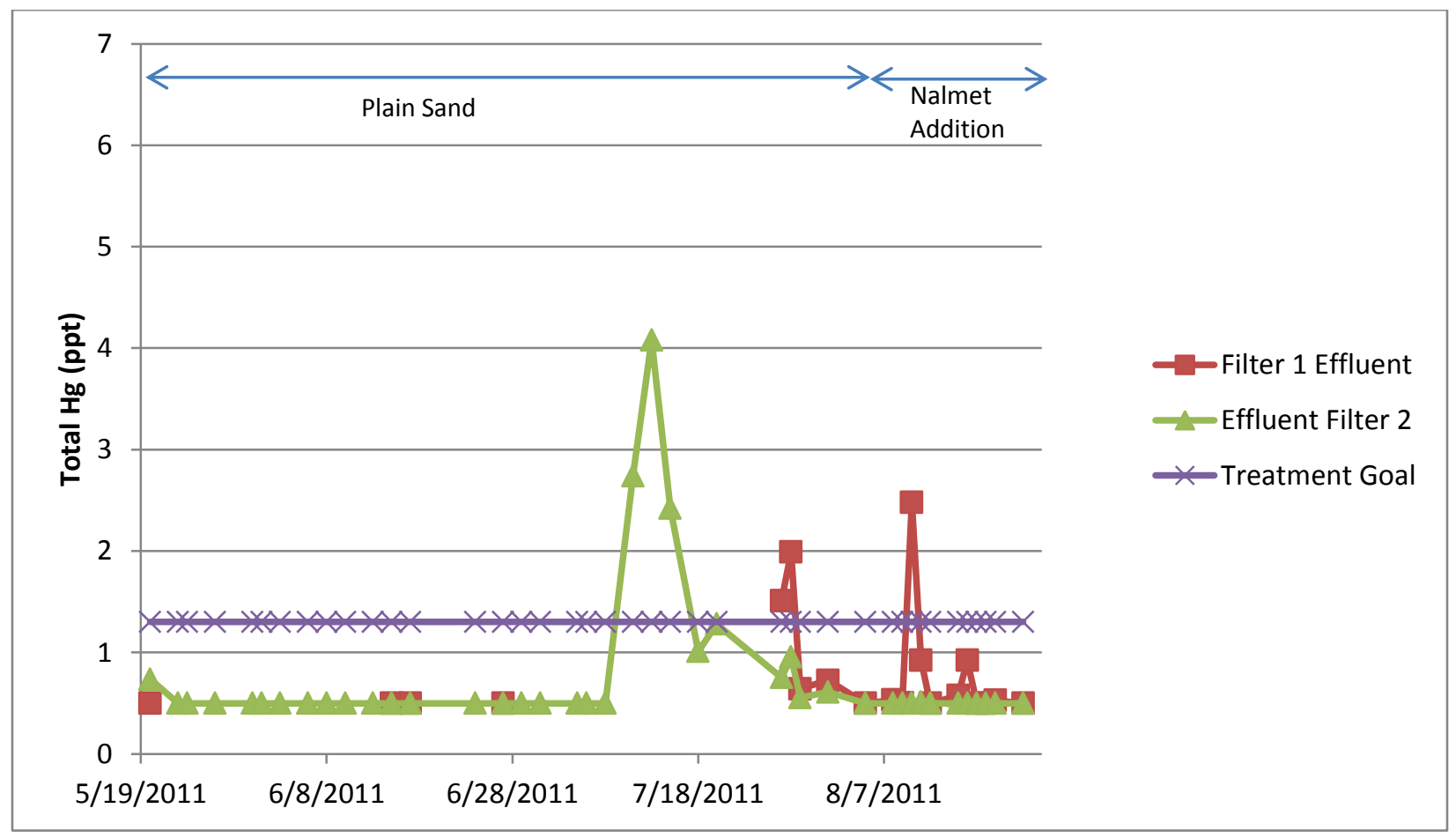

Figure 3.7 Comparison of Filter 1 and Filter 2 Effluents 


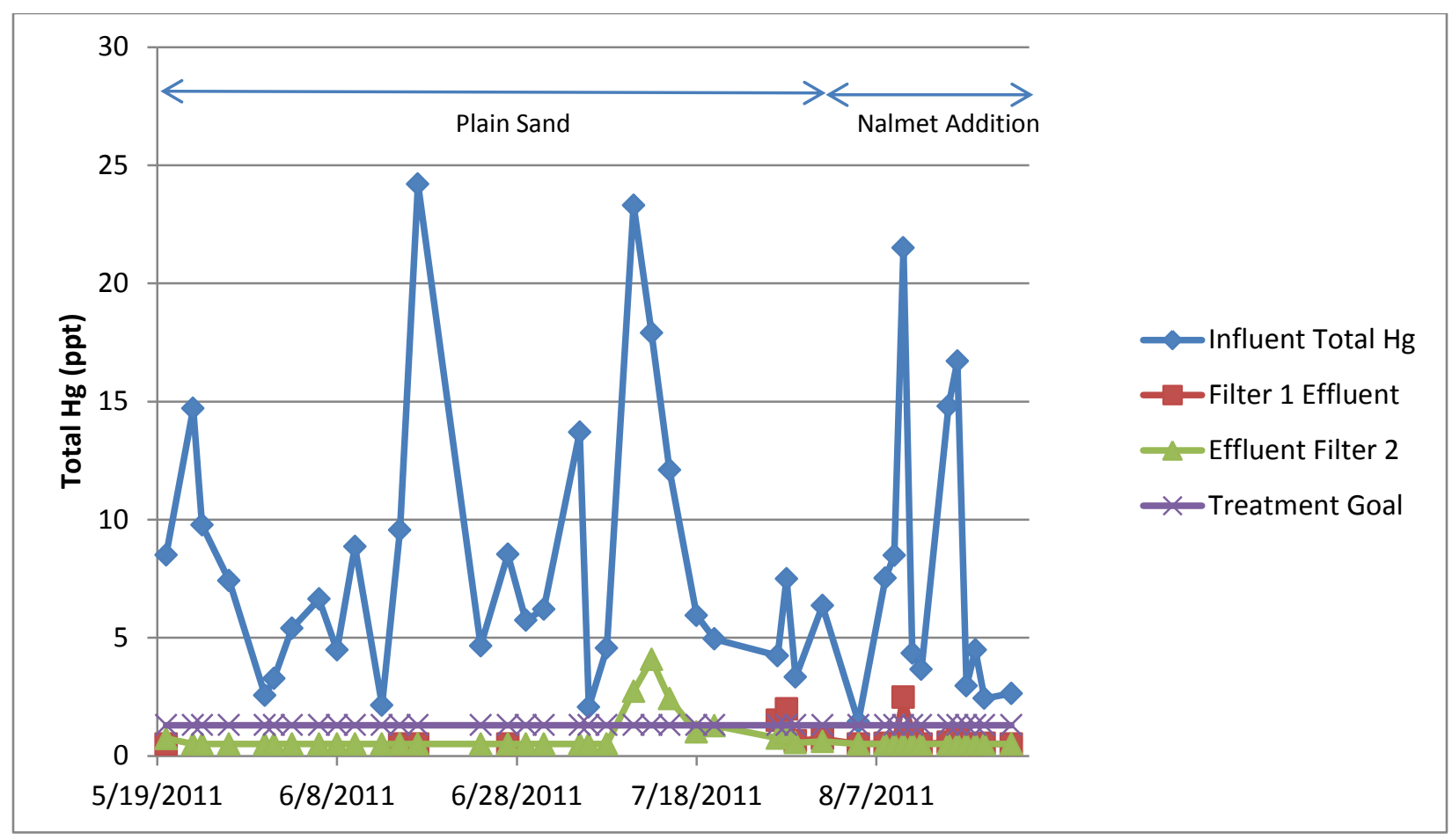

Figure 3.8 Filter 1 and 2 Effluents Compared to Feed

\subsubsection{Pilot Removal Performance of As, Se and V}

In addition to $\mathrm{Hg}$, the pilot removal performance for heavy metals such as As, Se and V was also assessed, as shown in Table 3.14. This table reflects sampling from the first seven weeks of the pilot during which plain sand was used without chemical addition. The plain sand filters removed essentially none of the As, Se and V, as expected, since these contaminants are in the dissolved form. Per Module 3 testing, most likely if ferric sulfate addition had been used, there would have been some removal of these contaminants (1).

Table 3.14 Removal of As, Se and V

\begin{tabular}{|l|c|c|c|}
\hline & $\begin{array}{c}\text { Total As } \\
\text { Avg. (range) } \\
\text { (ppm) }\end{array}$ & $\begin{array}{c}\text { Total Se } \\
\text { Avg. (range) } \\
\text { (ppm) }\end{array}$ & $\begin{array}{c}\text { Total V } \\
\text { Avg. (range) } \\
\text { (ppm) }\end{array}$ \\
\hline Influent & $\begin{array}{c}0.0106 \\
(<0.01-0.016)\end{array}$ & $\begin{array}{c}0.0305 \\
(<0.03-0.037)\end{array}$ & $\begin{array}{c}0.195 \\
(0.008-2.5)\end{array}$ \\
\hline Filter 2 Effluent & 0.0104 & 0.0306 & 0.195 \\
$(<0.01-0.015)$ & $(<0.03-0.037)$ & $(<0.008-2.4)$ \\
\hline $\begin{array}{l}\text { Combined Reject 1 } \\
\text { and 2 }\end{array}$ & 0.0108 & 0.0304 & 0.0728 \\
$(<0.01-0.016)$ & $(<0.03-0.038)$ & $(0.008-0.44)$ \\
\hline
\end{tabular}




\subsubsection{Pilot Particulate Removal Performance}

The Total Suspended Solids (TSS) removal is summarized in Table 3.15 and Figure 3.9 below. The influent TSS was consistently at or below the maximum TSS of $25 \mathrm{ppm}$ specified by the vendor for peak system performance. Initially the pilot system performance did not appear to be affected by TSS influent spikes, as demonstrated by the 25 ppm spike on 5/31, which resulted in $<1.0$ ppm TSS in the Filter 2 effluent. However, as the testing continued, Filter 2 effluent TSS spikes corresponded to feed TSS spikes. The increase in Filter 2 effluent TSS spikes appeared to be slightly smaller during Nalmet ${ }^{\circledR}$ addition compared to Filter 2 effluent TSS spikes observed towards the end of the plain sand testing. The Filter 2 effluent stayed below 5 ppm TSS throughout the pilot.

Table 3.15 Summary of TSS Removal Performance (b)

\begin{tabular}{|c|c|c|}
\hline & $\begin{array}{l}\text { TSS } \\
\text { Avg. } \\
\text { (ppm) }\end{array}$ & $\begin{array}{l}\text { TSS Range } \\
\text { (ppm) }\end{array}$ \\
\hline $\begin{array}{l}\text { Influent } \\
\text { Before Nalmet@ Addition } \\
\text { During Nalmet@ Addition }\end{array}$ & $\begin{array}{l}6.20 \\
6.38\end{array}$ & $\begin{array}{l}(2-25) \\
(3.2-12)\end{array}$ \\
\hline $\begin{array}{l}\text { Filter } 1 \text { Effluent } \\
\text { Before Nalmet }{ }^{\circledR} \text { Addition (a) } \\
\text { During Nalmet@ Addition }\end{array}$ & $\begin{array}{l}1.50 \\
3.12\end{array}$ & $\begin{array}{l}(<1-2.4) \\
(<1-4.8)\end{array}$ \\
\hline $\begin{array}{l}\text { Filter } 2 \text { Effluent } \\
\text { Before Nalmet } ₫ \text { Addition } \\
\text { During Nalmet@ Addition }\end{array}$ & $\begin{array}{l}1.80 \\
1.82\end{array}$ & $\begin{array}{l}(1-4.8) \\
(1-3.2)\end{array}$ \\
\hline $\begin{array}{l}\text { Reject Combined } \\
\text { (until } 7 / 29 \text {, Before Nalmet@ } \\
\text { Addition) }\end{array}$ & 21.1 & $(10-38)$ \\
\hline $\begin{array}{l}\text { Reject } 1 \text { (starting 8/1, During } \\
\text { Nalmet } ₫ \text { Addition) }\end{array}$ & 75.2 & $(44-180)$ \\
\hline $\begin{array}{l}\text { Reject } 2 \text { (starting } 8 / 1 \text {, During } \\
\text { Nalmet }{ }^{\circledR} \text { Addition) }\end{array}$ & 27.2 & $(1.6-75)$ \\
\hline
\end{tabular}

(a) Filter 1 effluent was not consistently sampled until 7/27/11.

(b) Excludes time period from 6/23 - 7/6/11 when Filter 2 reject sampling line was actually sampling effluent. 


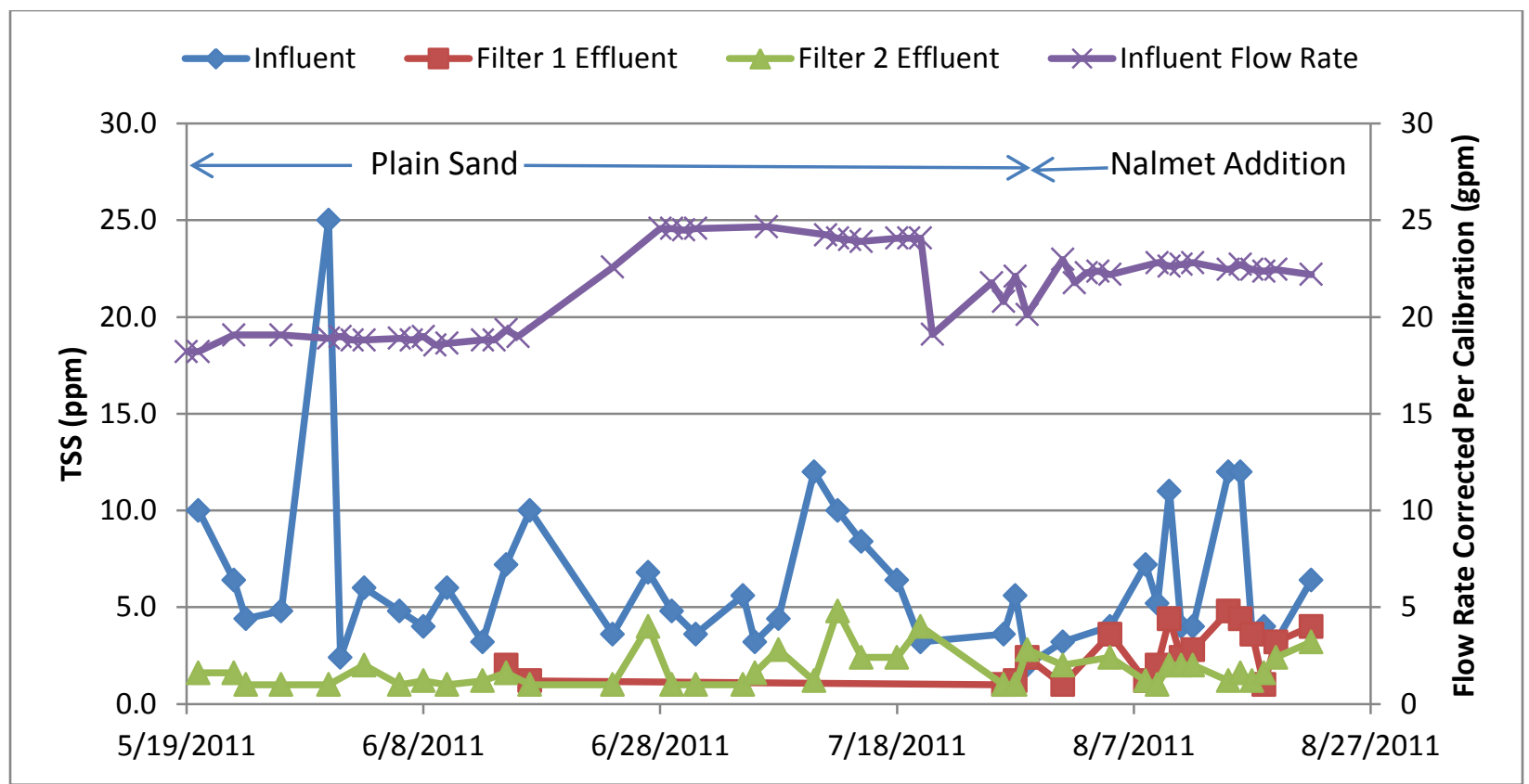

Figure 3.9 Summary of TSS Removal

Throughout the pilot the reject TSS levels were greater than those of the feed, as shown in Figure 3.10. The ratio of combined reject to influent TSS averaged 4.0 during plain sand operation, and 8.5 during Nalmet $\AA$ addition. A combined reject TSS during Nalmet $\AA$ addition was estimated by using equal amounts of each reject's TSS concentration, similar to how the actual combined reject sampling was done during the first phase of the testing.

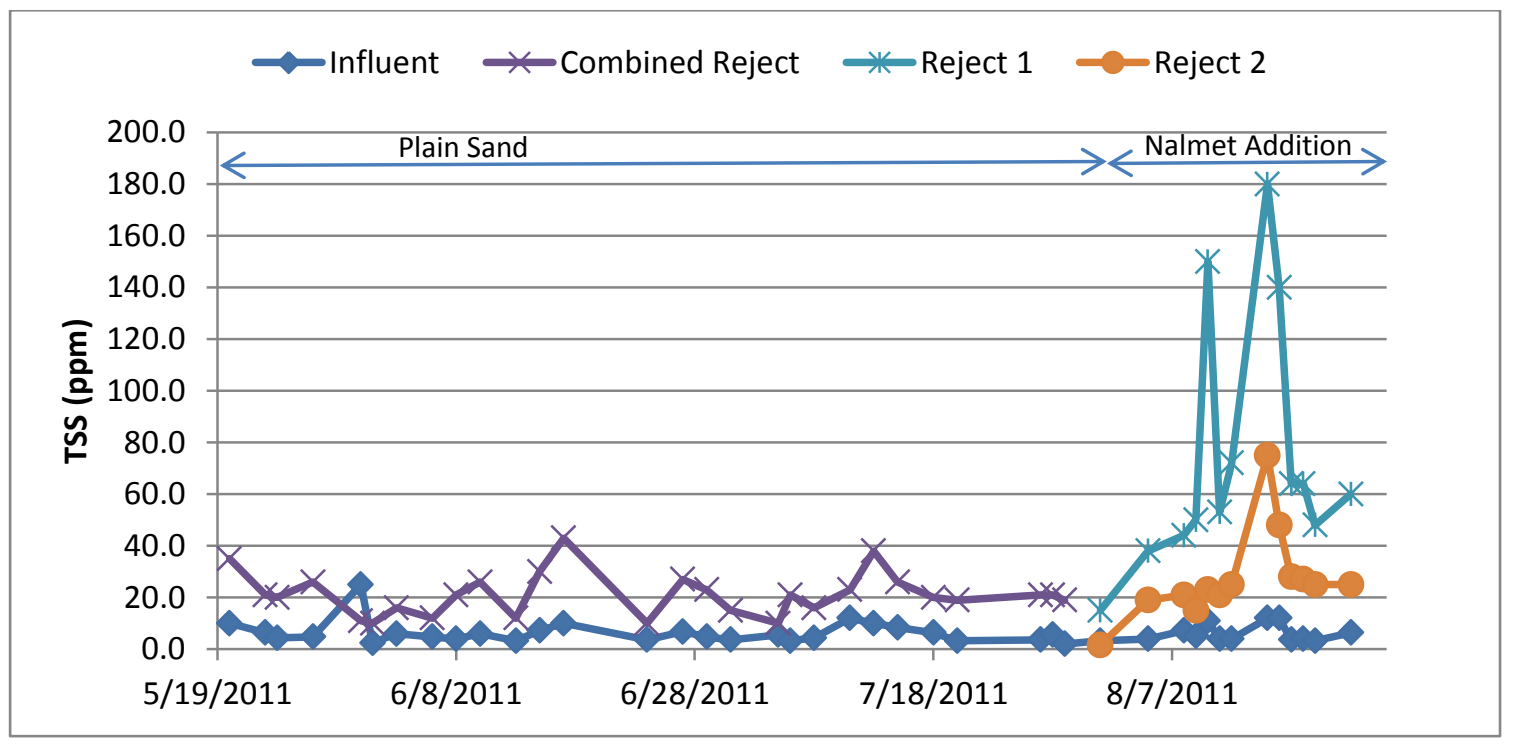

Figure 3.10 TSS in Reject 
In addition to TSS analyses, particle size distribution (PSD) analyses were done on samples taken on four separate days during the Nalmet ${ }^{\circledR}$ addition phase of the pilot. Samples were taken of the feed, the Filter 2 effluent and the combined reject. On all four of these days, the Filter 2 effluent was $<0.5 \mathrm{ppt} \mathrm{Hg}$. Although both number based and volume based analyses were performed, only number based analyses are presented and discussed here.

As shown in Figure 3.11, the feed to the pilot, which has already passed through upstream sand filters, essentially contains particles that are $<4 \mu \mathrm{m}$ in size. The diameter of $90 \%$ of the particles contained in the ETL was $<1.4 \mu \mathrm{m}$. Less than $50 \%$ of the particles in all of the tested feed samples were below $0.54 \mu \mathrm{m}$. The diameter of $90 \%$ of the particles in reject samples was below $1.6 \mu \mathrm{m}$ while less than $50 \%$ of the particles in all of the tested reject samples were below $0.9 \mu \mathrm{m}$. During this limited sampling, essentially two types of feed were seen. One type of feed, seen on 8/10/11 and 8/15/11, contained fairly evenly distributed particles between the sizes of 0.3 and $4 \mu \mathrm{m}$. For this type of feed, the reject PSD was similar to that of the feed PSD. The reject contains a larger amount of small particles (about $0.2 \mu \mathrm{m}$ ) than the feed, suggesting that the system is grinding the feed particulates to a smaller size. The effluent appears to contain slightly larger coagulated particles than what was seen in the feed, as indicated by the two effluent peaks on 8/10/11 that are for slightly larger particles than the feed peaks preceding them. The other type of feed, seen on $8 / 12 / 11$ and $8 / 19 / 11$, essentially contains only a large number of small particles (approximately $0.04 \mu \mathrm{m}$ ). For this type of feed, the majority of these small particles are leaving with the effluent. Although it appears that a few are coagulated to a larger size and leave with the reject, this data suggests that the Nalmet® coagulates/flocculates larger sized particles $(0.3$ to $4 \mu \mathrm{m})$ better than the smaller particles $(0.04 \mu \mathrm{m})$. 

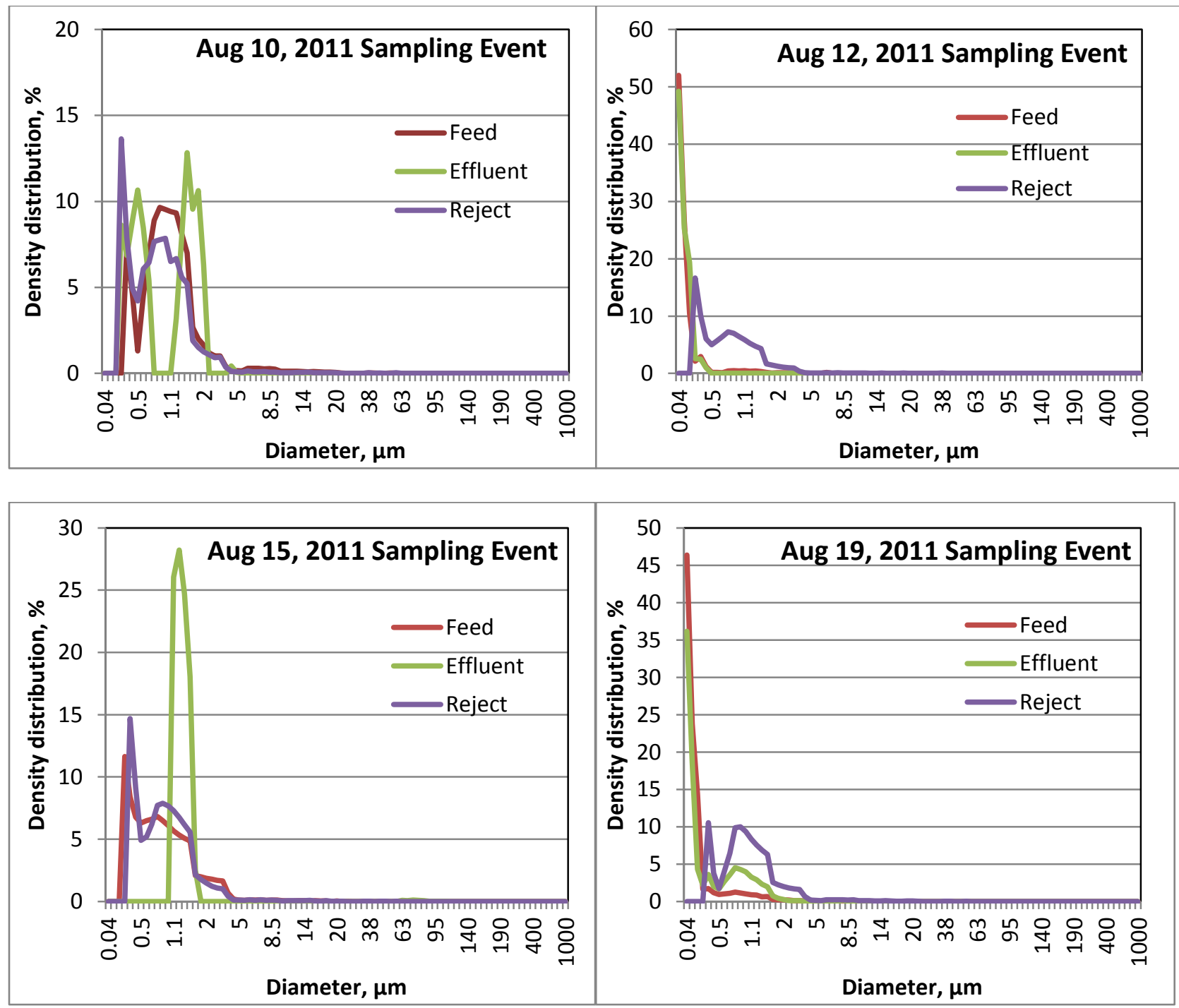

Figure 3.11 Particle Size Distribution Results - Number Based

\subsubsection{Pilot Residuals - Sand}

\section{Sand Loss}

Sand bed height measurements were taken at the beginning, middle and end of the pilot to determine if sand loss was occurring as shown in Table 3.16. These bed measurements were done by placing a long PVC pipe along the inner wall of the filter in each quadrant, and measuring the distance between the top of the filter and the top of the sand bed. The measurements were done during operation and hence may vary due to changes in the angle of repose of the sand cone on the top of the bed. Ideally, these measurements would 
have been done with the unit offline and drained so that the sand bed could be manually leveled out before measuring, thereby eliminating the angle of repose variability. To prevent this downtime, however, the measurements were done during operation. Per the vendor, the yearly sand loss for the Blue PRO ${ }^{\circledR}$ process is $<2 \%$ (8). This would translate to a 0.60 " loss in bed height over the course of the three month pilot, which may be difficult to see due to inaccuracies in the measuring method.

Table 3.16 Sand Bed Height Measurements

\begin{tabular}{|c|c|c|c|c|c|c|c|}
\hline & $\begin{array}{l}5 / 19 / 11 \\
\text { Height } \\
\text { From Top } \\
\text { of Filter } \\
\text { to Sand } \\
\text { Bed (in.) } \\
\text { (a) }\end{array}$ & $\begin{array}{l}\text { 7/21/11 } \\
\text { Height } \\
\text { From Top } \\
\text { of Filter } \\
\text { to Sand } \\
\text { Bed (in.) } \\
\text { (a) }\end{array}$ & $\begin{array}{l}\text { 8/18/11 } \\
\text { Height } \\
\text { From Top } \\
\text { of Filter } \\
\text { to Sand } \\
\text { Bed (in.) } \\
\text { (a) }\end{array}$ & $\begin{array}{c}\text { Height } \\
\text { Decrease } \\
\text { (in.) } \\
5 / 19 \text { vs. } \\
8 / 18\end{array}$ & $\begin{array}{c}\text { Volume } \\
\text { loss } \\
\text { (\%) } \\
5 / 19 \\
\text { vs. } \\
8 / 18\end{array}$ & $\begin{array}{c}\text { Height } \\
\text { Decrease } \\
\text { (in.) } \\
7 / 21 \text { vs. } \\
8 / 18\end{array}$ & $\begin{array}{c}\text { Volume } \\
\text { loss (\%) } \\
7 / 21 \text { vs. } \\
8 / 18\end{array}$ \\
\hline Filter 1 & & & & & & & \\
\hline $\begin{array}{r}\text { Quadrant } \\
1\end{array}$ & 65 & 68 & 64.5 & 0.5 & & 3.5 & \\
\hline $\begin{array}{r}\text { Quadrant } \\
2\end{array}$ & 65 & 66.5 & 65.75 & -0.8 & & 0.8 & \\
\hline $\begin{array}{r}\text { Quadrant } \\
3\end{array}$ & 65 & 69.5 & 66.25 & -1.3 & & 3.3 & \\
\hline $\begin{array}{r}\text { Quadrant } \\
4\end{array}$ & (b) & (b) & (b) & & & & \\
\hline average & 65.00 & 68.00 & 65.50 & -0.5 & $-0.83 \%$ & 2.5 & $4.17 \%$ \\
\hline Filter 2 & & & & & & & \\
\hline $\begin{array}{r}\text { Quadrant } \\
1\end{array}$ & 61 & 60.75 & 59.75 & 1.3 & & 1.0 & \\
\hline $\begin{array}{r}\text { Quadrant } \\
2\end{array}$ & 60.5 & 60.75 & 60.125 & 0.4 & & 0.6 & \\
\hline $\begin{array}{r}\text { Quadrant } \\
3\end{array}$ & 60.5 & 62 & 60.375 & 0.1 & & 1.6 & \\
\hline $\begin{array}{r}\text { Quadrant } \\
4\end{array}$ & 60.5 & (c) & (c) & & & & \\
\hline average & 60.625 & 61.17 & 60.08 & 0.5 & $0.90 \%$ & 1.1 & $1.81 \%$ \\
\hline
\end{tabular}

(a) 5/19/11 measurements done by BWT technician. $7 / 21$ and $8 / 18 / 11$ measurements done by BP site engineer.

(b) Level sensor placement prevented measurement.

(c) BP site engineer was unable to perform measurement due to arm length. 
When the bed heights at the beginning and end of the pilot are compared (5/19 vs. 8/18), Filter 1 showed a gain of $1 / 2$ " while Filter 2 showed a loss of $0.9 "$. These measurements were made by two different people, which could possibly explain the gain in Filter 1. Comparison of the bed heights at the middle and end of the pilot (7/21 vs. 8/18), which were measured by the same person, show a loss of 2.5" from Filter 1 and 1.1" from Filter 2 in roughly a one month time period. This corresponds to a monthly volume loss of $4.2 \%$ and $1.8 \%$ respectively. This is more than the $0.2 "$ /month (or $<2 \%$ a year) predicted by the vendor, but these results should be interpreted with caution since the unit was operating (with its varying sand angle of repose) while the measurements were made. Most likely there was some small sand loss but conclusions about the amount cannot be made due to inaccuracies in the measurement method.

\section{Mercury Accumulation}

A more notable aspect about the pilot's sand residuals was the accumulation of $\mathrm{Hg}$ in the filter sand. Although the Blue PRO® process uses a washbox at the top of each filter to remove contaminants and particulates from the sand, sampling of the sand beds suggests that $\mathrm{Hg}$ accumulation is occurring. Figure 3.12 shows the $\mathrm{Hg}$ content of sand sampled from the top of each filter's sand bed. Samples were taken from the same location during each sampling event, and care was taken to sample only the very top of the sand beds. Only one sample was taken from each filter on $7 / 15$, however, subsequent samplings were done in triplicate. Figure 3.12 shows that the sand sampled from the top of the filters increased in $\mathrm{Hg}$ concentration with each sampling event. This increase indicates that $\mathrm{Hg}$ was accumulating in the filter sand. At the end of the pilot when the sand was being removed from the filters, samples of the sand from the top, middle and bottom of each filter were taken. As shown in Figure 3.13, the Hg was fairly equally distributed throughout the filters, with each filter averaging $10,500 \mathrm{ng} / \mathrm{kg} \mathrm{Hg}$ on a dry basis. The visual difference between the sand sampled on $7 / 20$ after two months of plain sand operation and that sampled at the end of the pilot on 8/24 after Nalmet ${ }^{\circledR}$ addition is shown in Figure 3.14. 


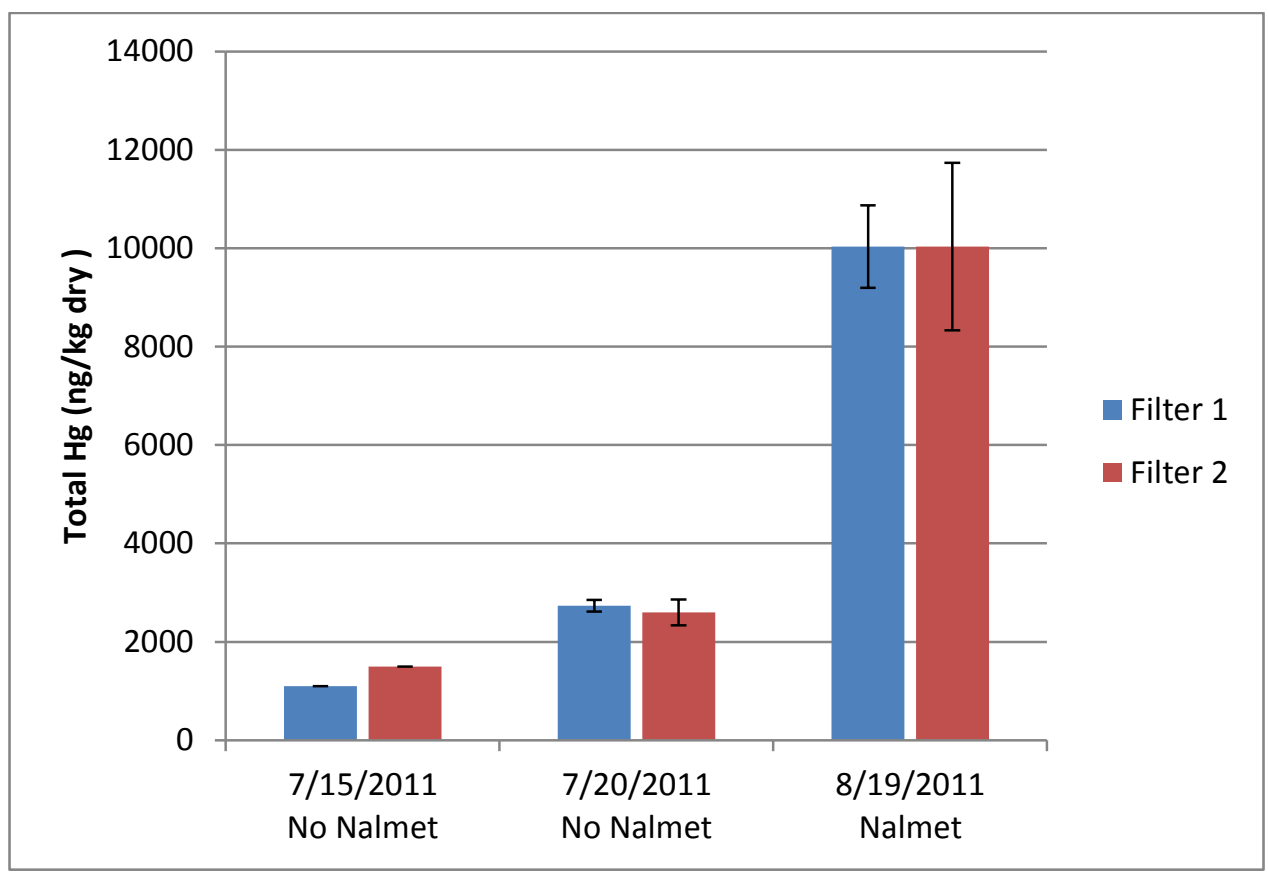

Figure 3.12 Hg Content of Sand Sampled at Top of Bed

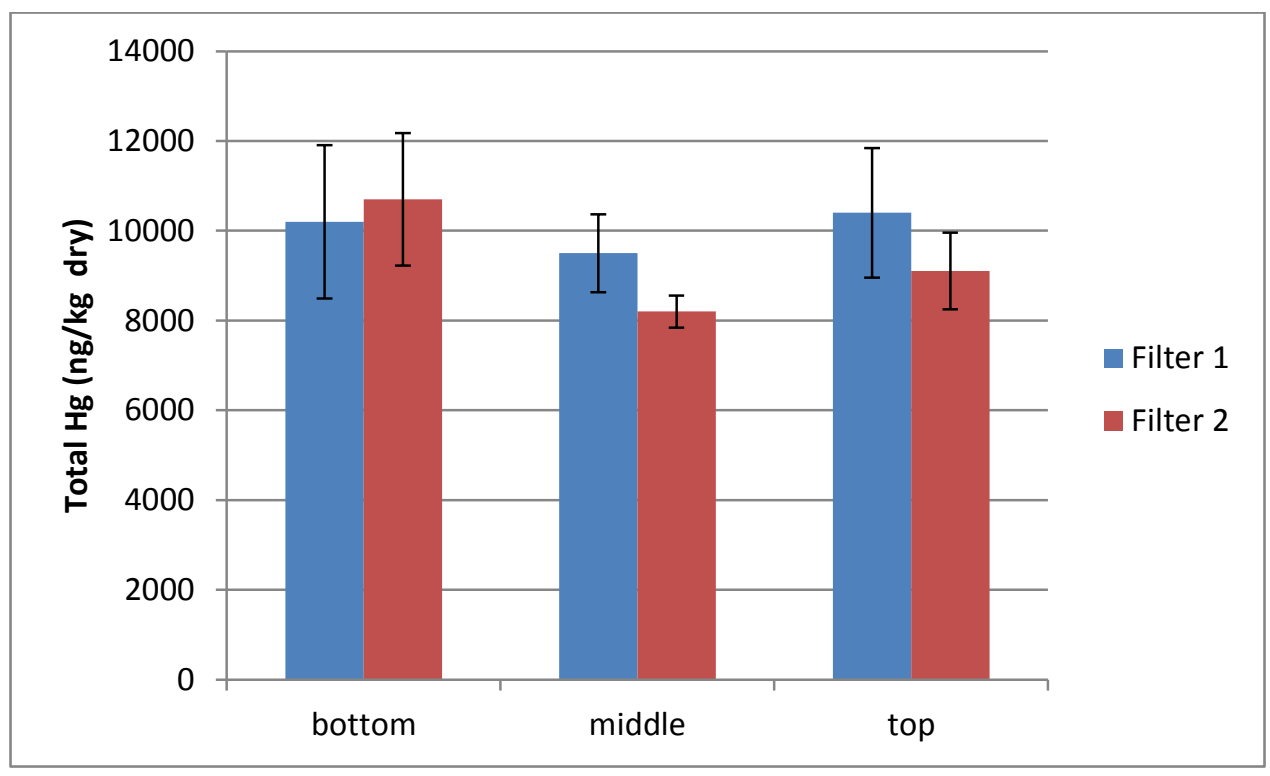

Figure 3.13 Hg Content of Sand Sampled at End of Pilot 


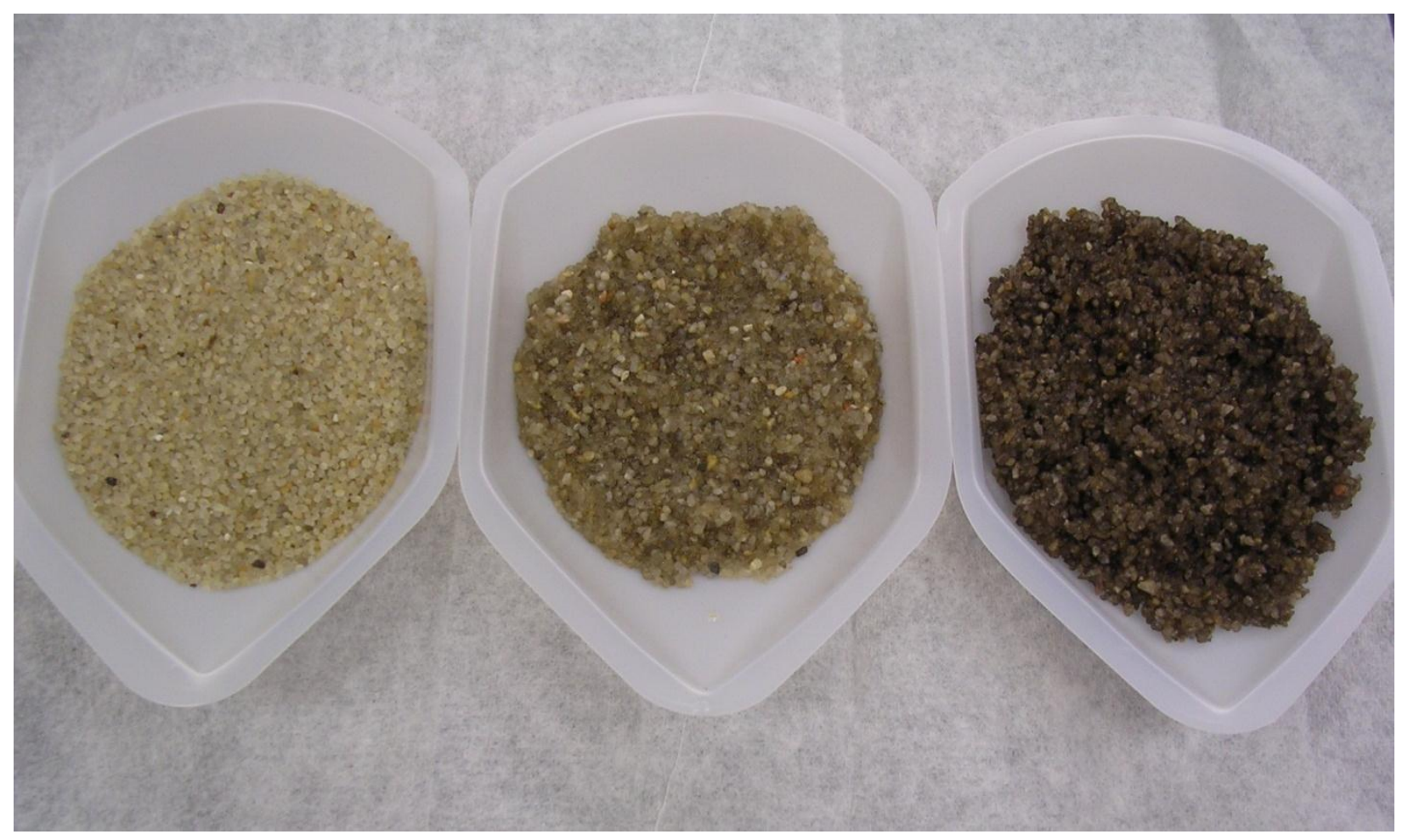

Figure 3.14 Sand Samples from left to right: unused sand, from $7 / 20 / 11$, from 8/24/11

It is important to note that the sand analyses were done with EPA Method 7471a, which either uses aqua regia (a mixture of nitric acid and $\mathrm{HCl}$ ) or an alternative sulfuric acid/nitric acid solution for the digestion followed by cold-vapor atomic absorption (9). The strength of the acid digestion appears to affect the amount of Hg removed from the solid. For example, a TCLP analysis done on the filter sand sampled at the end of the pilot showed $<0.001 \mathrm{ppm}$ of Hg. During the TCLP analysis, the sample leaching is done with acetic acid, a milder acid (10). The complete TCLP analysis for the end of pilot filter sand is shown in Appendix 3D.

In an attempt to estimate whether $\mathrm{Hg}$ was initially present in the sand at the beginning of the pilot, sand of the same size (12-20 mesh) was purchased after the pilot from Agsco Corp., the supplier of sand for the pilot. An analysis of triplicate samples showed that the purchased sand was $7833 \pm 404 \mathrm{ng} / \mathrm{kg} \mathrm{Hg}$ on a dry basis, which is roughly six times more than the first sand sample taken on $7 / 15$. One explanation for this discrepancy might be that the pilot sand also started at a similar Hg level, and during the course of the pilot the action of the moving bed ground off some of the Hg associated with the sand. Mercury can be associated with sand either through adsorption onto quartz and metal oxides as seen by Liao, L. et al. (11), or by being bound to organic matter associated with sand $(12,13)$. 
Ashing of the purchased sand by ANL showed an organic content of $0.25 \pm 0.06 \mathrm{wt}$. \% $(\mathrm{n}=10)$. Another more likely explanation is that this discrepancy demonstrates the variability of $\mathrm{Hg}$ in sand. A recent study by the Portland Cement Association analyzed the Hg content of sand samples from 33 suppliers equally distributed throughout the United States and Canada. Of the 33 samples, the mean $\mathrm{Hg}$ concentration was $13 \mu \mathrm{g} / \mathrm{kg}$. The range of the samples was 1 to $80 \mu \mathrm{g} / \mathrm{kg}$ of $\mathrm{Hg}(14)$. Another study also found ppb levels of $\mathrm{Hg}$ in sand sampled from sandboxes in public parks $(1.6-35 \mu \mathrm{g} / \mathrm{kg})(15)$. Both of these studies used EPA Method 7473 for analyses, which uses thermal desorption followed by atomic adsorption detection (16). No acid digestion is used. Hence, it is likely that the initial sand used for the pilot contained a measurable amount of $\mathrm{Hg}$, however, the exact amount cannot be estimated.

\subsubsection{Pilot Hg Mass Balance}

As part of the pilot data analysis, a Hg mass balance was done with the pilot study data. Given that the Hg analyses are an integral part of the mass balance, on four different days the pilot streams were sampled and sent to both the main third party lab used for the study (Lab A) as well as a different third party lab that was previously used in the bench-scale testing for comparison (Lab B). The samples were not true split samples but rather sequential samples, taken about a minute apart. The results are shown in Table 3.17. Analyzing each group of samples (feed, effluent and reject) with a paired t-test at a 95\% confidence interval indicated that for each group of samples the differences in the test results obtained from both labs are not statistically significant. Hence, the Lab B results confirm the Lab A results.

Although composite sampling was not done for the Blue PRO® pilot, the composite sampling done for the GE pilot's feed provides insights as to the variability of the wastewater feed. Both the GE pilot and the Blue PRO® pilot feed came from the same pipeline leading to the Effluent To Lake outfall. During the two 24 hour GE pilot feed composite samplings, the standard deviations were about $50 \%$ of the reported averages $(1.51 \pm 0.70 \mathrm{ppt}$ and $1.05 \pm 0.58 \mathrm{ppt})$, which demonstrates the variability of the wastewater composition.. The combination of the feed variability, the system's hydraulic retention time and the fact that grab samples were used for the pilot suggest that a high level of closure for the Hg mass balance may be difficult to achieve. 
Table 3.17 Comparison of Hg Analyses (a)

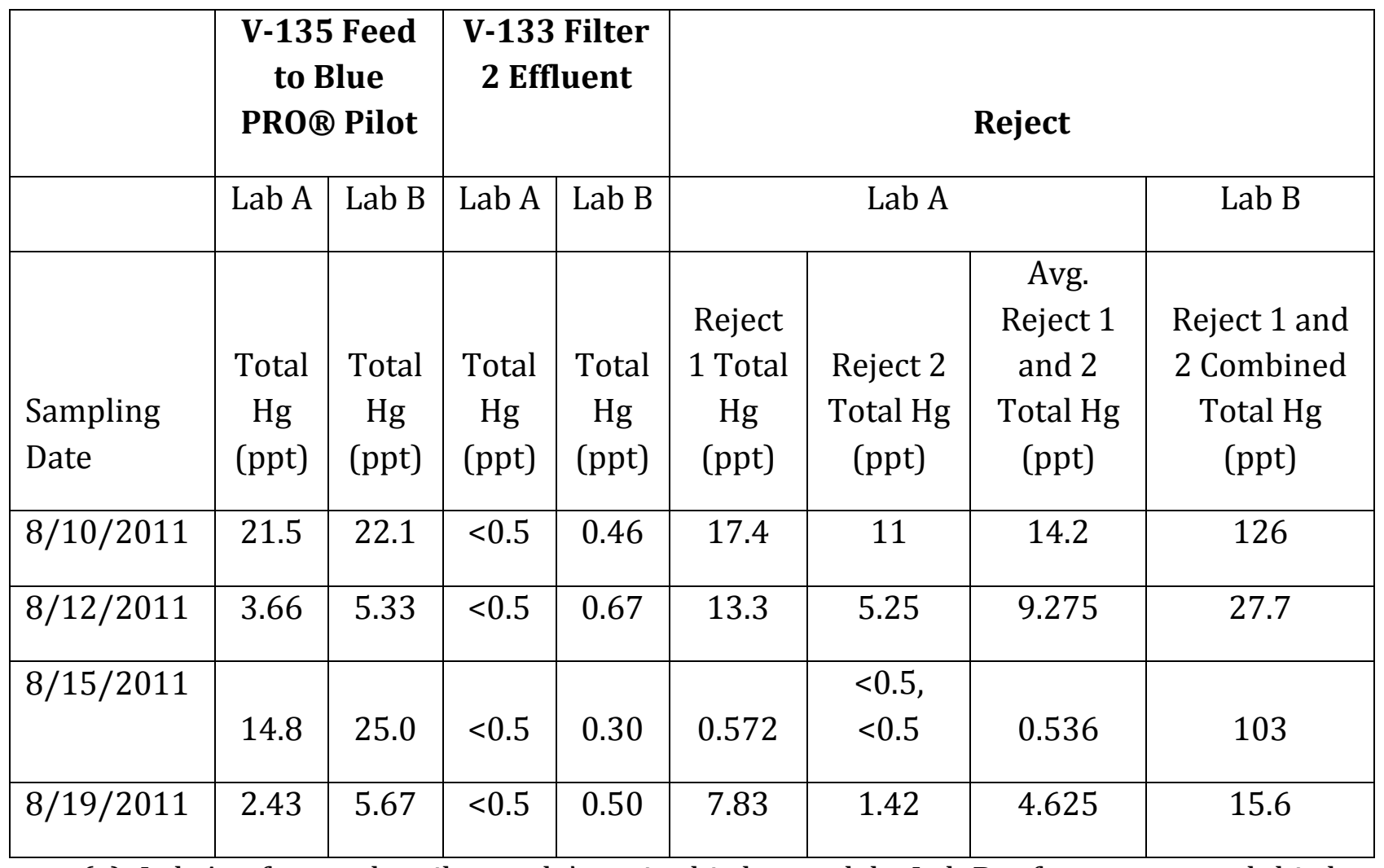

(a) Lab A refers to the pilot study's main third party lab. Lab B refers to a second third party lab.

The assumptions made prior to doing the mass balance are as follows:

1. Missing flow rate or $\mathrm{Hg}$ data was interpolated from known data.

2. Flow data and analyses for $8 / 23$ and $8 / 24$ were estimated from the average of the previous 5 days.

3. The influent flow meter calibration was assumed to be valid, which in turn assumed that the levels in the filters were constant despite the surging seen during calibration.

4. Pilot effluent that was reported to be $<0.5 \mathrm{ppt} \mathrm{Hg}$ by the pilot study's third party lab was assumed to be $0.48 \mathrm{ppt} \mathrm{Hg}$ (average Lab B analysis).

5. Averages of duplicate samples were used.

6. Lab B's Hg analyses for Filter 2 effluent were used on the days those samples were taken. 
7. For $6 / 23-7 / 5 / 11$ when the Filter 2 's reject line was actually sampling effluent, assumed Reject 1 gave $72.7 \%$ of the total reject $\mathrm{Hg}$ and Reject 2 gave $27.3 \%$ of the total reject $\mathrm{Hg}$, based on what was seen during individual reject analyses performed during Nalmet ${ }^{\circledR}$ addition.

8. Assumed initial sand had same $\mathrm{Hg}$ content as sand on $7 / 20$ when triplicate sampling was done.

9. Assumed no gain of $\mathrm{Hg}$ from equipment, as per equipment blank done at beginning of pilot.

10. Assumed no Hg method loss since method loss testing at beginning of the pilot was inconclusive.

11. Assumed that the Hg loss due to volatilization was negligible since the pilot system was a closed system.

12. Assumed Hg content of 27-36 ppm Nalmet ${ }^{\circledR}$ solution was the same as the analyzed 25 ppm Nalmet ${ }^{\circledR}$ solution.

13. Assumed 7/5/11 combined reject was 19.4 and $19.6 \mathrm{ppt} \mathrm{Hg}$ in duplicate sampling, and Filter 2 effluent was $<0.5 \mathrm{ppt}$. The study's third party lab had reported the Filter 2 effluent as $19.4 \mathrm{ppt}$ and one of the combined rejects as $<0.5 \mathrm{ppt}$.

14. Assumed 8/15/11 Filter 1 effluent was $0.572 \mathrm{ppt} \mathrm{Hg}$ and that Reject 1 was $5.08 \mathrm{ppt}$ Hg. The study's third party lab had reported the Filter 1 effluent as $5.08 \mathrm{ppt}$ and the Reject 1 as $0.572 \mathrm{ppt}$, but pilot data trends suggest that the sample labeling was switched for this particular sampling event.

The daily Hg mass for each pilot stream was calculated and plotted in Figure 3.15. The daily $\mathrm{Hg}$ discrepancy is based on the difference between the incoming $\mathrm{Hg}$ from the feed and the exiting $\mathrm{Hg}$ from the effluent and reject. The $\mathrm{Hg}$ content of the filter sand was not considered for the daily discrepancy. As shown in Figure 3.15, the daily discrepancy varies between positive and negative values. 


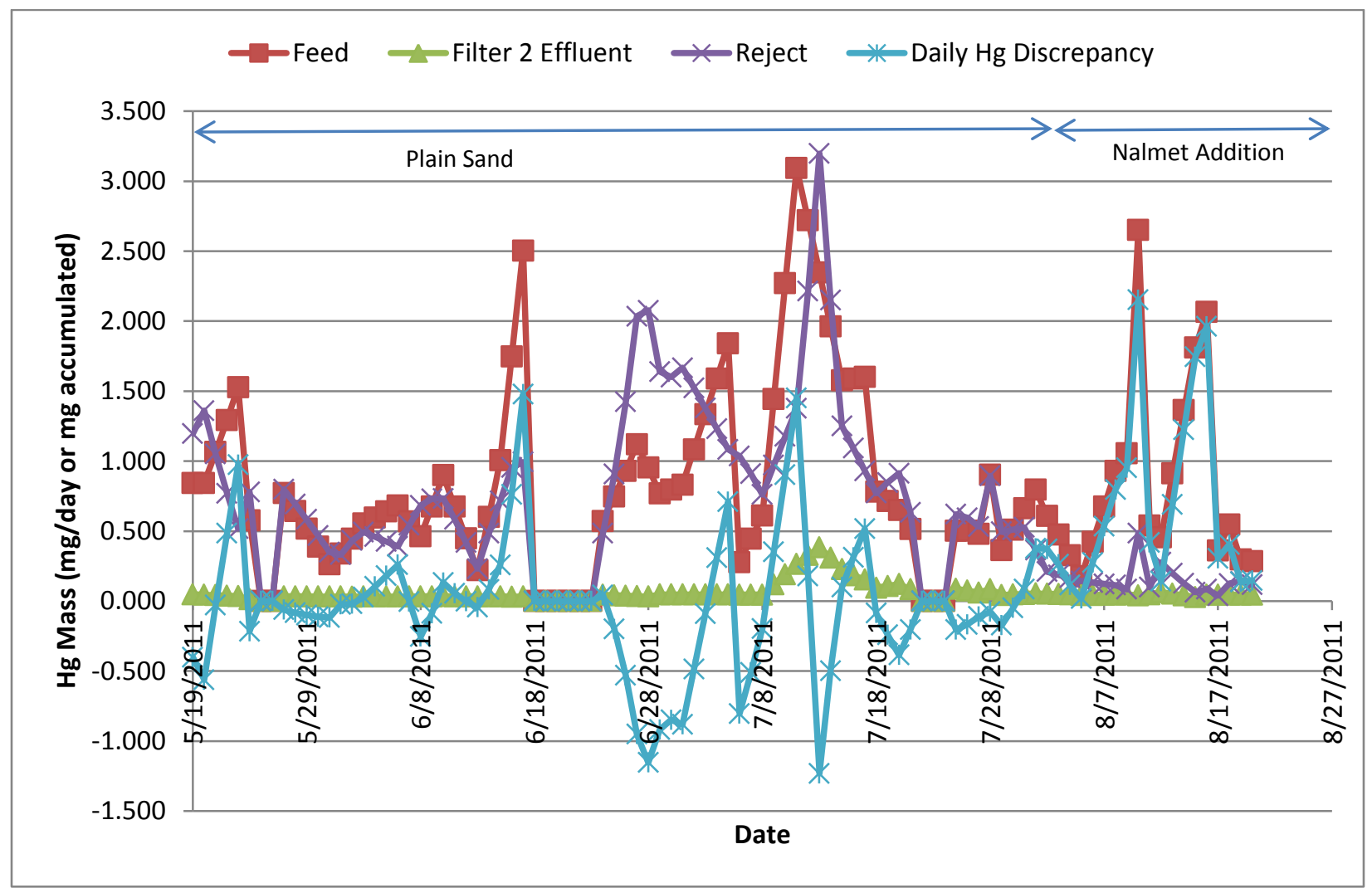

Figure 3.15 Daily Hg Mass for Each Pilot Stream

The Hg accumulation in the system was calculated from the daily Hg discrepancies and is shown in Figure 3.16. Initially the system fluctuated between very small gains and losses of Hg which could possibly be due to variability in the data. Around mid-June, larger swings in Hg gain and loss started to be seen. With the onset of Nalmet ${ }^{\circledR}$ addition, the system clearly began to accumulate $\mathrm{Hg}$, as was confirmed by the filter sand analyses. 


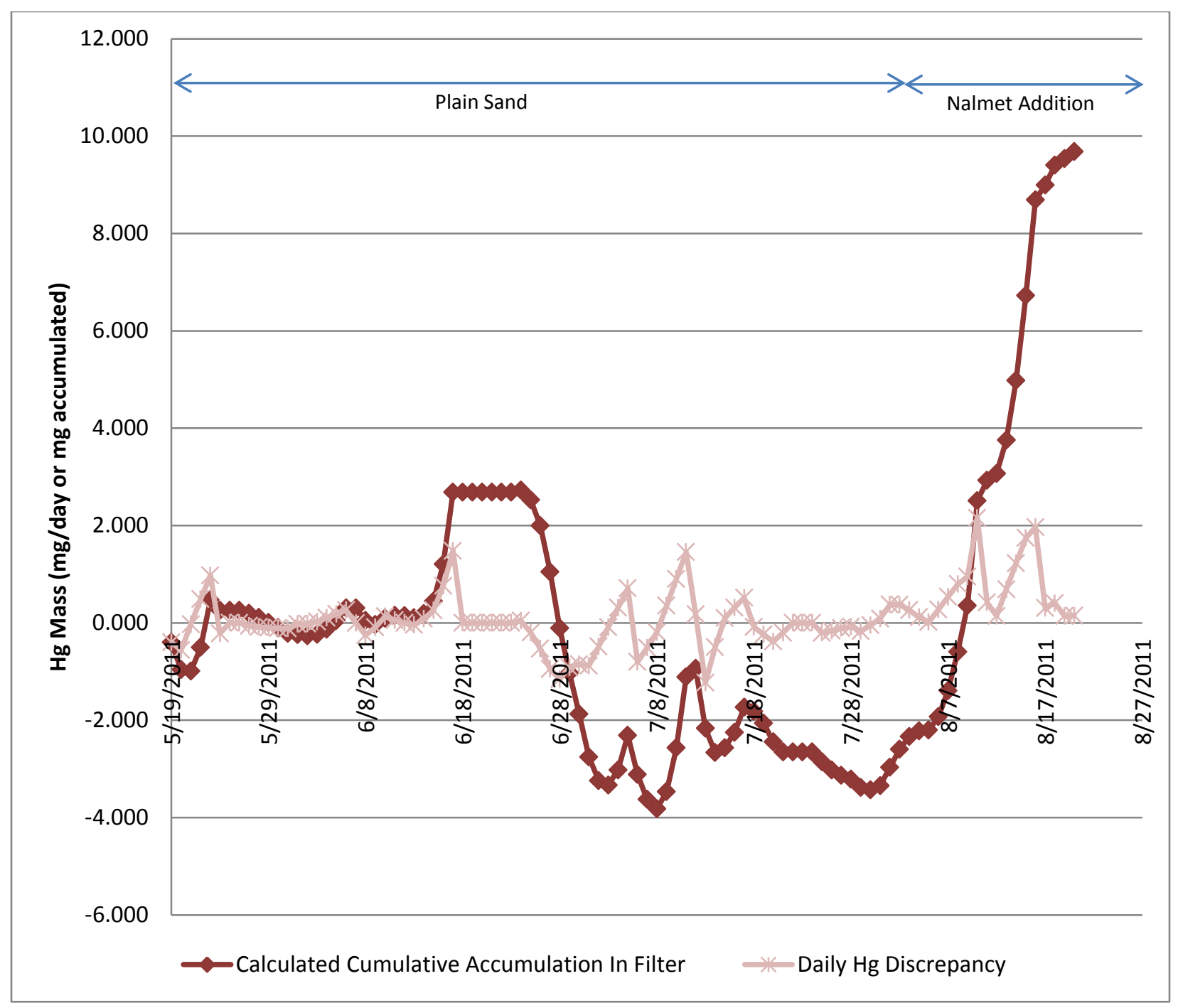

Figure 3.16 Pilot Hg Accumulation

As shown in Table 3.18, mass balances for individual time periods corresponding to sand sampling events as well as an overall mass balance for the pilot were calculated. For each time period,

Total Hg In = Feed Hg + Nalmet $®$ Hg + Sand Hg at Start of Time Period,

and

Total Hg Out = Effluent Hg + Reject Hg + Sand Hg at End of Time Period

As was stated previously, one of the assumptions for this mass balance was that the initial sand had the same $\mathrm{Hg}$ content as the filter sand that was sampled on $7 / 20$. It has been 
documented that sands from 33 different suppliers in the U.S. and Canada all contained ppb levels of $\mathrm{Hg}(14)$, suggesting that in the absence of an actual analysis, an assumption of some Hg content is valid. The 7/20 analytical results were used instead of the 7/15 analysis because the $7 / 20$ results were based on triplicate samples whereas the $7 / 15$ analysis was based on one sample. The Hg content of the sand is a major contributor to the overall $\mathrm{Hg}$ mass balance, and hence the mass balance is sensitive to the assumed $\mathrm{Hg}$ content of the sand. Although the entire pilot's mass balance is presented below for completeness, the first time period $(5 / 19-7 / 20)$ and the entire pilot $(5 / 19-8 / 24)$ mass balances are based on this initial sand assumption which may or may not be correct. The second time period $(7 / 21-8 / 19)$ is based on a complete set of data, that is, the initial and final $\mathrm{Hg}$ content of the sand is known. For this time period, the Hg mass balance closure is $70 \%$. Although the initial and final $\mathrm{Hg}$ content of the sand for the 8/20 - 8/24 time period is also known, the flow rates and $\mathrm{Hg}$ analyses of the feed, effluent and reject were estimated for two of the period's five days. Hence for the 8/20 - 8/24 time period, the data set is not complete and therefore the mass balance done for that time period may not be valid. Given the sensitivity of the mass balance to the $\mathrm{Hg}$ content of the sand, it is noteworthy that the $8 / 24$ sand analytical results are within the standard deviation of the $8 / 19$ sand analytical results (as shown in Figures 3.12 and 3.13) - what appears to be a decline in sand $\mathrm{Hg}$ content and a subsequent mass balance closure that is greater than $100 \%$ may in fact be due to variation in sampling and analysis. 
Table 3.18 Pilot Mass Balance

\begin{tabular}{|c|c|c|c|c|c|c|c|c|}
\hline & $\begin{array}{c}\text { Feed } \\
\text { Hg } \\
(\mathrm{mg})\end{array}$ & $\begin{array}{l}\text { Nalmet } \\
\text { ® Hg } \\
\text { (mg) }\end{array}$ & $\begin{array}{c}\text { Effluent } \\
\text { Hg } \\
\text { (mg) }\end{array}$ & $\begin{array}{c}\text { Reject } \\
\text { Hg } \\
\text { (mg) }\end{array}$ & $\begin{array}{c}\text { Sand } \\
\text { Analysis } \\
\text { applied } \\
\text { to entire } \\
\text { sand bed } \\
\text { (mg) (a) }\end{array}$ & $\begin{array}{l}\text { Total } \\
\text { Hg In } \\
\text { (mg) }\end{array}$ & $\begin{array}{c}\text { Total } \\
\text { Hg } \\
\text { Out } \\
\text { (mg) }\end{array}$ & $\begin{array}{l}\text { Hg In/ } \\
\text { Hg Out }\end{array}$ \\
\hline $\begin{array}{l}\text { Initial } \\
\text { Sand }\end{array}$ & & & & & 9.07 (a) & & & \\
\hline $\begin{array}{l}5 / 19 \text { - } \\
7 / 20 / 11 \\
7 / 20 / 11 \\
\text { sand } \\
\text { sampling }\end{array}$ & 56.47 & 0.00 & 4.10 & 54.82 & 9.07 & 65.54 & 67.98 & $96.4 \%$ \\
\hline $\begin{array}{l}7 / 21 \text { - } \\
8 / 19 / 11 \\
8 / 19 / 11 \\
\text { sand } \\
\text { sampling }\end{array}$ & 20.91 & 0.46 & 1.42 & 7.97 & 34.13 & 30.44 & 43.52 & $70.0 \%$ \\
\hline $\begin{array}{l}8 / 20 \text { - } \\
8 / 24 / 11 \\
8 / 24 / 11 \\
\text { sand } \\
\text { sampling }\end{array}$ & 1.52 & 0.13 & 0.23 & 0.51 & 32.94 & 35.79 & 33.68 & $106.3 \%$ \\
\hline $\begin{array}{l}\text { 5/19 - } \\
8 / 24 / 11 \\
\text { (entire } \\
\text { pilot) } \\
8 / 24 / 11 \\
\text { sand } \\
\text { sampling }\end{array}$ & 78.90 & 0.59 & 5.75 & 63.29 & 32.94 & 88.56 & $\begin{array}{c}101.9 \\
8\end{array}$ & $86.8 \%$ \\
\hline
\end{tabular}

(a) Assumed, based on 7/20/11 sand sampling results. 


\subsubsection{Pilot Testing Conclusions}

- Effluent from the 97 day long Blue PRO $®$ pilot study met the 1.3 ppt Hg treatment goal $92 \%$ of the time ( 23 out of 25 samples), confirming bench-scale testing results.

- Although effluent from the first filter met the treatment goal when a monthly average was calculated, the treatment goal was exceeded for 3 of the 16 samples taken during a 27 day period (19\% of samples taken). A more conservative approach would be to use two filters to provide additional removal capacity and better ensure compliance since pilot performance may not directly scale up to fullscale performance.

- Operation without chemical addition showed Hg breakthrough in the second filter's effluent after 46 days. Although the data is not conclusive, the addition of Nalmet ${ }^{\circledR}$ 1689 to the pilot feed appeared to help improve the effluent quality. Inclusion of a chemical feed system for the full-scale design would be prudent.

- Hg accumulation in the filter sand was seen while Nalmet ${ }^{\circledR} 1689$ was added to the pilot feed, suggesting that the washbox and/or the Nalmet ${ }^{\circledR}$ dosage (which was significantly higher than had been used in bench-scale testing) may need further optimization. Further testing is needed to determine if lower doses of Nalmet ${ }^{\circledR}$ reduce $\mathrm{Hg}$ accumulation in the filter sand. Additionally, further testing is needed to determine if effluent quality could be maintained with long-term Nalmet ${ }^{\circledR}$ addition, since the sand may have a finite capacity for the polymer and the $\mathrm{Hg}$ attached to it.

- As, Se and V removal during seven weeks of plain sand operation was negligible.

- Although the overall reliability of the system was good (operational $90.7 \%$ of the time during the pilot), the reject analyses and operational experience suggested that the washbox plugged at times.

\subsection{Engineering and Cost Evaluation}

\subsubsection{Preliminary Blue PRO® Full-scale System}

For a full-scale Blue PRO ${ }^{\circledR}$ system, the vendor recommended that the equivalent of a single filter be used, i.e. that the wastewater be treated with only one filter, unlike the pilot in which the wastewater was treated with two filters in series. Using the design criteria shown in Table 3.19, the vendor's single filter full-scale version would have $23 \mathrm{in}$-ground concrete filters with a total filter area of $5888 \mathrm{ft}^{2}$. The estimated footprint is $241^{\prime} \mathrm{x} 44^{\prime}$. The complete budgetary quote is provided in Appendix 3G. Although from the vendor's perspective the pilot data does not clearly demonstrate the need for chemical addition, the vendor included the capability to add Nalmet $\AA$ in their quote based on their past experience. The vendor also recommended that the reject from the Blue PRO® system be 
recycled upstream to an unspecified location, and therefore did not consider sludge treatment and disposal costs (Appendix 3F).

Table 3.19 Blue PRO® Vendor Design Criteria

\begin{tabular}{|l|c|c|}
\hline & Influent & Effluent \\
\hline Design Flow & $18.6 \mathrm{MGD}$ & \\
\hline Peak Instantaneous Flow & $40 \mathrm{MGD}$ & \\
\hline Continuous Reject Flow & $1380 \mathrm{gpm}$ & $<1.3 \mathrm{ppt}$ \\
\hline Total Mercury & $<15 \mathrm{ppt}$ & $<10 \mathrm{ppm}$ \\
\hline Dissolved Mercury & $<1 \mathrm{ppt}$ & \\
\hline TSS & $<20 \mathrm{ppm}$ & \\
\hline Peak Instantaneous TSS & $<30 \mathrm{ppm}$ & \\
\hline Average loading rate & $2.4 \mathrm{gpm} / \mathrm{ft}^{2}$ & \\
\hline Peak loading rate & $5.0 \mathrm{gpm} / \mathrm{ft}^{2}$ & \\
\hline
\end{tabular}

The vendor's "single filter" design was based on their interpretation of the pilot's results, which showed that the first filter met the treatment goal when a monthly average was calculated over a 27 day period. As was discussed in Section 3.2.4, a more conservative approach would be to design for the equivalent of two filters in series, so that the wastewater would be treated by two different filters sequentially. This would provide additional removal capacity and better ensure compliance since pilot performance may not directly scale up to full-scale performance. Using two filters in series would essentially double the system - 46 in-ground concrete filters for a total filter area of $11,776 \mathrm{ft}^{2}$ with a $241^{\prime} \times 88^{\prime}$ footprint. This footprint size may be difficult to fit into the existing site. A simplified process flow diagram for this system is shown in Figure 3.17. 


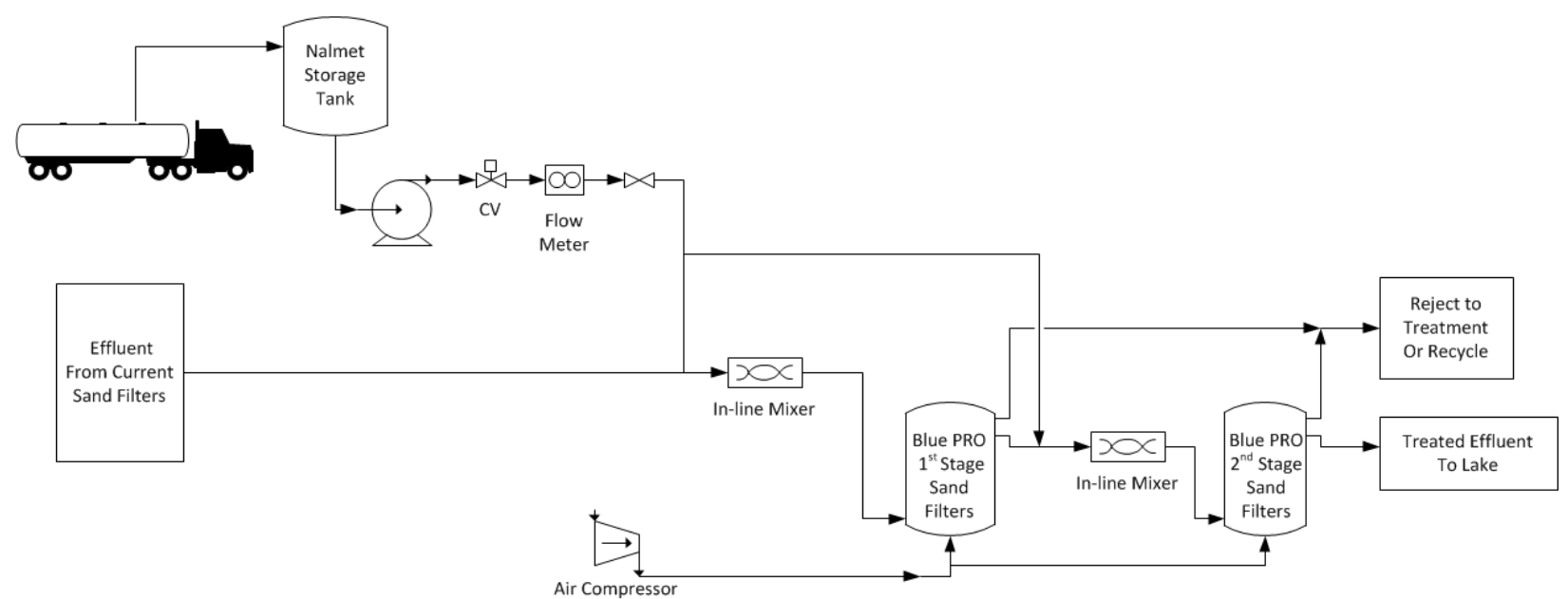

Figure 3.17 Two Stage Blue PRO® Process with Nalmet ${ }^{\circledR}$ Addition

The limited testing period of the pilot did not allow for an optimization of the Nalmet ${ }^{\circledR}$ dosage to be done. The goal instead was to rectify the Hg breakthrough and demonstrate that the effluent could once again meet the treatment goal. Hence, a relatively high dosage of $25 \mathrm{ppm}$ of Nalmet ${ }^{\circledR}$ was used for the pilot. (In actuality the pump calibrations showed that the dosage was 36 and $28 \mathrm{ppm}$ to the first and second filter respectively.) For fullscale application, dosing Nalmet ${ }^{\circledR}$ at 25 ppm corresponds to approximately 380 gallons per day, suggesting that a storage tank is needed rather than a tote tank. Although this high dosage was recommended by the vendor (7), it is significantly higher than the dosage successfully used for the bench-scale testing $(0.5 \mathrm{ppm})$, which was also recommended by the vendor (17). Most likely a lower dosage of Nalmet ${ }^{\circledR}$ will be sufficient to meet the treatment goal, but this needs to be determined through testing. Given that the cost of Nalmet@ 1689 is $\$ 1.08$ per pound delivered (18), optimizing the Nalmet@ dosage is important to minimize Hg treatment costs.

Preliminary full-scale costs were developed two different ways. First, an installed capital cost was developed from the vendor provided equipment cost. This was done using a factored approach, where individual direct and indirect costs are estimated as a percentage of the total installed capital cost. Typical ranges for these costs for a battery limit plant addition were used as guidance (19). Details are provided in Appendix 3E. Given that independent equipment costs for the Blue PRO $®$ system are not publicly available, for comparison, a second installed capital cost was developed from the equipment cost for a conventional sand filter preceded by chemical addition. Although this is not identical to the Blue PRO $®$ process, it is an established technology with many similarities to the Blue 
PRO ${ }^{\circledR}$ process. The equipment cost for a conventional sand filter with chemical addition was developed with the CapdetWorks software program by Hydromantis (version 2.5, 2007), using the same design flow and loading rate used in the Blue PRO® vendor's quote. The system design provided by the Capdet Works program gave a total filtration area of $7408 \mathrm{ft}^{2}$, which is about $20 \%$ higher than the $5888 \mathrm{ft}^{2}$ proposed by the Blue PRO ${ }^{\circ}$ vendor. The Capdet Works program also provided a unit installed cost, which is the cost to install the chemical addition system and the sand filters alone, without any utility hook-ups, site preparation, etc. The equipment cost for backwash sludge treatment is not included. October 2011 cost indices were used to update the program's costs from September 2007 to current dollars $(20,21)$. A total installed capital cost was then determined using the same factored approach that was used with the Blue PRO® vendor's equipment cost. Details are provided in Appendix 3E. Although this second installed capital cost does not include the air compressor, as shown in Table 3.20, it is similar to the first installed capital cost developed with the Blue PRO $®$ vendor's equipment cost, particularly when the difference in filtration area is considered. The two installed capital costs are within $20 \%$ of each other.

The $0 \& \mathrm{M}$ cost is based on the Blue PRO® vendor's recommendation of using a full-time technician to run a "single filter" system of 23 filters (Appendix 3G). For this "double filter" system the cost of two full-time technicians (at $\$ 25 / \mathrm{hr}$ ) was used. Supervisory time was not included in the 0\&M cost. The energy cost is also a doubling of the vendor's estimate for a "single filter" system. This energy cost includes the electricity for the compressed air and the pump to return the reject flow upstream (22). For comparison, the cost of dosing Nalmet ${ }^{\circledR}$ to both the first and second filter at both a $25 \mathrm{ppm}$ level and a $10 \mathrm{ppm}$ level is shown. Given that the vendor is recommending that the reject be recycled to an upstream location, costs for the treatment and disposal of sludge are not provided. 
Table 3.20 Costs for Two Stage Blue PRO ${ }^{\circ}$ Process with Nalmet $®$ Addition

\begin{tabular}{|c|c|c|c|c|c|}
\hline & $\begin{array}{c}\text { Installed } \\
\text { Capital Cost } \\
\text { (\$) (a) }\end{array}$ & $\begin{array}{l}0 \& M \\
(\$ / y r) \\
(b)\end{array}$ & $\begin{array}{l}\text { Chemical, } \\
25 \text { ppm dose } \\
\text { to each filter, } \\
(\$ / \mathrm{yr})(\mathrm{c})\end{array}$ & $\begin{array}{l}\text { Chemical, } \\
10 \text { ppm } \\
\text { dose to each } \\
\text { filter } \\
(\$ / y r)(c)\end{array}$ & $\begin{array}{c}\text { Energy } \\
(\$ / y r) \\
\text { (d) }\end{array}$ \\
\hline $\begin{array}{l}\text { Based on BWT } \\
\text { equipment } \\
\text { quote }\end{array}$ & $28,959,000$ & 146,000 & $3,060,000$ & $1,224,000$ & 130,000 \\
\hline $\begin{array}{l}\text { Based on } \\
\text { Capdet } \\
\text { chemical } \\
\text { addition and } \\
\text { sand filter } \\
\text { approximatio } \\
\text { n }\end{array}$ & $36,374,000$ & & & & \\
\hline
\end{tabular}

(a) Details of factored cost estimate provided in Appendix 3E.

(b) Includes operator cost only, based on $\$ 25 / \mathrm{hr}$.

(c) Based on $\$ 1.08 / \mathrm{lb}$ per Nalco quote.

(d) Based on $\$ 0.10 / \mathrm{kWh}$.

\subsubsection{Alternative Option for Further Consideration}

A second potential option for a full-scale $\mathrm{Hg}$ treatment system would be a simplification of the Blue $P R O \circledR$ process. Instead of adding additional sand filters, as would be the case with the Blue PRO® process, the removal performance of BP Whiting's sand filters could potentially be improved by adding Nalmet ${ }^{\circledR}$ before these filters, as shown in Figure 3.18. Although this option needs to be verified with further testing, bench-scale testing of plain sand with Nalmet ${ }^{\circledR}$ addition showed $99 \% \mathrm{Hg}$ removal with a $0.23 \pm 0.06$ ppt effluent, suggesting that this may be a viable option. The amount of Nalmet ${ }^{\circ}$ required would need to be determined through testing. The Blue PRO® pilot showed good removal when two different doses of 25 ppm Nalmet ${ }^{\circledR}$ were used, one before each filter. Hence, for this simplified option a maximum dose of 50 ppm Nalmet® would be needed. Most likely this 
dose can be reduced, which will be important to minimize treatment cost. Another aspect of this treatment system that would require further study is the fate of the sand filter's backwash - whether it could be recycled upstream or would require solids removal prior to recycling upstream. Without additional study it is not clear whether the particulate $\mathrm{Hg}$ could be removed, for example, with the upstream clarifier sludge or whether perhaps it would go into solution and hence not be removed from the overall wastewater treatment system.

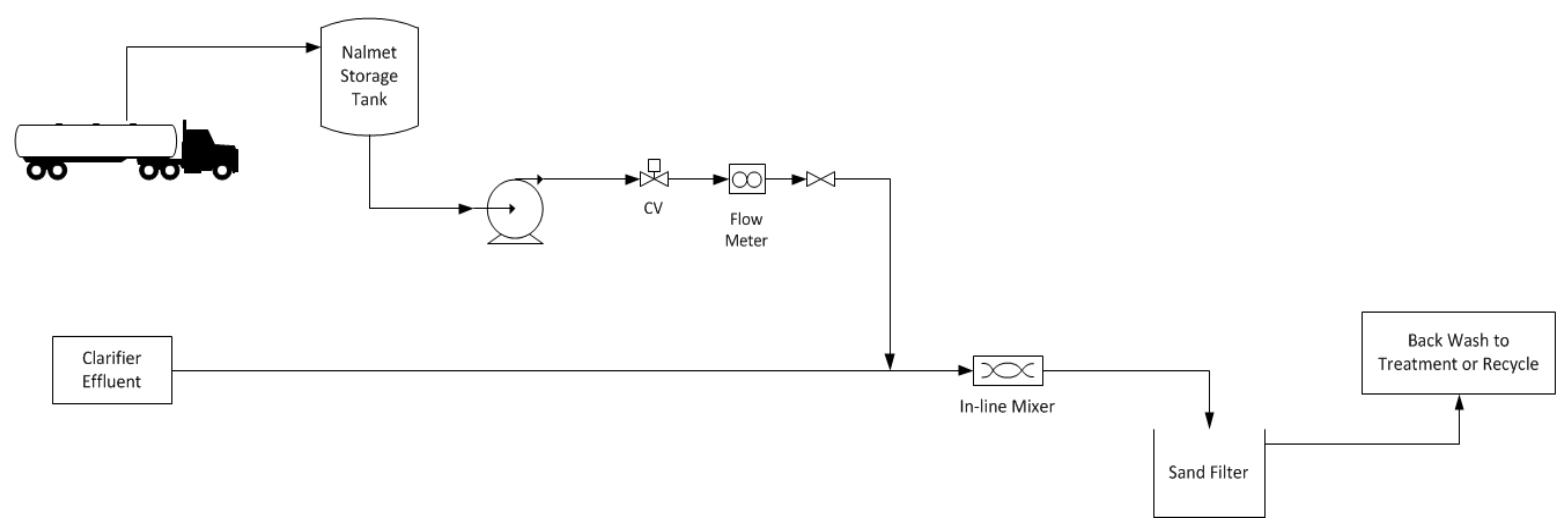

Figure 3.18 Nalmet ${ }^{\circledR}$ Addition Before Sand Filters

Preliminary full-scale costs for the chemical feed system were developed with the CapdetWorks software program by Hydromantis because of the potential attractiveness of this option, even though it has not been tested yet. As was done with the sand filter costing above, a unit installed cost for the chemical addition system was determined with the program. An installed capital cost, shown in Table 3.21, was then developed using a factored approach as was done with the Blue PRO ${ }^{\circledR}$ and sand filter costing above. Details are provided in Appendix 3E. Both the 0\&M and Energy cost are from the CapdetWorks software. As was done with the Blue PRO® process above, the O\&M cost is for an operator only - supervision costs are not included. For comparison, the cost of dosing Nalmet ${ }^{\circledR}$ at both a $50 \mathrm{ppm}$ level and a $20 \mathrm{ppm}$ level is shown. Given the potential cost savings, further testing of this option should be done. 
Table 3.21 Costs for Nalmet ${ }^{\circledR}$ Addition Before Sand Filters

\begin{tabular}{|l|c|c|c|c|c|}
\hline & $\begin{array}{c}\text { Installed } \\
\text { Capital } \\
\text { Cost, }\end{array}$ & $\begin{array}{c}\mathbf{0 \& M} \\
\mathbf{( \$ / y r )}\end{array}$ & $\begin{array}{c}\text { Chemical, } \\
\mathbf{5 0} \mathbf{~ p p m} \\
\text { dosage, }\end{array}$ & $\begin{array}{c}\text { Chemical, } \\
\mathbf{2 0} \mathbf{~ p p m} \\
\text { dosage, }\end{array}$ & Energy \\
& $\mathbf{( \mathbf { } ) \mathbf { ( a ) }}$ & $\mathbf{( \$ / y r )}$ & $\mathbf{( \$ / y r )}$ & $\mathbf{( \$ / y r )}$ \\
\hline Capdet & $1,448,000$ & 31,000 & $3,060,000$ & $1,224,000$ & 3,300 \\
\hline
\end{tabular}

(a) Details of factored cost estimate provided in Appendix 3E.

(b) Includes operator cost only, based on $\$ 25 / \mathrm{hr}$.

(c) Based on $\$ 1.08 / \mathrm{lb}$ per Nalco quote.

(d) Based on $\$ 0.10 / \mathrm{kWh}$.

\subsubsection{Full-Scale Options for Reject Management}

An important aspect of a full-scale $\mathrm{Hg}$ treatment system is determining how to manage the process residual streams. For the Blue $\mathrm{PRO} 囚$ process, the preliminary full-scale design provided by the vendor in Appendix 3G estimates that the reject flow with all filter cells in operation would be 1380 gpm (1.99 MGD), or $10.7 \%$ of the average influent flow of 18.6 MGD. For comparison, the pilot combined reject flow rate was a higher percentage of the influent (average flow 5.9 gpm, or $24-32 \%$ of the influent flow) due to washbox size constraints. The pilot reject composition is summarized in Table 3.22. Reject samples taken for particle size distribution analysis during Nalmet ${ }^{\circledR}$ addition showed that the solids did not settle readily. 
Table 3.22 Summary of Blue PRO® Pilot Reject Composition

\begin{tabular}{|l|c|c|c|c|}
\hline & $\begin{array}{c}\text { Total Hg } \\
\text { avg. (ppt) }\end{array}$ & $\begin{array}{c}\text { Total Hg } \\
\text { range (ppt) }\end{array}$ & $\begin{array}{c}\text { TSS avg. } \\
\text { (ppm) }\end{array}$ & $\begin{array}{c}\text { TSS range } \\
\text { (ppm) }\end{array}$ \\
\hline $\begin{array}{l}\text { Combined } \\
\begin{array}{l}\text { Reject (a) } \\
\text { (through } \\
7 / 29)\end{array}\end{array}$ & 24.4 & $6.91-86$ & 21.1 & $10-38$ \\
\hline $\begin{array}{l}\text { Reject 1 } \\
\text { (starting } \\
\text { 8/1) }\end{array}$ & 6.9 & $0.572-18.7$ & 75.2 & $44-180$ \\
\hline $\begin{array}{l}\text { Reject 2 } \\
\text { (starting } \\
8 / 1)\end{array}$ & 3.2 & $<0.5-11$ & 27.2 & $1.6-75$ \\
\hline
\end{tabular}

(a) Excludes time period from 6/23 - 7/6/11 when Filter 2 reject sampling line was actually sampling effluent.

There are three options for treating the full-scale Blue PRO® reject, which are essentially variations on recycling the reject upstream. Recycling to an unspecified upstream location was recommended in the vendor's report in Appendix 3F. The first option would be to recycle the reject stream directly upstream to either the DAF unit or the clarifier. In order for this to work, the solids and particulate Hg would need to settle rapidly in the upstream unit so that the $\mathrm{Hg}$ can be removed from the overall wastewater treatment system and hence prevent Hg accumulation. A second option would be to treat the reject stream with a precipitant such as ferric sulfate prior to recycling upstream. The precipitant would facilitate the settling of the solids and particulate $\mathrm{Hg}$ in the upstream unit. Module 3 testing showed good floc formation and settling when clarifier effluent was treated with ferric sulfate, so potentially this may be the case for the Blue PRO® reject stream as well. One unknown about either the first or second option is whether the $\mathrm{Hg}$ will remain with the solids or detach and rejoin the liquid stream, which could lead to an accumulation of $\mathrm{Hg}$ within the overall wastewater treatment plant. A third option would be to treat the reject stream with a precipitant, remove the solids and particulate $\mathrm{Hg}$ from the reject stream, and then recycle the liquid portion of the reject stream to an upstream location. This would have the advantage of concentrating the $\mathrm{Hg}$ into a smaller residual stream, but this smaller residual stream could potentially be classified as hazardous due to Hg content.

For the second Hg treatment system option, which consists of Nalmet@ addition prior to the sand filters, the options for treating the sand filter backwash are similar. These options, 
however, are subject to the additional evaluation of the fate of Hg. The sand filter backwash is currently recycled to the DAF unit. One option for treating the backwash containing Nalmet ${ }^{\circledR}$ precipitated particles would be to send the entire backwash upstream as-is to the DAF unit. Again, the success of this option is dependent on how well the backwash solids settle in the presence of Nalmet ${ }^{\circledR}$. Similarly, it is not known if the $\mathrm{Hg}$ would stay attached to the particulates and be removed with the sludge in downstream units, or instead transfer back to the liquid phase. A second option for treating the backwash would be to add an additional chemical to the backwash to facilitate the settling of the solids and particulate Hg. For this option, the entire stream would be recycled upstream. A third option would be to treat the backwash stream with an additional chemical and remove the solids prior to recycling the liquid portion upstream. Again, the $\mathrm{Hg}$ would be concentrated into a smaller residual stream but this stream could potentially be classified as hazardous due to Hg content.

In order to determine the viability of these treatment options, further bench-scale testing of these options is planned. Current plans are to test the backwash generated from a sand filter when the influent has been either treated or not treated with Nalmet ${ }^{\circledR}$. The testing will determine how well the solids settle and if a precipitant is needed, what dosage is needed to remove the solids from solution.

\subsection{Blue PRO® Pilot Summary and Conclusions}

- Effluent from the $25 \mathrm{gpm}$ Blue PRO® pilot met the $1.3 \mathrm{ppt} \mathrm{Hg}$ treatment goal $92 \%$ of the time during the 97 day pilot.

- In general, the unit operated well mechanically, running $91 \%$ of the time during the pilot.

- Mercury breakthrough in the effluent was seen after 46 days of operation without chemical addition.

- Effluent quality after Hg breakthrough was restored when Nalmet ${ }^{\circledR} 1689$ was added to each filter's influent.

- Mercury accumulation was seen in the filter sand during Nalmet ${ }^{\circledR}$ addition, suggesting that the effluent quality may decline over long-term operation - the filter sand may have a finite capacity for Nalmet ${ }^{\circledR}$ and the associated $\mathrm{Hg}$.

- Pilot data suggests that a full-scale Blue PRO® treatment system should have the equivalent of two filters in series, and Nalmet ${ }^{\circledR} 1689$ addition to the influent of each filter, with an installed capital cost of approximately $\$ 32 \mathrm{M}$.

- Another option for full-scale Hg treatment that has arisen from consideration of the Blue PRO $®$ process is Nalmet ${ }^{\circledR}$ addition before BP Whiting's sand filters, which would have a significantly lower installed capital cost of approximately $\$ 1.5 \mathrm{M}$. 
Although this option has not been tested at the pilot scale, it is a simplification of the Blue PRO $®$ process, which successfully treated effluent. Additionally, bench-scale testing of plain sand with Nalmet ${ }^{\circledR}$ addition showed $99 \% \mathrm{Hg}$ removal with a $0.23 \pm$ 0.06 ppt effluent. A long-term pilot test of this option is recommended.

- Optimization of the Nalmet® 1689 dosage is needed to minimize treatment costs.

- Testing is also needed to determine how to manage the reject or backwash streams of the full-scale options. Bench-scale testing is planned.

\subsection{References}

1. Argonne National Laboratory, "Emerging Technologies and Approaches to Minimize Discharges Into Lake Michigan, Phase 2, Module 3 Report”, October 2010.

2. Schowengerdt, Matt, Blue Water Technologies, Inc., "Blue PRO® Pilot Proposal \#100219-3", 2/15/11.

3. EPA Method 1669, "Sampling Ambient Water for Trace Metals at EPA Water Quality Criteria Levels", July 1996, http://www.ecy.wa.gov/programs/wq/wastewater/method 1669.pdf, accessed 7/22/09.

4. Moye, David, BP-Whiting, email communication, 2/28/11.

5. Strain, CJ, Blue Water Technologies, Inc., email communication, 5/13/11.

6. Blue Water Technologies, Inc., "Operating and Maintenance Instructions, Blue PROß”, received 2/8/11.

7. Strain, CJ, Blue Water Technologies, Inc., email communication, 5/20/11.

8. Strain, CJ, Blue Water Technologies, Inc., project team teleconference, 6/17/11.

9. EPA Method 7471a, "Mercury in Solid or Semisolid Waste (Manual Cold-Vapor Technique), Sept. 1994, http://www.epa.gov/epawaste/hazard/testmethods/sw846/online/7 series.htm accessed 10/6/11.

10. EPA Method 1311, "Toxicity Characteristic Leaching Procedure", July 1992, http://www.epa.gov/epawaste/hazard/testmethods/sw846/pdfs/1311.pdf, accessed $10 / 6 / 11$.

11. Liao, L., Selim, H.M., and DeLaune, R.D., "Mercury Adsorption-Desorption and Transport in Soils”, J. Environ. Qual., 38:1608-1616 (2009).

12. Gabriel, M.C. and Williamson, D.G., "Principal biogeochemical factors affecting the speciation and transport of mercury through the terrestrial environment", Environmental Geochemistry and Health, 26: 421-434, 2004.

13. Yin, Y., et al., "Kinetics of Mercury (II) Adsorption and Desorption on Soil", Environmental Science \& Technology, Vol. 31, No. 2, 1997.

14. Hills, L. M. and Stevenson, R.W., The Portland Cement Association, "Mercury and Lead Content in Raw Materials", PCA R\&D Serial No. 2888, 2006, https://www.cement.org/bookstore/profile.asp?id=10546, accessed 10/5/11. 
15. Fayad, P. B., et al., "Total Mercury Determination in Sand Boxes from Montreal", J. Environ. Monit., 2004, 6, 903-906.

16. EPA Method 7473, "Mercury in Solids and Solutions by Thermal Decomposition, Amalgamation and Atomic Absorption Spectrophotometry", Feb. 2007, http://www.epa.gov/epawaste/hazard/testmethods/sw846/pdfs/7473.pdf, accessed $10 / 6 / 11$.

17. Newcombe, Remy, Blue Water Technologies, Inc., email communication, 6/17/2010.

18. Lesniak, Michael, Nalco Company, email communication, 9/10/11.

19. Peters, M. and Timmerhaus, K., Plant Design and Economics for Chemical Engineers, $3^{\text {rd }}$ edition, McGraw Hill Book Co., New York, 1980.

20. Chemical Engineering, Economic Indicators, p. 80, October 2011.

21. http://enr.construction.com/economics /, accessed 11/18/11.

22. Strain, CJ, Blue Water Technologies, Inc., email communication, 11/2/11. 


\section{Summary and Conclusions}

The Great Lakes Initiative established new water quality-based discharge criteria for mercury (Hg), thereby increasing the need for many municipal and industrial wastewater treatment plants (WWTPs) in the region to lower the mercury in their effluents. Information on deployable technologies to satisfy these requirements for industrial and municipal dischargers in the Great Lakes region is scarce. Therefore, BP funded Purdue University Calumet and Argonne to identify deployable Hg removal technologies to meet future wastewater discharge limits at its Whiting Refinery in Indiana.

Module 3 bench testing results showed that that some technologies were effective on particulate mercury while others were effective on dissolved mercury. One emerging technology was found to be effective on both particulate and dissolved mercury. Most of the mercury in the wastewater to be treated was found to be associated with particulates, and very little mercury was found to be in the dissolved form, i.e. present after $0.45 \mu \mathrm{m}$ filtration (28 out of 29 samples met the 1.3 ppt after $0.45 \mu \mathrm{m}$ filtration). Results from Module 3 also showed that particulate mercury removal was in most cases sufficient to enable the wastewater to meet the proposed 1.3 ppt mercury discharge standard. However, historical data from the spring of 2009 showed that mercury in the dissolved form was present in the Whiting ETL at levels above non-detect levels ( $0.5 \mathrm{ppt})$ during 4 of 9 sampling events. In addition, 3 out of 9 samples were above 1.3 ppt. Hence, options were devised for wastewater treatment of both particulate and dissolved mercury removal. Given these requirements, at the end of Module 3 three different technologies were chosen for further evaluation:

- Ultrafiltration (using GE ZeeWeed® Technology, $0.04 \mu \mathrm{m}$ pore size and made up of PVDF),

- Adsorption using Mersorb® LW, a sulfur-impregnated activated carbon, and

- The Blue PRO® reactive filtration process.

In this project module, Argonne and Purdue conducted pilot-scale testing on two of the promising Hg removal technologies that were identified as a result of the bench-scale testing and technology evaluation done in Module 3. Ultrafiltration, an established technology with many full-scale applications, was tested for particulate mercury removal.

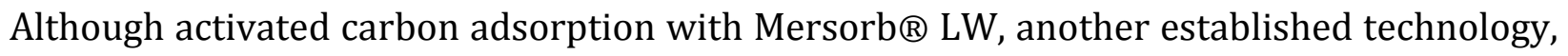
was selected at the end of Module 3 for dissolved mercury removal, this technology was not pilot tested because of a lack of dissolved mercury in the test wastewater for the duration of the test period. An emerging technology, the Blue PRO $®$ reactive filtration process, was also pilot tested because it combines several different processes that may be able to control both particulate and dissolved mercury at the same time. 
The ultrafiltration and the Blue $\mathrm{PRO}{ }^{\circledR}$ reactive filtration pilot studies were done simultaneously at the BP Whiting refinery using a slipstream of wastewater taken just prior to the Effluent To Lake outfall. In preparation for the Blue PRO® pilot, some additional bench-scale testing was also done in this module to identify operating conditions that should be tested at the pilot-scale. It was the intention of this pilot testing to demonstrate proof of concept, i.e. can the discharge limits obtained at bench scale be consistently met at the pilot scale. Optimization for full-scale design was outside of the scope of this work.

The major findings in this module can be summarized as follows:

\section{Ultrafiltration Pilot Study:}

\section{Ultrafiltration effluent water quality:}

- The UF membrane process consistently provided a constant permeate quality at the tested operating conditions, virtually independent of the feed water characteristics and feed $\mathrm{Hg}$ concentration. The treatment target of less than $1.3 \mathrm{ppt}$ of Hg was met and exceeded for all tested conditions during the pilot study. This demonstrates that there is no fundamental physical or chemical barrier in achieving <1.3ppt Hg in the tested refinery wastewater at the pilot-scale at least under these testing conditions of little dissolved mercury in the pre-ETL $(<0.5-1.05 \mathrm{ppt})$.

- Turbidity measurements were less than $0.5 \mathrm{NTU} 85 \%$ of the time (MDL=0.5 NTU).

- The particle size and size distribution analysis of the permeate confirmed the excellent performance of ultrafiltration in removing particulate bound $\mathrm{Hg}$ from the feed.

Ultrafiltration process performance:

- TMP values were below the vendor's specification of (negative) 7-12 psi at all tested conditions during the pilot study.

- Weekly maintenance cleans and the monthly CIP were very effective in restoring the membrane permeability consistently during the pilot-study.

- Low membrane fouling rates ranging $0.0125-0.05 \mathrm{psi} /$ day at $20^{\circ} \mathrm{C}$ resulted in an expected cleaning interval of greater than 90 days when the unit was operated at a Flux A flux rate and $\mathrm{X}, \mathrm{Y}$ and $\mathrm{Z} \%$ percent recoveries.

- The fouling rate increased $\left(0.836 \mathrm{psi} /\right.$ day at $\left.20^{\circ} \mathrm{C}\right)$ when the system was operated at a Flux $\mathrm{B}$ flux rate and $\mathrm{X} \%$ recovery, resulting in a corresponding expected cleaning interval of 14.4 days. Running the membrane at this higher flux rate did not impact the Hg removal performance, but it did impact the cleaning interval of the membrane unit.

- Solids accumulation was noticed in the membrane unit at the conclusion of the pilot, and interfered with the ability to achieve a better mercury mass balance closure. 
- Despite the technical success, the auxiliary operation was problematic. Although minor shutdowns resulted in a gap in operation of less than 24 hours, fixing the feed line related problems took more than 30 days.

Ultrafiltration full-scale considerations and planning:

- The four months of operating experience provided many useful insights into the design, operational and performance aspect of implementing an UF membrane process.

- The proven effectiveness of ultrafiltration in the removal of other particulate contaminants at existing full-scale applications suggests an increased likelihood of success under conditions of little dissolved Hg in the pre-ETL $(<0.5-1.05 \mathrm{ppt})$ in achieving target mercury concentrations at the Whiting Refinery, following optimization and scalability studies.

- Argonne's estimate of the full-scale cost varied between \$39M-147M for a 40 MGD design capacity process depending on the criteria used in cost calculations, such as land acquisition, engineering, site development, waste disposal, etc. It should be noted that the vendor did not provide a full-scale cost estimate therefore this estimate was produced using literature data and methodologies.

- Based on the four month pilot-study test results, Argonne recommends ultrafiltration membrane technology for further evaluation at the Whiting Refinery.

Reactive Filtration Pilot Study:

Reactive filtration effluent water quality:

- Effluent from the 25 gpm Blue PRO® pilot met the 1.3 ppt Hg treatment goal $92 \%$ of the time during the 97 day pilot.

- Mercury breakthrough in the effluent was seen after 46 days of operation without chemical addition. This Hg breakthrough lasted for five consecutive days.

- Effluent quality after Hg breakthrough was restored when Nalmet® 1689 was added to each filter's influent, however, the brevity of these test conditions (three weeks) prevent definitive conclusions from being made

Reactive filtration process performance:

- In general, the unit operated well mechanically, running $91 \%$ of the time during the pilot. Of the 9 days of shutdown, 8 of the days were related to feed supply or sampling location modifications. Only 1 of the shutdown days was related to the process.

- Mercury accumulation was seen in the filter sand during Nalmet® addition, suggesting that the effluent quality may decline over long-term operation - the filter 
sand may have a finite capacity for Nalmet ${ }^{\circledR}$ and the associated $\mathrm{Hg}$ and this trial did not last long enough to determine when this capacity might be reached.

Reactive filtration considerations for full-scale implementation:

- Pilot data suggests that a full-scale Blue PRO® treatment system should have the equivalent of two filters in series, and Nalmet ${ }^{\circ} 1689$ addition to the influent of each filter. Based on the vendor supplied equipment cost, the installed capital cost estimate including equipment purchase and installation, instrumentation, construction and land acquisition would be approximately $\$ 20$ - 36M. It should be noted that site-specific installation costs are needed to develop refined costs. This cost estimate also does not include the treatment and disposal costs for the reject stream since the vendor has recommended that this stream be recycled upstream.

- Optimization of the Nalmet® 1689 dosage is needed to minimize treatment costs.

- Testing is also needed to determine how to manage the full-scale reject stream

- Argonne does not recommend further pilot testing of the Blue PROß process until the $\mathrm{Hg}$ accumulation in the sand issue is better understood.

\section{Alternative option for consideration:}

Another potential option for full-scale $\mathrm{Hg}$ treatment that has arisen from consideration of the Blue PRO $®$ process is Nalmet $\AA$ addition before BP Whiting's sand filters, which would have a significantly lower installed capital cost of approximately $\$ 1.5 \mathrm{M}$. Although this option is outside of the scope of this work and has not been tested at the pilot scale, it is suggested as it is a simplification of the Blue PRO® process, which successfully treated effluent. Additionally, bench-scale testing of plain sand with Nalmet $\AA$ addition showed $99 \% \mathrm{Hg}$ removal with a $0.23 \pm$ 0.06 ppt effluent.

- Testing is needed to determine how to manage the full-scale backwash stream. Bench-scale testing on the reject stream is planned.

- Before moving forward with any further testing of the Blue PROß process, Argonne suggests that a pilot test of this alternative option (Nalmet $\AA$ addition before the sand filters) be done.

\section{Challenges and limitations during both pilot studies:}

- Representative wastewater samples were difficult to obtain due to the variability in wastewater composition as well as the heterogeneity of the wastewater samples, which affected $\mathrm{Hg}$ analyses due to the presence of $\mathrm{Hg}$ in the particulate form. In particular, this impacted mass balance efforts. Two days of composite sampling 
events for the ultrafiltration pilot showed that the standard deviations were very high and ranged from 41.5 to $59 \%$ in feed and membrane backwash samples.

- Future pilot work should consider the use of grab samples for the rapid preliminary assessment of pilot performance. These grab samples should be supplemented with the use of composite sampling in order to obtain more representative samples and improved process analysis.

In summary, both of the pilot technologies demonstrated the ability to meet and exceed the treatment goal of $1.3 \mathrm{ppt} \mathrm{Hg}$ on a consistent basis during the 3 month simultaneous studies, maintaining the effluent quality despite variations in the wastewater feed. These proof of concept pilots demonstrated that there is no fundamental physical or chemical barrier in achieving $<1.3 \mathrm{ppt} \mathrm{Hg}$ in the tested refinery wastewater at the pilot-scale at least under these testing conditions of little dissolved mercury in the pre-ETL $(<0.5-1.05 \mathrm{ppt})$. Argonne recommends long term pilot studies for both ultrafiltration and an alternative approach consisting of adding Nalmet ${ }^{\circledR} 1689$ before BP Whiting's sand filters to obtain the information needed for full-scale design and implementation of a Hg removal technology for BP-Whiting's ETL. The information from these long term pilot studies will help BPWhiting to meet the future GLI discharge criterion. 
5 Results Evaluation from Purdue University Calumet Water Institute 


\title{
Pilot Scale Mercury Treatability Study
}

\author{
Purdue University Calumet Water Institute \\ George Nnanna \\ Jinsong Yu \\ Izabela Jannotta
}

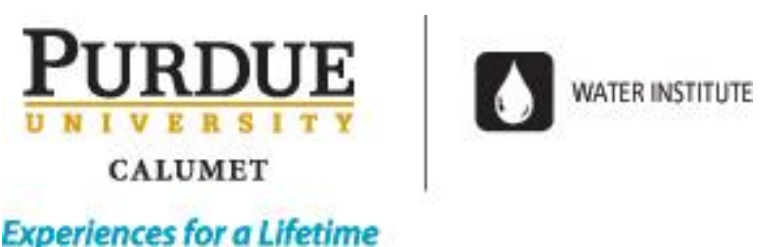




\section{Chapter 5}

\section{Executive Summary}

This Report presents an overview of pilot-scale treatability study conducted at BP Whiting refinery, administrated by a joint team of Purdue University Water Institute (PWI) and Argonne National Laboratory (ANL). The aim of this study was to evaluate the mercury removal performances of two pilot-scale technologies: reactive filtration (Blue Water Technologies) and Ultrafiltration (UF) membrane process (GE ZeeWeed® 500).

Review of published literatures revealed that limited investigations have been carried out on removal of heavy metals from refinery wastewater. Most of the tests whose results were reported in literature and by vendors were not conducted with refinery wastewater; hence removal efficiency may be different than that reported when refinery wastewater is tested. Furthermore, the concentrations of mercury in the wastewater reported in literature and vendors' tests in most cases were higher (often by several orders of magnitude) than those generally found at BP's Whiting facility. Another issue in the reported data for mercury removal technologies is the relatively high detection limits. Much of the data was apparently generated before the new Method 1631E was finalized, or was collected with other mercury analytical techniques.

This study was a Module 4 continuation of Phase II of a Purdue/Argonne joint project. During the previous stage of this project, Module 3, a subset of technologies identified in a previous Purdue/Argonne study (Module 1) was conducted at the bench-scale. The benchscale experimental results of the reactive filtration and UF membrane process tests showed that these two technologies were capable of meeting the $1.3 \mathrm{ppt}$ mercury discharge permit limit (US EPA will enforce this new permit regulation on mercury starting 2012). Therefore, these two technologies were tested in the pilot-scale in this study so that technological performances and sustainability measures such as cost, waste generation, and power consumption may be evaluated. The experimental results would also assist in designing full-scale units.

The wastewater samples as well as Field Blanks and Field Duplicates were collected from the BP Whiting Refinery by an independent analytical laboratory, Lab A. The clean-hands sampling procedure was employed for untreated and treated wastewater sample collection. Both untreated and treated wastewater samples were analyzed for total/dissolved mercury and relevant wastewater parameters (TSS, TDS, pH, TOC, and other) by Lab A as well. Additional samples were analyzed by a specialized lab, Lab B.

The experimental apparatuses were set up by the vendors of the two technologies tested in this pilot-scale study. The daily operation and monitoring of the equipments were 
performed by dedicated BP Whiting Refinery personnel. Operational parameters such as flow rates and pressures were recorded either by dedicated BP personnel or remotely. Purdue and Argonne, on the other hand, focused on the selection of the performance deterministic parameters and the interpretation of the analytical results.

Analytical results on the untreated wastewater samples agreed with that from the previous study, Module 3, that the Hg in the BP Whiting refinery wastewater was primarily associated with the particulates.

Experimental results showed that both technologies were capable of meeting the $1.3 \mathrm{ppt}$ mercury discharge criterion. However, both technologies had their own constraints. For example, for reactive filtration, several sampling events resulted in treated wastewater containing more than $1.3 \mathrm{ppt}$ mercury and experimental data indicated the tendency of mercury accumulation within the unit could not be ignored. For UF membrane process, while effluents consistently showed less than $0.5 \mathrm{ppt}$ mercury (quantification limit), the pilot-scale unit was down on several occasions due to various causes. Also the reject stream contained elevated mercury (compared to the feed or influent) and suspended solids and may require additional handling prior to being disposed of. 


\subsection{Introduction and Background}

Purdue University Calumet Water Institute (Purdue) and Argonne National Laboratory (Argonne) have conducted an independent study to identify deployable technologies that could help the BP Whiting Refinery, and other petroleum refineries, meet future wastewater discharge limits. This study has been funded by BP.

The Purdue/Argonne project is divided into two phases. Phase I, which started in the fall of 2007, focused on identifying emerging technologies for the treatment of total suspended solids and of ammonia in refinery wastewater. Results from this phase have been previously reported and are available on the Purdue University Calumet Water Institute Web site, www.purduecal.edu/pwi. This phase was completed in June 2008.

Phase II focuses on the identification and testing of technologies that are able to reduce the levels of vanadium and mercury in refinery effluent to meet very stringent criteria - for example, to meet the Great Lakes mercury criterion of 1.3 parts per trillion (ppt) (monthly average). The objectives of Phase II are: to identify, list, pre-screen, select, and test technologies for the treatment of heavy metals; to characterize test wastewater; and to complete a comparative analysis of pollutant discharges to Lake Michigan. Phase II is divided into four modules.

Module 1, which was conducted from February 1, 2009, through May 31, 2009, was comprised of two major tasks:

- to identify from the literature technologies that could potentially reduce metals, in particular mercury, but also vanadium, selenium, and arsenic, from refinery wastewater, and to select, from available information on their performance, those to recommend for bench-scale testing; and

- to expand to the entire Lake Michigan the comparative analysis of discharges that was started in Phase I of the project.

The Module 1 study identified several processes for metals removal from wastewater streams such as precipitation, adsorption, ion exchange, biological/hybrid treatment, membrane filtration, chemical reaction, and electrical/magnetic processes. A few technologies were found that show promise in the achievement of the required low-level concentrations in industrial wastewater.

Module 2 included the sampling and analysis of a number of waste streams at the Whiting Refinery. This study of the characterization of wastewater ended in June 2009, and provided the wastewater knowledge base for the design of the Module 3 bench-scale tests. 
In summary, the study revealed that the majority of the mercury in the effluent-to-lake (ETL) or clarifier effluent (CE) was in the particulate form.

Module 3 covered the bench-scale testing of the technologies selected in Module 1 to provide comparable, transparent, and uniform test results for a range of wastewater treatment technologies to remove mercury and vanadium from the Whiting Refinery wastewater. To provide BP with a selection of best candidate technologies for pilot-scale testing at the Whiting Refinery, Module 3 also comprises data processing and review to determine each technology's preliminary performance, engineering configuration, cost, energy usage, waste generation, and readiness to deployment in a pilot-scale demonstration.

Experimental results from Module 3 showed that UF membrane process has high potential in removing particulate mercury and ANL bench-scale tests indicated that reactive filtration is capable of removing both particulate and dissolved mercury. In addition, ANL bench-scale tests also suggested that Mersorb $®$ adsorption may remove dissolved mercury. The UF membrane process and the reactive filtration technology were tested at the pilot-scale at the BP Whiting Refinery and further study of Mersorb® adsorption media was conducted at ANL.

Module 4 covers the pilot-scale testing of selected technologies and is the focus of this report. This report presents separately the interpretation of the experimental data generated during this pilot-scale study.

The main objectives of Module 4 were to:

- Test at the pilot-scale two technologies identified in Module 3 for the removal of mercury down to 1.3 parts per trillion of mercury (1.3 ppt $\mathrm{Hg}$ );

- Review and analyze pilot-scale test results to estimate and compare preliminary performance, cost-effectiveness, and sustainability of technologies.

Under BP funding, Purdue and Argonne have been working jointly as a research team with the objective of identifying and testing for BP a portfolio of technologies, readily deployable or emerging, which could be applied to meet future stringent discharge limits for mercury. Because of its bioaccumulation and toxicity, mercury has special regulatory status in the EPA Great Lakes water quality guidance, where it is included on the list of "bioaccumulative chemicals of concern." As such, mercury discharges to the Great Lakes and their tributaries will be regulated to a limit (1.3 ppt or ng/L) that is stricter than other U.S. waters.

Mercury is present in crudes worldwide, in concentrations ranging from detection limits to approximately $600 \mathrm{ppb}$ (or 600,000 ppt), with the highest concentrations found in Asian crudes. Canadian crudes appear to contain relatively lower amounts of mercury, with 
reported concentrations ranging around 2-4 ppb (Wilhelm et al. 2007). Mercury can be found in the environment in several different forms, generally grouped into two main groups: inorganic (elemental $\left(\mathrm{Hg}^{0}\right), \mathrm{HgS}$, ionic, complexed) and organic (methyl-, di-methyl mercury, alkyl- and dialkyl mercury). Toxicity, solubility, reactivity and bioavailability of mercury are dependent on the specific form. Microbial processes are able to transform mercury into more or less toxic, volatile, bioaccumulative or bioavailable forms. Examples are the microbially mediated reduction of $\mathrm{Hg}^{+2}$ to $\mathrm{Hg}^{0}$, the degradation of organic mercury, the oxidation of $\mathrm{Hg}^{0}$ to $\mathrm{Hg}^{+2}$, and mercury methylation.

Elemental mercury is slightly soluble in water $(\sim 60 \mathrm{ppb})$ and has a higher solubility in liquid aliphatic hydrocarbons (to 1-3 ppm, or 1,000-3,000 ppb). It therefore will preferentially partition to the hydrocarbon phase of a hydrocarbon/water system. Elemental mercury is considered to be the most represented form of mercury in oil: it is volatile, reactive and highly adsorptive on metallic surfaces and on sand formation solids. Ionic mercury will preferentially partition to the water phase. Complexed ionic $\mathrm{Hg}$ is believed to be a minor component of $\mathrm{Hg}$ in oil but is expected in aqueous systems. Organic mercury, highly soluble in hydrocarbons, can be found in oil in different concentrations depending on the compound and oil origin. For example, methyl mercury is reported to be a trace component of oil hydrocarbons, whereas asphaltene-complexed $\mathrm{Hg}$ can be a major component of some crudes (Wilhelm and Bloom, 2000).

Total mercury concentrations may be comprised of dissolved forms and particulate mercury. Dissolved mercury is mostly represented by elemental mercury and ionic halides, while particulate mercury - believed to be the dominant species in oil - may be represented by micron- to nano-sized $\mathrm{HgS}$ particles, possibly colloidal (ibid). Additionally, elemental mercury particles may be formed when drops in temperature occur, thereby reducing $\mathrm{Hg}^{0}$ solubility and causing it to precipitate (WERF, 2009). Studies have reported that the efficiency of municipal wastewater treatment plants at reducing the concentration of mercury in the effluent is directly related to their efficiency at controlling total suspended solids (WERF 2009).

The pilot-scale testing of two technologies: reactive filtration from Blue Water Technologies and UF membrane process from GE (ZeeWeed® 500) started in May and ended in September 2011. During this period of time, the mercury concentration in the wastewater varied from less than the quantification limit $(0.5 \mathrm{ppt})$ to $24.2 \mathrm{ppt}$. The mercury profile is illustrated in figure 5.1, which shows that for the majority of sampling events, the mercury concentrations were less than $10 \mathrm{ppt}$. It appears that there are three periods where mercury concentration exhibited spikes (around June $10^{\text {th }}$, July $14^{\text {th }}$, and August $9^{\text {th }}$ ) with peak values of 24.2, 23.2, and 21.5 ppt. For the majority of sampling events, no dissolved mercury is found. These analytical results agree with what had been observed in Module 3. In addition, a plot of the influent TSS vs. influent mercury 
concentration is shown in figure 5.2. Figure 5.2 suggests that generally the influent mercury concentration increased with the increase in TSS.

The mercury concentration fluctuation is more evident through composite sampling, which is shown in table 5.1. Table 5.1 shows the untreated wastewater mercury concentration analyses for two composite sampling events. The standard deviation is about $50 \%$, indicating high degree of fluctuation in the influent mercury concentrations. Such fluctuation is more evident if the results from two consecutive composite sampling events are considered. Event one results in a mean mercury concentration of $1.51 \mathrm{ppt}$ with maximum of $2.02 \mathrm{ppt}$ and minimum of $0.93 \mathrm{ppt}$. For event two, average is $1.05 \mathrm{ppt}$ with maximum of $2.22 \mathrm{ppt}$ and minimum of $0.5 \mathrm{ppt}$. These results clearly show high variability in influent mercury concentration. Therefore, in this report, only the absolute concentration is reported, but not the percentage removals. 


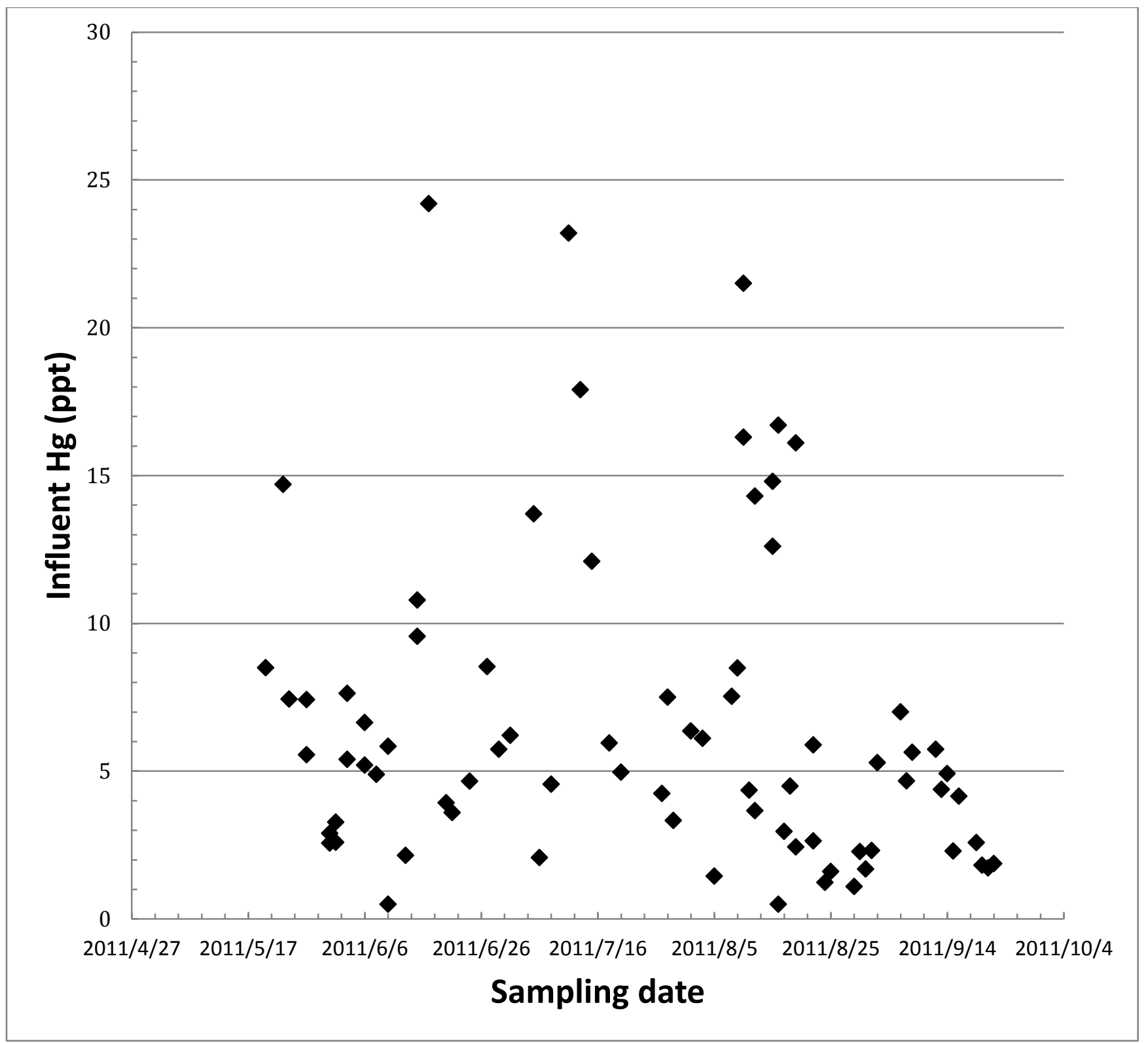

Figure 5.1: Mercury profile of the wastewater tested in this study 


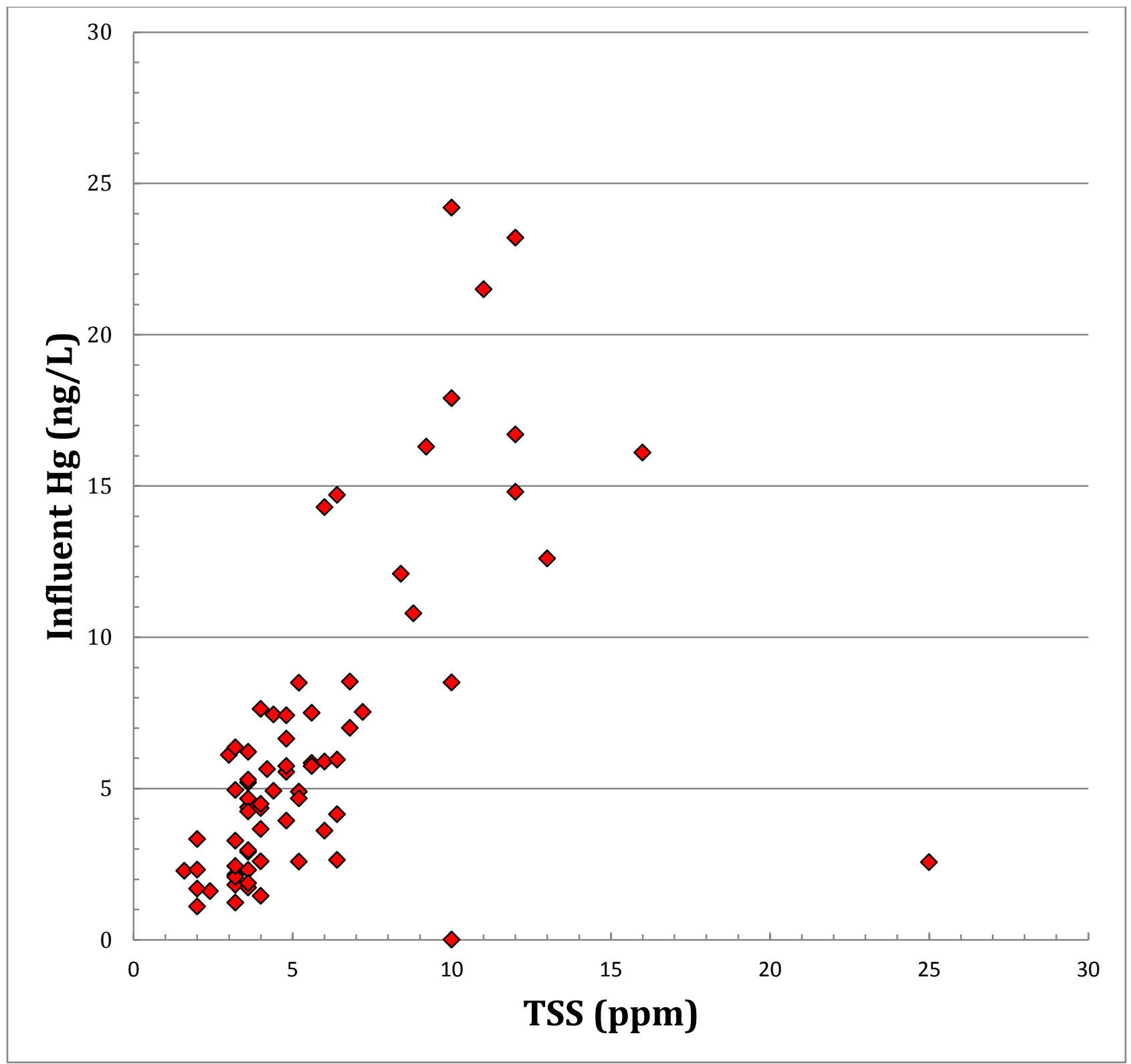

Figure 5.2: Correlation between the TSS and mercury concentration in the untreated wastewater 
Table 5.1: Two composite analyses of mercury concentration in the untreated wastewater

\begin{tabular}{|l|l|l|l|}
\hline Sample & Collection Time & Total Hg & Dissolved Hg \\
(ppt) & (ppt) \\
\hline 1 & $9: 20-11: 20$ & 0.929 & $<0.5$ \\
\hline 2 & $12: 20-14: 20$ & 1.2 & $<0.5$ \\
\hline 3 & $15: 20-17: 20$ & 2.02 & $<0.5$ \\
\hline 4 & $18: 20-20: 20$ & 1.33 & $<0.5$ \\
\hline 5 & $21: 20-23: 20$ & 1.51 & $<0.5$ \\
\hline 6 & $0: 20-2: 20$ & 1.11 & $<0.5$ \\
\hline 7 & $3: 20-5: 20$ & 0.985 & $<0.5$ \\
\hline 8 & $6: 20-8: 20$ & 3 & $<0.5$ \\
\hline \multirow{2}{*}{9} & Composite 1-8 & 1.49 & $<0.5$ \\
\hline & & 1.51 & $<0.5$ \\
\hline & Avg. of 1-8 & $0.70(46 \%)$ & \\
\hline & Stdev. of $1-8$ & & \\
\hline
\end{tabular}




\begin{tabular}{|l|l|l|l|}
\hline Sample & Collection Time & $\begin{array}{l}\text { Total Hg } \\
\text { (ppt) }\end{array}$ & $\begin{array}{l}\text { Dissolved Hg } \\
\text { (ppt) }\end{array}$ \\
\hline 1 & $11: 15-13: 15$ & 0.5 & $<0.5$ \\
\hline 2 & $14: 15-16: 15$ & 0.66 & $<0.5$ \\
\hline 3 & $17: 15-19: 15$ & 0.575 & $<0.5$ \\
\hline 4 & $20: 15-22: 15$ & 0.873 & $<0.5$ \\
\hline 5 & $23: 15-1: 15$ & 0.789 & $<0.5$ \\
\hline 6 & $2: 15-4: 15$ & 2.22 & $<0.5$ \\
\hline 7 & $5: 15-7: 15$ & 1.34 & $<0.5$ \\
\hline 8 & $8: 15-10: 15$ & 1.44 & $<0.5$ \\
\hline \multirow{2}{*}{9} & Composite 1-8 & 2.07 & $<0.5$ \\
\hline & & 1.05 & $<0.5$ \\
\hline & Avg. of 1-8 & & \\
\cline { 2 - 4 } & & $0.58(55 \%)$ & \\
\hline
\end{tabular}




\section{2: Reactive Filtration: Blue PRO ${ }^{\circledR}$ Process by Blue Water Technologies Inc.}

\subsubsection{Background}

The reactive filtration process employed in this study is the Blue PRO $®$ process patented by the Blue Water Technologies Inc. According to the vendor it relies on the combinational effects of iron coprecipitation, adsorption, and filtration to remove dissolved as well as particulate species. The basic principles of this technology involve the in-situ formation of ferric hydroxide on the surface of carrier (sand particles), the adsorption of species to be removed to the ferric hydroxide layer, the dynamic flow of carriers that breaks the ferric hydroxide layer, and the aggregation of small particles because of the addition of polymer materials (Nalmet ${ }^{\circledR}$ by Nalco Inc.) The moving sand bed itself also contributes to the removal of particles.

The primary control parameters for the Blue $P R O \circledast$ process include: influent flow rate, reject flow rate, air flow rate, and chemical dose. Influent flow, reject flow, and according to vendor the air flow can be tailored to the flow rates, the removal needs, and the characteristics of the wastewaters at individual sites but they typically have optimized values that do not change significantly. The use of chemicals and their doses are determined for each site individually based on local water chemistry. Chemical optimization for the Blue $\mathrm{PRO} \circledast$ process consists of varying the iron chemical dose along with any polymers employed to create the proper hydrous ferric oxide sand coating to achieve the desired discharge limits and to maintain a low iron residual in the effluent.

\subsubsection{Objective}

In this study, the Blue PRO $®$ process was tested in the continuous flow condition to evaluate the mercury removal performance of this technology and to determine whether under continuous flow condition, GLI criterion on mercury (1.3 ppt) could be consistently achieved.

\subsubsection{Experimental apparatus}

Blue Water Technologies Inc. provided a small package treatment system for the demonstration consisting of a two CF7 filters in series. This package plant was capable of $24 \mathrm{gpm}$ average flow for treatment of wastewater. Equipment for the pilot project at BP's Whiting refinery included two separate Centra- $\mathrm{flo}^{\mathrm{TM}}$ continuous backwash filters with cross-sectional filtration area of $7 \mathrm{ft} 2$ (CF-7). The sand bed depth within the filters was 60 inches. The pilot filters were configured with containerized control systems, influent water pumps, air compressor, chemical containment, chemical pumps, and various meters, valves and appurtenances. The experimental setup was illustrated in figure 5.3. 


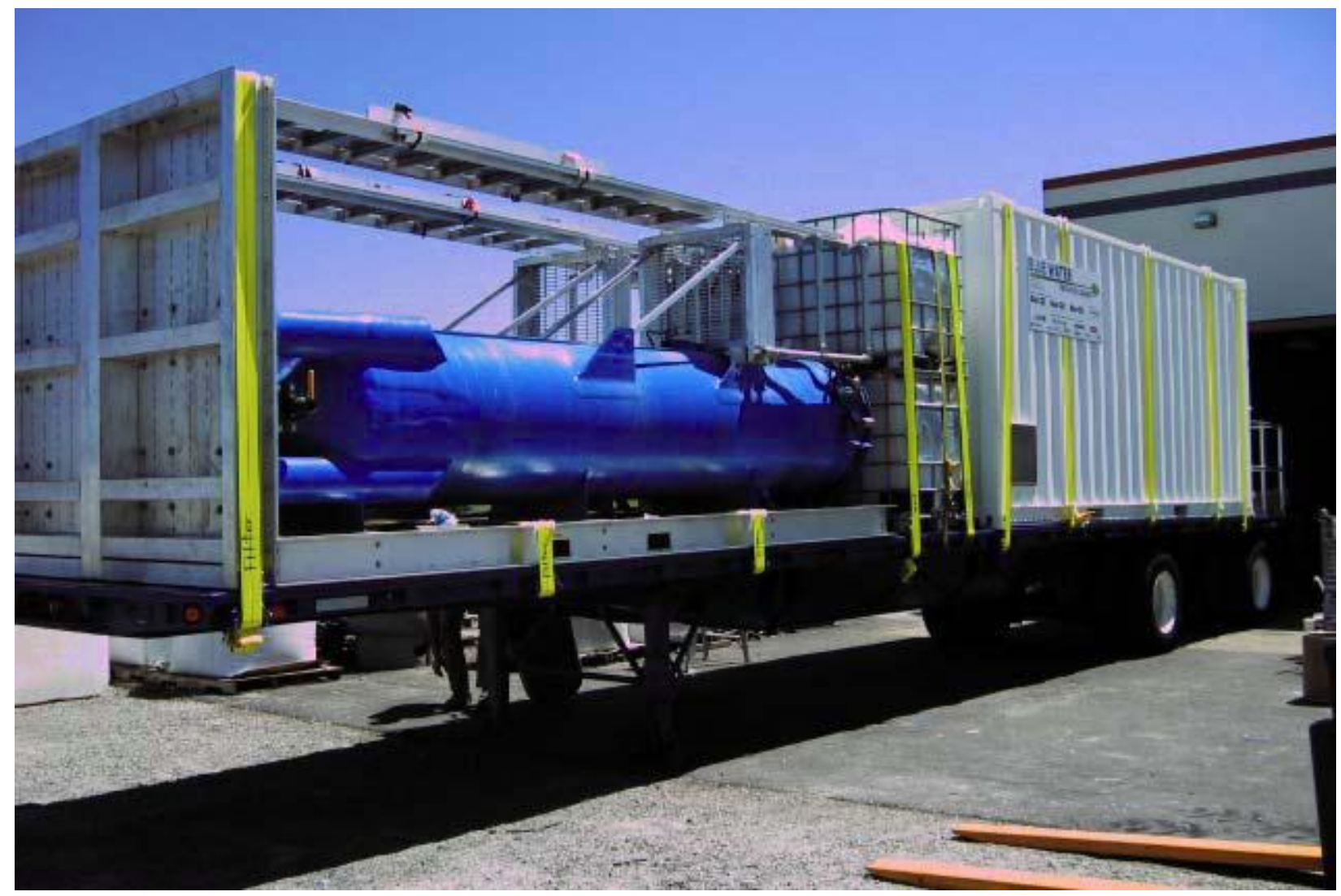

Figure 5.3: Experimental apparatus for the reactive filtration pilot-scale testing (Permission to use photograph granted by Blue Water Technologies Inc.)

\subsubsection{Experimental procedure}

The treated effluent from BP Whiting Refinery (feed) was pumped into the first tower at the bottom as the feed at a desired flow rate. Part of the feed was rejected by the first tower and the rest effluent entered the second tower as the feed for the second tower. Each tower typically rejected small portion of the flow, the actual value was adjusted according to the influent flow rates and the head losses. If there is addition of chemicals, they can be either injected into the first tower or both towers.

The average hydraulic loading rate for the Blue PRO® process is $3.5 \mathrm{gpm} / \mathrm{sq}-\mathrm{ft}$, corresponding to about $24 \mathrm{gpm}$ for the pilot system. The hydraulic load may be increased for short periods depending on the needs and/or the stringency of the site's permit regarding performance excursions. Depending on solids content of the process stream, a maximum loading rate of $5 \mathrm{gpm} / \mathrm{sq}$-ft is allowed to maintain filtration standards, corresponding to roughly $35 \mathrm{gpm}$ for the pilot system. The loading may be decreased to a minimum flow rate necessary to maintain operation of the continuous backwash cycle, or since the filters are installed in a modular fashion, individual filters in a Blue PROß system may be shut off intermittently for low flow periods. The waste reject flow rate during pilot 
operations is typically $7-25 \%$ of the forward process flow, corresponding to roughly 6 gpm for both of the pilot filters. Blue Water Technologies Inc. stated that the smaller pilot-scale filters are designed for an average flow between 10 and 35 gpm and proportionally reject more flow than full-scale installations due to limitations in scale-down efficiencies and hydrodynamics. According to Blue Water Technologies, at full-scale the waste reject from the filters is reduced to approximately $7 \%$ of the forward flow for a single pass system. Less water may be rejected depending on the performance requirements for any given installation. The reject water may be returned to the front of the plant, either before the primary or secondary systems. Blue Water Technologies' recommendation for the reject is to recycle the reject to the front of the plant.

When ferric chemical is employed for the Blue PRO® process, the dose is typically low, averaging 8-10 mg/L as Fe. Such low enough ferric iron usage ensures that $\mathrm{pH}$ adjustment is rarely necessary.

\subsubsection{Results and discussion}

\subsubsection{Mercury removal performance}

While the Blue PRO® process tested in this study was based on ferric hydroxide coprecipitation/adsorption, in the early stage of the testing, merely operating the system with bare sand and no ferric addition met the mercury GLI criterion of $1.3 \mathrm{ppt}$. Therefore, during the entire pilot-scale testing, no ferric addition was administrated in order to simplify the operation. The first and last sampling event for the reactive filtration occurred on May $20^{\text {th }}$ and August $22^{\text {nd }}$, respectively.

The operation of the reactive filtration pilot-scale system could be divided into two stages: in the first stage, no chemical was used; in the second stage, polymer Nalmet $\AA$ was injected to both towers. The addition of Nalmet $\AA$ started on August $3^{\text {rd }}$, which represented the beginning of the second stage. The addition of Nalmet $\AA$ was deemed necessary because at the end of the first stage, the mercury concentration of the effluents were measured to be above the quantification limit ( $0.5 \mathrm{ppt})$. In several occasions, they were over the GLI criterion of 1.3 ppt (2.74 ppt on July $11^{\text {th }}, 4.08$ ppt on July $13^{\text {th }}$, and 2.42 ppt on July $15^{\text {th }}$ ). Apparently, at the end of the first stage, mercury breakthrough occurred. Such breakthrough could not be tolerated. Therefore, Nalmet $®$ was used to evaluate its effects on mercury removal performance. Experimental results showed that during the last 20 days of testing, mercury concentration in the effluent consistently met the mercury GLI criterion of $1.3 \mathrm{ppt}$. Mercury analyses on the influent, effluent, and reject streams are listed in table 5.2 together with the corresponding flow rates. During the operation, only influent and reject flow rates are recorded. Therefore, the effluent flow rate is calculated, which is the difference between influent and reject flow rates. Several data points in table 5.2 are in red color and highlighted with yellow to emphasize the fact that while the rest of the 
sampling events for the Blue $\mathrm{PRO} 囚$ process result in below quantification limit of mercury in the effluent, several occasions occur that mercury concentrations in the effluent of the unit exceed the quantification limit and three of them are above the mercury GLI criterion of $1.3 \mathrm{ppt}$.

Figures 5.4 and 5.5 show the effluent and reject mercury concentration as a function of the influent mercury concentration, respectively. Figure 5.4 (redline signifies the targeted mercury GLI criterion of $1.3 \mathrm{ppt}$ ) clearly shows that while for the majority of the testing, the mercury GLI criterion of 1.3 ppt is met, there are three exceptions. Figure 5.5 on the other hand, shows although the reject mercury concentration generally increases with the increase in influent mercury concentration, the data points are scattered (especially for influent concentration above $10 \mathrm{ppt}$ ), statistical correlation is not clear.

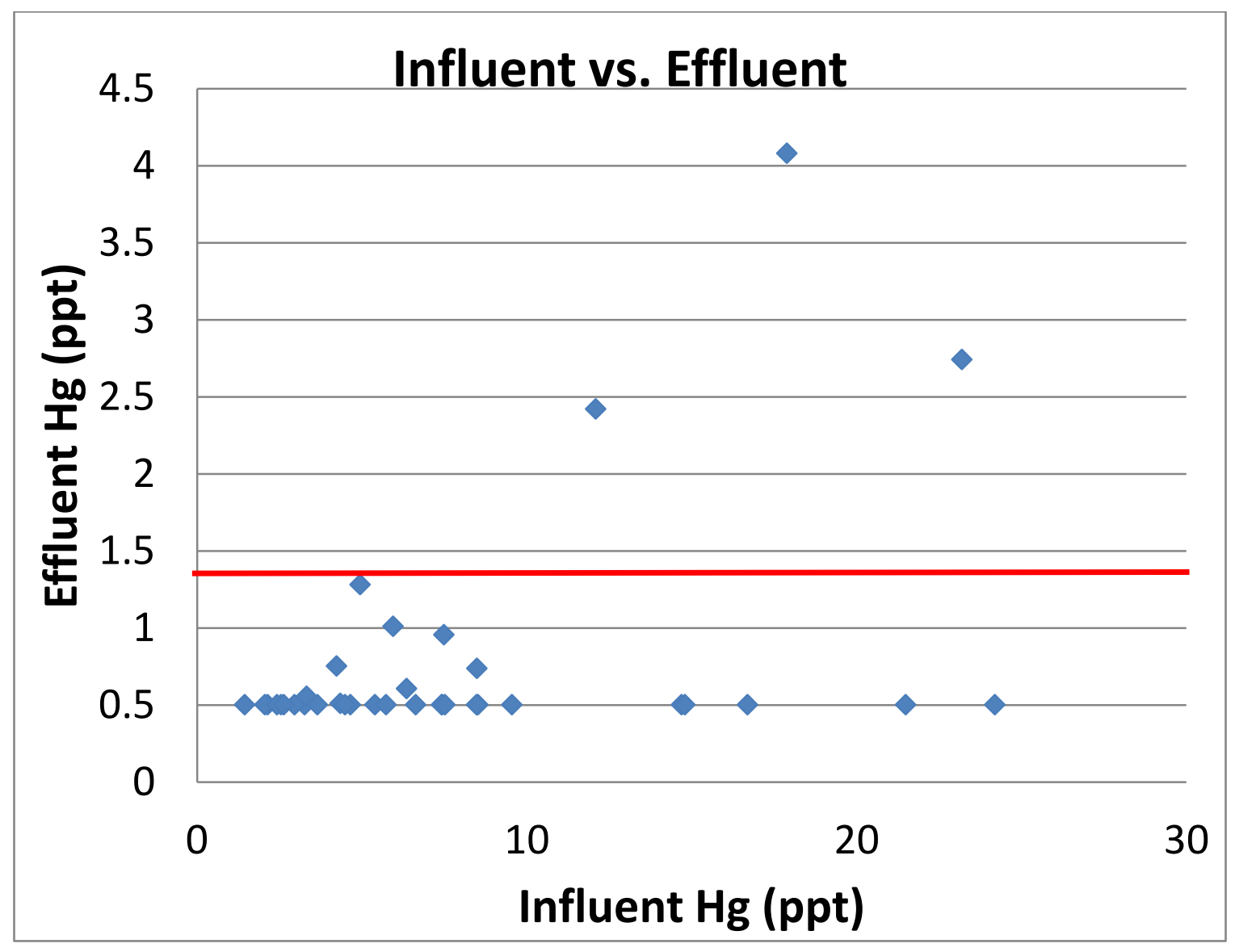

Figure 5.4: Effluent mercury as a function of influent mercury 


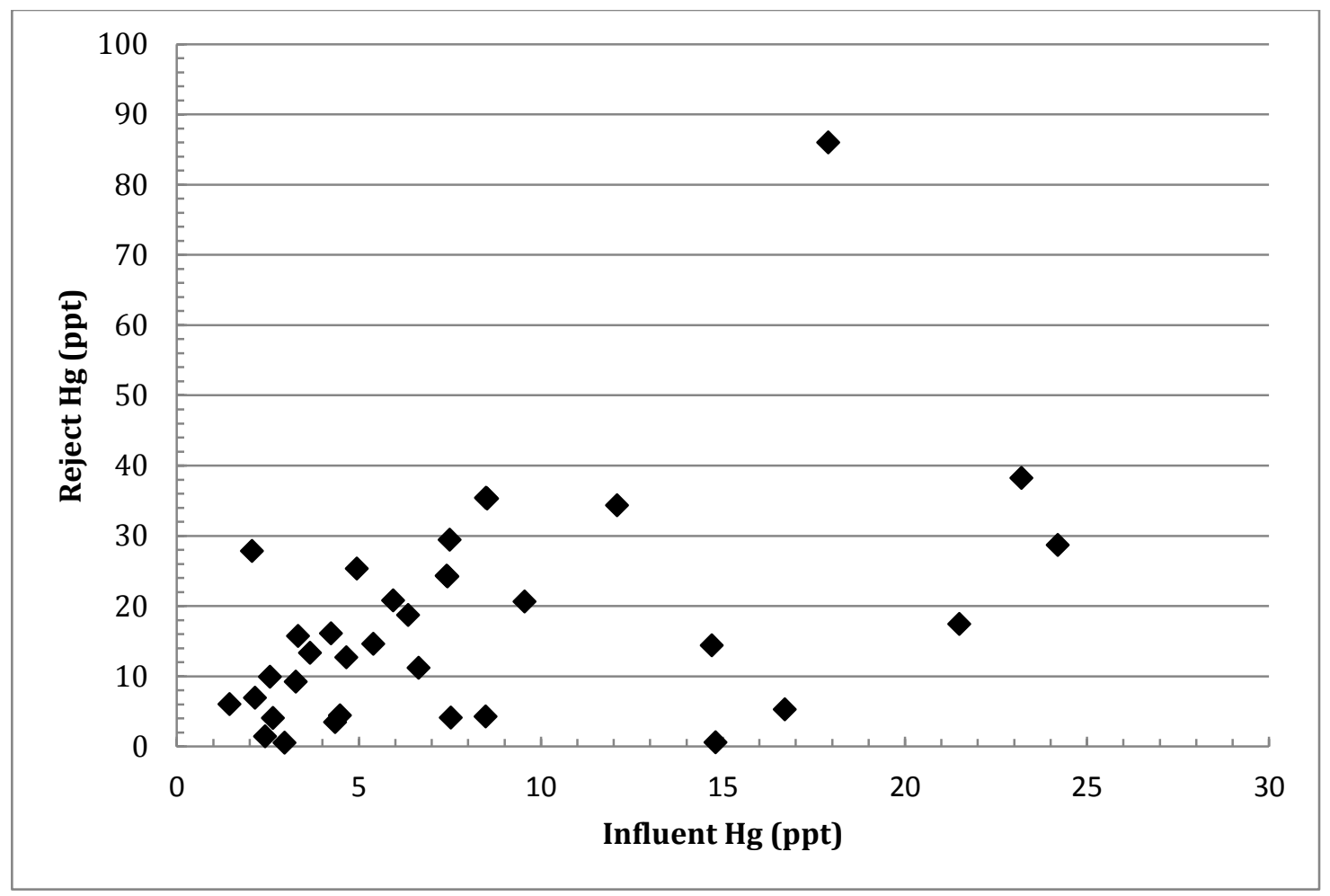

Figure 5.5: Reject mercury as a function of influent mercury

Table 5.2: Tabulation of flow rates and mercury concentrations

\begin{tabular}{|c|c|c|c|c|c|c|}
\hline \multirow{2}{*}{$\begin{array}{l}\text { Sample } \\
\text { Date }\end{array}$} & \multicolumn{2}{|c|}{ Influent } & \multicolumn{2}{|c|}{ Effluent } & \multicolumn{2}{|l|}{ Reject } \\
\hline & $\begin{array}{l}\text { Flow } \\
\text { (gpm) }\end{array}$ & $\begin{array}{l}\mathrm{Hg} \\
\text { (ppt) }\end{array}$ & $\begin{array}{l}\text { Flow } \\
\text { (gpm) }\end{array}$ & $\begin{array}{l}\mathrm{Hg} \\
\text { (ppt) }\end{array}$ & $\begin{array}{l}\text { Flow } \\
\text { (gpm) }\end{array}$ & $\begin{array}{l}\mathrm{Hg} \\
\text { (ppt) }\end{array}$ \\
\hline $05 / 20$ & 21 & 8.5 & 14 & 0.74 & 7 & 35.4 \\
\hline $05 / 23$ & 22 & 14.7 & 16.2 & $<0.5$ & 5.8 & 14.4 \\
\hline $05 / 24$ & $11-14$ & 7.44 & NA & $<0.5$ & NA & 24.2 \\
\hline $05 / 27$ & 22 & 7.42 & NA & $<0.5$ & NA & 24.3 \\
\hline $05 / 31$ & 21.8 & 2.56 & NA & $<0.5$ & NA & 9.89 \\
\hline $06 / 01$ & 21.9 & 3.27 & 15.3 & $<0.5$ & 6.6 & 9.20 \\
\hline $06 / 03$ & 21.7 & 5.4 & 15.5 & $<0.5$ & 6.2 & 14.6 \\
\hline $06 / 06$ & 21.8 & 6.64 & 15.4 & $<0.5$ & 6.4 & 11.2 \\
\hline
\end{tabular}




\begin{tabular}{|l|l|l|l|l|l|l|}
\hline $06 / 10$ & 21.5 & 8.86 & 15.74 & $<0.5$ & 5.76 & 25.2 \\
\hline $06 / 13$ & 21.7 & 2.15 & 15.12 & $<0.5$ & 6.58 & 6.91 \\
\hline $06 / 15$ & 22.3 & 9.56 & 15.93 & $<0.5$ & 6.37 & 20.6 \\
\hline $06 / 17$ & NA & 24.2 & NA & $<0.5$ & NA & 28.7 \\
\hline $06 / 24$ & 27 & 4.66 & 21.4 & $<0.5$ & 5.6 & 12.7 \\
\hline $06 / 27$ & NA & 8.53 & NA & $<0.5$ & NA & 35.3 \\
\hline $06 / 29$ & 29.4 & 5.74 & 22.83 & $<0.5$ & 6.57 & NA \\
\hline $07 / 01$ & 29.4 & 6.21 & 22.81 & $<0.5$ & 6.59 & 30.5 \\
\hline $07 / 06$ & NA & 2.07 & NA & $<0.5$ & NA & 27.8 \\
\hline $07 / 11$ & NA & 23.3 & NA & 2.74 & NA & 38.2 \\
\hline $07 / 13$ & 28.8 & 17.9 & 21.08 & 4.08 & 6.82 & 86 \\
\hline $07 / 15$ & 28.6 & 12.1 & 21.01 & 2.42 & 6.69 & 34.3 \\
\hline $07 / 18$ & 28.8 & 5.95 & 22.2 & 1.01 & 6.8 & 20.8 \\
\hline $07 / 20$ & 28.8 & 4.95 & 22.18 & 1.28 & 6.62 & 25.3 \\
\hline $07 / 27$ & 24 & 4.24 & 17.94 & 0.753 & 6.06 & 16.1 \\
\hline $07 / 28$ & 25.5 & 7.5 & 19.92 & 0.956 & 5.58 & 29.4 \\
\hline $07 / 29$ & 23.2 & 3.33 & NA & 0.556 & NA & 15.7 \\
\hline $08 / 01$ & 26.5 & 6.36 & 20.15 & 0.605 & 6.35 & 18.7 \\
\hline $08 / 05$ & 25.6 & 1.45 & 19.43 & $<0.5$ & 6.17 & 6 \\
\hline $08 / 08$ & NA & 7.53 & NA & $<0.5$ & NA & 4.42 \\
\hline $08 / 09$ & 26.3 & 8.49 & 21.58 & $<0.5$ & 4.72 & 4.27 \\
\hline $08 / 10$ & 26.1 & 21.5 & 19.93 & $<0.5$ & 6.17 & 17.4 \\
\hline
\end{tabular}




\begin{tabular}{|l|l|l|l|l|l|l|}
\hline $08 / 11$ & 26.2 & 4.35 & 23.73 & $\mathbf{0 . 5 1 0}$ & 2.47 & 3.82 \\
\hline $08 / 12$ & 26.3 & 3.66 & 20.86 & $<0.5$ & 5.44 & 13.3 \\
\hline $08 / 15$ & 25.9 & 14.8 & 21.4 & $<0.5$ & 4.5 & 0.572 \\
\hline $08 / 16$ & 26.2 & 16.7 & 20.78 & $<0.5$ & 5.42 & 5.25 \\
\hline $08 / 17$ & 25.9 & 2.96 & 20.5 & $<0.5$ & 5.4 & $<0.5$ \\
\hline $08 / 18$ & 25.8 & 4.49 & 20.7 & $<0.5$ & 5.1 & 5.41 \\
\hline $08 / 19$ & 25.9 & 2.43 & 20.52 & $<0.5$ & 5.38 & 1.42 \\
\hline $08 / 22$ & 25.6 & 2.64 & 20.99 & $<0.5$ & 4.61 & 4.02 \\
\hline
\end{tabular}

\subsubsection{Potential mercury accumulation in the pilot-scale unit}

Since in most cases the effluent mercury concentration was below the quantification limit of the analytical method 1631E ( $0.5 \mathrm{ppt}$ ), the majority of mercury should exit the pilot unit through the reject stream. Assuming the effluent has negligible mercury content, the following equation would be true as long as there is no accumulation of mercury within the filters:

\section{$\frac{\mathrm{F}_{\text {in }}}{\mathrm{F}_{\text {reject }}} \approx \frac{\mathrm{C}_{\text {reject }}}{\mathrm{C}_{\text {in }}}$}

Where $F_{\text {in }}$ and $F_{\text {reject }}$ refer to the influent and reject flow rate (gpm), respectively and $C_{\text {in }}$ and $\mathrm{C}_{\text {reject }}$ are the influent and reject mercury concentration (ppt), respectively.

Figure 5.6 shows the plot of the ratios of $\mathrm{F}_{\text {in }} / \mathrm{F}_{\text {reject }}$ and $\mathrm{C}_{\text {reject }} / \mathrm{C}_{\text {in }}$ for different sampling events, whereby $F_{\text {in }} / F_{\text {reject }}$ and $C_{\text {reject }} / C_{\text {in }}$ represent mercury in and out, respectively. Idealy these two ratios should be comparable (when there is no mercury accumulation within the filters). However, large deviations are observed during the second stage (upon the injection of Nalmet ${ }^{\circledR}$ polymer starting August $3^{\text {rd }}$ ). Such observation suggests that there may be the occurrence of mercury accumulation within the unit. Therefore mercury balance calculation is performed according to equation 2 (where $\mathrm{F}_{\text {effluent }}$ and $\mathrm{C}_{\text {effluent }}$ refer to the flow rate and mercury concentration of the effluent, respectively) and the data were ploted in figure 5.7.

Ratio of $\frac{\text { Mercury }_{\text {out }}}{\text { Mercury }_{\text {in }}}=\frac{\mathrm{F}_{\text {reject }} * \mathrm{C}_{\text {reject }}+\mathrm{F}_{\text {effluent }} * \mathrm{C}_{\text {effluent }}}{\mathrm{F}_{\text {in }} * \mathrm{C}_{\text {in }}}$ 
Figure 5.7 clearly indicates that the mercury exiting through the reject stream could not balance the mercury entering in the influent stream for the second stage of testing. Therefore, we suspect mercury accumulation within the filters may have occurred within the filters.

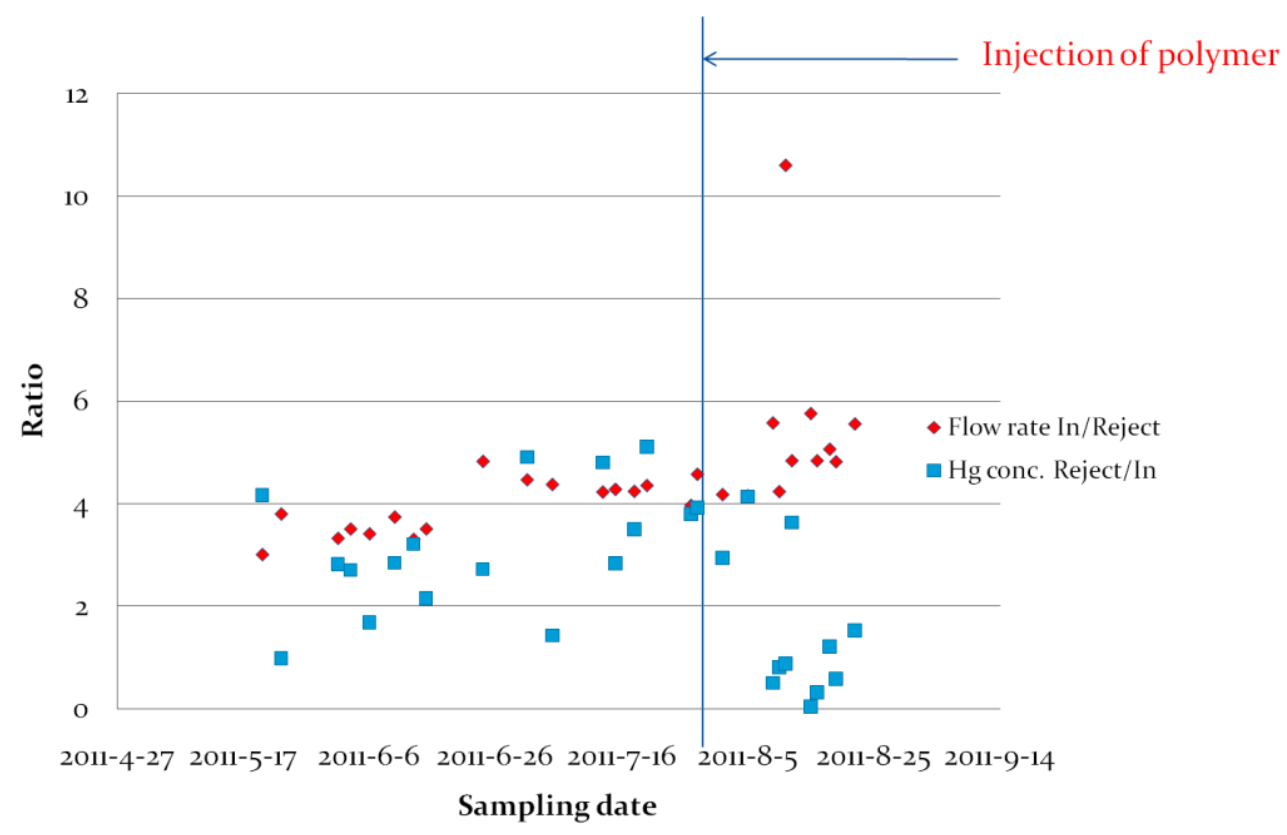

Figure 5.6: Comparing the mercury in and out of the pilot-scale unit

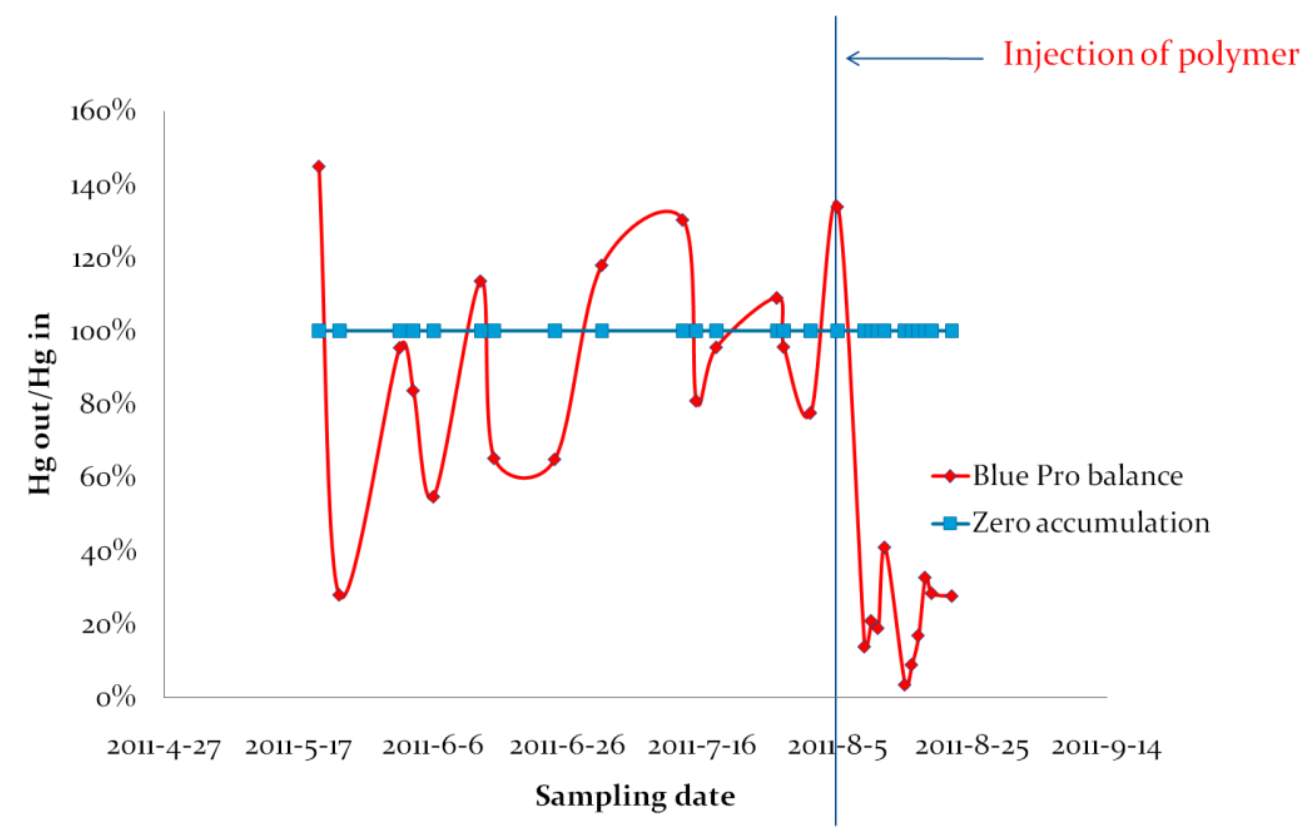

Figure 5.7: Caluating the ratio of mercury out/mercury in 


\subsubsection{Conclusion}

The Blue PRO $®$ Process (Blue Water Technologies Inc.) was tested at the pilot-scale in this study to remove the mercury from the wastewater treated effluents of the BP Whiting Refinery. The testing of this technology could be divided into two stages: the first stage of plain sand only and the second stage of adding polymer Nalmet ${ }^{\circledR}$. The majority of the sampling events during the first stage showed that the effluents from the unit were measured (using EPA approved Method 1631E for low mercury analysis) to be below the quantification limit $(0.5 \mathrm{ppt})$ and met the mercury GLI criterion (1.3 ppt). However, towards the end of the first stage, mercury breakthrough was evident and three consecutive sampling events showed mercury concentrations above $1.3 \mathrm{ppt}$. This determined that Nalmet ${ }^{\circledR}$ was added, which signified the beginning of the second stage. The sampling events during the second stage showed that the effluents were consistently meeting the mercury GLI criterion. However, after the addition of Nalmet ${ }^{\circledR}$, alternation in reject flow rates was observed, as shown in table 1.1. Before adding Nalmet ${ }^{\circledR}$, the total reject flow rate averaged at about $6.35 \pm 0.43 \mathrm{gpm}$; after adding Nalmet ${ }^{\circledR}$, it changed to $5.03 \pm 1.01 \mathrm{gpm}$ and on day August $11^{\text {th }}$ it fell to $2.47 \mathrm{gpm}$, well below the normal rate. Correspondingly, the mercury balance calculation showed that there exhibited tendencies for the mercury to accumulate within the pilot unit. It appeared that if only plain sands are used and the pilot unit is run for a short period of time (2-3 weeks), satisfactory mercury removal (in terms of meeting the mercury GLI criterion) could be expected. However, if the pilot unit is to run for an extended period of time (several months for example), mercury breakthrough (effluent contains mercury concentration exceeding the $1.3 \mathrm{ppt}$ ) may occur. Therefore, it is not possible to predict the long-term performance of this technology, based on the experimental results obtained in this study. Should the Blue PRO® Process be further considered, in order to assess the long-term performance, addition of chemicals such as ferric sulphate and/or Nalmet ${ }^{\circledR}$ may be needed and further testing over a long period of time is necessary. 


\section{3: ZeeWeed ${ }^{\circledR} 500$ Ultrafiltration Membrane Process by GE}

\subsubsection{Background}

Membrane filtration is considered as a promising technique for removing heavy metals from wastewater due to the short treatment time and high process capacity (according to literature survey). Experimental results for the bench-scale testing of UF membrane process during Module 3 showed that the effluent from the UF membrane process for discrete batches of wastewater tested in Module 3 consistently showed non-detectable in mercury concentration. Moreover, the mercury in the BP Whiting Refinery treated effluent was primarily in particulate form and physical barriers such as the UF membranes via a sieving mechanism based on the size of the membrane pores relative to that of the particulate matter would be a competitive candidate in the pilot-scale testing.

\subsubsection{Objective}

In this study, pilot-scale UF membrane process unit was tested under continuous flow condition to remove the mercury from BP Whiting Refinery treated effluent. The main goals were to confirm bench-scale performance to achieve concentrations less than $1.3 \mathrm{ppt}$ (ng/L) mercury, to demonstrate stable performance under continuous feed conditions and variable wastewater composition, to assist in understanding the implications for scale up to full-scale, to provide the data necessary (but not necessarily sufficient) for full-scale process design, to estimate residue generation rate, frequency of backwashing and waste disposal consideration (sustainability indices), and to identify and investigate treatability and utilization options for reject stream.

\subsubsection{Experimental apparatus}

GE Water \& Process Technologies supplied a pilot-scale ZeeWeed ${ }^{\circledR} 500$ system for this study, as illustrated in figure 5.8. The experimental setup was assembled by GE and the daily operation was performed by designated BP personnel. The characteristics of the ZeeWeed ${ }^{\circledR} 500$ membrane module is shown in table 5.3.

Table 5.3: ZeeWeed ${ }^{\circledR} 500$ Membrane Module characteristics

\begin{tabular}{|l|l|}
\hline Configuration & Outside-in hollow fiber \\
\hline Membrane material & PVDF \\
\hline Typical operating transmembrane pressure & -1 to $-12 \mathrm{psi}$ \\
\hline Maximum operating temperature & $40^{\circ} \mathrm{C}\left(104^{\circ} \mathrm{F}\right)$ \\
\hline
\end{tabular}




\begin{tabular}{|l|l|}
\hline Operating $\mathrm{pH}$ range & 5 to 9.5 \\
\hline
\end{tabular}

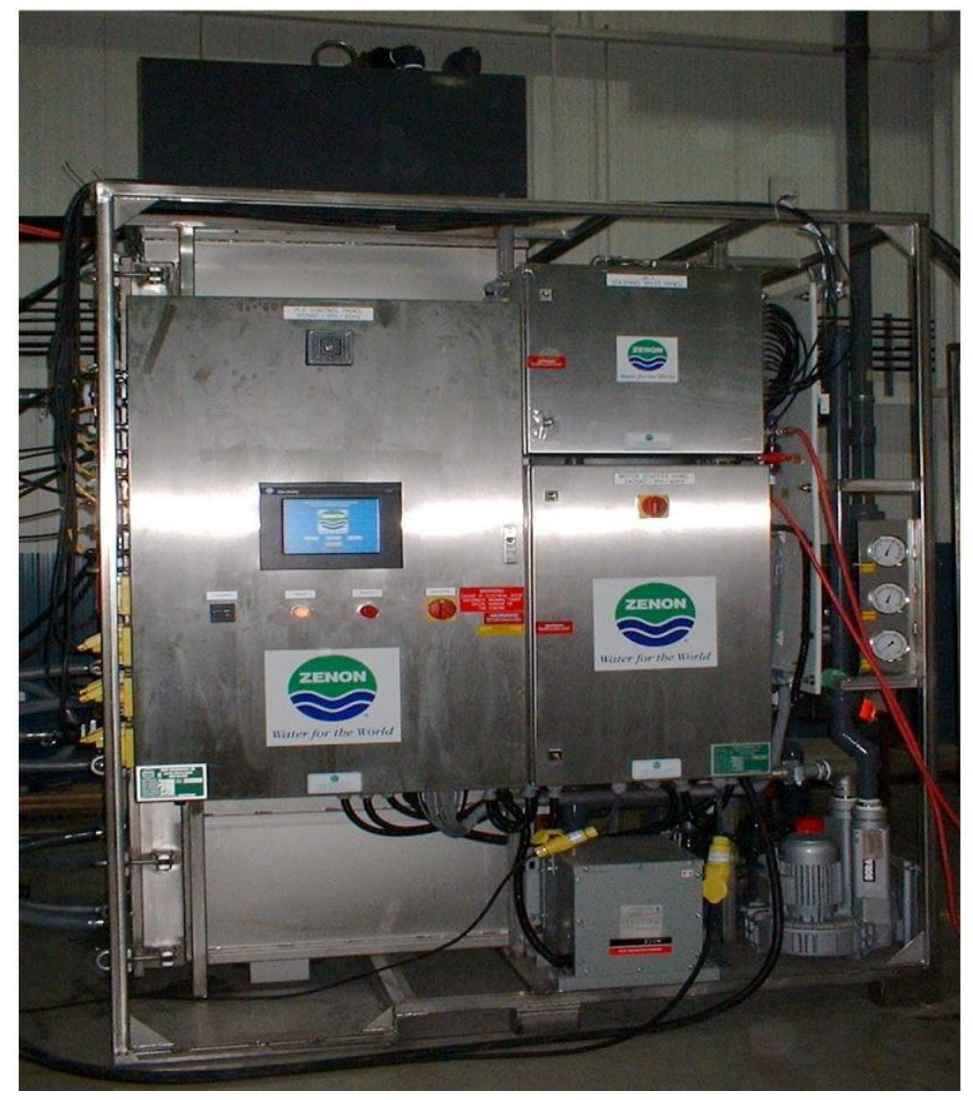

Figure 5.8: Pictogram of a typical pilot-scale GE ZeeWeed® 500 UF membrane filtration system (Permission to use photograph granted by GE Power \& Water)

\subsubsection{Experimental procedure}

The ZeeWeed ${ }^{\circledR} 500$ system is operated as a simple semi-batch process where filtration and backwash alternate in sequence. During the filtration cycle, permeate is withdrawn through the membranes by applying vacuum to the permeate piping. Simultaneously, a waste discharge stream is utilized to maintain a constant concentration of contaminants in the membrane tank and achieve a desired recovery. Water exiting the tank replaced with feed water to maintain a constant level in the tank. No aeration is used while in filtration mode. At the end of each filtration cycle (typically 15 - 30 minutes), a backwash is performed (typically for 10-20 seconds). During the backwash, the membranes are simultaneously aerated and backpulsed to dislodge solids. Solids are loosened from the surface of the membranes and suspended in the process tank due to the aeration. The filtration cycle then resumes.

\subsubsection{Results and discussion}




\subsubsection{Operational conditions}

The testing of the GE ZeeWeed® 500 UF membrane system could be divided into 4 phases, corresponding to different combinations of the permeate flux and the recovery rate. Two permeate fluxes $\left(\mathrm{F}_{A}\right.$ and $\mathrm{F}_{B}$ with $\left.\mathrm{F}_{\mathrm{A}}<\mathrm{F}_{B}\right)$ and three recovery rates $\left(\mathrm{R}_{1}, \mathrm{R}_{2}\right.$, and $\mathrm{R}_{3}$ with $\mathrm{R}_{1}<\mathrm{R}_{2}<\mathrm{R}_{3}$ ) were applied in this study. The reject flow rate was regulated so that for each permeate flux the desired recovery rate could be achieved. For all 4 phases, the transmembrane pressure (TMP) was generally kept constant and it was corrected from the actual operating temperature to $20^{\circ} \mathrm{C}$. The overall permeate flux and TMP remained fairly consistent with the desired values. Due to the failures of some parts and the mechanical difficulties during the testing, the pilot unit was down during late June and early August (total 47 days).

\subsubsection{Turbidity and Mercury reduction performance}

The turbidity profiles of the wastewater feed and the effluent for the pilot-scale system are illustrated in figure 5.9. The average turbidity of the feed and the effluent is about 2.1 NTU (95\% below $4.9 \mathrm{NTU}$ ) and $0.07 \mathrm{NTU}$ (95\% below $0.164 \mathrm{NTU}$ ), respectively. It is apparent that the UF membrane filtration process reduced the turbidity to very low levels.

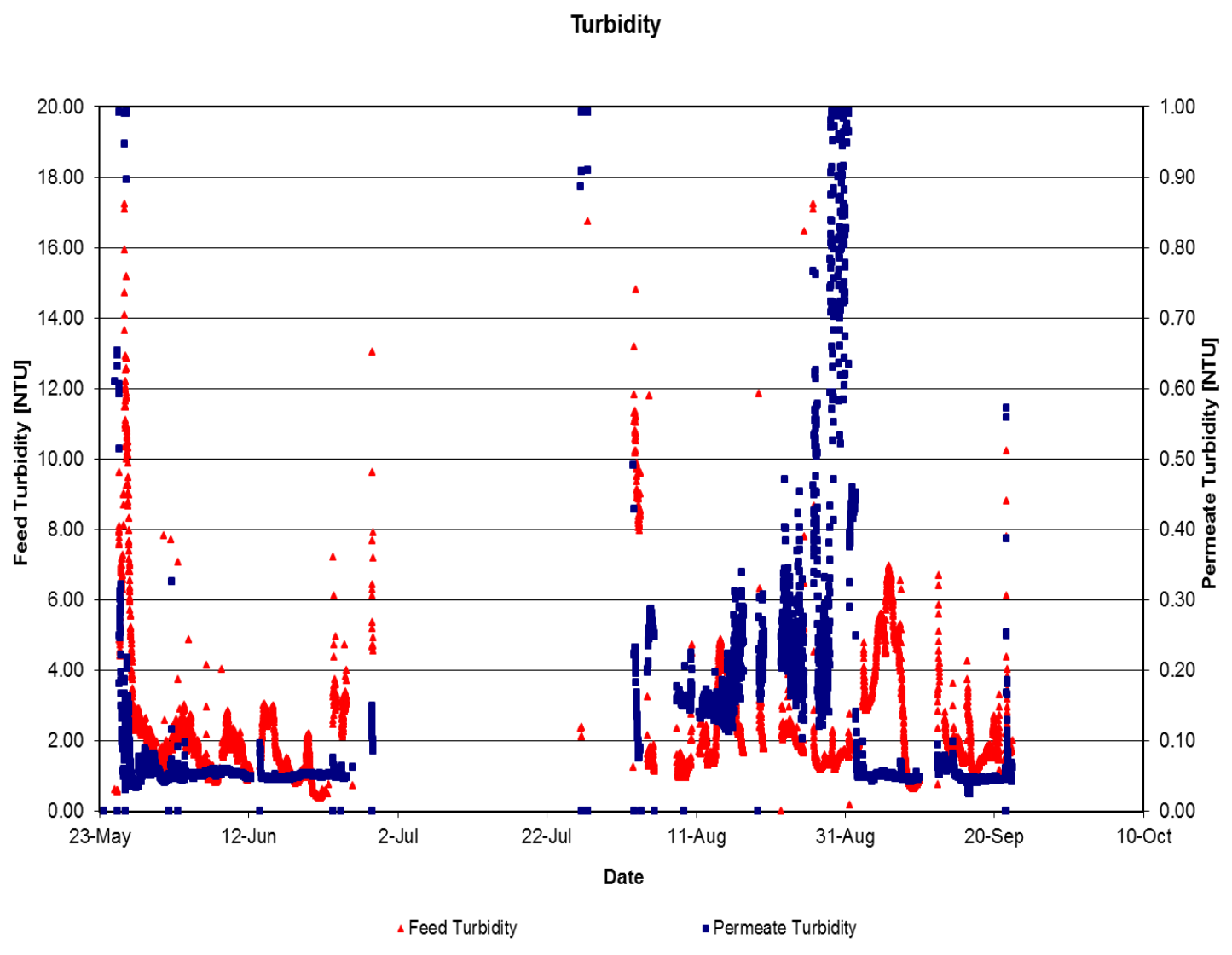


Figure 5.9: Comparison of the turbidities for the feed and the permeate

Table 5.4 lists the mercury concentrations of the feed, the permeate, and the reject streams for the various sampling events, illustrating the permeate mercury concentration as a function of the feed mercury concentration. Table 5.4 clearly shows that the permeate mercury concentration met the mercury GLI criterion of 1.3 ppt consistently (below the quantification limit $(0.5 \mathrm{ppt})$ for all the sampling events). These experimental results show that the GE ZeeWeed® 500 UF membrane system performed well in terms of meeting the GLI criterion during this test. Moreover, since the effluent mercury is very low (below quantification limit), the majority of the mercury should either exit the membrane system through the reject stream or accumulate in the filters. Figure 5.10 shows the reject mercury concentration as a function of the feed mercury concentrations. Data depicted in figure 5.10 indicate that the reject mercury concentration is generally proportional to that of the influent and the slopes are consistent with the recovery percentages. However, in order to determine whether or not accumulation of mercury occurs in the filters, mercury balance taking into account of the flow rates for the entire testing period should be carried out. Due to the high degree of fluctuation in influent mercury concentrations, such a mercury balance was not carried out. Also figure 5.10 appears to indicate that the permeate flux rate would not have noticeable impact of the correlation between reject and influent mercury concentrations.

Table 5.4: Summary of the mercury concentrations of the feed, permeate, and reject streams

\begin{tabular}{|l|l|l|l|}
\hline \multirow{2}{*}{$\begin{array}{l}\text { Sampling } \\
\text { date }\end{array}$} & \multicolumn{3}{|l|}{$\mathrm{Hg}(\mathrm{ppt})$} \\
\cline { 2 - 4 } & Influent & Effluent & Reject \\
\hline $05 / 26$ & 19.3 & $<0.5$ & 162 \\
\hline $05 / 27$ & 5.55 & $<0.5$ & 71.2 \\
\hline $05 / 31$ & 2.9 & $<0.5$ & 39.4 \\
\hline $06 / 01$ & 2.59 & $<0.5$ & 29.3 \\
\hline $06 / 03$ & 7.63 & $<0.5$ & 69.9 \\
\hline $06 / 06$ & 5.2 & $<0.5$ & 47.9 \\
\hline $06 / 08$ & 4.89 & $<0.5$ & 43.2 \\
\hline $06 / 10$ & 5.84 & $<0.5$ & 64.4 \\
\hline
\end{tabular}




\begin{tabular}{|c|c|c|c|}
\hline $06 / 15$ & 10.79 & $<0.5$ & 91.8 \\
\hline $06 / 20$ & 3.93 & $<0.5$ & 58.1 \\
\hline $06 / 21$ & 3.6 & $<0.5$ & 35.1 \\
\hline $08 / 03$ & 6.11 & $<0.5$ & 30.6 \\
\hline $08 / 10$ & 16.3 & $<0.5$ & 138 \\
\hline $08 / 12$ & 14.3 & $<0.5$ & 53.5 \\
\hline $08 / 15$ & 12.6 & $<0.5$ & 135 \\
\hline $08 / 19$ & 16.1 & $<0.5$ & 189 \\
\hline $08 / 22$ & 5.89 & $<0.5$ & 148 \\
\hline $08 / 24$ & 1.23 & $<0.5$ & 83.9 \\
\hline $08 / 25$ & 1.6 & $<0.5$ & 69.9 \\
\hline $08 / 29$ & 1.1 & $<0.5$ & 81.7 \\
\hline $08 / 30$ & 2.28 & $<0.5$ & 81.7 \\
\hline $08 / 31$ & 1.69 & $<0.5$ & 56.1 \\
\hline 09/01 & 2.31 & $<0.5$ & 33 \\
\hline $09 / 02$ & 5.29 & $<0.5$ & 57.5 \\
\hline $09 / 06$ & 7 & $<0.5$ & 207 \\
\hline $09 / 07$ & 4.67 & $<0.5$ & 133 \\
\hline $09 / 08$ & 5.03 & $<0.5$ & 174 \\
\hline $09 / 12$ & 5.74 & $<0.5$ & 123 \\
\hline $09 / 13$ & 4.38 & $<0.5$ & 169 \\
\hline $09 / 14$ & 4.92 & $<0.5$ & 81.4 \\
\hline $09 / 15$ & 2.3 & $<0.5$ & 84.8 \\
\hline $09 / 16$ & 4.15 & $<0.5$ & 314 \\
\hline
\end{tabular}




\begin{tabular}{|l|l|l|l|}
\hline $09 / 19$ & 2.58 & $<0.5$ & 291 \\
\hline $09 / 20$ & 1.82 & $<0.5$ & 274 \\
\hline $09 / 21$ & 1.72 & $<0.5$ & 101 \\
\hline $09 / 22$ & 1.87 & $<0.5$ & 64.2 \\
\hline
\end{tabular}

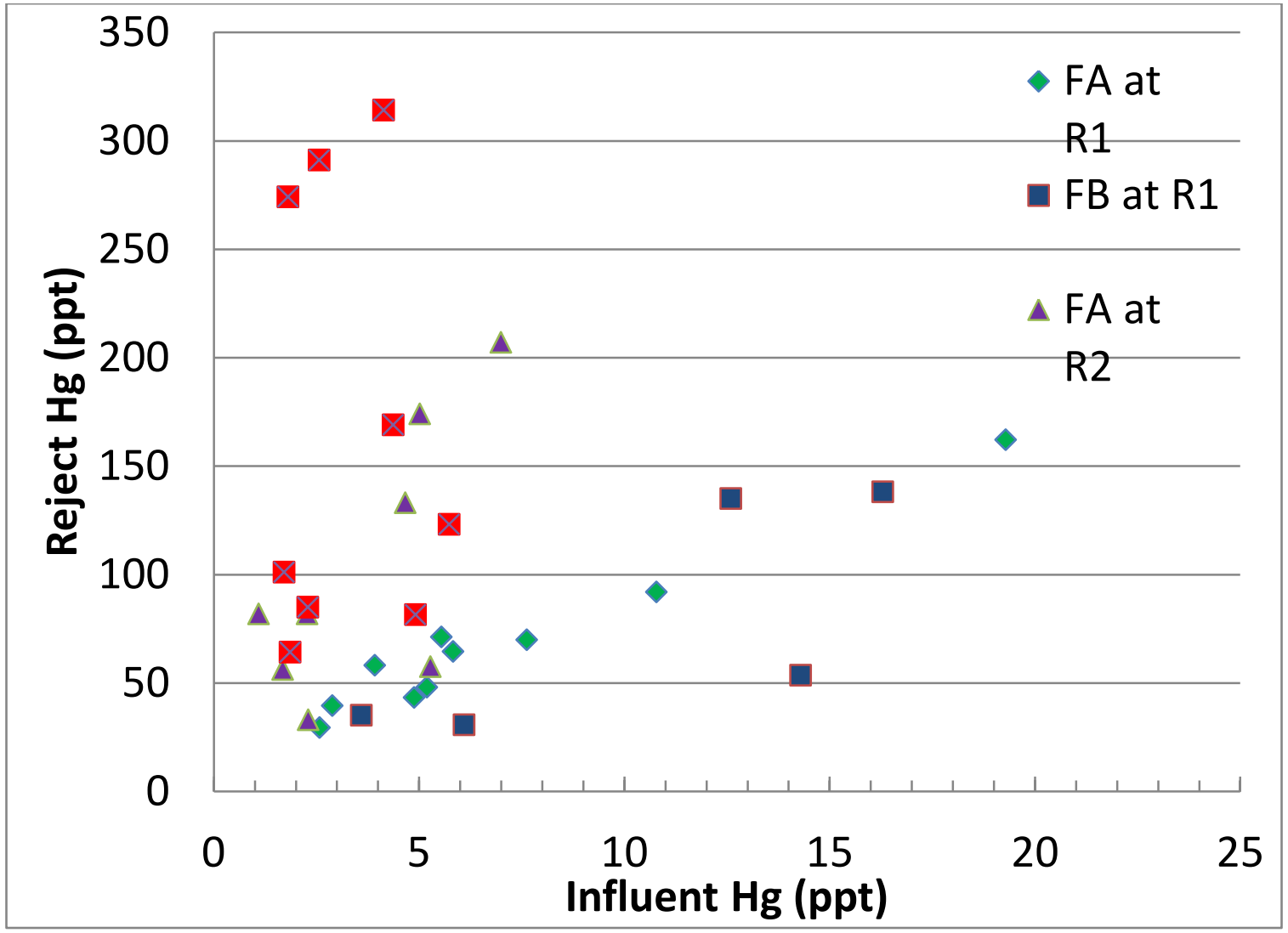

Figure 5.10: Reject mercury concentration as a function of that of the influent for various operating conditions (flow rate $\mathrm{F}$ and recovery $\mathrm{R}$ )

\subsubsection{Mercury on the hollow-fiber membrane}

After the pilot-scale testing of the GE ZeeWeed® 500 UF membrane filtration system, the hollow fiber membranes were disassembled and the mercury contents in the membranes were analyzed and the sample location and its corresponding mercury content were shown in figure 5.11. Data in figure 5.11 show that mercury content is found in the used membranes and the distribution of the mercury is fairly uniform along the vertical 
direction (which is parallel to the clean water flow direction). According to GE, the unused membranes were measured to have no mercury content (the minimum detection limit for the method used for mercury analysis by GE was however, relatively high in the ppb level and may not be actually none detectable at the ppt level). If the fiber mass is taken into account, however, the accumulated mercury on the fiber is about $20 \mathrm{ng} /$ fiber. Compared with the mercury exiting the system via the reject stream, the mercury accumulated on the fibers are negligible during the testing period. Nonetheless, additional long-term testing may be necessary to determine whether mercury may accumulate in the filters and whether a mercury breakthrough may occur in the long-run.

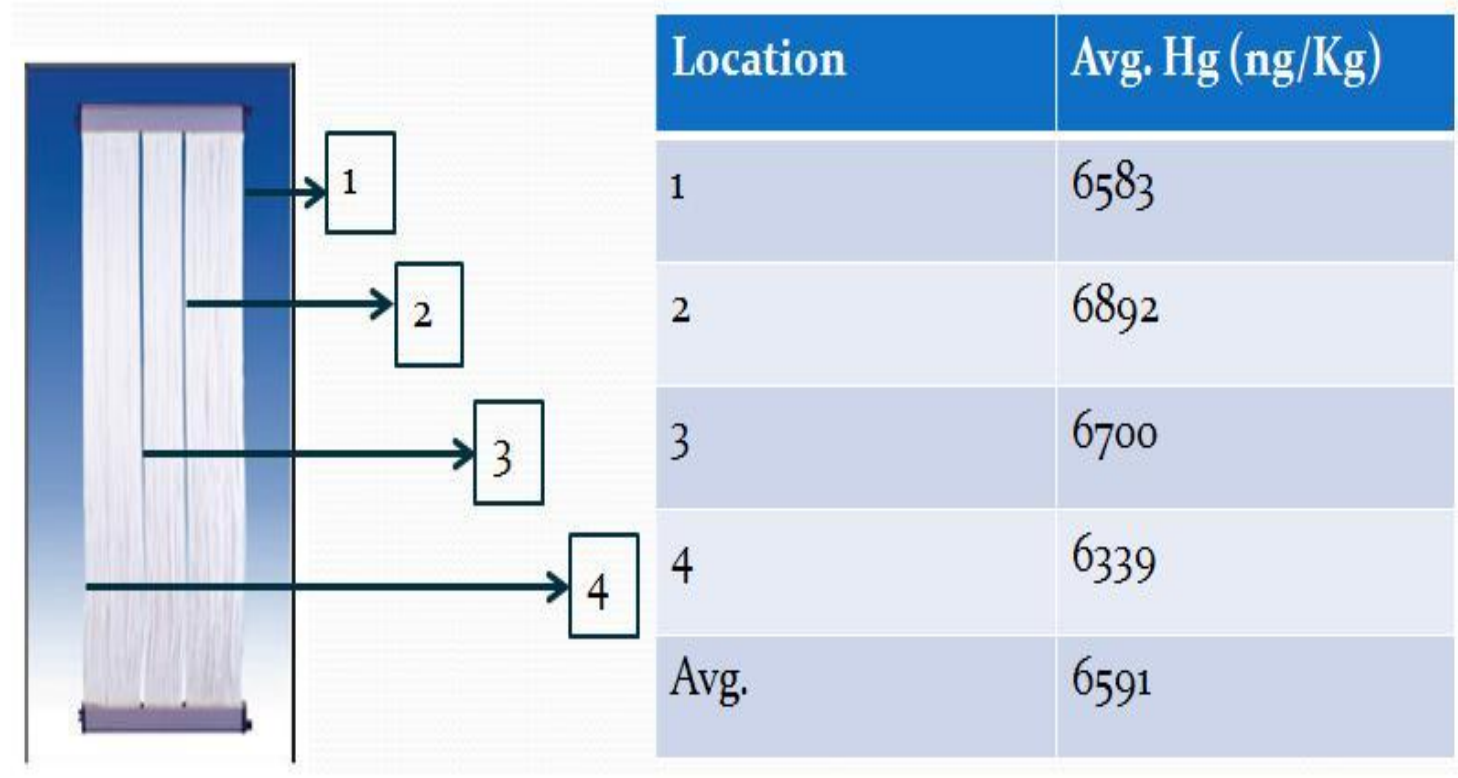

Figure 5.11: Analysis of the mercury content in the used membrane fibers (Permission to use photograph granted by GE Power \& Water)

\subsubsection{Conclusion}

Experimental results from the pilot-scale testing of the GE ZeeWeed ${ }^{\circledR} 500$ UF membrane filtration process showed that for the refinery treated effluent tested in this study, the UF membrane filtration consistently resulted in effluents (permeate) meeting the mercury GLI criterion of $1.3 \mathrm{ppt}$ during the duration of this study. However, it should be noted that the reject stream from the membrane system generally showed elevated mercury concentrations (although it should also be noted that they are still in the ppt range) and relatively high TSS values. Although it is preferred that the mercury goes to the reject stream and it was what appeared to have happened during this pilot-scale study, the reject stream may need additional handling before it can be properly disposed of. Some options of handling the reject stream include either recycle the reject stream to the front or employ 
secondary membrane filtration system to further concentration the reject stream should be evaluated so that solids and mercury in the reject stream may be disposed of via solid wastes. The concern over recycling the reject stream is that its high level of TSS may adversely affect the performance of the membrane system due to fouling. However, the handling of the reject stream for the GE UF membrane filtration technology was out of the scope of this work and should be addressed in full-scale. Overall, the GE ZeeWeed® 500 UF membrane system performed well during this study despite the unexpected downtimes. In order to determine the feasibility of this technology, however, additional long-term testing may be needed to determine whether or not mercury accumulation in the filters and mercury breakthrough may occur and in turn determine the life-span of the membranes. 


\subsection{Summary}

In this report, the experimental results from pilot-scale testing (under continuous flow condition) of two technologies: reactive filtration (Blue Water Technologies) and UF membrane filtration (GE ZeeWeed $囚 500$ ) were analyzed and summarized.

For the Blue PRO® Process from Blue Water Technologies Inc., when plain sand was used, the majority of the sampling events showed that the treated effluent can meet the mercury GLI criterion of 1.3 ppt but mercury breakthroughs (effluent mercury concentration exceeding $1.3 \mathrm{ppt}$ ) were observed. When polymer material Nalmet ${ }^{\circledR}$ was added, the effluents showed mercury concentrations typically below quantification limit ( $0.5 \mathrm{ppt})$. However, primitive mercury balance calculation indicated that there might be mercury accumulation occurring within the unit. Therefore, should this technology be further considered, additional long-term testing with the usage of polymer Nalmet $\AA$ and even iron reagents such as ferric sulphate would be needed to determine whether or not mercury breakthrough may occur.

For the ZeeWeed ${ }^{\circledR} 500$ UF membrane filtration system from GE, the permeate consistently showed mercury concentration below the quantification limit ( $0.5 \mathrm{ppt})$ and therefore met the mercury GLI criterion of $1.3 \mathrm{ppt}$. One concern is that reject stream has relatively high mercury concentrations and therefore may require additional treatment so that it could be properly disposed of. In addition, analyses of the used membrane fibers showed some mercury contents while mercury analysis on unused membrane fibers resulted nondetectable. Therefore, should this technology be further considered, additional long-term testing will be desired to determine whether or not mercury accumulation and mercury breakthrough may occur. 


\section{Module 4 Report Argonne and PUC Joint Summary and Conclusions}

The Great Lakes Initiative (GLI) established new water quality-based discharge criteria for mercury (Hg), thereby increasing the need for many municipal and industrial wastewater treatment plants (WWTPs) in the region to lower the mercury in their effluents. Information on deployable technologies to satisfy these requirements for industrial and municipal dischargers in the Great Lakes region is scarce. Therefore, BP funded Purdue University Calumet and Argonne to identify deployable Hg removal technologies to meet the future GLI discharge criterion at its Whiting Refinery in Indiana.

Module 3 bench testing of clarifier effluent samples from the Whiting refinery showed that some technologies were effective in removing particulate mercury while others were effective on dissolved mercury. One emerging technology was found to be effective on both particulate and dissolved mercury. Most of the mercury in the tested clarifier effluent was found to be associated with particulates, and very little mercury was found to be in the dissolved form, i.e. present after $0.45 \mu \mathrm{m}$ filtration ( 28 out of 29 samples met the $1.3 \mathrm{ppt}$ after $0.45 \mu \mathrm{m}$ filtration). Results from Module 3 also showed that particulate mercury removal was in most cases sufficient to enable the clarifier effluent to meet the proposed 1.3 ppt GLI mercury discharge criterion. However, historical data from the spring of 2009 showed that mercury in the dissolved form was present in the Whiting ETL at levels above non-detect levels ( $0.5 \mathrm{ppt}$ ) during 4 of 9 sampling events. In addition, 3 out of 9 samples were above 1.3 ppt. Hence, options were devised for wastewater treatment that would remove both particulate and dissolved mercury. Given these requirements, at the end of Module 3 three different technologies were chosen for further evaluation:

- Ultrafiltration (using GE ZeeWeed® Technology, $0.04 \mu \mathrm{m}$ pore size and made up of PVDF) for particulate mercury removal,

- Adsorption using Mersorb® LW, a sulfur-impregnated activated carbon, for dissolved mercury removal if present and

- The Blue PRO® reactive filtration process for both particulate and dissolved mercury removal.

In this project module, Argonne and Purdue conducted pilot-scale testing on two of the promising $\mathrm{Hg}$ removal technologies that were identified as a result of the bench-scale testing and technology evaluation done in Module 3. Ultrafiltration, an established technology with many full-scale applications in water and wastewater treatment as well as in membrane bioreactors, was tested for particulate mercury removal. Although activated carbon adsorption with Mersorb ${ }^{\circledR} \mathrm{LW}$, another established technology, was selected at the end of Module 3 for dissolved mercury removal, this technology was not pilot-tested 
because of a lack of dissolved mercury in the pre-ETL for the duration of the test period. An emerging technology, the Blue PRO® reactive filtration process, was also pilot tested because it combines several different processes that may be able to control both particulate and dissolved mercury at the same time.

The ultrafiltration and the Blue PRO® reactive filtration pilot studies were conducted simultaneously at the BP Whiting refinery using a slipstream of Effluent To Lake (ETL) taken just prior to the ETL outfall (hereafter referred to as pre-ETL to avoid confusion with ETL outfall). In preparation for the Blue PRO® pilot, some additional bench-scale testing was also conducted in this module to identify operating conditions that should be tested at the pilot-scale. It was the intention of this pilot testing to demonstrate proof of concept, i.e. can the discharge limits obtained at bench scale be consistently met at the pilot scale. Optimization for full-scale design was outside of the scope of this work. In addition to demonstrating whether the $\mathrm{Hg}$ criterion can be met, information on residue generation rate, frequency of backwashing and other maintenance issues were collected to better understand the implications for a full-scale system.

Key findings and achievements resulting from this project include:

\section{Wastewater Characterization}

- Pre-ETL samples throughout Module 4 confirmed what was seen during Module 3 bench-scale testing, namely, that the $\mathrm{Hg}$ in the BP Whiting refinery wastewater was primarily associated with particulates - very little dissolved $\mathrm{Hg}$ was measured during the test period.

\section{Ultrafiltration Pilot Study:}

- Both Argonne and Purdue have concluded that the UF membrane pilot unit consistently provided permeate that was less than $0.5 \mathrm{ppt} \mathrm{Hg}$, which met and exceeded the treatment target of $1.3 \mathrm{ppt}$ of $\mathrm{Hg}$. This permeate quality was consistently produced at all tested operating conditions and was independent of the feed water characteristics and feed Hg concentration. This confirms the bench-scale Module 3 findings that there is no fundamental physical or chemical barrier in achieving $<1.3 \mathrm{ppt} \mathrm{Hg}$ in the tested refinery wastewater at the pilot-scale at least under these testing conditions of little dissolved mercury in the pre-ETL $(<0.5-$ $1.05 \mathrm{ppt})$.

- Argonne's estimate of the full-scale cost varied between $\$ 39 \mathrm{M}-147 \mathrm{M}$ depending on the criteria used in cost calculations, such as land acquisition, engineering, site development, waste disposal, etc. It should be noted that the vendor did not provide a full-scale cost estimate, therefore this estimate was produced using literature data and methodologies. 
- Turbidity measurements were less than $0.5 \mathrm{NTU}$ (the turbidity measurement detection limit) $85 \%$ of the time. .

- The particle size and size distribution analysis conducted by Argonne on the permeate samples confirmed the excellent performance of ultrafiltration in removing particulates and consequently the particle-bound $\mathrm{Hg}$ from the feed.

- Transmembrane pressure (TMP) values were below the vendor's specification of (negative) 7-12 psi at all tested conditions during the pilot study.

- Weekly maintenance cleans with hypochlorite solution and the monthly CIP were very effective in consistently restoring the membrane permeability during the pilotstudy.

- Low membrane fouling rates ranging from $0.0125-0.05 \mathrm{psi} /$ day at $20^{\circ} \mathrm{C}$ resulted in an expected CIP cleaning interval of greater than 90 days when the unit was operated at a Flux A flux rate and X, Y and Z\% percent recoveries.

- The fouling rate increased $\left(0.836 \mathrm{psi} /\right.$ day at $\left.20^{\circ} \mathrm{C}\right)$ when the system was operated at a Flux B flux rate and X\% recovery, resulting in a corresponding expected cleaning interval of 14.4 days. Running the membrane at this higher flux rate did not impact the Hg removal performance, but it did impact the CIP cleaning interval of the membrane unit.

- Solids accumulation was noticed in the membrane unit at the conclusion of the pilot. While this accumulation did not affect the membrane performance, it did affect the mass balance closure since quantification was not possible.

- Purdue has interpreted that the used membrane fiber analysis showed an increase in mercury content (averaging $6500 \mathrm{ng} / \mathrm{kg}$ of membrane fiber). Purdue recommends that the source of the mercury content in the used membrane fibers be determined to ensure that no mercury accumulation on the fiber and/or breakthrough may occur. Argonne's interpretation of the analytical results is that very low levels of $\mathrm{Hg}$ were found on the membrane fibers at the end of the pilot ( $22.35 \mathrm{ng} /$ fiber), and hence $\mathrm{Hg}$ accumulation on the membranes was minimal $(0.7 \%$ of the total $\mathrm{Hg}$ fed) since the total amount of $\mathrm{Hg}$ fed to the membrane unit was estimated as $33.2 \mathrm{mg}$ during the pilot test.

- Testing is needed to determine treatment options for the full scale reject stream which collects and concentrates the mercury removed from the pre-ETL.

- In contrast to the technical success, the auxiliary operation (i. e. the support system to the pilot unit) was problematic. Although minor pilot unit shutdowns resulted in a gap in operation of less than 24 hours each time, addressing feed line related problems so that feed could be supplied to the unit at the required pressure took more than 30 days. This decreased the planned test duration, which was partially compensated by a test extension into September. 


\section{Reactive Filtration Pilot Study:}

- Both Argonne and Purdue have concluded that effluent from the $25 \mathrm{gpm}$ Blue PROß pilot met the $1.3 \mathrm{ppt} \mathrm{Hg}$ treatment goal $92.7 \%$ of the time during the 97 day pilot.

- Mercury breakthrough in the effluent was seen after 46 days of operation without chemical addition. This Hg breakthrough lasted for five consecutive days.

- Effluent quality after $\mathrm{Hg}$ breakthrough was restored when Nalmet ${ }^{\circledR} 1689$ was added to each filter's influent, however, the brevity of these test conditions (three weeks) prevent definitive conclusions from being made regarding long term effectiveness.

- Mercury accumulation was seen in the filter sand during Nalmet ${ }^{\circledR}$ addition, suggesting that the effluent quality may decline over long-term operation - the filter sand may have a finite capacity for Nalmet ${ }^{\circledR}$ and the associated $\mathrm{Hg}$ and this trial did not last long enough to determine when this capacity might be reached.

- Argonne's interpretation of the pilot data is that a full-scale Blue PRO® treatment system should have the equivalent of two filters in series, and Nalmet ${ }^{\circledR} 1689$ addition to the influent of each filter. Based on the vendor supplied equipment cost, the installed capital cost including equipment purchase and installation, instrumentation, construction and land acquisition would be approximately $\$ 21$ 38M. It should be noted that site-specific installation costs are needed to develop refined costs. This cost estimate also does not include the treatment and disposal costs for the reject stream since the vendor has recommended that this stream be recycled upstream; however the feasibility of doing so has not been evaluated.

- Optimization of the Nalmet ${ }^{\circledR} 1689$ dosage is needed to minimize treatment costs.

- Testing is also needed to determine how to manage the full-scale reject stream.

- In general, the unit operated well mechanically, running $91 \%$ of the time during the pilot. Of the 9 days of shutdown, 8 of the days were related to feed supply or sampling location modifications. Only 1 of the shutdown days was related to the process.

\section{Alternative option for consideration:}

- Another potential Hg treatment option that has arisen from testing the Blue PRO® process is Nalmet ${ }^{\circledR}$ addition before BP Whiting's sand filters. Although this has not been tested yet, if successful it would have a significantly lower installed capital cost. Although this option is outside of the scope of this work and has not been tested at the pilot scale, Argonne has suggested this as it is a simplification of the Blue PRO $®$ process, which successfully treated pre-ETL $92.7 \%$ of the time. Additionally, bench-scale testing with clarifier effluent using plain sand with Nalmet@ addition showed $99 \% \mathrm{Hg}$ removal with a $0.23 \pm 0.06$ ppt effluent. 
- Testing is needed to determine how to manage the full-scale backwash stream that will be generated from this process. Bench-scale testing on the reject stream is planned.

\section{Challenges and limitations during both pilot studies:}

- Statistically representative wastewater samples were difficult to obtain through grab sampling. This may be caused by the variability in wastewater composition as well as the heterogeneity of the wastewater samples caused by the presence of solids. To obtain a measure of variability, two days of composite sampling events for the ultrafiltration pilot were conducted. These two sampling events showed that the standard deviations were very high and ranged from 41.5 to $59 \%$ in feed and membrane backwash samples

- In consideration of this data, Argonne suggests that future pilot work should consider the use of grab samples for the rapid preliminary assessment of pilot performance and that these grab samples be supplemented with the use of composite sampling in order to obtain more representative samples and improved process analysis.

- Despite the technical success of both pilots, both Argonne and Purdue have some operational concerns. Further testing is needed to determine appropriate disposal of the ultrafiltration reject, which contains concentrated levels of $\mathrm{Hg}$. The accumulation of $\mathrm{Hg}$ in the Blue $\mathrm{PRO} 囚$ sand is also a concern. Argonne does not recommend further pilot testing of the Blue $\mathrm{PRO} \circledast$ process until the $\mathrm{Hg}$ accumulation in the sand issue is better understood.

In summary, Argonne and Purdue have concluded that both pilot technologies have demonstrated the ability to meet and exceed the treatment goal of $1.3 \mathrm{ppt} \mathrm{Hg}$ on a consistent basis during the 3 month simultaneous studies, maintaining the effluent quality despite variations in the pre-ETL feed. For this report, exceeding the treatment goal refers to pilot unit effluent that was $<0.5 \mathrm{ppt} \mathrm{Hg}$ (i.e. below the detection limit). For the ultrafiltration pilot, the effluent was $<0.5 \mathrm{ppt} \mathrm{Hg} 100 \%$ of the time while for the Blue PROß pilot the effluent was $<1.3 \mathrm{ppt} \mathrm{Hg} 92.7 \%$ of the time and $<0.5 \mathrm{ppt} \mathrm{Hg} 73 \%$ of the time. These proof of concept pilots demonstrated that there is no fundamental physical or chemical barrier in achieving $<1.3 \mathrm{ppt} \mathrm{Hg}$ in the tested refinery wastewater at the pilot-scale at least under these testing conditions of little dissolved mercury in the pre-ETL $(<0.5-1.05 \mathrm{ppt})$. Despite the technical success of both pilots, both Argonne and Purdue have some operational concerns. For the ultrafiltration process, Purdue is concerned with the downtime even though the majority of the downtime was not associated with the technology itself and suggests that the auxiliary system for the technology should be flexible and equipped to handle various feed conditions (such as feed pressure). However, Argonne disagrees with this conclusion since the pilot unit was down mostly due to the 
feed being supplied at too high of a pressure (more than 30 days). Both Purdue and Argonne have concluded that further testing is needed to determine appropriate disposal of the ultrafiltration reject, which contains concentrated levels of Hg. Bench-scale testing of reject treatment is planned. Purdue is recommending that the chronological change of the $\mathrm{Hg}$ on the used ultrafiltration membrane fibers be monitored, but the Hg content of the used membrane fibers is not a concern to Argonne since the total $\mathrm{Hg}$ accumulation is minimal based on the overall mass balance calculations on the membrane fibers. For the Blue PRO $®$ process, the accumulation of $\mathrm{Hg}$ in the sand is a concern for both Argonne and Purdue. Argonne does not recommend further pilot testing of the Blue PRO® process until the $\mathrm{Hg}$ accumulation in the sand issue is better understood. Purdue, on the other hand, recommends that if the Blue PRO® process is further considered, there should be additional long-term testing with Nalmet ${ }^{\circledR}$ polymer addition to determine whether or not mercury breakthrough will occur.

Based on the Module 4 pilot study test results, both PUC and Argonne recommend that a long term pilot study of ultrafiltration membrane technology be conducted at the Whiting Refinery. Purdue suggests that if the Blue $P R O \circledR$ process is further considered, long term testing of the Blue PRO ${ }^{\circledR}$ process with Nalmet ${ }^{\circledR}$ addition is needed to determine whether Hg breakthrough would occur. Argonne recommends that long term testing of the alternative option developed by Argonne, namely, Nalmet® 1689 addition prior to the sand filters, be conducted prior to any long term Blue PRO® testing. These long term pilot studies, together with a study of treatment options for concentrated reject and backwash streams, will help provide information needed for full-scale design and implementation of a Hg removal technology for BP-Whiting's ETL, hence will help BP Whiting to meet the future GLI discharge criterion. 


\section{APPENDICES}

\section{APPENDIX A}

\section{Appendix 2A- Pilot Commissioning and Start-up}

Permeability and flux rates measurements of virgin membrane module

TMP (psi), flux rate (gfd) and temperature $\left({ }^{\circ} \mathrm{C}\right.$ ) were measured at different feed pump settings to determine the clean membrane permeability. Reagent and Equipment blanks

Prior to testing the GE UF process, potable water samples were collected to determine time $=0 \mathrm{Hg}$ concentrations in the water. Then, the membrane unit was filled with potable water and operated at batch-mode for 24 hours to determine whether the equipment was contributing mercury to the system. After 24 hours, the water was drained from the system and five samples were collected from the permeate and backwash sampling valves. Table 2A-1 shows the changes in the Hg concentrations after 24 hours of membrane operation. Although test results showed that the permeate contained an average of $1.32 \mathrm{ppt}$ of $\mathrm{Hg}$, the next day sampling test results showed less than $0.5 \mathrm{ppt}$ of $\mathrm{Hg}$. In other words, there was no $\mathrm{Hg}$ contribution from the membrane module to the system.

Table 2A-1 Reagent Blanks

\begin{tabular}{|c|l|}
\hline Sample Description & Hg, ppt \\
\hline & 1.18 \\
& 1.32 \\
Potable Water & 1.61 \\
& 1.14 \\
& 1.34 \\
\hline & $<0.5$ \\
Permeate after 24 hours & $<0.5$ \\
& $<0.5$ \\
& $<0.5$ \\
& 0.524 \\
\hline & 1.96 \\
Backwash after 24 hours & 1.86 \\
& 1.30 \\
& 1.70 \\
& 1.26 \\
\hline
\end{tabular}

\section{Environmental blanks}

Environmental blanks ( $\mathrm{N}=5$ ) were collected by Lab A to demonstrate whether samples were contaminated by the sample collection (Table 2A-2). Five bottles filled with MilliQ 
were left open for one hour to measure the background $\mathrm{Hg}$ level in the pilot area. Three bottles were kept close to the feed line and two of them were kept close to the permeate and waste lines. Lab A sampling time was recorded $(\mathrm{N}=5)$ to determine the exposure time of the sample to the background $\mathrm{Hg}$ level. Each low level Hg sample collection took approximately $1 \mathrm{~min} 15 \mathrm{sec}$. However, environmental blanks were collected at the end of 1 hour. The test results of 1 hour of environmental blank samples showed that there was no background Hg contribution during the sample collection event.

Table 2A-2. Environmental Blanks ( $\mathrm{N}=5)$

\begin{tabular}{|l|l|l|}
\hline Sample ID & Sample Description & Hg, ppt \\
\hline $\begin{array}{l}\text { UF-ENV B-0525 } \\
\text { P100011 }\end{array}$ & MilliQ Water & $<0.5$ \\
\hline $\begin{array}{l}\text { UF-ENV B-0525 } \\
\text { P100012 }\end{array}$ & MilliQ Water & $<0.5$ \\
\hline $\begin{array}{l}\text { UF-ENV B-0525 } \\
\text { P100013 }\end{array}$ & MilliQ Water & $<0.5$ \\
\hline $\begin{array}{l}\text { UF-ENV B-0525 } \\
\text { P100014 }\end{array}$ & MilliQ Water & $<0.5$ \\
\hline $\begin{array}{l}\text { UF-ENV B-0525 } \\
\text { P100015 }\end{array}$ & MilliQ Water & $<0.5$ \\
\hline
\end{tabular}

\section{Reagent blanks}

The reagents were sampled to determine any impurities in the used chemicals. Although the stock solutions of citric acid and hypochlorite contained <15-34 ppt of $\mathrm{Hg}$, the measured concentrations were negligible as these stock solutions were diluted to $100 \mathrm{ppm}$ in the membrane tank (Table 2A-3). In other words, the residual Hg concentrations in the membrane unit were less than the targeted mercury effluent concentrations.

Table 2A-3. Potable Water $(\mathrm{N}=5)$

\begin{tabular}{|l|l|l|}
\hline Sample ID & Sample Description & $\mathrm{Hg}, \mathrm{ppt}$ \\
\hline UF-0524 FB- P10001 & Field Blank & $<0.5$ \\
\hline UF-0524-P10002 & Potable Water & $<0.5$ \\
\hline UF-0524-P10003 & Potable Water & $<0.5$ \\
\hline UF-0524-P10004 & Potable Water & $<0.5$ \\
\hline UF-0524-P10005 & Potable Water & $<0.5$ \\
\hline UF-0524-P10006 & Potable Water & $<0.5$ \\
\hline UF-0524-P10007 & Potable Water & 0.524 \\
\hline
\end{tabular}




\section{Table 2B-3. Reagents Blanks}

\begin{tabular}{|l|l|}
\hline Chemicals & $\begin{array}{l}\text { Hg (Method 245.1) } \\
\text { ppt }\end{array}$ \\
\hline Na-hypochlorite & 33 \\
\hline Na-hypochlorite & 37 \\
\hline Na-hypochlorite & 30 \\
\hline Citric Acid* & $<15$ \\
\hline Citric Acid* & $<15$ \\
\hline Citric Acid* & $<15$ \\
\hline
\end{tabular}

\section{Chemical feed pumps calibration}

Prior to use, the chemical dosing pumps were calibrated by measuring flow rate as a function of pump setting. During calibration, each flow rate was measured with a graduate cylinder and stopwatch three times. The flow rates were determined at different pump settings (20-100\%). An average flow rate for each pump setting was determined and used over the study. The flow rate data were plotted to create a calibration curve with five readings representing the full range of the pump. Please see attached pilot start up file for more information. 
Appendix 2B- Data Collection and Recordkeeping 
Table 2B-1. Sample Collection and Analysis Schedule for First 4 Weeks of Piloting

\begin{tabular}{|c|c|c|c|c|c|c|c|c|}
\hline Parameter & Method & Unit & Feed & Permeate & $\begin{array}{l}\text { Backwash } \\
\text { Reject }\end{array}$ & $\begin{array}{l}\text { Maintenance } \\
\text { Clean Waste }\end{array}$ & $\begin{array}{l}\text { Recovery } \\
\text { Clean } \\
\text { Waste }\end{array}$ & $\begin{array}{c}\text { Sample } \\
\text { Analysis/ } \\
\text { Collection }\end{array}$ \\
\hline Turbidity & $=$ & NTU & On-line & On-line & - & - & - & On-line $(B P)$ \\
\hline Temperature & $=$ & $\mathrm{C}$ & On-line & -- & - & - & - & On-line $(B P)$ \\
\hline $\mathrm{pH}$ & $\frac{\mathrm{SM} 4500}{\underline{\mathrm{H}+\mathrm{B}}}$ & - & Daily & Daily & $\mathrm{W}$ & $\mathrm{W}$ & $\begin{array}{l}\text { First W of } \\
\text { Month }\end{array}$ & $\frac{\text { Hand Held }}{(B P)}$ \\
\hline TSS & $\frac{\text { SM 2540 }}{\underline{D}}$ & ppm & MWF & - & MWF & $\mathrm{W}$ & $\begin{array}{l}\text { First W of } \\
\text { Month }\end{array}$ & $\underline{L a b A}$ \\
\hline Specific conductivity & $=$ & $\mathrm{uS} / \mathrm{cm}$ & MWF & MWF & MWF & $\mathrm{W}$ & $\begin{array}{c}\text { First W of } \\
\text { Month }\end{array}$ & $\frac{\text { Hand Held }}{(B P)}$ \\
\hline $\begin{array}{l}\text { Oxidation-reduction } \\
\text { potential (ORP) }\end{array}$ & $=$ & $\mathrm{mV}$ & MWF & MWF & MWF & W & $\begin{array}{l}\text { First W of } \\
\text { Month }\end{array}$ & $\frac{\text { Hand Held }}{(B P)}$ \\
\hline TOC (total) & $\underline{\mathrm{SM}} \underline{\underline{510 \mathrm{C}}}$ & ppm & $\mathrm{W}$ & $\mathrm{W}$ & $\mathrm{W}$ & $\mathrm{W}$ & $\begin{array}{c}\text { First W of } \\
\text { Month }\end{array}$ & $\underline{\operatorname{LabA} A}$ \\
\hline DOC (dissolved) & $\underline{5 \mathrm{SM}}$ & ppm & W & - & W & W & -- & $\underline{L a b A}$ \\
\hline COD (chemical) & $\underline{\mathrm{SM}}$ & ppm & $\mathrm{W}$ & $\mathrm{W}$ & - & & $\begin{array}{l}\text { First W of } \\
\text { Month }\end{array}$ & $\underline{\operatorname{LabA} A}$ \\
\hline Fats, Oils, \& Grease & $1664 \mathrm{~A}$ & ppm & MWF & MWF & MWF & $\mathrm{W}$ & $\begin{array}{l}\text { First W of } \\
\text { Month }\end{array}$ & $\underline{\operatorname{LabA} A}$ \\
\hline $\begin{array}{l}\text { Anions (Cl, Br, F, SO4, } \\
\text { N03, N02, P04) }\end{array}$ & $\underline{300.0}$ & ppm & W & $\mathrm{W}$ & W & $\mathrm{W}$ & $\begin{array}{l}\text { First W of } \\
\text { Month }\end{array}$ & $\underline{L a b A}$ \\
\hline $\begin{array}{l}\text { Cations (Ca, Mg, Na, } \\
\mathrm{K}, \mathrm{V}, \mathrm{As}, \mathrm{Se} \text { ) }\end{array}$ & $\underline{200.7}$ & ppm & $\mathrm{W}$ & $\mathrm{W}$ & $\mathrm{W}$ & $\mathrm{W}$ & $\begin{array}{l}\text { First W of } \\
\text { Month }\end{array}$ & $\underline{\operatorname{LabA} A}$ \\
\hline Total Alkalinity & $\frac{\text { SM2320 }}{\underline{B}}$ & ppm & $\mathrm{W}$ & $\mathrm{W}$ & - & - & - & $\underline{\operatorname{LabA} A}$ \\
\hline Manganese & $\underline{200.7}$ & ppm & $\mathrm{W}$ & $\mathrm{W}$ & - & - & $\begin{array}{l}\text { First W of } \\
\text { Month }\end{array}$ & $\underline{\operatorname{LabA} A}$ \\
\hline
\end{tabular}


Table. 2B-1 Sample Collection and Analysis Schedule for First 4 Weeks of Piloting (continued)

\begin{tabular}{|c|c|c|c|c|c|c|c|c|}
\hline Parameter & Method & Unit & Feed & Permeate & $\begin{array}{c}\text { Backwash } \\
\text { Reject }\end{array}$ & $\begin{array}{l}\text { Maintenance } \\
\text { Clean Waste }\end{array}$ & $\begin{array}{c}\text { Recovery } \\
\text { Clean } \\
\text { Waste } \\
\end{array}$ & $\begin{array}{c}\text { Sample } \\
\text { Analysis/ } \\
\text { Collection }\end{array}$ \\
\hline Iron & $\underline{200.7}$ & ppm & $\mathrm{W}$ & $\mathrm{W}$ & - & - & $\begin{array}{c}\text { First W of } \\
\text { Month }\end{array}$ & $\underline{L a b A}$ \\
\hline Aluminum & $\underline{200.7}$ & ppm & W & W & - & 一 & $\begin{array}{l}\text { First Wed } \\
\text { of Month }\end{array}$ & $\underline{\operatorname{Lab} A}$ \\
\hline Silica & $\underline{200.7}$ & $\mathrm{ppm}$ & W & W & - & - & $\begin{array}{l}\text { First Wed } \\
\text { of Month }\end{array}$ & $\underline{\operatorname{LabA} A}$ \\
\hline $\begin{array}{l}\text { Mercury Size } \\
\text { Distribution }\end{array}$ & $\begin{array}{c}\frac{\underline{\text { Laser }}}{\text { diffractio }} \\
\underline{\mathrm{n}} \\
\frac{\text { spectros }}{\text { copy }}\end{array}$ & - & W & W & W & W & $\begin{array}{l}\text { First Wed } \\
\text { of Month }\end{array}$ & Argonne \\
\hline Total Hg & $\underline{1631 \mathrm{E}}$ & $\mathrm{ng} / \mathrm{L}$ & MWF & MWF & MWF & W & $\begin{array}{l}\text { First Wed } \\
\text { of Month }\end{array}$ & $\underline{\operatorname{Lab} A}$ \\
\hline Dissolved Hg & $\underline{1631 \mathrm{E}}$ & $\mathrm{ng} / \mathrm{L}$ & MWF & -- & MWF & W & $\begin{array}{l}\text { First Wed } \\
\text { of Month }\end{array}$ & $\underline{\operatorname{Lab} A}$ \\
\hline
\end{tabular}

1. Hand held sensors were utilized for onsite measurement. Results were recorded on the daily log sheet.

2. On-line results were recorded on the provided pilot equipment at 5 minute intervals. 


\section{Daily Log Sheet - BP Whiting}

\begin{tabular}{|c|c|c|c|c|}
\hline \multirow[t]{2}{*}{ Date: } & \multirow{2}{*}{\multicolumn{2}{|c|}{ Piloting Phase: }} & \multicolumn{2}{|c|}{ UF Pilot System } \\
\hline & & & Sample 1 & Sample \\
\hline \multicolumn{3}{|l|}{ Time Sampled: } & & \\
\hline \multicolumn{3}{|l|}{ Operator Initials: } & & \\
\hline \multicolumn{5}{|l|}{ Parameter: } \\
\hline \multicolumn{2}{|l|}{ Pilot Feed Flow } & gpm & & \\
\hline \multicolumn{2}{|l|}{ Permeate Flow } & gpm & & \\
\hline \multicolumn{2}{|l|}{ Process Temperature } & ${ }^{\circ} \mathrm{C}$ & & \\
\hline \multicolumn{2}{|l|}{ Membrane TMP } & psi & & \\
\hline \multicolumn{2}{|c|}{ Backwash Airflow } & scfm & & \\
\hline \multicolumn{5}{|c|}{ Chemical Species Used for Clean (leave blank if none) } \\
\hline \multicolumn{2}{|c|}{ Feed $\mathrm{pH}$} & SU & & \\
\hline \multicolumn{2}{|l|}{ Permeate $\mathrm{pH}$} & SU & & \\
\hline \multicolumn{2}{|l|}{ Feed Conductivity } & $\mathrm{uS} / \mathrm{cm}$ & & \\
\hline \multicolumn{2}{|l|}{ Permeate Conductivity } & $\mathrm{uS} / \mathrm{cm}$ & & \\
\hline \multicolumn{2}{|l|}{ Feed ORP } & $\mathrm{mV}$ & & \\
\hline \multicolumn{2}{|l|}{ Permeate ORP } & $\mathrm{mV}$ & & \\
\hline \multicolumn{5}{|l|}{ Comments: } \\
\hline
\end{tabular}


Sample Collection Documentation Forms Used by Lab A

\begin{tabular}{|l|l|l|l|l|}
\hline $\begin{array}{l}\text { Collection date } \\
\text { and time }\end{array}$ & Collected by & Sample location & Sample ID & Measurements/Comments \\
\hline & & & Please affix preprinted labels here! & \\
\hline \hline & & & Please affix preprinted labels here! & \\
& & & & \\
\end{tabular}




\section{CALIBRATION DOCUMENTATION WORKSHEET}

Calibration date:

Instrument Name: YSI Professional Plus

Please record the following calibration values:

\begin{tabular}{|c|c|c|}
\hline Probe & Pre Cal & After Cal \\
\hline $\mathrm{pH}$ & & \\
\hline $\begin{array}{l}\text { Conductivity } \\
84 \text { microS/cm } \\
1413 \text { microS/cm }\end{array}$ & & \\
\hline $\begin{array}{l}\text { ORP } \\
\text { Zobell Solution }\end{array}$ & & \\
\hline
\end{tabular}

Comments for YSI Professional Plus:

Instrument Name: HACH 1720 Turbidimeter

Please record the following calibration values:

\begin{tabular}{|l|l|l|}
\hline Turbidity Standard Name & Pre Cal & After Cal \\
\hline HACH StablCal@20.0 NTU & & \\
\hline
\end{tabular}

Comments for HACH 1720 Turbidimeter: 


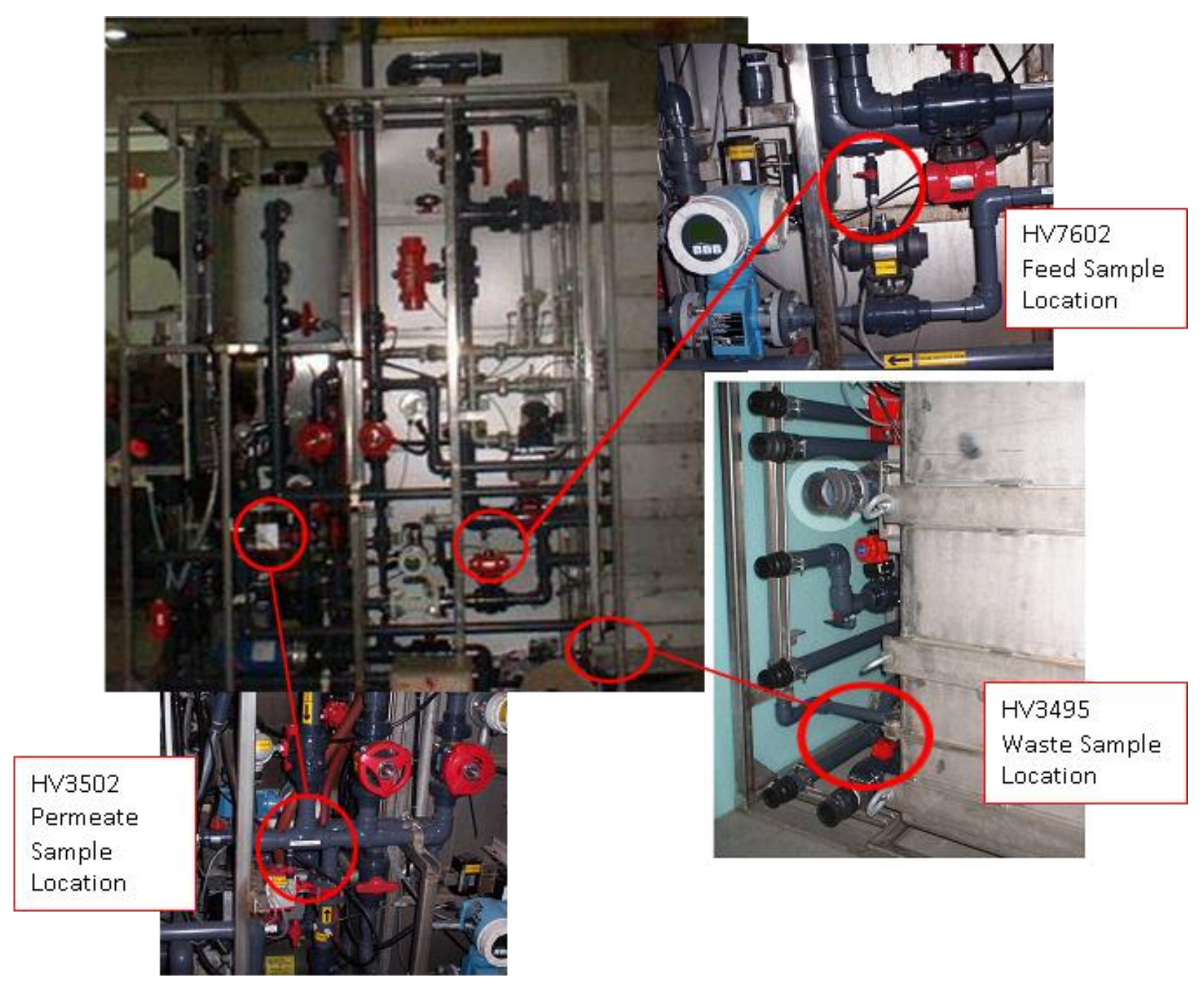

Figure 2B-1. Sample Locations (back of pilot-skid pictured)

(Permission to use photograph granted by GE Power \& Water) 
Appendix 2C- Pilot Calendar 


\begin{tabular}{|c|c|c|c|c|c|c|c|}
\hline & SUNDAY & MONDAY & TUESDAY & WEDNESAY & THURSDAY & 1 FRIDAY & 2 SATURDAY \\
\hline \multirow{4}{*}{$\begin{array}{l}\text { April } \\
2011\end{array}$} & 3 & $\begin{array}{l}4 \text { The pilot equipment } \\
\text { and membranes were } \\
\text { shipped to Whiting. }\end{array}$ & 5 & 6 & 7 & 8 & 9 \\
\hline & 10 & 11 & 12 & 13 & 14 & 15 & 16 \\
\hline & 17 & 18 & 19 & 20 & 21 & 22 & 23 \\
\hline & 24 & 25 & 26 & 27 & 28 & 29 & 30 \\
\hline \multirow{5}{*}{$\begin{array}{l}\text { May } \\
2011\end{array}$} & 1 & 2 & 3 & 4 & 5 & 6 & 7 \\
\hline & 8 & 9 & 10 & 11 & 12 & 13 & 14 \\
\hline & 15 & 16 & 17 & 18 & 19 & 20 & 21 \\
\hline & 22 & 23 Start Up! & 24 Start Up! & $\begin{array}{l}25 \text { Start Up! } \\
\text { ETL was introduced to the } \\
\text { pilot unit at } 2.00 \mathrm{pm} \text {. } \\
\text { Unit was operated at Flux } \\
\text { A and } X \% \text { recovery. }\end{array}$ & 26 Start Up! & 27 Start Up! & 28 \\
\hline & 29 & 30 & 31 & 1 & 2 & 3 & 4 \\
\hline \multirow{2}{*}{$\begin{array}{l}\text { June } \\
2011\end{array}$} & 5 & 6 & 7 & 8 & 9 & 10 & 11 \\
\hline & $\begin{array}{l}12 \text { Unit was down at } 8.30 \\
\text { am. }\end{array}$ & $\begin{array}{l}\mathbf{1 3} \text { The unit was restarted } \\
\text { up at } 1.19 \mathrm{pm} \text {. }\end{array}$ & 14 & 15 & 16 & 17 & 18 \\
\hline
\end{tabular}




\section{Appendix 2D- Full-scale Cost Calculations}

1. Cost Calculations based on the AWWA and US Bureau of Reclamation funded study (2005)[12]:

The AWWA report (2005) is an evaluation of membrane technology installed and operated at 450 plants. The data presented in Table 2D-1 is based on the evaluation of membrane processes employed to treat surface water, ground water, reclaimed water and wastewater. Please note that over half of the 450 plants were for the treatment of surface water. The plant capacities ranged from $1 \mathrm{mgd}$ to $70 \mathrm{mgd}$. Approximate capital costs for MF and UF systems are provided in Table 2D-2. The land acquisition, engineering, site development were not included in the capital cost calculations. O\& M costs include power, replacement parts, membrane replacement, CIP chemicals, chemical disposal and maintenance labor. All costs were adjusted to 2011 October prices by using the Engineering News Record Construction Index (ENR CCI)[15] since all costs were based on the 2003 ENR CCI.

Total plant cost as a function of design capacity can be calculated using the equation given below:

US\$ M/mgd=2.19* MGD-0.261 [12]

To treat 40 MGD of ETL, the required capital cost was calculated to be $\$ 46 \mathrm{M}$. Please note that this cost estimate did not include pre-treatment and post-treatment processes as well as the land acquisition, engineering, site development. All costs were adjusted to 2011 October prices by using the Engineering News Record Construction Index (ENR CCI) since all costs were based on the 2003 ENR CCI.

Table 2D-1 Capital Cost Calculations

\begin{tabular}{|l|l|l|l|r|}
\hline & & & & \multicolumn{1}{|c|}{ ENR CCI } \\
\hline 40 & & & Year & \\
MGD & 0.836193 & $\$ 33 \mathrm{M}$ & 2003 & 6695 \\
\hline & & & Year & \\
& & $\$ 46 \mathrm{M}$ & 2011 & 9116 \\
\hline
\end{tabular}

The membrane system cost for the 40 MGD design capacity of plant was calculated as $\$ 12,261,121$ using the equation US\$ M/mgd=0.935*MGD-0.386 developed in the AWWA 
report (2005). This calculation did not include the land acquisition, engineering or site development either.

Table 2D-2 Membrane System Cost

\begin{tabular}{|l|l|l|l|r|}
\hline & & & & \multicolumn{1}{|l|}{$\begin{array}{l}\text { ENR } \\
\text { CCI }\end{array}$} \\
\hline 40 & & & Year & \\
MGD & 0.225121 & $\$ 9 M$ & 2003 & 6695 \\
\hline & & & Year & \\
& & $\$ 12 \mathrm{M}$ & 2011 & 9116 \\
\hline
\end{tabular}

Total annual O\& $\mathrm{M}$ costs with a median of US $\$ 0.34$ per 1,000 gallons were calculated as $2.3 \mathrm{M}$ for a plant with an average daily flow of 18.6 million gallons. O\&M costs include labor costs, chemical costs, energy cost, parts, chemical disposal costs. The breakdown of the $0 \& \mathrm{M}$ costs is given in Table 2D-3.

Table 2D-3. The Breakdown of O\&M Costs (AWWA report, 2005)

\begin{tabular}{|l|r|r|r|l|}
\hline \multicolumn{5}{|c|}{ Median and maximum values of O\&M cost components } \\
\hline & Median & Maximum & & \\
\hline Labor & $32 \%$ & $67 \%$ & & \\
\hline Chemicals & $9 \%$ & $36 \%$ & & \\
\hline Energy & $30 \%$ & $61 \%$ & & \\
\hline Parts & $10 \%$ & $70 \%$ & & \\
\hline Chemical & & & & \\
Disposal & $2 \%$ & $5 \%$ & \\
\hline Other & $8 \%$ & $34 \%$ & & \\
\hline
\end{tabular}

2. Cost Calculations based on the Water Research Foundation and EPA funded study (2009):

Capital costs given in Table 2D-4 include membranes, feed pumps, associated chemical feed equipment, and electrical and instrumentation and do not include pre-treatment and posttreatment processes because they are highly dependent on the specific source water quality. Using data given in Table 2D-4, capital cost as a function of plant design capacity was plotted in Figure 2D-1 to determine the relationship that can be used to calculate capital cost to treat 40 MGD. From this equation, capital cost was calculated for $40 \mathrm{MGD}$ design capacity as \$34 M (2007 ENR Price Index).This cost would be \$39M when the cost adjusted to ENR 2011 Price index [12] as shown in Table 2D-5. 
Table 2D-4. Capital and O\&M Costs

\begin{tabular}{|l|l|l|l|}
\hline $\begin{array}{l}\text { Design } \\
\text { Flow mgd }\end{array}$ & $\begin{array}{l}\text { Average } \\
\text { flow mgd }\end{array}$ & $\begin{array}{l}\text { Capital } \\
\text { cost \$/gal }\end{array}$ & $\begin{array}{l}\text { O\&M } \\
\$ / \text { kgal }\end{array}$ \\
\hline 0.01 & 0.005 & 18 & 4.25 \\
\hline 0.1 & 0.03 & 4.3 & 1.1 \\
\hline 1 & 0.35 & 1.6 & 0.6 \\
\hline 10 & 4.4 & 1.1 & 0.3 \\
\hline 100 & 50 & 0.85 & 0.25 \\
\hline
\end{tabular}

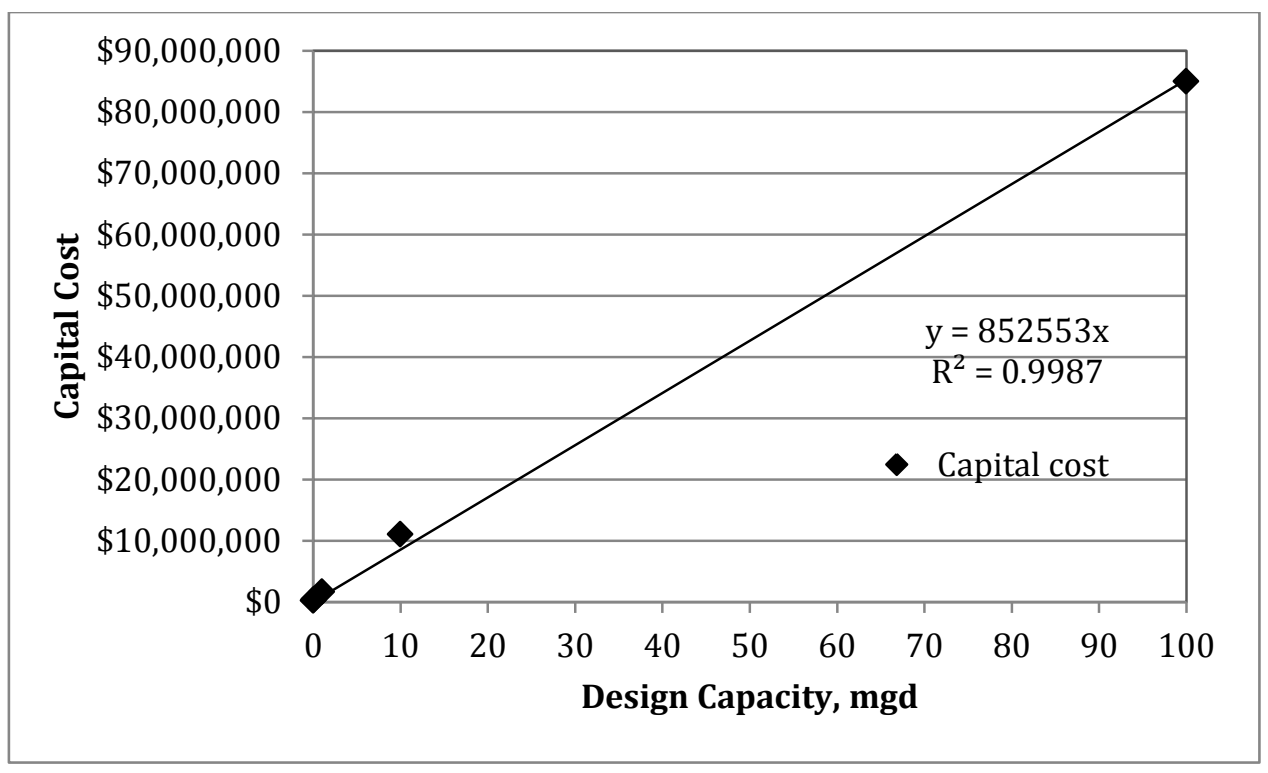

Figure 2D-1. Capital Cost Curves

\begin{tabular}{|l|l|l|}
\hline & Year & $\begin{array}{l}\text { ENR } \\
\text { CCI }\end{array}$ \\
\hline \$34 M & 2007 & 7967 \\
\hline$\$ 39 \mathrm{M}$ & 2011 & 9116 \\
\hline
\end{tabular}

Using $0 \& \mathrm{M}$ costs given in Table 2D-4, $0 \& \mathrm{M}$ costs as a function of plant design capacity was plotted in Figure 2D-2 to determine the relationship that can be used to calculate 0\&M costs to treat 18.6 MGD of annual average flow. Annual O\&M costs for a plant with an average daily flow of 18.6 million gallons would be approximately $\$ 850,000$ (2007 ENR Index).Using the 2011 price index, this cost can be calculated as $\$ 1 \mathrm{M}$. 0 \& M costs include power, replacement parts, membrane replacement and maintenance labor. 


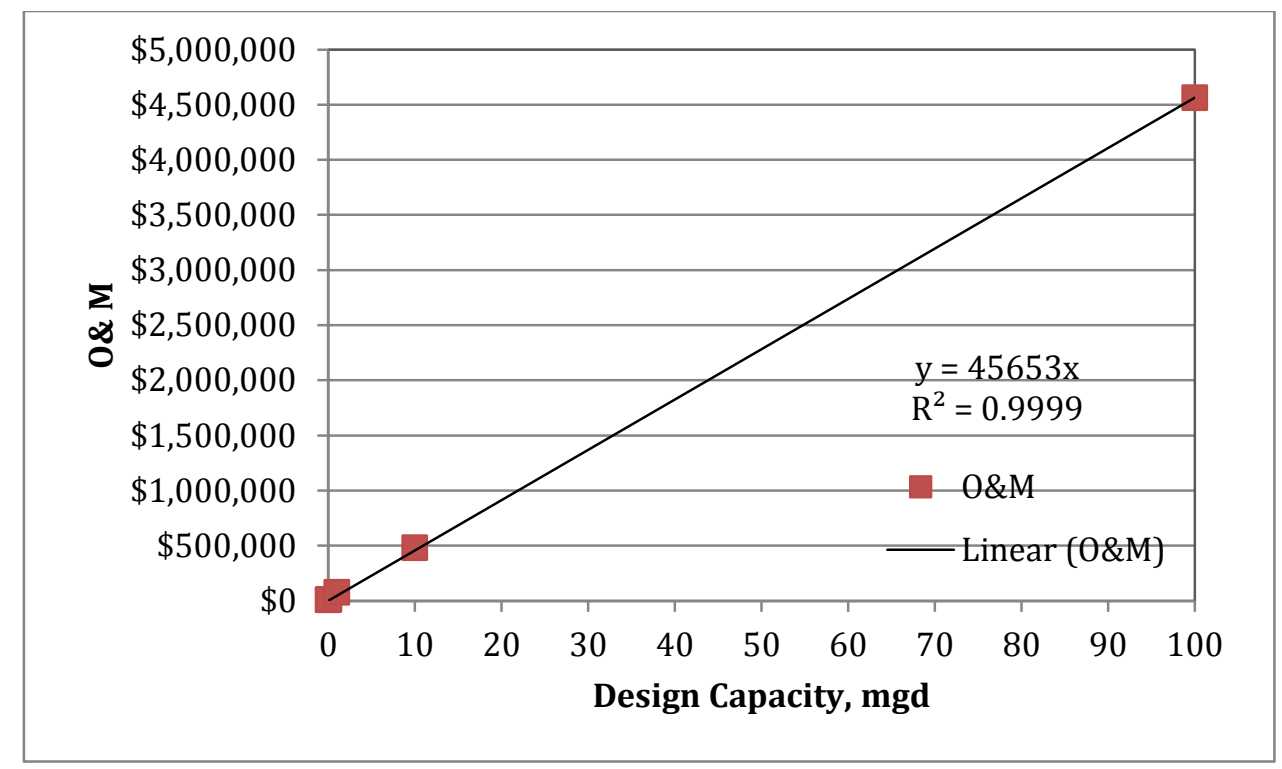

Figure 2D-2. 0\& M Costs Curves

\begin{tabular}{|l|r|r|}
\hline & Year & $\begin{array}{l}\text { ENR } \\
\text { CCI }\end{array}$ \\
\hline$\$ 849,146$ & 2007 & 7967 \\
\hline$\$ 971,610$ & 2011 & 9116 \\
\hline
\end{tabular}

If the costs of $10 \mathrm{mgd}$ and $100 \mathrm{mgd}$ plants are interpolated for $40 \mathrm{mgd}$, the capital cost would be $\$ 35,666,666$ (2007 ENR) and the 0\&M costs would be $\$ 871,734$ (2007 ENR).

3. 1 US cent per $\mathrm{m}^{3}$ (taking into account a membrane life time of eight years and a service life of 20 years). TCO of UF would be approximately 12 to 16 US cents per $\mathrm{m}^{3}$ (Knops and Fay 2008 and Alhumoud et al., 2010)

The total cost of ownership (TCO) is the cost calculated over the life-cycle of a UF plant. In this cost estimation, the technical life of the mechanical and civil constructions was estimated as 20 years (Table 2D-5).

The life expectancy of a membrane depends on the manufacturer's warranty (typically 7-10 years). Membrane replacement frequency is a significant factor in operation and maintenance cost comparisons and should be considered in the selection of the process. 
Table 2D-5. Total Cost of Ownership

\begin{tabular}{|c|c|c|c|c|c|}
\hline \multicolumn{3}{|c|}{$\begin{array}{l}12 \text { to } 16 \text { US cents per } \mathrm{m} 3 \text { of water } \\
\text { produced }\end{array}$} & & \multirow{2}{*}{$\frac{\text { ENR }}{2007}$} & \multirow[b]{2}{*}{7966} \\
\hline & & & & & \\
\hline & & & & 2011 & 9115.95 \\
\hline & $\begin{array}{l}\text { Design flov } \\
\text { permeate) }\end{array}$ & $=40 \mathrm{MGD}(38$ & MGD & & \\
\hline Cents $/ \mathrm{m}^{3}$ & 1 year & 20 years & ENR 2011, \$ & & \\
\hline 12 & $6,432,381$ & $128,647,608$ & $147,218,825$ & & \\
\hline 16 & $8,576,506$ & $171,530,127$ & $196,291,748$ & & \\
\hline
\end{tabular}

(Knops and Fay 2008 and Alhumoud et al., 2010)

\section{Appendix 2E- Miscellaneous}

The viscosity, in centipoise, can be approximated using the following polynomial equation when the temperatures $(\mathrm{T})$ are between 0 and $30^{\circ} \mathrm{C}$

$\mu(c P)=1.77-0.052 T+0.00067 T^{2}$

This correlation is approximate to within \pm 2 percent.

If the facility is required to meet the full design capacity requirement under cold-water conditions, additional membrane surface area will be required if the cleaning interval is maintained.

Water viscosity (AWWA, 2005 and Metcalf and Eddy, Inc., 2004)

\begin{tabular}{|l|l|l|}
\hline $\begin{array}{l}\text { Temperature } \\
\left(\mathbf{} \mathbf{C} / \mathbf{~}^{\mathbf{F}}\right)\end{array}$ & $\begin{array}{l}\text { Absolute } \\
\text { Viscosity } \\
(\mathbf{c P})\end{array}$ & $\begin{array}{l}\text { Viscosity Correction } \\
\text { Factor* } \\
\mathbf{( \% )}\end{array}$ \\
\hline 40 & 0.653 & -34.7 \\
\hline 30 & 0.798 & -20.2 \\
\hline $25 / 77$ & 0.891 & -10.9 \\
\hline $20 / 68$ & 1.00 & 0 \\
\hline $15 / 59$ & 1.15 & +15 \\
\hline $10 / 50$ & 1.30 & +30 \\
\hline $5 / 41$ & 1.55 & +55 \\
\hline $0.1 / 32$ & 1.79 & +79 \\
\hline
\end{tabular}




\section{APPENDIX B}

\section{Appendix 3A: Flow Meter Calibrations}

\section{Procedure}

The influent flow meter was calibrated on two separate days. Lower flow rates were calibrated during the pilot start-up using a direct method where influent ETL passing through the turbine flow meter was collected sequentially in two calibrated 5 gallon buckets. A stopwatch was used to time the collection period. Three measurements were made for each flow meter setting that was calibrated. The higher flow rates were calibrated mid-way through the pilot operation using an indirect method so that the calibration could be done without shutting down pilot operation. The indirect method consisted of separately measuring the flow rates of each filter's reject and the Filter 2 effluent - the sum of all of the pilot system exit streams should equal the influent stream. Each flow rate was measured by a timed collection in a calibrated 5 gallon pail. Five measurements were made for each flow meter setting that was calibrated. This indirect method assumes a constant liquid level in both filters, however, during the calibration, surging was seen in all of the streams measured.

The Nalmet® 1689 chemical feed systems for each filter did not have flow meters. In order to determine the flow of Nalmet $®$ to each filter, the chemical feed pump for each filter was individually calibrated with a graduate cylinder and a stopwatch. Each chemical feed pump's setting was held constant during the Nalmet $®$ addition portion of the pilot and hence the calibration was done only at those settings. For each pump setting that was calibrated, the flow was measured for three different 15 - 20 minute time periods.

\section{Calibration Results}

The feed pump calibrations are summarized in Table 3A.1 and Figure 3A.1 below. At lower flow rates, the influent flow meter reading was similar to the measured flow rates (within 5 - 7\%). However, as the flow rate increased, the discrepancy between the flow meter reading and the measured flows also increased. At a flow meter reading of $21.5 \mathrm{gpm}$, the actual measured flow rate was $18.65 \mathrm{gpm}$ (13.3\% low) while at a flow meter reading of 28.6 gpm the measured flow was 23.9 gpm (16.4\% low). It should be noted that surging was seen in all of the streams measured, and also that the standard deviations for the indirectly calibrated flow rates were larger than the directly calibrated flow rates (6-11\% indirect vs. 1\% direct). 
Table 3A.1 Influent Flow Meter Calibration

\begin{tabular}{|c|c|c|c|r|}
\hline $\begin{array}{c}\text { Flow } \\
\text { meter } \\
\text { Read Out } \\
\text { (gpm) }\end{array}$ & $\begin{array}{c}\text { Measured } \\
\text { (gpm) }\end{array}$ & Std. Dev. & $\begin{array}{c}\text { \% std. } \\
\text { dev. }\end{array}$ & $\begin{array}{c}\text { \% } \\
\text { Difference }\end{array}$ \\
\hline 15 & 14.16 & 0.99 & 0.07 & $5.6 \%$ low \\
\hline 18.9 & 18.64 & 0.18 & $1 \%$ & $1.4 \%$ low \\
\hline 19.6 & 18.21 & 0.00 & $0 \%$ & $7.1 \%$ low \\
\hline 21.5 & 18.65 & 2.01 & $11 \%$ & $13.3 \%$ low \\
\hline 28.6 & 23.90 & 1.36 & $6 \%$ & $16.4 \%$ low \\
\hline
\end{tabular}

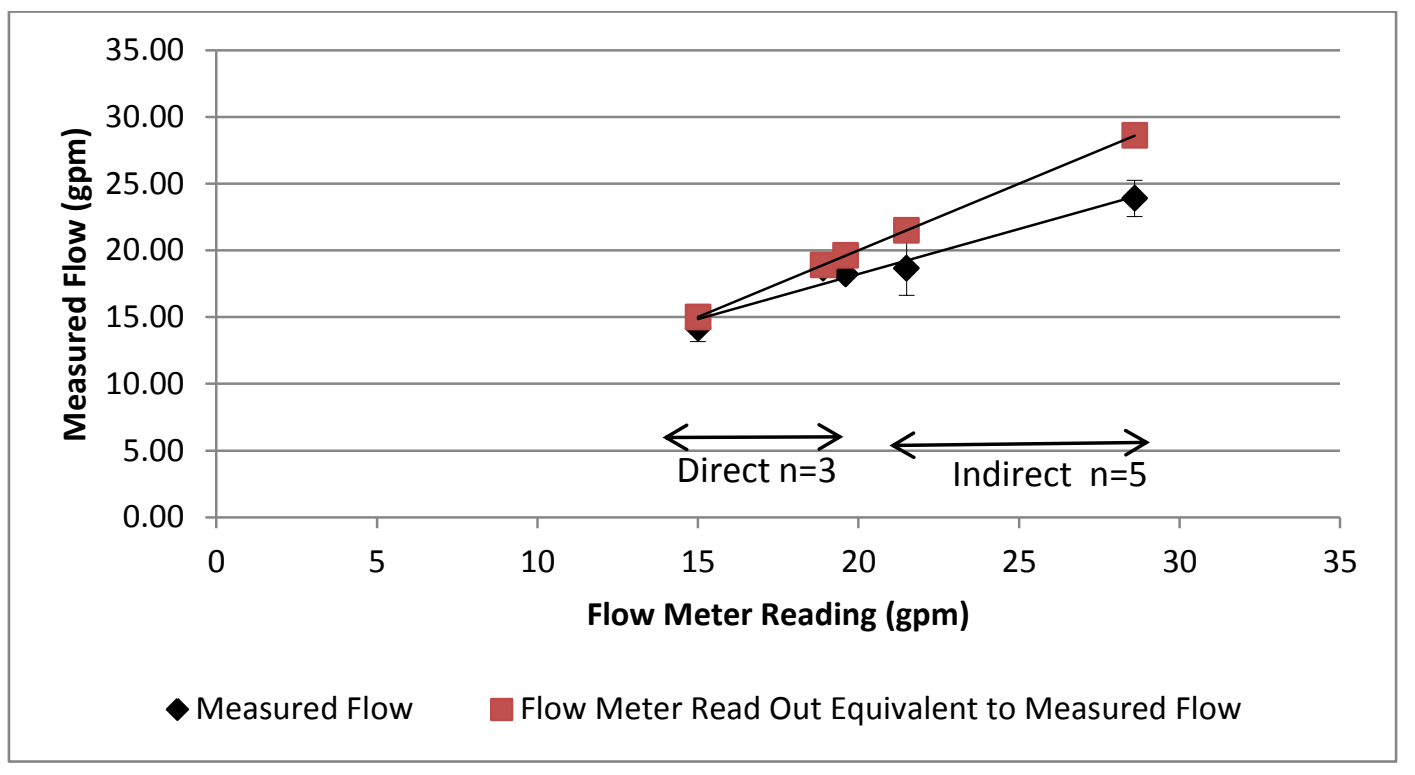

Figure 3A.1 Influent Flow Meter Calibration

The chemical feed pump calibrations are summarized in Table 3A.2. Although both measured feed rates were higher than the respective pump setting, the measured chemical feed to the first filter was significantly higher (30\%) than the pump setting. This led to a higher than anticipated amount of chemical feed being fed to the first filter. The chemical feed rate to the first filter was also found to be dependent on the level in the chemical feed tank - the lower the tank level, the slower the feed rate. However, this deviation was found to be relatively small, resulting in flows that were within $3 \%$ of the calculated average flow rate. 
Table 3A.2 Chemical Feed Pump Calibration Summary

\begin{tabular}{|l|c|r|c|r|}
\hline & $\begin{array}{r}\text { Pump } \\
\text { Setting } \\
\text { (mL/hr) }\end{array}$ & $\begin{array}{r}\text { Average } \\
\text { Flow } \\
\text { Rate } \\
\text { (mL/hr) }\end{array}$ & $\begin{array}{r}\text { Std. } \\
\text { Dev. }\end{array}$ & $\begin{array}{r}\text { \% } \\
\text { Std. } \\
\text { Dev. }\end{array}$ \\
\hline $\begin{array}{l}\text { Chemical Feed } \\
\text { Pump to Filter } \\
1\end{array}$ & 230 & 299.8 & 9.4 & $3.1 \%$ \\
\hline $\begin{array}{l}\text { Chemical Feed } \\
\text { Pump to Filter } \\
2\end{array}$ & 190 & 200.4 & 2.6 & $1.3 \%$ \\
\hline
\end{tabular}


Appendix 3B: Equipment, Method, Reagent and Background Blanks

Table 3B.1 Equipment Blank for Blue PRO® Pilot System

\begin{tabular}{|c|c|c|c|}
\hline & $\begin{array}{c}\text { Total Hg } \\
\text { (ppt) }\end{array}$ & $\begin{array}{c}\text { Average Total } \\
\text { Hg (ppt) }\end{array}$ & Std. Dev. \\
\hline Potable Water Feed & & 1.14 & 0.13 \\
\hline BP-V135-0516 - P10001 & 1.02 & & \\
\hline BP-V135-0516 - P10003 & 1.12 & & \\
\hline BP-V135-0516 - P10004 & 1.27 & & 0.055 \\
\hline Filter 1 effluent (potable water) & & 0.710 & \\
\hline BP-V134-0516 - P10005 & 0.765 & & \\
\hline BP-V134-0516 - P10006 & 0.656 & & \\
\hline BP-V134-0516 - P10007 & 0.71 & & \\
\hline Filter 2 effluent (potable water) & & 0.973 & \\
\hline BP-V133-0516 - P10008 & 0.925 & & \\
\hline BP-V133-0516 - P10009 Dup. & 0.873 & & \\
\hline BP-V133-0516 - P10010 & 0.834 & & \\
\hline BP-V133-0516 - P10011 & 1.26 & & \\
\hline
\end{tabular}

Table 3B.2 Method Blank for Blue PRO® Pilot System

\begin{tabular}{|c|c|c|c|c|c|}
\hline & $\begin{array}{c}\text { Total Hg } \\
\text { (ppt) }\end{array}$ & $\begin{array}{c}\text { Average } \\
\text { Total Hg } \\
\text { of all } \\
\text { Samples } \\
\text { (ppt) }\end{array}$ & Std. Dev. & $\begin{array}{c}\text { Average } \\
\text { Total Hg } \\
\text { Excluding } \\
\text { Outlier } \\
\text { (ppt) }\end{array}$ & Std. Dev. \\
\hline Feed & & 11.58 & 1.02 & - & - \\
\hline BP-V135-0517 - P10018 & 12.00 & & & & \\
\hline BP-V135-0517 - P10019 & 13.10 & & & & \\
\hline BP-V135-0517 - P10020 & 10.80 & & & & \\
\hline BP-V135-0517 - P10021 & 10.40 & & & & \\
\hline BP-V135-0517 - P10022 & 12.20 & & & & \\
\hline BP-V135-0517 - P10023 & 11.00 & & & & \\
\hline Filter 2 effluent & & 42.90 & 20.87 & 51.38 & 2.21 \\
\hline BP-V133-0517 - P10012 & 0.50 & & & & \\
\hline BP-V133-0517 - P10013 & 50.10 & & & & \\
\hline BP-V133-0517 - P10014 & 49.60 & & & & \\
\hline BP-V133-0517 - P10015 & 54.30 & & & & \\
\hline BP-V133-0517 - P10016 & 49.70 & & & & \\
\hline BP-V133-0517 - P10017 & 53.20 & & & & \\
\hline $\begin{array}{c}\text { Method gain - excludes } \\
\text { Filter 2 effluent outlier }\end{array}$ & $444 \%$ & & & & \\
\hline
\end{tabular}


Table 3B.3 Nalmet ${ }^{\circledR} 1689$ Reagent Blank

\begin{tabular}{|l|c|}
\hline & Total Hg (ppt) \\
\hline Sample 1 & 0.18 \\
\hline Sample 2 & 0.33 \\
\hline Sample 3 & 0.15 \\
\hline average & 0.22 \\
\hline std. dev. & 0.10 \\
\hline
\end{tabular}

Table 3B.4 Background Blanks for Blue PRO® Pilot System

\begin{tabular}{|c|c|c|}
\hline \multirow{2}{*}{ Date } & \multicolumn{2}{|c|}{ Total Hg (ppt) } \\
\cline { 2 - 3 } & $\begin{array}{c}\text { Influent } \\
\text { (Valve } \\
\text { 135) }\end{array}$ & $\begin{array}{c}\text { Filter 2 } \\
\text { Effluent } \\
\text { (Valve 133) }\end{array}$ \\
\hline $6 / 15 / 2011$ & $<0.5$ & $<0.5$ \\
\hline $6 / 24 / 2011$ & $<0.5$ & $<0.5$ \\
\hline $6 / 29 / 2011$ & 0.856 & $<0.5$ \\
\hline $7 / 6 / 2011$ & $<0.5$ & $<0.5$ \\
\hline
\end{tabular}


Appendix 3C: Daily Operating Log and Analytical Results

Table 3C.1: Blue PRO® Pilot Feed Characterization

\begin{tabular}{|c|c|c|c|c|c|c|c|c|c|c|}
\hline & $\begin{array}{c}\text { Alkalinity } \\
\text { Bicarbon } \\
\text { ate } \\
\text { (as } \\
\left.\mathrm{CaCO}_{3}\right) \\
(\mathrm{ppm})\end{array}$ & $\begin{array}{c}\text { Alkalinity } \\
\text { Carbonat } \\
\text { e (as } \\
\left.\mathrm{CaCO}_{3}\right) \\
(\mathrm{ppm})\end{array}$ & $\begin{array}{l}\text { Alkalini } \\
\text { ty } \\
\text { Hydroxi } \\
\text { de } \\
\text { (as } \\
\left.\mathrm{CaCO}_{3}\right) \\
\text { (ppm) }\end{array}$ & $\begin{array}{c}\text { Alkalini } \\
\text { ty Total } \\
\text { (as } \\
\mathrm{CaCO}_{3} \text { ) } \\
\text { (ppm) }\end{array}$ & $\begin{array}{c}\text { Ca } \\
\text { (ppm) }\end{array}$ & $\begin{array}{c}\mathrm{Cu} \\
(\mathrm{ppm})\end{array}$ & $\begin{array}{c}\text { Pb } \\
(\mathrm{ppm})\end{array}$ & $\begin{array}{c}\text { Mn } \\
(\mathrm{ppm})\end{array}$ & $\begin{array}{c}K \\
(p p m)\end{array}$ & $\begin{array}{c}\mathbf{S i} \\
(\mathbf{p p m})\end{array}$ \\
\hline $6 / 1 / 2011$ & 130 & $<20$ & $<20$ & 130 & 61 & $<0.010$ & $<0.0075$ & 0.11 & 5.7 & 4.8 \\
\hline $6 / 8 / 2011$ & 130 & $<20$ & $<20$ & 130 & 59 & $<0.010$ & $<0.0075$ & 0.10 & 4.7 & 4.0 \\
\hline $6 / 15 / 2011$ & 120 & $<20$ & $<20$ & 120 & 53 & $<0.010$ & $<0.0075$ & 0.11 & 4.3 & 4.6 \\
\hline $6 / 29 / 2011$ & 160 & $<20$ & $<20$ & 160 & 66 & $<0.010$ & $<0.0075$ & 0.11 & 5.7 & 4.7 \\
\hline $7 / 6 / 2011$ & 140 & $<20$ & $<20$ & 140 & 60 & $<0.010$ & $<0.0075$ & 0.072 & 6.4 & 5.2 \\
\hline $7 / 13 / 2011$ & 44 & $<20$ & $<20$ & 44 & & & & & & \\
\hline
\end{tabular}

\begin{tabular}{|l|c|c|c|c|c|c|c|c|}
\hline & $\mathbf{N a}$ & $\begin{array}{c}\mathbf{Z n} \\
\mathbf{( p p m )}\end{array}$ & $\begin{array}{c}\text { Phosphorous, } \\
\text { Total (as P) } \\
\text { (ppm) }\end{array}$ & $\begin{array}{c}\mathbf{C l} \\
\mathbf{( p p m )}\end{array}$ & $\begin{array}{c}\mathbf{F} \\
\text { (ppm) }\end{array}$ & $\begin{array}{c}\text { Bromide } \\
\text { (ppm) }\end{array}$ & $\begin{array}{c}\text { Nitrate + } \\
\text { Nitrite } \\
\text { (as N) } \\
\text { (ppm) }\end{array}$ & $\begin{array}{c}\text { Sulfate } \\
\text { (ppm) }\end{array}$ \\
\hline $6 / 1 / 2011$ & 370 & $<0.020$ & $<0.20$ & 217 & 0.414 & $<4.99$ & 0.06 & 686 \\
\hline $6 / 8 / 2011$ & & $<0.020$ & 0.26 & 184 & 0.34 & $<4.99$ & $<0.00560$ & 480 \\
\hline $6 / 15 / 2011$ & 330 & $<0.020$ & 0.27 & 226 & 0.397 & $<4.99$ & 0.133 & 585 \\
\hline $6 / 29 / 2011$ & 430 & $<0.020$ & 0.3 & 288 & 0.452 & $<4.99$ & 0.126 & 707 \\
\hline $7 / 6 / 2011$ & 430 & 0.034 & 0.4 & 206 & 0.354 & $<4.99$ & 0.835 & 818 \\
\hline $7 / 13 / 2011$ & 530 & & 0.5 & & & & & \\
\hline
\end{tabular}


Table 3C.2 Blue PRO® Pilot Daily Operating Summary -Flow Rates

(1) Nalmet® was diluted $50 / 50$ with water.

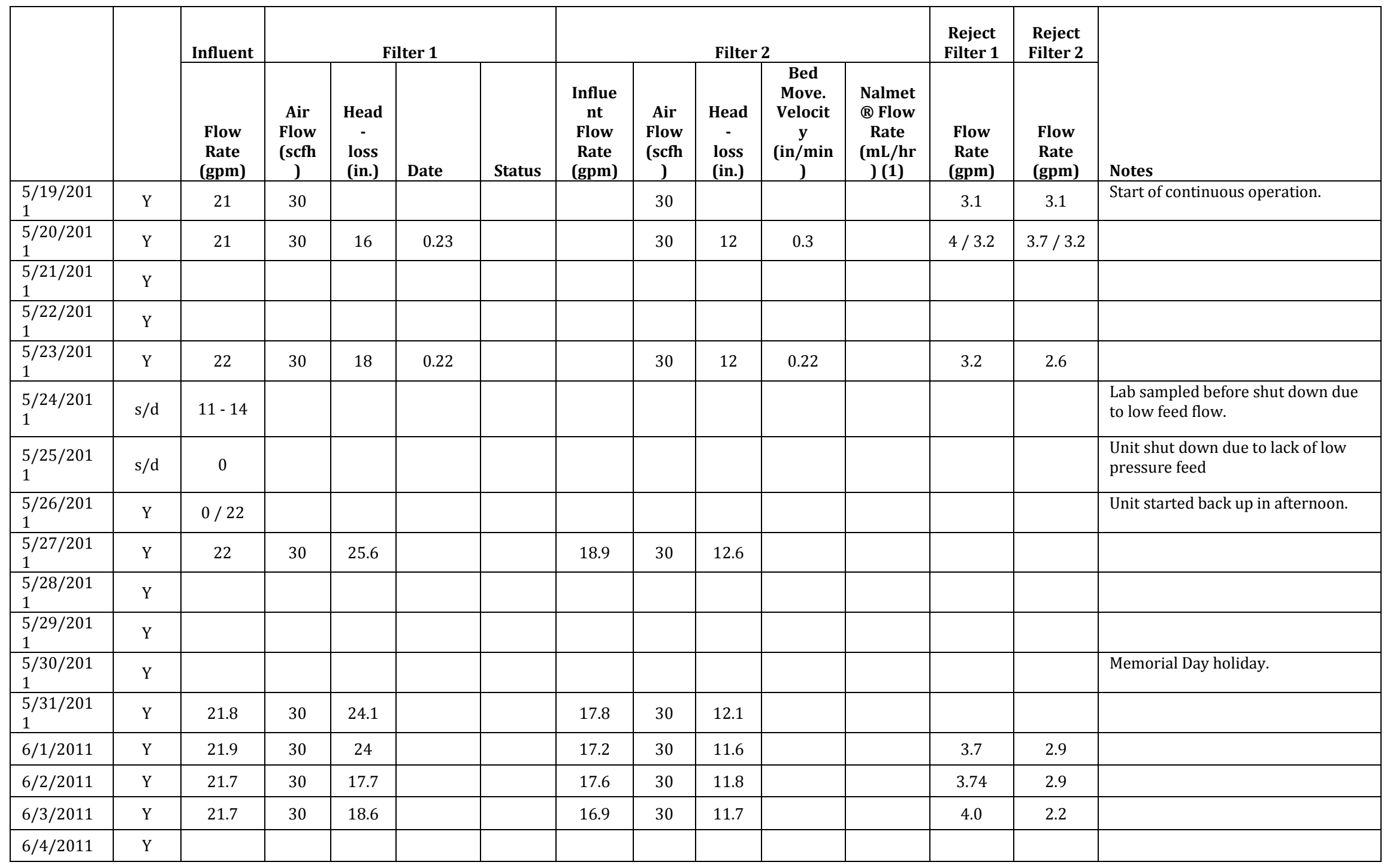




\begin{tabular}{|c|c|c|c|c|c|c|c|c|c|c|c|c|c|c|}
\hline & & Influent & $\begin{array}{c}\text { Filter } \\
1\end{array}$ & $\begin{array}{c}\text { Filter } \\
2\end{array}$ & $\begin{array}{c}\text { Reject } \\
\text { Filter } 1 \\
\end{array}$ & $\begin{array}{c}\text { Reject } \\
\text { Filter } \\
2 \\
\end{array}$ & Notes & & & Influent & Filter 1 & Filter 2 & $\begin{array}{l}\text { Reject } \\
\text { Filter } 1\end{array}$ & Reject Filter 2 \\
\hline $6 / 5 / 2011$ & $\mathrm{Y}$ & & & & & & & & & & & & & \\
\hline $6 / 6 / 2011$ & $\mathrm{Y}$ & 21.8 & 30 & 23.2 & 0.2 & & 16.6 & 30 & 11.5 & 0.22 & & 3.8 & 2.6 & \\
\hline $6 / 7 / 2011$ & $\mathrm{Y}$ & 21.7 & 30 & 24.1 & & & 16.6 & 30 & 11.3 & & & 3.9 & 2.4 & \\
\hline $6 / 8 / 2011$ & Y & 21.9 & 30 & 21.3 & & & 16.8 & 30 & 11.5 & & & 4.0 & 1.82. 2.6 & \\
\hline $6 / 9 / 2011$ & Y & 21.4 & 30 & 17.9 & & & 17.8 & 30 & 11.6 & & & 3.82 & $1.66,2.5$ & \\
\hline $\begin{array}{l}6 / 10 / 201 \\
1\end{array}$ & Y & 21.5 & 30 & 19.3 & & & 18.1 & 30 & 12.3 & & & 3.26 & $1.66,2.5$ & \\
\hline $\begin{array}{l}6 / 11 / 201 \\
1\end{array}$ & $\mathrm{Y}$ & & & & & & & & & & & & & \\
\hline $\begin{array}{l}6 / 12 / 201 \\
1\end{array}$ & $\mathrm{Y}$ & & & & & & & & & & & & & \\
\hline $\begin{array}{l}6 / 13 / 201 \\
1\end{array}$ & Y & 21.7 & 30 & 26.2 & 0.22 & & 17.7 & 30 & 12.1 & 0.215 & & 4.08 & $1.65,2.5$ & \\
\hline $\begin{array}{l}6 / 14 / 201 \\
1\end{array}$ & Y & 21.7 & 30 & 19.4 & & & 17.5 & 30 & 12.0 & & & 3.83 & 2.6 & \\
\hline $\begin{array}{l}6 / 15 / 201 \\
1\end{array}$ & $\mathrm{Y}$ & 22.3 & 30 & 19.2 & & & 17.7 & 30 & 12.5 & & & 3.6 & 2.77 & \\
\hline $\begin{array}{l}6 / 16 / 201 \\
1\end{array}$ & $\mathrm{Y}$ & 21.9 & 30 & 20.5 & & & 19.5 & 30 & 13.0 & & & 4.0 & 3.1 & \\
\hline $\begin{array}{l}6 / 17 / 201 \\
1\end{array}$ & Y & & & & & & & & & & & & & $\begin{array}{l}\text { Unit shut down. High headloss } \\
\text { Filter } 1\end{array}$ \\
\hline $\begin{array}{l}6 / 18 / 201 \\
1\end{array}$ & $\mathrm{~s} / \mathrm{d}$ & & & & & & & & & & & & & \\
\hline $\begin{array}{l}6 / 19 / 201 \\
1\end{array}$ & $\mathrm{~s} / \mathrm{d}$ & & & & & & & & & & & & & \\
\hline $\begin{array}{l}6 / 20 / 201 \\
1\end{array}$ & $\mathrm{~s} / \mathrm{d}$ & & & & & & & & & & & & & Unit down \\
\hline $\begin{array}{l}6 / 21 / 201 \\
1\end{array}$ & $\mathrm{~s} / \mathrm{d}$ & & & & & & & & & & & & & Unit down \\
\hline $\begin{array}{l}6 / 22 / 201 \\
1\end{array}$ & $\mathrm{~s} / \mathrm{d}$ & & & & & & & & & & & & & Unit down for modifications. \\
\hline $\begin{array}{l}6 / 23 / 201 \\
1\end{array}$ & $\mathrm{Y}$ & & & & & & & & & & & & & $\begin{array}{l}\text { Unit down, but started back up with } \\
\text { new reject sampling valves - note: } \\
\text { Filter } 2 \text { reject sample is actually } \\
\text { effluent, installed incorrectly. }\end{array}$ \\
\hline $\begin{array}{l}6 / 24 / 201 \\
1 \\
\end{array}$ & $\mathrm{Y}$ & 27 & 30 & 25.5 & 0.25 & & 22.4 & 30 & 15.5 & 0.2 & & 2.6 & 3.0 & $\begin{array}{l}\text { Filter } 2 \text { reject sampling valve is } \\
\text { sampling effluent. }\end{array}$ \\
\hline $\begin{array}{l}6 / 25 / 201 \\
1 \\
\end{array}$ & Y & & & & & & & & & & & & & \\
\hline
\end{tabular}




\begin{tabular}{|c|c|c|c|c|c|c|c|c|c|c|c|c|c|c|}
\hline & & Influent & & & ter 1 & & & & Filter & & & $\begin{array}{r}\text { Reject } \\
\text { Filter } 1 \\
\end{array}$ & $\begin{array}{r}\text { Reject } \\
\text { Filter } 2 \\
\end{array}$ & \\
\hline & & $\begin{array}{c}\text { Flow } \\
\text { Rate } \\
\text { (gpm) }\end{array}$ & $\begin{array}{c}\text { Air } \\
\text { Flow } \\
\text { (scfh } \\
\text { ) } \\
\end{array}$ & $\begin{array}{c}\text { Head } \\
- \\
\text { loss } \\
\text { (in.) }\end{array}$ & Date & Status & $\begin{array}{c}\text { Influe } \\
\text { nt } \\
\text { Flow } \\
\text { Rate } \\
\text { (gpm) } \\
\end{array}$ & $\begin{array}{c}\text { Air } \\
\text { Flow } \\
\text { (scfh } \\
\text { ) } \\
\end{array}$ & $\begin{array}{c}\text { Head } \\
- \\
\text { loss } \\
\text { (in.) }\end{array}$ & $\begin{array}{c}\text { Bed } \\
\text { Move. } \\
\text { Velocit } \\
y \\
\text { (in/min } \\
\text { ) }\end{array}$ & $\begin{array}{c}\text { Nalmet } \\
\text { ® Flow } \\
\text { Rate } \\
(\mathrm{mL} / \mathrm{hr} \\
\text { )(1) }\end{array}$ & $\begin{array}{c}\text { Flow } \\
\text { Rate } \\
\text { (gpm) }\end{array}$ & $\begin{array}{c}\text { Flow } \\
\text { Rate } \\
\text { (gpm) }\end{array}$ & Notes \\
\hline $\begin{array}{l}6 / 26 / 201 \\
1 \\
\end{array}$ & Y & & & & & & & & & & & & & \\
\hline $\begin{array}{l}6 / 27 / 201 \\
1\end{array}$ & Y & & & & & & & & & & & & & $\begin{array}{l}\text { Filter } 2 \text { reject sampling valve is } \\
\text { sampling effluent. }\end{array}$ \\
\hline $\begin{array}{l}6 / 28 / 201 \\
1\end{array}$ & Y & 29.4 & 30 & 27.1 & & & 24.1 & 30 & 15.7 & & & 4.29 & 7.9 & $\begin{array}{l}\text { Filter } 2 \text { reject sampling valve is } \\
\text { sampling effluent. }\end{array}$ \\
\hline $\begin{array}{l}6 / 29 / 201 \\
1\end{array}$ & Y & 29.4 & 30 & 29.3 & & & 24.8 & 30 & 16.3 & & & 3.71 & 2.86 & $\begin{array}{l}\text { Filter } 2 \text { reject sampling valve is } \\
\text { sampling effluent. }\end{array}$ \\
\hline $\begin{array}{l}6 / 30 / 201 \\
1\end{array}$ & $\mathrm{Y}$ & 29.3 & 30 & 27.1 & 0.25 & & 24.7 & 30 & 16.5 & 0.24 & & 3.57 & 2.95 & $\begin{array}{l}\text { Filter } 2 \text { reject sampling valve is } \\
\text { sampling effluent. }\end{array}$ \\
\hline $7 / 1 / 2011$ & Y & 29.4 & 30 & 27.1 & & & 24.7 & 30 & 16.5 & & & 3.67 & 2.92 & $\begin{array}{l}\text { Filter } 2 \text { reject sampling valve is } \\
\text { sampling effluent. }\end{array}$ \\
\hline $7 / 2 / 2011$ & $\mathrm{Y}$ & & & & & & & & & & & & & \\
\hline $7 / 3 / 2011$ & $\mathrm{Y}$ & & & & & & & & & & & & & \\
\hline $7 / 4 / 2011$ & Y & & & & & & & & & & & & & Fourth of July holiday \\
\hline $7 / 5 / 2011$ & Y & 29.5 & 30 & 27.8 & & & 24.7 & 30 & 15.9 & & & 3.75 & 3.0 & $\begin{array}{l}\text { Filter } 2 \text { reject sampling valve is } \\
\text { sampling effluent. }\end{array}$ \\
\hline $7 / 6 / 2011$ & Y & & & & & & & & & & & & & $\begin{array}{l}\text { Filter } 2 \text { reject sampling valve } \\
\text { corrected, now sampling reject. }\end{array}$ \\
\hline $7 / 7 / 2011$ & Y & 29.5 & 30 & 31.5 & & & 24.7 & 30 & 16.4 & & & 3.96 & 2.96 & \\
\hline $7 / 8 / 2011$ & Y & & & & & & & & & & & & & \\
\hline
\end{tabular}




\begin{tabular}{|c|c|c|c|c|c|c|c|c|c|c|c|c|c|c|}
\hline & & Influent & & & ter 1 & & & & Filte & & & $\begin{array}{c}\text { Reject } \\
\text { Filter } 1 \\
\end{array}$ & $\begin{array}{c}\text { Reject } \\
\text { Filter } 2 \\
\end{array}$ & \\
\hline & & $\begin{array}{c}\text { Flow } \\
\text { Rate } \\
\text { (gpm) }\end{array}$ & $\begin{array}{c}\text { Air } \\
\text { Flow } \\
\text { (scfh } \\
\text { ) } \\
\end{array}$ & $\begin{array}{c}\text { Head } \\
- \\
\text { loss } \\
\text { (in.) } \\
\end{array}$ & Date & Status & $\begin{array}{c}\text { Influe } \\
\text { nt } \\
\text { Flow } \\
\text { Rate } \\
\text { (gpm) }\end{array}$ & $\begin{array}{c}\text { Air } \\
\text { Flow } \\
\text { (scfh } \\
\text { ) }\end{array}$ & $\begin{array}{c}\text { Head } \\
- \\
\text { loss } \\
\text { (in.) } \\
\end{array}$ & $\begin{array}{c}\text { Bed } \\
\text { Move. } \\
\text { Velocit } \\
y \\
\text { (in/min } \\
\text { ) }\end{array}$ & $\begin{array}{c}\text { Nalmet } \\
\text { ß Flow } \\
\text { Rate } \\
(\mathrm{mL} / \mathrm{hr} \\
\text { )(1) }\end{array}$ & $\begin{array}{c}\text { Flow } \\
\text { Rate } \\
\text { (gpm) }\end{array}$ & $\begin{array}{c}\text { Flow } \\
\text { Rate } \\
\text { (gpm) }\end{array}$ & Notes \\
\hline $7 / 9 / 2011$ & Y & & & & & & & & & & & & & \\
\hline $7 / 10 / 2011$ & $\mathrm{Y}$ & & & & & & & & & & & & & \\
\hline $7 / 11 / 2011$ & Y & & & & & & & & & & & & & \\
\hline $7 / 12 / 2011$ & Y & 29 & 30 & 27.7 & 0.27 & & 24.2 & 30 & 16.6 & 0.23 & & 3.6 & 2.94 & \\
\hline $7 / 12 / 2011$ & $\mathrm{Y}$ & 29 & 30 & 27.7 & 0.27 & & 24.2 & 30 & 16.6 & 0.23 & & 3.6 & 2.94 & \\
\hline $7 / 13 / 2011$ & $\mathrm{Y}$ & 28.8 & 30 & 28.5 & & & 24.3 & 30 & 16.6 & & & 3.6 & 3.22 & \\
\hline $7 / 14 / 2011$ & $\mathrm{Y}$ & 28.7 & 30 & 28.7 & 0.25 & & 24 & 30 & 16.4 & 0.23 & & 3.45 & 3.11 & \\
\hline $7 / 15 / 2011$ & Y & 28.6 & 30 & 28.96 & & & 24 & 30 & 16.3 & & & 3.69 & 3.0 & \\
\hline $7 / 16 / 2011$ & Y & & & & & & & & & & & & & \\
\hline $7 / 17 / 2011$ & Y & & & & & & & & & & & & & \\
\hline $7 / 18 / 2011$ & $\mathrm{Y}$ & 28.8 & 30 & 30.7 & & & 24 & 30 & 16.3 & & & 3.84 & 2.96 & \\
\hline $7 / 19 / 2011$ & $\mathrm{Y}$ & 28.8 & 30 & 30.3 & 0.25 & & 24 & 30 & 16.6 & 0.24 & & 3.95 & 2.79 & \\
\hline $7 / 20 / 2011$ & $\mathrm{Y}$ & 28.8 & 30 & 30.6 & & & 24.2 & 30 & 16.5 & & & 3.76 & 2.86 & \\
\hline $7 / 21 / 2011$ & Y & 22.0 & 35 & 30.8 & & & 18.1 & 35 & 13.0 & & & 2.64 & 2.42 & \\
\hline
\end{tabular}




\begin{tabular}{|c|c|c|c|c|c|c|c|c|c|c|c|c|c|c|}
\hline & & Influent & & & ter 1 & & & & FilteI & & & $\begin{array}{r}\text { Reject } \\
\text { Filter } 1 \\
\end{array}$ & $\begin{array}{c}\text { Reject } \\
\text { Filter } 2 \\
\end{array}$ & \\
\hline & & $\begin{array}{c}\text { Flow } \\
\text { Rate } \\
\text { (gpm) }\end{array}$ & $\begin{array}{c}\text { Air } \\
\text { Flow } \\
\text { (scfh } \\
\text { ) }\end{array}$ & $\begin{array}{c}\text { Head } \\
- \\
\text { loss } \\
\text { (in.) } \\
\end{array}$ & Date & Status & $\begin{array}{c}\text { Influe } \\
\text { nt } \\
\text { Flow } \\
\text { Rate } \\
\text { (gpm) }\end{array}$ & $\begin{array}{c}\text { Air } \\
\text { Flow } \\
\text { (scfh } \\
\text { ) } \\
\end{array}$ & $\begin{array}{c}\text { Head } \\
- \\
\text { loss } \\
\text { (in.) } \\
\end{array}$ & $\begin{array}{c}\text { Bed } \\
\text { Move. } \\
\text { Velocit } \\
y \\
\text { (in/min } \\
\text { ) } \\
\end{array}$ & $\begin{array}{c}\text { Nalmet } \\
\text { ß Flow } \\
\text { Rate } \\
\text { (mL/hr } \\
\text { ) (1) }\end{array}$ & $\begin{array}{c}\text { Flow } \\
\text { Rate } \\
\text { (gpm) }\end{array}$ & $\begin{array}{c}\text { Flow } \\
\text { Rate } \\
\text { (gpm) }\end{array}$ & Notes \\
\hline $\begin{array}{l}7 / 21 / 201 \\
1\end{array}$ & Y & 22.0 & 35 & 30.8 & & & 18.1 & 35 & 13.0 & & & 2.64 & 2.42 & \\
\hline $\begin{array}{l}7 / 22 / 201 \\
1\end{array}$ & $\mathrm{~s} / \mathrm{d}$ & & & & & & & & & & & & & $\begin{array}{l}\text { Unit shut down due to overflow } \\
\text { from Filter } 1 \text {. Lab did not sample }\end{array}$ \\
\hline $\begin{array}{l}7 / 23 / 201 \\
1\end{array}$ & Y & & & & & & & & & & & & & \\
\hline $\begin{array}{l}7 / 24 / 201 \\
1\end{array}$ & Y & & & & & & & & & & & & & \\
\hline $\begin{array}{l}7 / 25 / 201 \\
1\end{array}$ & $\mathrm{Y}$ & & & & & & & & & & & & & $\begin{array}{l}\text { Unit running erratically (flow } \\
\text { fluctuations), lab did not sample }\end{array}$ \\
\hline $\begin{array}{l}7 / 26 / 201 \\
1\end{array}$ & Y & 25.1 & 35 & 25 & & & 20.1 & 35 & 12.4 & & & 2.8 & 3.13 & \\
\hline $\begin{array}{l}7 / 27 / 201 \\
1\end{array}$ & Y & 24.0 & 35 & 24 & & & 19.5 & 35 & 12.6 & & & 2.9 & 3.16 & \\
\hline $\begin{array}{l}7 / 28 / 201 \\
1\end{array}$ & Y & 25.5 & 35 & 22.8 & 0.21 & & 19.2 & 35 & 12.7 & 0.21 & & 2.48 & 3.1 & \\
\hline $\begin{array}{l}7 / 29 / 201 \\
1\end{array}$ & Y & 23.2 & 35 & 27.8 & & & 20.2 & 35 & 12.9 & & & & & \\
\hline $\begin{array}{l}7 / 30 / 201 \\
1\end{array}$ & Y & & & & & & & & & & & & & \\
\hline $\begin{array}{l}7 / 31 / 201 \\
1\end{array}$ & Y & & & & & & & & & & & & & \\
\hline $8 / 1 / 2011$ & Y & 26.5 & 35 & 26.6 & & & 19.6 & 35 & 12.9 & & & 3.16 & 3.19 & \\
\hline $8 / 2 / 2011$ & $\mathrm{Y}$ & 25.1 & 35 & 28.1 & 0.346 & & 19.3 & 35 & 12.5 & 0.33 & & 2.02 & 3.04 & $\begin{array}{l}\left.\text { Nalmet }{ }^{\circledR} \text { feed ( } 25 \text { ppm each filter }\right) \\
\text { started late in afternoon }\end{array}$ \\
\hline $8 / 3 / 2011$ & $\mathrm{~s} / \mathrm{d}$ & 25.7 & 40 & 23 & & & 23.2 & 40 & 15.0 & & & 2.21 & 3.0 & $\begin{array}{l}\text { Unit down due to leak in feed line, } \\
\text { Nalmet@ feed was not shut off. }\end{array}$ \\
\hline $8 / 4 / 2011$ & Y & 25.8 & 40 & 23.8 & 0.34 & & 21.7 & 40 & 14.2 & 0.32 & & 2.56 & 2.99 & $\begin{array}{l}\text { Unit started up without Nalmet } ® \\
\text { feed. }\end{array}$ \\
\hline $8 / 5 / 2011$ & Y & 25.6 & 40 & 23.1 & & & 22 & 40 & 14.2 & & & 3.27 & 2.9 & $\begin{array}{l}\text { Nalmet@ feed started up again } \\
15: 30 . .\end{array}$ \\
\hline $8 / 6 / 2011$ & $\mathrm{Y}$ & & & & & & & & & & & & & \\
\hline $8 / 7 / 2011$ & $\mathrm{Y}$ & & & & & & & & & & & & & \\
\hline $8 / 8 / 2011$ & $\mathrm{Y}$ & & & & & & & & & & & & & \\
\hline $8 / 9 / 2011$ & $\mathrm{Y}$ & 26.3 & $\begin{array}{c}40 / \\
35 \\
\end{array}$ & 23.7 & 0.46 & & 23.6 & $\begin{array}{c}40 / \\
35\end{array}$ & 17.3 & 0.44 & & 2.17 & 2.55 & \\
\hline
\end{tabular}




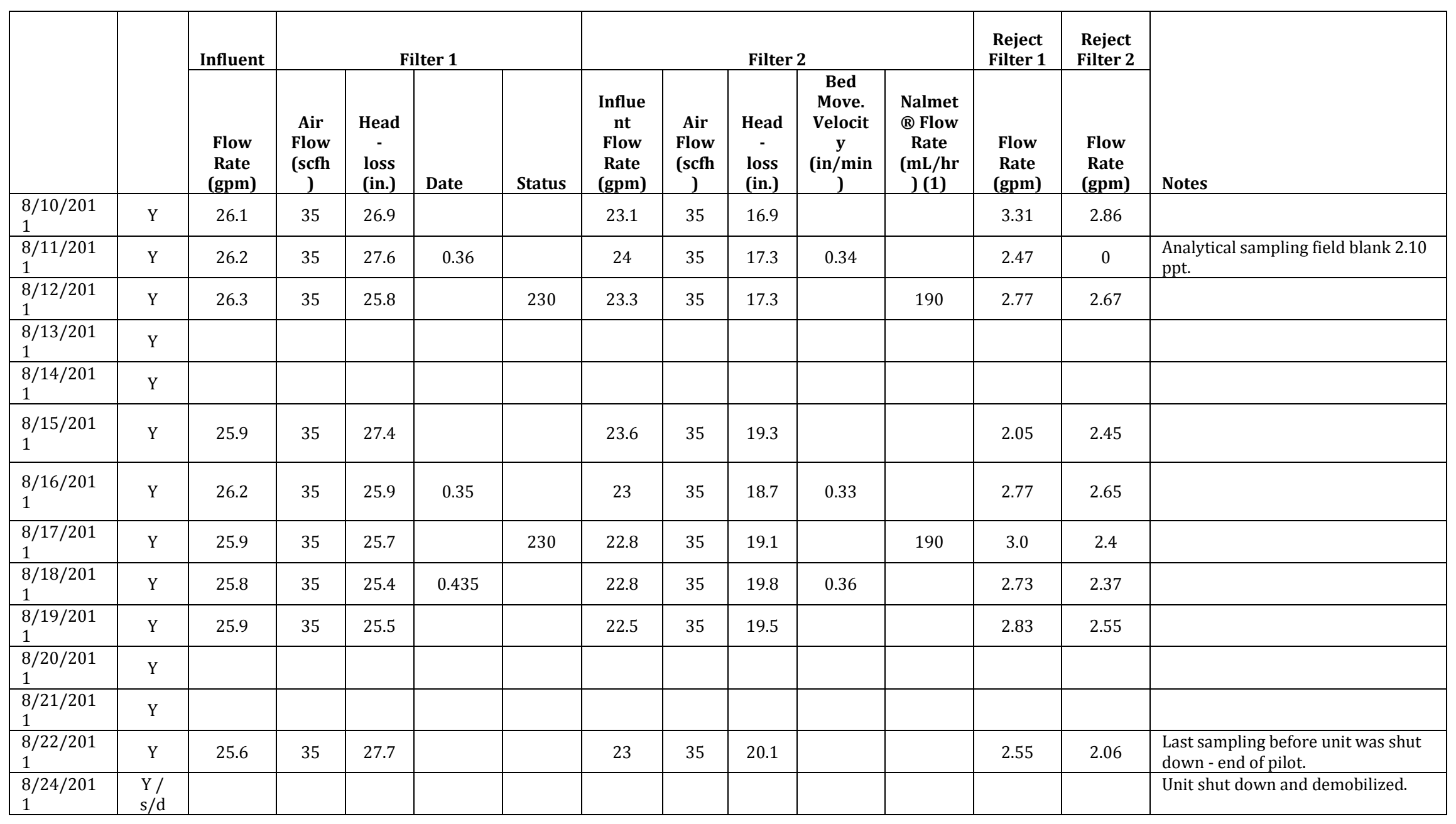


Table 3C.3 Blue PRO® Pilot Daily Operating Summary - Process Variables Measured On-Site

\begin{tabular}{|c|c|c|c|c|c|c|c|c|c|c|c|}
\hline & \multicolumn{3}{|c|}{ Influent } & \multicolumn{3}{|c|}{ Filter 1} & \multicolumn{3}{|c|}{ Filter 2} & \multicolumn{2}{|c|}{$\begin{array}{c}\text { Combined Reject } 1 \\
\text { and } 2\end{array}$} \\
\hline & $\begin{array}{l}\text { Temp. } \\
\text { (deg. } \\
\text { C) }\end{array}$ & pH & $\begin{array}{l}\text { Turbidity } \\
\text { (NTU) }\end{array}$ & $\begin{array}{l}\text { Temp. } \\
\text { (deg. } \\
\text { C) }\end{array}$ & pH & $\begin{array}{l}\text { Turbidity } \\
\text { (NTU) }\end{array}$ & $\begin{array}{l}\text { Temp. } \\
\text { (deg. } \\
\text { C) }\end{array}$ & pH & $\begin{array}{l}\text { Turbidity } \\
\text { (NTU) }\end{array}$ & pH & $\begin{array}{l}\text { Turbidity } \\
\text { (NTU) }\end{array}$ \\
\hline $5 / 19 / 2011$ & & & & & & & & & & & \\
\hline $5 / 20 / 2011$ & 26.9 & 6.81 & 24 & & 6.95 & 2 & & 6.92 & 1 & 7.01 & 22 \\
\hline $5 / 21 / 2011$ & & & & & & & & & & & \\
\hline $5 / 22 / 2011$ & & & & & & & & & & & \\
\hline $5 / 23 / 2011$ & 87 & 6.48 & 29.7 & & 6.77 & 1 & & 6.30 & 1 & 6.65 & 25 \\
\hline $5 / 24 / 2011$ & & & & & & & & & & & \\
\hline $5 / 25 / 2011$ & & & & & & & & & & & \\
\hline $5 / 26 / 2011$ & & & & & & & & & & & \\
\hline $5 / 27 / 2011$ & 23.8 & 6.16 & 13 & 23.2 & 6.34 & 1 & 22.5 & 6.37 & 1 & 6.53 & 57 \\
\hline $5 / 28 / 2011$ & & & & & & & & & & & \\
\hline $5 / 29 / 2011$ & & & & & & & & & & & \\
\hline $5 / 30 / 2011$ & & & & & & & & & & & \\
\hline $5 / 31 / 2011$ & 31.1 & 6.87 & 62 & 29.9 & 6.8 & 1 & 30.2 & 6.84 & 1 & 6.87 & 9 \\
\hline $6 / 1 / 2011$ & 29.5 & 7.08 & 13 & 29.6 & 7.05 & 1 & 29.3 & 7.11 & 1 & 7.15 & 8 \\
\hline $6 / 2 / 2011$ & 28.9 & 7.17 & 22 & 28.9 & 7.02 & 1 & 27.5 & 7.19 & 1 & & 8 \\
\hline $6 / 3 / 2011$ & 31.3 & 7.71 & 25 & 31.4 & 7.55 & 1 & 31.3 & 7.43 & 1 & 7.79 & 8 \\
\hline $6 / 4 / 2011$ & & & & & & & & & & & \\
\hline $6 / 5 / 2011$ & & & & & & & & & & & \\
\hline $6 / 6 / 2011$ & 31 & 7.65 & 22 & 31.4 & 7.66 & 1 & 31.2 & 7.55 & 1 & 7.43 & 8 \\
\hline $6 / 7 / 2011$ & 32.6 & 7.69 & 70 & 33 & 7.6 & 1 & 32.6 & 7.58 & 1 & 7.8 & 6 \\
\hline $6 / 8 / 2011$ & 33.4 & 7.74 & 15 & 32.8 & 7.74 & 1 & 33.4 & 7.72 & 1 & 7.84 & 7 \\
\hline $6 / 10 / 2011$ & 28.8 & 7.92 & 37 & 28.6 & 7.79 & 2 & 28.1 & 7.71 & 2 & 7.97 & 33 \\
\hline
\end{tabular}




\begin{tabular}{|c|c|c|c|c|c|c|c|c|c|c|c|}
\hline & \multicolumn{3}{|c|}{ Influent } & \multicolumn{3}{|c|}{ Filter 1} & \multicolumn{3}{|c|}{ Filter 2} & \multicolumn{2}{|c|}{$\begin{array}{c}\text { Combined Reject } 1 \\
\text { and } 2\end{array}$} \\
\hline & $\begin{array}{l}\text { Temp. } \\
\text { (deg. } \\
\text { C) }\end{array}$ & pH & $\begin{array}{l}\text { Turbidity } \\
\text { (NTU) }\end{array}$ & $\begin{array}{l}\text { Temp. } \\
\text { (deg. } \\
\text { C) }\end{array}$ & pH & $\begin{array}{l}\text { Turbidity } \\
\text { (NTU) }\end{array}$ & $\begin{array}{l}\text { Temp. } \\
\text { (deg. } \\
\text { C) }\end{array}$ & pH & $\begin{array}{l}\text { Turbidity } \\
\text { (NTU) }\end{array}$ & pH & $\begin{array}{c}\text { Turbidity } \\
\text { (NTU) }\end{array}$ \\
\hline \multicolumn{12}{|l|}{$6 / 11 / 2011$} \\
\hline \multicolumn{12}{|l|}{$6 / 12 / 2011$} \\
\hline $6 / 13 / 2011$ & 28.8 & 7.89 & 26 & 28.8 & 7.8 & 1 & 28.2 & 7.77 & 1 & 7.97 & 6 \\
\hline $6 / 14 / 2011$ & 30.1 & 7.8 & 36 & 30.2 & 7.78 & 2 & 29.8 & 7.76 & 2 & 7.87 & 15 \\
\hline $6 / 15 / 2011$ & 29.6 & 7.88 & 31 & 29.6 & 7.89 & 2 & 29.8 & 7.93 & 2 & 8.02 & 18 \\
\hline $6 / 16 / 2011$ & 31.4 & 7.66 & 43 & 31.4 & 7.62 & 2 & 31.0 & 7.62 & 1 & 7.76 & 13 \\
\hline \multicolumn{12}{|l|}{$6 / 17 / 2011$} \\
\hline \multicolumn{12}{|l|}{$6 / 18 / 2011$} \\
\hline \multicolumn{12}{|l|}{$6 / 19 / 2011$} \\
\hline \multicolumn{12}{|l|}{$6 / 20 / 2011$} \\
\hline \multicolumn{12}{|l|}{$6 / 21 / 2011$} \\
\hline \multicolumn{12}{|l|}{$6 / 22 / 2011$} \\
\hline \multicolumn{12}{|l|}{$6 / 23 / 2011$} \\
\hline $6 / 24 / 2011$ & 33.3 & 8.34 & 8 & 32.9 & 8.34 & 5 & 32.1 & 8.31 & & 8.42 & 21 \\
\hline \multicolumn{12}{|l|}{$6 / 25 / 2011$} \\
\hline \multicolumn{12}{|l|}{$6 / 26 / 2011$} \\
\hline \multicolumn{12}{|l|}{$6 / 27 / 2011$} \\
\hline $6 / 28 / 2011$ & 34.6 & 8.04 & 44 & 34.6 & 8 & & 34.3 & 8.02 & & 8.17 & 23 \\
\hline $6 / 29 / 2011$ & 34.4 & 8.05 & 24 & 34.5 & 7.99 & 2 & 34.0 & 7.98 & 1 & 8.16 & 34.3 \\
\hline $6 / 30 / 2011$ & 34.8 & 7.99 & 13 & 34.9 & 7.94 & 2 & 34.7 & 7.98 & 2 & 8.15 & 35 \\
\hline $7 / 1 / 2011$ & 33.2 & 8.13 & 15 & 33.2 & 8.04 & 2 & 32.3 & 8.02 & 2 & 8.19 & 17 \\
\hline \multicolumn{12}{|l|}{$7 / 2 / 2011$} \\
\hline \multicolumn{12}{|l|}{$7 / 3 / 2011$} \\
\hline \multicolumn{12}{|l|}{$7 / 4 / 2011$} \\
\hline $7 / 5 / 2011$ & 35.1 & 7.77 & 44 & 35.2 & 7.78 & 2 & 35.4 & 7.86 & 2 & 7.85 & 21 \\
\hline
\end{tabular}




\begin{tabular}{|c|c|c|c|c|c|c|c|c|c|c|c|}
\hline & \multicolumn{3}{|c|}{ Influent } & \multicolumn{3}{|c|}{ Filter 1} & \multicolumn{3}{|c|}{ Filter 2} & \multicolumn{2}{|c|}{$\begin{array}{c}\text { Combined Reject } 1 \\
\text { and } 2\end{array}$} \\
\hline & $\begin{array}{l}\text { Temp. } \\
\text { (deg. } \\
\text { C) }\end{array}$ & pH & $\begin{array}{l}\text { Turbidity } \\
\text { (NTU) }\end{array}$ & $\begin{array}{l}\text { Temp. } \\
\text { (deg. } \\
\text { C) }\end{array}$ & pH & $\begin{array}{l}\text { Turbidity } \\
\text { (NTU) }\end{array}$ & $\begin{array}{l}\text { Temp. } \\
\text { (deg. } \\
\text { C) }\end{array}$ & pH & $\begin{array}{l}\text { Turbidity } \\
\text { (NTU) }\end{array}$ & $\mathbf{p H}$ & $\begin{array}{c}\text { Turbidity } \\
\text { (NTU) }\end{array}$ \\
\hline \multicolumn{12}{|l|}{$7 / 6 / 2011$} \\
\hline $7 / 7 / 2011$ & 33.6 & 7.98 & 13 & 33.4 & 7.93 & 2 & 32.8 & 8.07 & 2 & 8.07 & 9 \\
\hline \multicolumn{12}{|l|}{$7 / 8 / 2011$} \\
\hline \multicolumn{12}{|l|}{$7 / 9 / 2011$} \\
\hline \multicolumn{12}{|l|}{$7 / 10 / 2011$} \\
\hline \multicolumn{12}{|l|}{$7 / 11 / 2011$} \\
\hline $7 / 12 / 2011$ & 36.3 & 7.86 & 25 & 36.3 & 7.81 & 4 & 35.9 & 7.91 & 3 & 8.04 & 15 \\
\hline $7 / 13 / 2011$ & 35.5 & 7.61 & 23 & 35.6 & 7.58 & 5 & 34.8 & 7.63 & 5 & 7.77 & 31 \\
\hline $7 / 14 / 2011$ & 35.8 & 7.72 & 22 & 35.9 & 7.67 & 4 & 34.1 & 7.73 & 4 & 7.87 & 34.2 \\
\hline $7 / 15 / 2011$ & 35.2 & 8.11 & 21 & 35.3 & 8.09 & 4 & 35.1 & 8.11 & 4 & 8.31 & 34.8 \\
\hline \multicolumn{12}{|l|}{$7 / 16 / 2011$} \\
\hline \multicolumn{12}{|l|}{$7 / 17 / 2011$} \\
\hline $7 / 18 / 2011$ & 37.2 & 8.17 & 25 & 37.2 & 8.16 & 2 & 36.7 & 8.18 & 3 & 8.39 & 19 \\
\hline $7 / 19 / 2011$ & 36.7 & 7.56 & 16 & 36.8 & 7.51 & 4 & 36.2 & 7.53 & 4 & 7.72 & 19 \\
\hline $7 / 20 / 2011$ & 37.8 & 7.53 & 28 & 38 & 7.46 & 4 & 37.8 & 7.48 & 4 & 7.73 & 24 \\
\hline $7 / 21 / 2011$ & 38.2 & 7.43 & 7 & 38.2 & 7.44 & 3 & 38.5 & 7.48 & 3 & 7.74 & 20 \\
\hline \multicolumn{12}{|l|}{$7 / 22 / 2011$} \\
\hline \multicolumn{12}{|l|}{$7 / 23 / 2011$} \\
\hline \multicolumn{12}{|l|}{$7 / 24 / 2011$} \\
\hline \multicolumn{12}{|l|}{$7 / 25 / 2011$} \\
\hline $7 / 26 / 2011$ & 36.7 & 7.53 & 27 & 36.6 & 7.47 & 4 & 36.3 & 7.51 & 4 & 7.74 & 27 \\
\hline $7 / 27 / 2011$ & 35.4 & 7.51 & 22 & 35.5 & 7.49 & 3 & 34.7 & 7.55 & 4 & 7.72 & 181 \\
\hline $7 / 28 / 2011$ & 35.5 & 7.67 & 12 & 35.5 & 7.68 & 3 & 34.9 & 7.68 & 3 & 7.89 & 19 \\
\hline $7 / 29 / 2011$ & 35.8 & 7.69 & 18 & 35.8 & 7.69 & 2 & 35.4 & 7.71 & 3 & 7.93 & 16 \\
\hline
\end{tabular}




\begin{tabular}{|c|c|c|c|c|c|c|c|c|c|c|c|}
\hline & \multicolumn{3}{|c|}{ Influent } & \multicolumn{3}{|c|}{ Filter 1} & \multicolumn{3}{|c|}{ Filter 2} & \multicolumn{2}{|c|}{$\begin{array}{c}\text { Combined Reject } 1 \\
\text { and } 2\end{array}$} \\
\hline & $\begin{array}{l}\text { Temp. } \\
\text { (deg. } \\
\text { C) }\end{array}$ & pH & $\begin{array}{l}\text { Turbidity } \\
\text { (NTU) }\end{array}$ & $\begin{array}{l}\text { Temp. } \\
\text { (deg. } \\
\text { C) }\end{array}$ & pH & $\begin{array}{l}\text { Turbidity } \\
\text { (NTU) }\end{array}$ & $\begin{array}{l}\text { Temp. } \\
\text { (deg. } \\
\text { C) }\end{array}$ & pH & $\begin{array}{l}\text { Turbidity } \\
\text { (NTU) }\end{array}$ & pH & $\begin{array}{l}\text { Turbidity } \\
\text { (NTU) }\end{array}$ \\
\hline \multicolumn{12}{|l|}{$7 / 30 / 2011$} \\
\hline \multicolumn{12}{|l|}{$7 / 31 / 2011$} \\
\hline $8 / 1 / 2011$ & 37.5 & 7.66 & 7 & 37.6 & 7.65 & 2 & 37.4 & 7.69 & 2 & 7.94 & 11 \\
\hline $8 / 2 / 2011$ & 37.5 & 7.71 & 9 & 37.6 & 7.76 & 1 & 37.5 & 7.72 & 1 & 7.96 & 11 \\
\hline \multicolumn{12}{|l|}{$8 / 3 / 2011$} \\
\hline $8 / 4 / 2011$ & 36.1 & 7.76 & 7 & 36.1 & 7.74 & 2 & 35.7 & 7.81 & 1 & 8.00 & 23 \\
\hline $8 / 5 / 2011$ & 36.1 & 7.37 & 4 & 36.2 & 7.49 & 2 & 36.4 & 7.61 & 1 & 7.77 & 78 \\
\hline \multicolumn{12}{|l|}{$8 / 6 / 2011$} \\
\hline \multicolumn{12}{|l|}{$8 / 7 / 2011$} \\
\hline \multicolumn{12}{|l|}{$8 / 8 / 2011$} \\
\hline $8 / 9 / 2011$ & 35.5 & 7.44 & 7 & 35.4 & 7.47 & 3 & 34.8 & 7.49 & 2 & 7.79 & 59 \\
\hline $8 / 10 / 2011$ & 35.5 & 7.47 & 15 & 35.4 & 7.49 & 3 & 34.6 & 7.51 & 1 & 7.76 & 86 \\
\hline $8 / 11 / 2011$ & 36.1 & 7.52 & 18 & 35.4 & 7.54 & 2 & 35.3 & 7.56 & 5 & 7.76 & 74 \\
\hline $8 / 12 / 2011$ & 36.2 & 7.26 & 8 & 35.8 & 7.29 & 4 & 35.2 & 7.36 & 3 & 7.61 & 76 \\
\hline \multicolumn{12}{|l|}{$8 / 13 / 2011$} \\
\hline \multicolumn{12}{|l|}{$8 / 14 / 2011$} \\
\hline $8 / 15 / 2011$ & 34.4 & 7.14 & 34 & 34.3 & 7.19 & 11 & 33.6 & 7.27 & 3 & 7.52 & 216 \\
\hline $8 / 16 / 2011$ & 35.5 & 7.18 & 14 & 35.3 & 7.18 & 3 & 35.2 & 7.21 & 2 & 7.46 & 111 \\
\hline $8 / 17 / 2011$ & 36.3 & 7.30 & 14 & 36.3 & 7.26 & 5 & 35.8 & 7.32 & 3 & 7.57 & 72 \\
\hline $8 / 18 / 2011$ & 36.9 & 7.36 & 6 & 36.8 & 7.35 & 3 & 36.1 & 7.39 & 1 & 7.64 & 63 \\
\hline $8 / 19 / 2011$ & 36.9 & 7.39 & 10 & 36.6 & 7.4 & 3 & 35.8 & 7.44 & 1 & 7.71 & 53 \\
\hline \multicolumn{12}{|l|}{$8 / 20 / 2011$} \\
\hline \multicolumn{12}{|l|}{$8 / 21 / 2011$} \\
\hline $8 / 22 / 2011$ & 36.9 & 7.43 & 8 & 36.8 & 7.42 & 5 & 36.2 & 7.45 & 1 & 7.74 & 59 \\
\hline
\end{tabular}




\section{Table 3C.4 Blue PRO® Pilot Daily Operating Summary - Hg and TSS Analytical Results}

(1) Filter 2 reject sampling valve is sampling effluent $(6 / 23-7 / 5 / 11)$.

(2) $7 / 5 / 11$ Filter 2 effluent reported from lab at $19.4 \mathrm{ppt}$, Reject reported as $<0.5 \mathrm{ppt}$. Sampling error suspected. Switched these values to align with historical values.

(3) 8/15/11 Filter 1 effluent reported from lab as 5.08 ppt, Reject 1 reported as 0.572 ppt. Sampling error suspected. Switched these values to align with historical values.

\begin{tabular}{|c|c|c|c|c|c|c|c|c|c|c|c|c|c|c|c|c|}
\hline & \multicolumn{3}{|c|}{ Influent } & \multicolumn{3}{|c|}{ Filter 1} & \multicolumn{3}{|c|}{ Filter 2} & \multicolumn{3}{|c|}{ Combined Reject 1 and 2} & \multicolumn{2}{|c|}{ Reject 1} & \multicolumn{2}{|c|}{ Reject 2} \\
\hline & $\begin{array}{c}\text { Total } \\
\text { Hg } \\
\text { (ppt) }\end{array}$ & $\begin{array}{c}\text { Diss. } \\
\text { Hg } \\
\text { (ppt) }\end{array}$ & $\begin{array}{c}\text { TSS } \\
\text { (ppm } \\
\text { ) }\end{array}$ & $\begin{array}{c}\text { Total } \\
\text { Hg } \\
\text { (ppt) }\end{array}$ & $\begin{array}{c}\text { Diss. } \\
\text { Hg } \\
\text { (ppt) }\end{array}$ & $\begin{array}{c}\text { TSS } \\
\text { (ppm } \\
\text { ) }\end{array}$ & $\begin{array}{c}\text { Total } \\
\text { Hg } \\
\text { (ppt) }\end{array}$ & $\begin{array}{c}\text { Diss. } \\
\text { Hg } \\
\text { (ppt) }\end{array}$ & $\begin{array}{c}\text { TSS } \\
\text { (ppm } \\
\text { ) }\end{array}$ & $\begin{array}{c}\text { Total } \\
\text { Hg } \\
\text { (ppt) }\end{array}$ & $\begin{array}{c}\text { Diss. } \\
\text { Hg } \\
\text { (ppt) }\end{array}$ & $\begin{array}{c}\text { TSS } \\
\text { (ppm } \\
\text { ) }\end{array}$ & $\begin{array}{c}\text { Total } \\
\text { Hg } \\
\text { (ppt) }\end{array}$ & $\begin{array}{c}\text { TSS } \\
\text { (ppm } \\
\text { ) }\end{array}$ & $\begin{array}{c}\text { Total } \\
\text { Hg } \\
\text { (ppt) }\end{array}$ & $\begin{array}{c}\text { TSS } \\
\text { (ppm } \\
\text { ) }\end{array}$ \\
\hline $\begin{array}{l}5 / 19 / 201 \\
1\end{array}$ & & & & & & & & & & & & & & & & \\
\hline $\begin{array}{l}5 / 20 / 201 \\
1\end{array}$ & 8.5 & $<0.5$ & 10.0 & $<0.5$ & $<0.5$ & & 0.737 & $<0.5$ & 1.6 & 35.4 & $<0.5$ & 35.0 & & & & \\
\hline $\begin{array}{l}5 / 21 / 201 \\
1\end{array}$ & & & & & & & & & & & & & & & & \\
\hline $\begin{array}{l}5 / 22 / 201 \\
1\end{array}$ & & & & & & & & & & & & & & & & \\
\hline $\begin{array}{l}5 / 23 / 201 \\
1\end{array}$ & 14.7 & $<0.5$ & 6.4 & & & & $<0.5$ & $<0.5$ & 1.6 & $\begin{array}{l}14.4, \\
18.4\end{array}$ & $\begin{array}{l}1.09 \\
<0.5\end{array}$ & 21.0 & & & & \\
\hline $\begin{array}{l}5 / 24 / 201 \\
1\end{array}$ & $\begin{array}{l}7.44 \\
12.1 \\
\end{array}$ & $\begin{array}{l}<0.5 \\
<0.5\end{array}$ & 4.4 & & & & $<0.5$ & $<0.5$ & $<1.0$ & 24.2 & $<0.5$ & 20.0 & & & & \\
\hline $\begin{array}{l}5 / 25 / 201 \\
1\end{array}$ & & & & & & & & & & & & & & & & \\
\hline $\begin{array}{l}5 / 26 / 201 \\
1\end{array}$ & & & & & & & & & & & & & & & & \\
\hline $\begin{array}{l}5 / 27 / 201 \\
1\end{array}$ & 7.42 & $<0.5$ & 4.8 & & & & $<0.5$ & $<0.5$ & $<1.0$ & 24.3 & & 26.0 & & & & \\
\hline $\begin{array}{l}5 / 28 / 201 \\
1\end{array}$ & & & & & & & & & & & & & & & & \\
\hline $\begin{array}{l}5 / 29 / 201 \\
1\end{array}$ & & & & & & & & & & & & & & & & \\
\hline $\begin{array}{l}5 / 30 / 201 \\
1\end{array}$ & & & & & & & & & & & & & & & & \\
\hline $\begin{array}{l}5 / 31 / 201 \\
1\end{array}$ & 2.56 & $<0.5$ & 25.0 & & & & $<0.5$ & $<0.5$ & $<1.0$ & 9.89 & & 11.0 & & & & \\
\hline
\end{tabular}




\begin{tabular}{|c|c|c|c|c|c|c|c|c|c|c|c|c|c|c|c|c|}
\hline & \multicolumn{3}{|c|}{ Influent } & \multicolumn{3}{|c|}{ Filter 1} & \multicolumn{3}{|c|}{ Filter 2} & \multicolumn{3}{|c|}{ Combined Reject 1 and 2} & \multicolumn{2}{|c|}{ Reject 1} & \multicolumn{2}{|c|}{ Reject 2} \\
\hline & $\begin{array}{c}\text { Total } \\
\text { Hg } \\
\text { (ppt) }\end{array}$ & $\begin{array}{c}\text { Diss. } \\
\text { Hg } \\
\text { (ppt) }\end{array}$ & $\begin{array}{c}\text { TSS } \\
\text { (ppm } \\
\text { ) }\end{array}$ & $\begin{array}{c}\text { Total } \\
\text { Hg } \\
\text { (ppt) }\end{array}$ & $\begin{array}{c}\text { Diss. } \\
\text { Hg } \\
\text { (ppt) }\end{array}$ & $\begin{array}{c}\text { TSS } \\
\text { (ppm } \\
\text { ) }\end{array}$ & $\begin{array}{c}\text { Total } \\
\text { Hg } \\
\text { (ppt) }\end{array}$ & $\begin{array}{c}\text { Diss. } \\
\text { Hg } \\
\text { (ppt) }\end{array}$ & $\begin{array}{c}\text { TSS } \\
\text { (ppm } \\
\text { ) }\end{array}$ & $\begin{array}{c}\text { Total } \\
\text { Hg } \\
\text { (ppt) }\end{array}$ & $\begin{array}{c}\text { Diss. } \\
\text { Hg } \\
\text { (ppt) }\end{array}$ & $\begin{array}{c}\text { TSS } \\
\text { (ppm } \\
\text { ) }\end{array}$ & $\begin{array}{c}\text { Total } \\
\text { Hg } \\
\text { (ppt) }\end{array}$ & $\begin{array}{c}\text { TSS } \\
\text { (ppm } \\
\text { ) }\end{array}$ & $\begin{array}{c}\text { Total } \\
\text { Hg } \\
\text { (ppt) }\end{array}$ & $\begin{array}{c}\text { TSS } \\
\text { (ppm } \\
\text { ) }\end{array}$ \\
\hline $6 / 1 / 2011$ & 3.27 & $<0.5$ & $\begin{array}{c}3.2 \\
1.6 \\
\end{array}$ & & & & $\begin{array}{l}<0.5 \\
<0.5\end{array}$ & $<0.5$ & & 9.2 & & 10.0 & & & & \\
\hline \multicolumn{17}{|l|}{$6 / 2 / 2011$} \\
\hline $6 / 3 / 2011$ & 5.4 & $<0.5$ & 6.0 & & & & $<0.5$ & & 2.0 & $\begin{array}{l}13.3, \\
15.9\end{array}$ & & 16.0 & & & & \\
\hline \multicolumn{17}{|l|}{$6 / 4 / 2011$} \\
\hline \multicolumn{17}{|l|}{$6 / 5 / 2011$} \\
\hline $6 / 6 / 2011$ & $\begin{array}{l}6.18 \\
7.09\end{array}$ & $\begin{array}{l}<0.50 \\
, 1.86\end{array}$ & 4.8 & & & & $<0.5$ & & $<1.0$ & 11.2 & & 12.0 & & & & \\
\hline \multicolumn{17}{|l|}{$6 / 7 / 2011$} \\
\hline $6 / 8 / 2011$ & 4.48 & $\begin{array}{l}<0.5 \\
<0.5\end{array}$ & 4.0 & & & & $\begin{array}{l}<0.5 \\
<0.5\end{array}$ & & 1.2 & 20.2 & & 21.0 & & & & \\
\hline \multicolumn{17}{|l|}{$6 / 9 / 2011$} \\
\hline $\begin{array}{l}6 / 10 / 201 \\
1\end{array}$ & 8.86 & $\begin{array}{l}<0.5 \\
<0.5\end{array}$ & 6.0 & & & & $\begin{array}{l}<0.5 \\
<0.5\end{array}$ & & $<1.0$ & 25.2 & & 26.0 & & & & \\
\hline \multicolumn{17}{|l|}{$\begin{array}{l}6 / 11 / 201 \\
1\end{array}$} \\
\hline \multicolumn{17}{|l|}{$\begin{array}{l}6 / 12 / 201 \\
1\end{array}$} \\
\hline $\begin{array}{l}6 / 13 / 201 \\
1\end{array}$ & 2.15 & $\begin{array}{l}<0.5 \\
<0.5\end{array}$ & 3.2 & & & & $\begin{array}{l}<0.5 \\
<0.5\end{array}$ & & 1.2 & 6.91 & & 12.0 & & & & \\
\hline \multicolumn{17}{|l|}{$\begin{array}{l}6 / 14 / 201 \\
1\end{array}$} \\
\hline $\begin{array}{l}6 / 15 / 201 \\
1\end{array}$ & 9.56 & $\begin{array}{l}<0.5, \\
<0.5\end{array}$ & 7.2 & $<0.5$ & $<0.5$ & 2.0 & $<0.5$ & & 1.6 & 20.6 & & 30 & & & & \\
\hline \multicolumn{17}{|l|}{$\begin{array}{l}6 / 16 / 201 \\
1\end{array}$} \\
\hline $\begin{array}{l}6 / 17 / 201 \\
1\end{array}$ & 24.2 & $\begin{array}{l}<0.5, \\
<0.5\end{array}$ & 10 & $<0.5$ & & 1.2 & $<0.5$ & & $<1.0$ & $\begin{array}{l}33.0, \\
24.4 \\
\end{array}$ & & 43 & & & & \\
\hline \multicolumn{17}{|l|}{$\begin{array}{l}6 / 18 / 201 \\
1\end{array}$} \\
\hline \multicolumn{17}{|l|}{$\begin{array}{l}6 / 19 / 201 \\
1\end{array}$} \\
\hline $\begin{array}{l}6 / 20 / 201 \\
1\end{array}$ & & & & & & & & & & & & & & & & \\
\hline
\end{tabular}




\begin{tabular}{|c|c|c|c|c|c|c|c|c|c|c|c|c|c|c|c|c|}
\hline & \multicolumn{3}{|c|}{ Influent } & \multicolumn{3}{|c|}{ Filter 1} & \multicolumn{3}{|c|}{ Filter 2} & \multicolumn{3}{|c|}{ Combined Reject 1 and 2} & \multicolumn{2}{|c|}{ Reject 1} & \multicolumn{2}{|c|}{ Reject 2} \\
\hline & $\begin{array}{c}\text { Total } \\
\text { Hg } \\
\text { (ppt) }\end{array}$ & $\begin{array}{c}\text { Diss. } \\
\text { Hg } \\
\text { (ppt) }\end{array}$ & $\begin{array}{c}\text { TSS } \\
\text { (ppm } \\
\text { ) }\end{array}$ & $\begin{array}{c}\text { Total } \\
\text { Hg } \\
\text { (ppt) }\end{array}$ & $\begin{array}{c}\text { Diss. } \\
\text { Hg } \\
\text { (ppt) }\end{array}$ & $\begin{array}{c}\text { TSS } \\
\text { (ppm } \\
\text { ) }\end{array}$ & $\begin{array}{c}\text { Total } \\
\text { Hg } \\
\text { (ppt) }\end{array}$ & $\begin{array}{c}\text { Diss. } \\
\text { Hg } \\
\text { (ppt) }\end{array}$ & $\begin{array}{c}\text { TSS } \\
\text { (ppm } \\
\text { ) }\end{array}$ & $\begin{array}{c}\text { Total } \\
\text { Hg } \\
\text { (ppt) }\end{array}$ & $\begin{array}{c}\text { Diss. } \\
\text { Hg } \\
\text { (ppt) }\end{array}$ & $\begin{array}{c}\text { TSS } \\
\text { (ppm } \\
\text { ) }\end{array}$ & $\begin{array}{c}\text { Total } \\
\text { Hg } \\
\text { (ppt) }\end{array}$ & $\begin{array}{c}\text { TSS } \\
\text { (ppm } \\
\text { ) }\end{array}$ & $\begin{array}{c}\text { Total } \\
\text { Hg } \\
\text { (ppt) }\end{array}$ & $\begin{array}{c}\text { TSS } \\
\text { (ppm } \\
\text { ) }\end{array}$ \\
\hline $\begin{array}{l}6 / 21 / 201 \\
1 \\
\end{array}$ & & & & & & & & & & & & & & & & \\
\hline $\begin{array}{l}6 / 22 / 201 \\
1\end{array}$ & & & & & & & & & & & & & & & & \\
\hline $\begin{array}{l}6 / 23 / 201 \\
1\end{array}$ & & & & & & & & & & (1) & & & & & & \\
\hline $\begin{array}{l}6 / 24 / 201 \\
1 \\
\end{array}$ & $\begin{array}{c}5.27 \\
4.04 \\
\end{array}$ & $\begin{array}{l}<0.5, \\
<0.5\end{array}$ & 3.6 & & & & $<0.5$ & & $<1.0$ & $\begin{array}{l}12.7 \\
(1)\end{array}$ & & 10 & & & & \\
\hline $\begin{array}{l}6 / 25 / 201 \\
1\end{array}$ & & & & & & & & & & & & & & & & \\
\hline $\begin{array}{l}6 / 26 / 201 \\
1\end{array}$ & & & & & & & & & & & & & & & & \\
\hline $\begin{array}{l}6 / 27 / 201 \\
1\end{array}$ & 8.53 & $\begin{array}{l}<0.5 \\
<0.5\end{array}$ & 6.8 & $<0.5$ & $<0.5$ & & $<0.5$ & & 4 & $\begin{array}{c}37.7 \\
32.9 \\
(1)\end{array}$ & & 27 & & & & \\
\hline $\begin{array}{l}6 / 28 / 201 \\
1 \\
\end{array}$ & & & & & & & & & & & & & & & & \\
\hline $\begin{array}{l}6 / 29 / 201 \\
1\end{array}$ & 5.74 & 1.21 & 4.8 & & & & $<0.5$ & & $<1.0$ & $\begin{array}{c}29.7 \\
(1)\end{array}$ & & 23 & & & & \\
\hline $\begin{array}{l}6 / 30 / 201 \\
1\end{array}$ & & & & & & & & & & & & & & & & \\
\hline $7 / 1 / 2011$ & 6.21 & $<0.5$ & 3.6 & & & & $<0.5$ & & $<1.0$ & $\begin{array}{c}30.5 \\
(1)\end{array}$ & & 15 & & & & \\
\hline $7 / 2 / 2011$ & & & & & & & & & & & & & & & & \\
\hline $7 / 3 / 2011$ & & & & & & & & & & & & & & & & \\
\hline $7 / 4 / 2011$ & & & & & & & & & & & & & & & & \\
\hline $7 / 5 / 2011$ & 13.7 & $\begin{array}{l}<0.5 \\
<0.5\end{array}$ & 5.6 & & & & $\begin{array}{l}<0.5 \\
(2) \\
\end{array}$ & & $<1.0$ & $\begin{array}{c}19.4 \\
19.6 \\
(1),(2 \\
)\end{array}$ & & 10 & & & & \\
\hline $7 / 6 / 2011$ & 2.07 & $<0.5$ & 3.2 & & & & $<0.5$ & & 1.6 & 27.8 & & 21 & & & & \\
\hline $7 / 7 / 2011$ & & & & & & & & & & & & & & & & \\
\hline $7 / 8 / 2011$ & 4.56 & $<0.5$ & 4.4 & & & & $<0.5$ & & 2.8 & 20.4 & & 16 & & & & \\
\hline $7 / 9 / 2011$ & & & & & & & & & & & & & & & & \\
\hline
\end{tabular}




\begin{tabular}{|c|c|c|c|c|c|c|c|c|c|c|c|c|c|c|c|c|}
\hline & $\begin{array}{c}\text { Influen } \\
\mathbf{t}\end{array}$ & $\begin{array}{c}\text { Filter } \\
1 \\
\end{array}$ & $\begin{array}{c}\text { Filter } \\
2 \\
\end{array}$ & $\begin{array}{c}\text { Combine } \\
\text { d Reject } 1 \\
\text { and } 2 \\
\end{array}$ & $\begin{array}{c}\text { Rejec } \\
\text { t } 1\end{array}$ & $\begin{array}{c}\text { Rejec } \\
\text { t } 2 \\
\end{array}$ & & & & & & & & & & \\
\hline & $\begin{array}{c}\text { Total } \\
\text { Hg } \\
\text { (ppt) }\end{array}$ & $\begin{array}{c}\text { Diss. } \\
\text { Hg } \\
\text { (ppt) }\end{array}$ & $\begin{array}{c}\text { TSS } \\
\text { (ppm } \\
\text { ) }\end{array}$ & $\begin{array}{c}\text { Total } \\
\text { Hg } \\
\text { (ppt) }\end{array}$ & $\begin{array}{c}\text { Diss. } \\
\text { Hg } \\
\text { (ppt) }\end{array}$ & $\begin{array}{c}\text { TSS } \\
\text { (ppm } \\
\text { ) }\end{array}$ & $\begin{array}{c}\text { Total } \\
\text { Hg } \\
\text { (ppt) }\end{array}$ & $\begin{array}{c}\text { Diss. } \\
\text { Hg } \\
\text { (ppt) }\end{array}$ & $\begin{array}{c}\text { TSS } \\
\text { (ppm } \\
\text { ) }\end{array}$ & $\begin{array}{c}\text { Total } \\
\text { Hg } \\
\text { (ppt) }\end{array}$ & $\begin{array}{c}\text { Diss. } \\
\text { Hg } \\
\text { (ppt) }\end{array}$ & $\begin{array}{c}\text { TSS } \\
\text { (ppm } \\
\text { ) }\end{array}$ & $\begin{array}{c}\text { Total } \\
\text { Hg } \\
\text { (ppt) }\end{array}$ & $\begin{array}{c}\text { TSS } \\
\text { (ppm } \\
\text { ) }\end{array}$ & $\begin{array}{c}\text { Total } \\
\text { Hg } \\
\text { (ppt) }\end{array}$ & $\begin{array}{c}\text { TSS } \\
\text { (ppm } \\
\text { ) }\end{array}$ \\
\hline $\begin{array}{l}7 / 11 / 201 \\
1\end{array}$ & & & & & & & & & & & & & & & & \\
\hline $\begin{array}{l}7 / 12 / 201 \\
1\end{array}$ & & & & & & & & & & & & & & & & \\
\hline $\begin{array}{l}7 / 13 / 201 \\
1\end{array}$ & 17.9 & $<0.5$ & 10 & & & & 4.08 & & 4.8 & 86 & & 38 & & & & \\
\hline $\begin{array}{l}7 / 14 / 201 \\
1\end{array}$ & & & & & & & & & & & & & & & & \\
\hline $\begin{array}{l}7 / 15 / 201 \\
1\end{array}$ & 12.1 & $<0.5$ & 8.4 & & & & 2.42 & & 2.4 & 34.3 & & 26 & & & & \\
\hline $\begin{array}{l}7 / 16 / 201 \\
1\end{array}$ & & & & & & & & & & & & & & & & \\
\hline $\begin{array}{l}7 / 17 / 201 \\
1\end{array}$ & & & & & & & & & & & & & & & & \\
\hline $\begin{array}{l}7 / 18 / 201 \\
1\end{array}$ & 5.95 & $\begin{array}{l}<0.5 \\
<0.5\end{array}$ & 6.4 & & & & $\begin{array}{l}0.957 \\
, 1.07 \\
\end{array}$ & & 2.4 & 20.8 & & 20 & & & & \\
\hline $\begin{array}{l}7 / 19 / 201 \\
1\end{array}$ & & & & & & & & & & & & & & & & \\
\hline $\begin{array}{l}7 / 20 / 201 \\
1\end{array}$ & 4.95 & 1.33 & 3.2 & & & & 1.28 & & 4 & 25.3 & & 19 & & & & \\
\hline $\begin{array}{l}7 / 21 / 201 \\
1\end{array}$ & & & & & & & & & & & & & & & & \\
\hline $\begin{array}{l}7 / 22 / 201 \\
1\end{array}$ & & & & & & & & & & & & & & & & \\
\hline $\begin{array}{l}7 / 23 / 201 \\
1\end{array}$ & & & & & & & & & & & & & & & & \\
\hline $\begin{array}{l}7 / 24 / 201 \\
1\end{array}$ & & & & & & & & & & & & & & & & \\
\hline $\begin{array}{l}7 / 25 / 201 \\
1\end{array}$ & & & & & & & & & & & & & & & & \\
\hline $\begin{array}{l}7 / 26 / 201 \\
1\end{array}$ & & & & & & & & & & & & & & & & \\
\hline $\begin{array}{l}7 / 27 / 201 \\
1\end{array}$ & 4.24 & $\begin{array}{c}0.703 \\
, \\
0.879 \\
\end{array}$ & 3.6 & $1.75,1.27$ & & $<1.0$ & 0.753 & & $<1.0$ & 16.1 & & 21 & & & & \\
\hline
\end{tabular}




\begin{tabular}{|c|c|c|c|c|c|c|c|c|c|c|c|c|c|c|c|c|}
\hline & $\begin{array}{c}\text { Influen } \\
\mathbf{t}\end{array}$ & $\begin{array}{c}\text { Filte } \\
\text { r } 1\end{array}$ & $\begin{array}{c}\text { Filter } \\
2 \\
\end{array}$ & $\begin{array}{c}\text { Combine } \\
\text { d Reject } \\
1 \text { and } 2 \\
\end{array}$ & $\begin{array}{c}\text { Rejec } \\
\text { t } 1\end{array}$ & $\begin{array}{c}\text { Rejec } \\
\text { t } 2\end{array}$ & & $\begin{array}{c}\text { Influen } \\
\mathbf{t}\end{array}$ & $\begin{array}{c}\text { Filter } \\
1\end{array}$ & $\begin{array}{c}\text { Filter } \\
2\end{array}$ & $\begin{array}{c}\text { Combine } \\
\text { d Reject } \\
1 \text { and } 2 \\
\end{array}$ & $\begin{array}{c}\text { Rejec } \\
\text { t } 1\end{array}$ & $\begin{array}{c}\text { Rejec } \\
\text { t } 2\end{array}$ & & $\begin{array}{c}\text { Influen } \\
t\end{array}$ & $\begin{array}{c}\text { Filter } \\
1\end{array}$ \\
\hline $\begin{array}{l}7 / 28 / 201 \\
1\end{array}$ & 7.5 & $\begin{array}{c}0.86 \\
9 \\
\end{array}$ & 5.6 & 1.99 & & 1.2 & 0.956 & & $<1.0$ & 29.4 & & 21 & & & & \\
\hline $\begin{array}{l}7 / 29 / 201 \\
1\end{array}$ & 3.33 & $<0.5$ & 2 & 0.642 & & 2.4 & 0.556 & & 2.8 & 15.7 & & 19 & & & & \\
\hline $\begin{array}{l}7 / 30 / 201 \\
1\end{array}$ & & & & & & & & & & & & & & & & \\
\hline $\begin{array}{l}7 / 31 / 201 \\
1\end{array}$ & & & & & & & & & & & & & & & & \\
\hline $8 / 1 / 2011$ & 6.36 & $\begin{array}{l}<0.5 \\
<0.5\end{array}$ & 3.2 & 0.726 & & $<1.0$ & $\begin{array}{c}0.643 \\
, \\
0.567 \\
\end{array}$ & & 2 & & & & 18.7 & 15 & 2.44 & 1.6 \\
\hline $8 / 2 / 2011$ & & & & & & & & & & & & & & & & \\
\hline $8 / 3 / 2011$ & & & & & & & & & & & & & & & & \\
\hline $8 / 4 / 2011$ & & & & & & & & & & & & & & & & \\
\hline $8 / 5 / 2011$ & 1.45 & $<0.5$ & 4 & $<0.5$ & & 3.6 & $<0.5$ & & 2.4 & & & & 6 & 38 & 2.27 & 19 \\
\hline $8 / 6 / 2011$ & & & & & & & & & & & & & & & & \\
\hline $8 / 7 / 2011$ & & & & & & & & & & & & & & & & \\
\hline $8 / 8 / 2011$ & 7.53 & $\begin{array}{l}1.20 \\
<0.5\end{array}$ & 7.2 & 0.531 & & 1.2 & $\begin{array}{l}<0.5 \\
<0.5\end{array}$ & & 1.2 & & & & 4.42 & 44 & 3.8 & 21 \\
\hline $8 / 9 / 2011$ & 8.49 & $<0.5$ & 5.2 & 0.502 & & 2 & $<0.5$ & & $<1.0$ & & & & 2.1 & 50 & 4.27 & 15 \\
\hline $\begin{array}{l}8 / 10 / 201 \\
1\end{array}$ & 21.5 & $<0.5$ & 11 & 2.48 & & 4.4 & $<0.5$ & & 2 & & & & 17.4 & 150 & 11 & 23 \\
\hline $\begin{array}{l}8 / 11 / 201 \\
1\end{array}$ & 4.35 & $<0.5$ & 4 & 0.925 & & 2.4 & 0.510 & & 2 & & & & 3.09 & 53 & 3.82 & 21 \\
\hline $\begin{array}{l}8 / 12 / 201 \\
1\end{array}$ & 3.66 & 3.61 & 4 & $<0.5$ & & 2.8 & $<0.5$ & & 2 & & & & 13.3 & 72 & 5.25 & 25 \\
\hline $\begin{array}{l}8 / 13 / 201 \\
1\end{array}$ & & & & & & & & & & & & & & & & \\
\hline $\begin{array}{l}8 / 14 / 201 \\
1\end{array}$ & & & & & & & & & & & & & & & & \\
\hline $\begin{array}{l}8 / 15 / 201 \\
1\end{array}$ & 14.8 & $\begin{array}{l}<0.5, \\
<0.5\end{array}$ & 12 & $0.572(3)$ & & 4.8 & $<0.5$ & & 1.2 & & & & $\begin{array}{l}5.08 \\
(3)\end{array}$ & 180 & $\begin{array}{l}<0.5 \\
<0.5\end{array}$ & 75 \\
\hline $\begin{array}{l}8 / 16 / 201 \\
1\end{array}$ & 16.7 & $<0.5$ & 12 & 0.922 & & 4.4 & $<0.5$ & & 1.6 & & & & 5.25 & 140 & $<0.5$ & 48 \\
\hline $\begin{array}{l}8 / 17 / 201 \\
1\end{array}$ & 2.96 & $<0.5$ & 3.6 & $<0.5$ & & 3.6 & $<0.5$ & & 1.2 & & & & 2 & 64 & $<0.5$ & 28 \\
\hline
\end{tabular}




\begin{tabular}{|c|c|c|c|c|c|c|c|c|c|c|c|c|c|c|c|c|}
\hline & $\begin{array}{c}\text { Influen } \\
t\end{array}$ & $\begin{array}{c}\text { Filter } \\
1\end{array}$ & $\begin{array}{c}\text { Filter } \\
2 \\
\end{array}$ & $\begin{array}{l}\text { Combine } \\
\text { d Reject } 1 \\
\text { and } 2 \\
\end{array}$ & $\begin{array}{c}\text { Rejec } \\
\text { t } 1\end{array}$ & $\begin{array}{c}\text { Rejec } \\
\text { t } 2\end{array}$ & & & & & & & & & & \\
\hline & $\begin{array}{c}\text { Total } \\
\text { Hg } \\
\text { (ppt) }\end{array}$ & $\begin{array}{c}\text { Diss. } \\
\text { Hg } \\
\text { (ppt) }\end{array}$ & $\begin{array}{c}\text { TSS } \\
\text { (ppm } \\
\text { ) }\end{array}$ & $\begin{array}{c}\text { Total } \\
\text { Hg } \\
\text { (ppt) }\end{array}$ & $\begin{array}{c}\text { Diss. } \\
\text { Hg } \\
\text { (ppt) }\end{array}$ & $\begin{array}{c}\text { TSS } \\
\text { (ppm } \\
\text { ) }\end{array}$ & $\begin{array}{c}\text { Tota } \\
\text { l } \\
\text { Hg } \\
\text { (ppt } \\
\text { ) }\end{array}$ & $\begin{array}{c}\text { Diss. } \\
\text { Hg } \\
\text { (ppt) }\end{array}$ & $\begin{array}{c}\text { TSS } \\
\text { (ppm } \\
\text { ) }\end{array}$ & $\begin{array}{c}\text { Tota } \\
\text { l } \\
\text { Hg } \\
\text { (ppt) }\end{array}$ & $\begin{array}{c}\text { Diss. } \\
\text { Hg } \\
\text { (ppt) }\end{array}$ & $\begin{array}{c}\text { TSS } \\
\text { (ppm } \\
\text { ) }\end{array}$ & $\begin{array}{c}\text { Total } \\
\text { Hg } \\
\text { (ppt) }\end{array}$ & $\begin{array}{c}\text { TSS } \\
\text { (ppm } \\
\text { ) }\end{array}$ & $\begin{array}{c}\text { Total } \\
\text { Hg } \\
\text { (ppt) }\end{array}$ & $\begin{array}{c}\text { TSS } \\
\text { (ppm } \\
\text { ) }\end{array}$ \\
\hline $\begin{array}{l}8 / 18 / 201 \\
1\end{array}$ & 4.49 & $<0.5$ & 4 & $<0.5$ & & $<1.0$ & $<0.5$ & & 1.6 & & & & 5.41 & 64 & 3.45 & 27 \\
\hline $\begin{array}{l}8 / 19 / 201 \\
1\end{array}$ & 2.43 & $<0.5$ & 3.2 & 0.528 & & 3.2 & $<0.5$ & & 2.4 & & & & 7.83 & 48 & 1.42 & 25 \\
\hline $\begin{array}{l}8 / 21 / 201 \\
1\end{array}$ & & & & & & & & & & & & & & & & \\
\hline $\begin{array}{l}8 / 22 / 201 \\
1\end{array}$ & 2.64 & $\begin{array}{l}0.574 \\
,<0.5 \\
\end{array}$ & 6.4 & $<0.5$ & & 4 & $\begin{array}{l}<0.5, \\
<0.5\end{array}$ & & 3.2 & & & & 4.02 & 60 & 1.72 & 25 \\
\hline
\end{tabular}


Table 3C.5 Blue PRO® Pilot Daily Operating Summary - As, Fe, Se and V analytical results

\begin{tabular}{|c|c|c|c|c|c|c|c|c|c|c|c|c|}
\hline & \multicolumn{4}{|c|}{ Influent } & \multicolumn{4}{|c|}{ Filter 2 Effluent } & \multicolumn{4}{|c|}{ Combined Reject 1 and 2} \\
\hline & $\begin{array}{c}\text { Total } \\
\text { As } \\
\text { (ppm) }\end{array}$ & $\begin{array}{c}\text { Total } \\
\text { Fe } \\
\text { (ppm) }\end{array}$ & $\begin{array}{c}\text { Total } \\
\text { Se } \\
\text { (ppm) }\end{array}$ & $\begin{array}{c}\text { Total } \\
\text { V } \\
\text { (ppm) }\end{array}$ & $\begin{array}{c}\text { Total } \\
\text { As } \\
\text { (ppm) }\end{array}$ & $\begin{array}{c}\text { Total } \\
\text { Fe } \\
\text { (ppm) }\end{array}$ & $\begin{array}{c}\text { Total } \\
\text { Se } \\
\text { (ppm) }\end{array}$ & $\begin{array}{c}\text { Total } \\
\text { V } \\
\text { (ppm) }\end{array}$ & $\begin{array}{c}\text { Total } \\
\text { As } \\
\text { (ppm) }\end{array}$ & $\begin{array}{c}\text { Total } \\
\text { Fe } \\
\text { (ppm) }\end{array}$ & $\begin{array}{c}\text { Total } \\
\text { Se } \\
\text { (ppm) }\end{array}$ & $\begin{array}{c}\text { Total } \\
\text { V } \\
\text { (ppm) }\end{array}$ \\
\hline $5 / 19 / 2011$ & & & & & & & & & & & & \\
\hline $5 / 20 / 2011$ & $<0.01$ & 0.32 & $<0.03$ & 0.1 & $<0.01$ & $<0.05$ & $<0.03$ & 0.076 & $<0.01$ & 1 & $<0.03$ & 0.1 \\
\hline $5 / 21 / 2011$ & & & & & & & & & & & & \\
\hline $5 / 22 / 2011$ & & & & & & & & & & & & \\
\hline $5 / 23 / 2011$ & $<0.01$ & 0.21 & $<0.03$ & 0.076 & $<0.01$ & $<0.05$ & $<0.03$ & 0.071 & $<0.01$ & 0.63 & $<0.03$ & 0.083 \\
\hline $5 / 24 / 2011$ & $<0.01$ & 3.8 & $<0.03$ & 0.12 & $<0.01$ & $<0.05$ & 0.033 & 0.058 & $<0.01$ & 0.57 & $<0.03$ & 0.065 \\
\hline $5 / 25 / 2011$ & & & & & & & & & & & & \\
\hline $5 / 26 / 2011$ & & & & & & & & & & & & \\
\hline $5 / 27 / 2011$ & $<0.010$ & 0.32 & $<0.030$ & 0.046 & $<0.010$ & 0.11 & $<0.030$ & 0.042 & $<0.010$ & 0.91 & $<0.030$ & 0.059 \\
\hline $5 / 28 / 2011$ & & & & & & & & & & & & \\
\hline $5 / 29 / 2011$ & & & & & & & & & & & & \\
\hline $5 / 30 / 2011$ & & & & & & & & & & & & \\
\hline $5 / 31 / 2011$ & $<0.010$ & 0.12 & 0.031 & 0.052 & $<0.010$ & $<0.050$ & 0.031 & 0.056 & $<0.010$ & 0.31 & $<0.030$ & 0.057 \\
\hline $6 / 1 / 2011$ & $<0.010$ & $<0.050$ & 0.033 & 0.03 & & & & & $<0.010$ & 0.38 & 0.031 & 0.036 \\
\hline $6 / 2 / 2011$ & & & & & & & & & & & & \\
\hline $6 / 3 / 2011$ & $<0.010$ & 0.3 & $<0.03$ & 0.029 & $<0.010$ & 0.078 & $<0.030$ & 0.023 & $<0.010$ & 0.49 & $<0.030$ & 0.029 \\
\hline $6 / 4 / 2011$ & & & & & & & & & & & & \\
\hline $6 / 5 / 2011$ & & & & & & & & & & & & \\
\hline $6 / 6 / 2011$ & $<0.010$ & 0.33 & $<0.030$ & 0.021 & $<0.010$ & 0.085 & $<0.030$ & 0.025 & $<0.010$ & 0.46 & $<0.030$ & 0.021 \\
\hline $6 / 7 / 2011$ & & & & & & & & & & & & \\
\hline $6 / 8 / 2011$ & $<0.010$ & 0.49 & $<0.030$ & 0.017 & $<0.010$ & 0.23 & $<0.030$ & 0.016 & $<0.010$ & 0.92 & $<0.030$ & 0.028 \\
\hline $6 / 9 / 2011$ & & & & & & & & & & & & \\
\hline $6 / 10 / 2011$ & $<0.010$ & 0.44 & $<0.030$ & 0.0097 & $<0.010$ & 0.16 & $<0.030$ & $<0.0080$ & $<0.010$ & 0.9 & $<0.030$ & 0.013 \\
\hline $6 / 11 / 2011$ & & & & & & & & & & & & \\
\hline
\end{tabular}




\begin{tabular}{|c|c|c|c|c|c|c|c|c|c|c|c|c|}
\hline & \multicolumn{4}{|c|}{ Influent } & \multicolumn{4}{|c|}{ Filter 2 Effluent } & \multicolumn{4}{|c|}{ Combined Reject 1 and 2} \\
\hline & $\begin{array}{c}\text { Total } \\
\text { As } \\
\text { (ppm) }\end{array}$ & $\begin{array}{c}\text { Total } \\
\text { Fe } \\
(\mathrm{ppm})\end{array}$ & $\begin{array}{c}\text { Total } \\
\text { Se } \\
(\mathrm{ppm})\end{array}$ & $\begin{array}{c}\text { Total } \\
\text { V } \\
\text { (ppm) }\end{array}$ & $\begin{array}{c}\text { Total } \\
\text { As } \\
\text { (ppm) }\end{array}$ & $\begin{array}{c}\text { Total } \\
\text { Fe } \\
(\mathrm{ppm})\end{array}$ & $\begin{array}{c}\text { Total } \\
\text { Se } \\
(\mathrm{ppm})\end{array}$ & $\begin{array}{c}\text { Total } \\
\text { V } \\
\text { (ppm) }\end{array}$ & $\begin{array}{c}\text { Total } \\
\text { As } \\
\text { (ppm) }\end{array}$ & $\begin{array}{c}\text { Total } \\
\text { Fe } \\
(\mathrm{ppm})\end{array}$ & $\begin{array}{c}\text { Total } \\
\text { Se } \\
(\mathrm{ppm})\end{array}$ & $\begin{array}{c}\text { Total } \\
\mathrm{V} \\
(\mathrm{ppm})\end{array}$ \\
\hline \multicolumn{13}{|l|}{$6 / 12 / 2011$} \\
\hline $6 / 13 / 2011$ & $<0.010$ & 0.11 & $<0.030$ & 0.046 & $<0.010$ & $<0.050$ & $<0.030$ & 0.15 & $<0.010$ & 0.42 & $<0.030$ & 0.051 \\
\hline \multicolumn{13}{|l|}{ 6/14/2011 } \\
\hline $6 / 15 / 2011$ & $<0.010$ & 0.55 & $<0.030$ & 0.0097 & $<0.010$ & 0.25 & $<0.030$ & $<0.0080$ & $<0.010$ & 1 & $<0.030$ & 0.018 \\
\hline \multicolumn{13}{|l|}{$6 / 16 / 2011$} \\
\hline $6 / 17 / 2011$ & 0.012 & 0.4 & $<0.030$ & 0.18 & $<0.010$ & 0.11 & $<0.030$ & 0.17 & $<0.010$ & 0.97 & $<0.030$ & 0.18 \\
\hline \multicolumn{13}{|l|}{ 6/18/2011 } \\
\hline \multicolumn{13}{|l|}{ 6/19/2011 } \\
\hline \multicolumn{13}{|l|}{$6 / 20 / 2011$} \\
\hline \multicolumn{13}{|l|}{$6 / 21 / 2011$} \\
\hline \multicolumn{13}{|l|}{$6 / 22 / 2011$} \\
\hline \multicolumn{13}{|l|}{$6 / 23 / 2011$} \\
\hline $6 / 24 / 2011$ & 0.013 & 0.15 & $<0.030$ & 0.079 & 0.013 & 0.054 & $<0.030$ & 0.071 & 0.015 & 0.86 & $<0.030$ & 0.069 \\
\hline \multicolumn{13}{|l|}{$6 / 25 / 2011$} \\
\hline \multicolumn{13}{|l|}{$6 / 26 / 2011$} \\
\hline 6/27/2011 & 0.016 & 0.44 & 0.037 & 0.008 & 0.015 & 0.22 & $<0.030$ & 0.032 & 0.016 & 0.86 & 0.038 & 0.038 \\
\hline \multicolumn{13}{|l|}{$6 / 28 / 2011$} \\
\hline $6 / 29 / 2011$ & 0.011 & 0.31 & $<0.030$ & 0.054 & $<0.010$ & 0.12 & 0.037 & 0.056 & 0.014 & 0.61 & $<0.030$ & 0.056 \\
\hline \multicolumn{13}{|l|}{$6 / 30 / 2011$} \\
\hline $7 / 1 / 2011$ & $<0.010$ & 0.4 & $<0.030$ & 0.043 & $<0.010$ & 1.4 & $<0.030$ & 0.046 & 0.011 & 0.78 & $<0.030$ & 0.04 \\
\hline \multicolumn{13}{|l|}{$7 / 2 / 2011$} \\
\hline \multicolumn{13}{|l|}{$7 / 3 / 2011$} \\
\hline \multicolumn{13}{|l|}{$7 / 4 / 2011$} \\
\hline $7 / 5 / 2011$ & $<0.010$ & 0.22 & $<0.030$ & 0.12 & $<0.010$ & $<0.050$ & $<0.030$ & 0.12 & $<0.010$ & 0.35 & $<0.030$ & 0.13 \\
\hline $7 / 6 / 2011$ & $<0.010$ & 0.089 & $<0.030$ & 0.075 & $<0.010$ & 0.17 & 0.031 & 0.072 & $<0.010$ & 0.48 & $<0.030$ & 0.008 \\
\hline \multicolumn{13}{|l|}{$7 / 7 / 2011$} \\
\hline $7 / 8 / 2011$ & $<0.010$ & 0.39 & $<0.030$ & 0.49 & $<0.010$ & 0.24 & $<0.030$ & 0.4 & $<0.010$ & 0.79 & $<0.030$ & 0.44 \\
\hline
\end{tabular}




\begin{tabular}{|c|c|c|c|c|c|c|c|c|c|c|c|c|}
\hline & \multicolumn{4}{|c|}{ Influent } & \multicolumn{4}{|c|}{ Filter 2 Effluent } & \multicolumn{4}{|c|}{ Combined Reject 1 and 2} \\
\hline & $\begin{array}{c}\text { Total } \\
\text { As } \\
\text { (ppm) }\end{array}$ & $\begin{array}{c}\text { Total } \\
\text { Fe } \\
(\mathrm{ppm})\end{array}$ & $\begin{array}{c}\text { Total } \\
\text { Se } \\
\text { (ppm) }\end{array}$ & $\begin{array}{c}\text { Total } \\
\text { V } \\
\text { (ppm) }\end{array}$ & $\begin{array}{c}\text { Total } \\
\text { As } \\
\text { (ppm) }\end{array}$ & $\begin{array}{c}\text { Total } \\
\text { Fe } \\
(\mathrm{ppm}) \\
\end{array}$ & $\begin{array}{c}\text { Total } \\
\text { Se } \\
(\mathrm{ppm})\end{array}$ & $\begin{array}{c}\text { Total } \\
\text { V } \\
\text { (ppm) }\end{array}$ & $\begin{array}{c}\text { Total } \\
\text { As } \\
\text { (ppm) }\end{array}$ & $\begin{array}{c}\text { Total } \\
\text { Fe } \\
(\mathrm{ppm}) \\
\end{array}$ & $\begin{array}{c}\text { Total } \\
\text { Se } \\
(\mathrm{ppm})\end{array}$ & $\begin{array}{c}\text { Total } \\
\mathrm{V} \\
\text { (ppm) }\end{array}$ \\
\hline $7 / 9 / 2011$ & & & & & & & & & & & & \\
\hline $7 / 10 / 2011$ & & & & & & & & & & & & \\
\hline $7 / 11 / 2011$ & $<0.010$ & 0.53 & $<0.030$ & 2.5 & $<0.010$ & 0.14 & $<0.030$ & 2.4 & $<0.010$ & 0.85 & $<0.030$ & 0.008 \\
\hline
\end{tabular}


Appendix 3D: TCLP Analysis of Filter Sand at End of Pilot

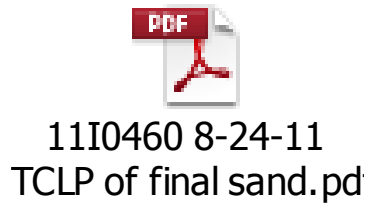




\section{Appendix 3E: Cost Estimate Details}

Installed capital costs were developed from equipment prices using a factored approach where individual direct and indirect costs are estimated as a percentage of the total installed capital cost. Typical ranges for these costs for a battery limit plant addition were used as guidance (19). It should be noted that installation costs are site-specific and that detailed information about utilities and infrastructure is needed to develop refined costs. For the Blue PRO® and the conventional sand filter cases, costs were developed for a single pass filter and then doubled to get the cost of a two pass filter system.

The first two tables are for the Blue PRO® with chemical feed $\mathrm{Hg}$ treatment system. As was explained in Section 3.3.1 of the report, for comparison, costs were developed using the vendor's quoted equipment price and using the equipment price given by Capdet for a conventional sand filter with chemical addition (a process that is similar to Blue PRO® with chemical addition, but not identical). Table 3E.1 below shows the costs for a Blue PRO ${ }^{\circledR}$ single pass filter and chemical feed system using the vendor's equipment price. The mid-range instrumentation and controls factor assumes that this addition will be tying into an existing control system. The mid-range electrical factor assumes that a local Motor Control Center (MCC) will be needed. The buildings factor assumes that a pump house and housing for the local MCC will be built. A higher factor for the service facilities was used to compensate for the need for a tank truck unloading area - this may or may not be valid depending on the current site capabilities. A relatively high contingency factor (25\% initial assumption) was used due to the lack of detailed information about the site's utilities and infrastructure.

Table 3E.1 Blue PRO® single pass filter and chemical feed system using BWT equipment price

\begin{tabular}{|l|c|c|c|r|}
\hline Direct Costs & $\begin{array}{c}\text { Typical } \\
\text { Range in } \\
\%(\mathrm{a})\end{array}$ & $\begin{array}{c}\text { Assumed } \\
\% \text { of } \\
\text { total }\end{array}$ & $\begin{array}{c}\text { Actual \% } \\
\text { of total }\end{array}$ & \multicolumn{1}{c|}{ Cost } \\
\hline Purchased equipment & $15-40$ & 30 & 19 & $2,784,473$ \\
\hline Equipment installation & $6-14$ & 10 & 6 & 928,158 \\
\hline $\begin{array}{l}\text { Instrumentation and controls } \\
\text { (installed) }\end{array}$ & $2-8$ & 6 & 4 & 556,895 \\
\hline Piping (installed) & $3-20$ & 15 & 9 & $1,392,237$ \\
\hline Electrical (installed) & $2-10$ & 10 & 6 & 928,158 \\
\hline Buildings (including services) & $3-18$ & 8 & 5 & 742,526 \\
\hline Yard improvements & $2-5$ & 5 & 3 & 464,079 \\
\hline Service facilities (installed) & $8-20$ & 20 & 12 & $1,856,315$ \\
\hline Total direct costs & & & & $\$ 9,652,840$ \\
\hline & & & & \\
\hline Indirect Costs & & & & $1,392,237$ \\
\hline Engineering and supervision & $4-21$ & 15 & 9 & 649,710 \\
\hline Construction expense & $4-16$ & 7 & 4 & 464,079 \\
\hline Contractor's fee & $2-6$ & 5 & 3 & $2,320,394$ \\
\hline Contingency & $5-15$ & 25 & 16 & \\
\hline & & & & \\
\hline
\end{tabular}


Total fixed-capital investment

$\$ 14,479,260$

(a) Peters and Timmerhaus (19)

Table 3E. 2 below develops similar costs using the Capdet equipment cost for a conventional sand filter and chemical feed system, which is similar but not identical to the Blue PRO $®$ process with chemical addition. For this case, the purchased equipment and equipment installation were combined since the Capdet program provides a unit installed cost, which is the cost to install the process equipment alone, without any utility hook-ups, site preparation, etc. The Capdet unit installed cost also includes the indirect construction expenses such as temporary construction and operation, construction tools and rentals, home office personnel located the construction site, construction payroll, travel and living expenses, taxes and insurance and other construction overhead. For the rest of the direct and indirect costs, the assumed percentages of the total cost were the same as were used for the case using the vendor equipment cost since the assumptions regarding the site utilities are the same. Likewise the same contingency assumption (25\% initial assumption) was used.

Table 3E.2 Conventional single pass sand filter and chemical feed system, using Capdet equipment cost

\begin{tabular}{|l|c|c|c|r|}
\hline Direct Costs & $\begin{array}{c}\text { Typical } \\
\text { Range } \\
\text { in \% (a) }\end{array}$ & $\begin{array}{c}\text { Assumed } \\
\text { \% of total }\end{array}$ & $\begin{array}{c}\text { Actual } \\
\text { \% of Total }\end{array}$ & \multicolumn{1}{c|}{ Cost } \\
\hline Purchased equipment and installation & $21-54$ & 40 & $27 \%$ & $4,882,350$ \\
\hline Instrumentation and controls (installed) & $2-8$ & 6 & $4 \%$ & 732,353 \\
\hline Piping (installed) & $3-20$ & 15 & $10 \%$ & $1,830,881$ \\
\hline Electrical (installed) & $2-10$ & 10 & $7 \%$ & $1,220,588$ \\
\hline Buildings (including services) & $3-18$ & 8 & $5 \%$ & 976,470 \\
\hline Yard improvements & $2-5$ & 5 & $3 \%$ & 610,294 \\
\hline Service facilities (installed) & $8-20$ & 20 & $13 \%$ & $2,441,175$ \\
\hline Total direct costs & & & & $\$ 12,694,11$ \\
& & & & 0 \\
\hline & & & & \\
\hline Indirect Costs & $4-21$ & 15 & $10 \%$ & $1,830,881$ \\
\hline Engineering and supervision & $4-16$ & 0 & 0 & 0 \\
\hline Construction expense & $2-6$ & 5 & $3 \%$ & 610,294 \\
\hline Contractor's fee & $5-15$ & 25 & $17 \%$ & $3,051,469$ \\
\hline Contingency & & & & $\$ 18,186,75$ \\
\hline & & & & 4 \\
\hline Total fixed-capital investment & & & & \\
\end{tabular}

(a) Peters and Timmerhaus (19) 
In addition to the Blue $\mathrm{PRO} 囚$ process, costs were also developed for the Hg treatment option that arose during the consideration of the Blue PRO $®$ process. This additional treatment option uses Nalmet ${ }^{\circledR}$ addition before the sand filters. As shown in Table 3E.3, costs were developed using the unit installed cost provided by the Capdet program. The unit installed cost is the cost to install the process equipment alone, without any utility hook-ups, site preparation, etc. It also includes the indirect construction expenses. It was assumed that the purchased equipment and installation would be a lower percentage of the total installed cost due to the relative simplicity of the equipment compared to the necessary site work. A lower instrumentation and controls factor than previously assumed for the Blue PRO $®$ system is based on the lower complexity of the system. It assumes that this addition will be tying into an existing control system. For similar reasons, the piping, electrical and building factors are lower than the Blue PRO® system. The electrical factor assumes that a local Motor Control Center (MCC) will be needed. The buildings factor assumes that a pump house and housing for the local MCC will be built. The service facilities factor was the same as was used for the Blue PRO® system to compensate for the need for a tank truck unloading area again, this may or may not be valid depending on the current site capabilities. As was done for the Blue PRO ${ }^{\circledR}$ system, a relatively high contingency factor (25\% initial assumption) was used due to the lack of detailed information about the site's utilities and infrastructure.

Table 3E.3 Chemical Feed System Budgetary Factored Estimate

\begin{tabular}{|l|c|c|c|r|}
\hline Direct Costs & $\begin{array}{c}\text { Typical } \\
\text { Range in \% } \\
\text { (a) }\end{array}$ & $\begin{array}{c}\text { Assumed } \\
\text { \% of } \\
\text { total }\end{array}$ & $\begin{array}{c}\text { Actual } \\
\text { \% of } \\
\text { total }\end{array}$ & \multicolumn{1}{c|}{ Cost } \\
\hline Purchased equipment and installation & $21-54$ & 25 & $26 \%$ & 381,050 \\
\hline $\begin{array}{l}\text { Instrumentation and controls } \\
\text { (installed) }\end{array}$ & $2-8$ & 4 & $4 \%$ & 60,968 \\
\hline Piping (installed) & $3-20$ & 10 & $11 \%$ & 152,420 \\
\hline Electrical (installed) & $2-10$ & 8 & $8 \%$ & 121,936 \\
\hline Buildings (including services) & $3-18$ & 5 & $5 \%$ & 76,210 \\
\hline Yard improvements & $2-5$ & 3 & $3 \%$ & 45,726 \\
\hline Service facilities (installed) & $8-20$ & 20 & $21 \%$ & 304,840 \\
\hline Total direct costs & & & & $\$ 762,100$ \\
\hline & & & & \\
\hline Indirect Costs & $4-21$ & 15 & $16 \%$ & 228,630 \\
\hline Engineering and supervision & $4-16$ & 0 & 0 & \\
\hline Construction expense & $2-6$ & 5 & $5 \%$ & 76,210 \\
\hline Contractor's fee & $5-15$ & 25 & $26 \%$ & 381,050 \\
\hline Contingency & & & & \\
\hline & & & & $\$ 1,447,990$ \\
\hline Total fixed-capital investment & & & &
\end{tabular}

(a) Peters and Timmerhaus (19) 
Appendix 3F: Vendor Pilot Report

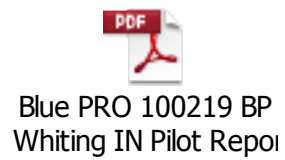

Appendix 3G: Vendor Budgetary Full-Scale Quote

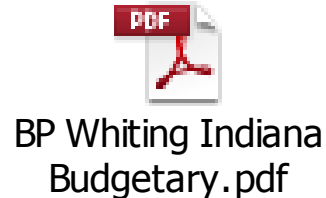




\section{Argonne}

\section{Energy Systems Division}

Argonne National Laboratory

9700 South Cass Avenue, Bldg. 362

Argonne, IL 60439-4815

www.anl.gov 